\title{
Measuring Discharge with Acoustic Doppler Current Profilers from a Moving Boat
}

Chapter 22 of

Section A, Surface-Water Techniques

Book 3, Applications of Hydraulics

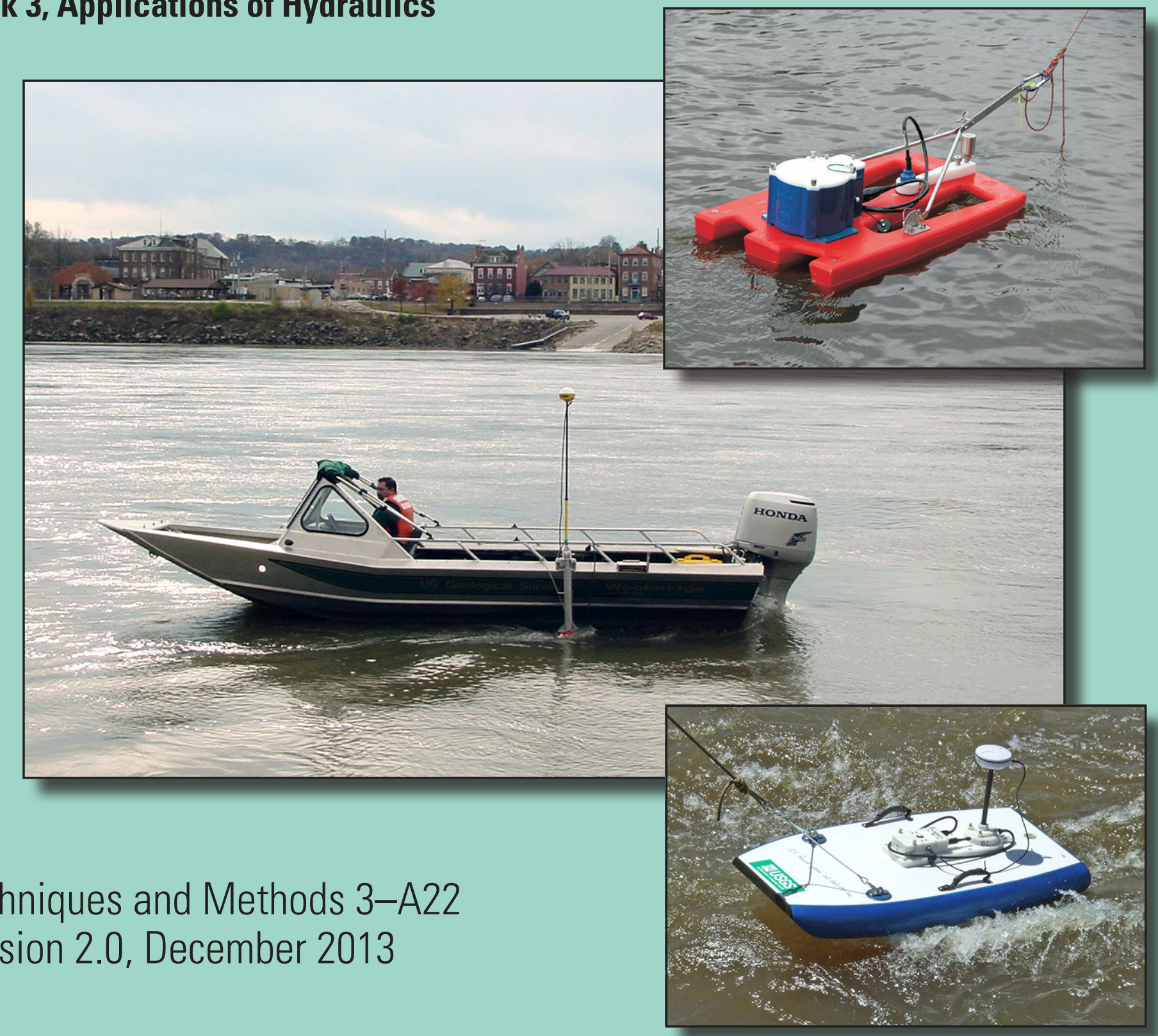

U.S. Department of the Interior

U.S. Geological Survey 



\section{Measuring Discharge with Acoustic Doppler Current Profilers from a Moving Boat}

By David S. Mueller, Chad R. Wagner, Michael S. Rehmel, Kevin A. Oberg, and

Francois Rainville

Chapter 22 of

Section A, Surface-Water Techniques

Book 3, Applications of Hydraulics

Techniques and Methods 3-A22

Version 2.0, December 2013 


\title{
U.S. Department of the Interior SALLY JEWELL, Secretary
}

\section{U.S. Geological Survey Suzette M. Kimball, Acting Director}

\author{
U.S. Geological Survey, Reston, Virginia: First release 2009 \\ Revised and printed: December 2013, version 2.0
}

For more information on the USGS - the Federal source for science about the Earth, its natural and living resources, natural hazards, and the environment, visit http://www.usgs.gov or call 1-888-ASK-USGS.

For an overview of USGS information products, including maps, imagery, and publications, visit http://www.usgs.gov/pubprod

To order this and other USGS information products, visit http://store.usgs.gov

Any use of trade, firm, or product names is for descriptive purposes only and does not imply endorsement by the U.S. Government.

Although this information product, for the most part, is in the public domain, it also may contain copyrighted materials as noted in the text. Permission to reproduce copyrighted items must be secured from the copyright owner.

Suggested citation:

Mueller, D.S., Wagner, C.R., Rehmel, M.S., Oberg, K.A,, and Rainville, Francois, 2013, Measuring discharge with acoustic Doppler current profilers from a moving boat (ver. 2.0, December 2013): U.S. Geological Survey Techniques and Methods, book 3, chap. A22, 95 p., http://dx.doi.org/10.3133/tm3A22.

ISSN 2328-7047 (print)

ISSN 2328-7055 (online) 


\section{Foreword}

The mission of the U.S. Geological Survey (USGS) Water Mission Area is to provide the information and understanding needed for wise management of the Nation's water resources. Inherent in this mission is the responsibility of collecting data that accurately describe the physical, chemical, and biological attributes of water systems. These data are used for environmental and resource assessments by the USGS, other government agencies and scientific organizations, and the general public. Reliable and quality-assured data are essential to the credibility and impartiality of the water-resources appraisals carried out by the USGS.

The development and use of guidelines for Measuring Discharge with Acoustic Doppler Current Profilers from a Moving Boat are necessary to achieve consistency in the use of scientific methods and procedures, document the methods and procedures used, and maintain technical expertise in the process. USGS hydrographers and hydrologists can use this manual to ensure that the data collected are of the quality required to fulfill our mission.

This 2013 update of Measuring Discharge with Acoustic Doppler Current Profilers from a Moving Boat contains the most current information and guidance regarding acoustic Doppler current profilers (ADCPs) used by the USGS at the time of publication. The following memoranda are considered superseded or duplicated by the policy and procedures in this report and need not be referenced in the future:

2012.01 - Processing ADCP Discharge Measurements On-site and Performing ADCP Check Measurements

2011.08 - Exposure time for ADCP moving-boat discharge measurements made during steady flow conditions

2009.05 - Publication of the Techniques and Methods Report Book 3-Section A22 "Measuring Discharge with Acoustic Doppler Current Profilers from a Moving Boat" and associated policy and guidance for moving boat discharge measurements

2009.02 - Release of WinRiver II Software (version 2.04) for Computing Streamflow from Acoustic Doppler Current Profiler Data

2006.04 - Availability of the report "Application of the Loop Method for Correcting Acoustic Doppler Current Profiler Discharge Measurements Biased by Sediment Transport" by David S. Mueller and Chad R. Wagner (USGS Scientific Investigations Report 2006-5079) and guidance on the application of the Loop Method

2005.05 - Guidance on the use of RD Instruments StreamPro Acoustic Doppler Profiler

2005.04 - Release of WinRiver Software version 10.06 for Computing Streamflow from Acoustic Profiler Data

2003.04 - Release of WinRiver Software version 10.05 for Computing Streamflow from Acoustic Profiler Data 
2002.03 - Release of WinRiver Software (version 10.03) for Computing Streamflow from Acoustic Profiler Data

2002.01 - Configuration of Acoustic Profilers (RD Instruments) for Measurement of Streamflow

2002.02 - Policy and Technical Guidance on Discharge Measurements using Acoustic Doppler Current Profilers

The development of new and improved ADCPs is ongoing, as are the research and practical field experience with existing and new ADCPs, which likely will lead to changes in the guidance on the application of ADCPs over time and revisions to this document. The user is encouraged to log onto the USGS Office of Surface Water Web site [http://hydroacoustics.usgs.gov/] for the latest revisions to this document and technical memorandums that may be issued prior to revisions to ensure that the best techniques are communicated for use in collecting and processing ADCP discharge measurements.

Robert R. Mason

Acting Chief, Office of Surface Water 


\section{Significant Updates and Changes}

The list below contains information on the important updates and changes in this revision when compared to the original publication (2009). The list is not exhaustive, but is intended to highlight differences of interest to the majority of those that perform moving-boat ADCP discharge measurements.

- Discussion of Instruments - Updated descriptions of instruments including signal processing, frequency, and transducers (p. 2).

- Data Management - Added that all aspects of data management must follow agency policy and be documented in the office's surface-water quality-assurance plan. Encourages scanning of paper measurement notes to an electronic file (p. 3).

- Training - Added that training must comply with agency required training standards and highly encourages additional training in order to stay current (p. 4).

- Unmeasured Areas in a Profile - Added discussion of blanking distances for additional instruments (p. 6).

- Configuration and Characteristics - Added characteristics for additional instruments (p. 7).

- Testing Requirements and Procedures - Added section describing when an instrument must be tested and a matrix of quality-assurance test requirements (p. 10).

- Transformation Matrix Check - Added description of methods for verifying that the correct transformation matrix is stored in the ADCP (p. 11).

- Instrument History Log - Added a discussion on the importance of logging instrument quality-assurance tests (p. 12).

- GPS Requirements and Specifications - Added specific precision requirements needed for the GPS data output and a discussion of VTG limitations (p. 12).

- Manned Boats - Added discussions of tethered boats used from a manned boat (p. 13).

- Tethered Boats - Added discussions about why to avoid wading with a tethered boat across the stream, recommendations of unmanned cableways, safety considerations, and use of tethered boats in high velocity situations (p. 14).

- Remote-Controlled Boats - Added concern of potential effect of motors and batteries on the compass (p. 18).

- Other Equipment - Added electronic field notes (p. 18).

- Variation in Speed of Sound with Depth - Added discussion that some software can correct the vertical velocity or depth for changes in the speed of sound and that phased array ADCPs horizontal velocities are unaffected by changes in speed of sound, but vertical velocity and depth are still dependent on correcting the speed of sound (p. 22).

- Water Temperature - Clarified that ADCP temperature comparisons are for quality assurance only and should not be released to the public when not using a thermometer that meets USGS water temperature field measurement standards (p. 22).

- Salinity - Set minimum bounds when salinity is expected to be sampled to 5 parts per thousand (p. 22). 
- Compass Calibration - Expanded descriptions of compass calibrations, highlighting potential issues (p. 23).

- Instrument Configuration - Expanded discussion to include new instruments with auto-adaptive capabilities (p. 24).

- Stationary Test with GPS and Loop Test - Added new table on moving-bed detection methods (p. 26-27).

- Changing and Tidal Flow Situations - Added discussion of moving-bed test requirements for multiple measurements in changing flow conditions (p. 27).

- Selecting the Measurement Method Based on Moving-Bed Test Results - Added discussion to emphasize that bottom track is the preferred navigation method, and GPS is preferred in moving-bed conditions when available (p. 28).

- Steady-Flow Conditions - Added new policy that measurement should have total exposure time greater than 720 seconds with at least 2 reciprocal transects (p. 28).

- Unsteady-Flow Conditions - Updated for 720 second exposure time policy (p. 29).

- Measuring in Difficult Conditions - Difficult conditions encountered in hydroacoustic discharge measurements are identified and the best procedures for collecting and processing data are discussed (p. 29).

- Critical Data-Quality Problems - Updated with recommendation to view track reference code in RiverSurveyor Live while collecting data and to watch for erroneous compass headings when using GPS or Loop moving-bed method (p. 31).

- Boat Operation - Updated to emphasize smooth, consistent boat motion (p. 31).

- Estimating Edge Discharge - Added that individual edge discharge greater than 5 percent of total discharge must be measured or estimated with alternative method and other additional guidance on edge discharges (p. 32).

- Field Notes - Updated to include electronic field notes (p. 33).

- Post-Measurement Field Procedures - Added steps to obtain final discharge prior to leaving site (p. 34).

- Data Storage and Database Entry - Added new good practice suggestions for storing field measurements with both electronic and paper notes (p. 37).

- Measurement Checking and Review - Noted that office policy on ADCP measurement checking and review should be documented in the local surface-water quality-assurance plan (p. 37).

- Added Glossary (p. 41). 
- Appendix A - Updated for newer instruments, including discussion of phased array transducers (p. 44).

- Appendix B - Collecting Data in Moving-Bed Conditions (p. 52) -

- Updated with information on using Stationary Moving Bed Analysis (SMBA) software for stationary moving-bed tests.

- Added additional details on the importance of compass accuracy when using loop moving-bed tests.

- Added new quality-assurance checks and guidelines for using the loop moving-bed method.

- Added potential inaccuracies in VTG-based discharges, particularly for boat speeds less than about 0.8 foot per second.

- Appendix C - Description of Water-Tracking Modes - Revised to include auto-adaptive capabilities of newer instruments (p. 64).

- Appendix D - Beam-Alignment Test - Revised to include RiverSurveyor M9/S5 and RiverRay beam matrix descriptions (p. 68).

- Appendix E - Forms and Quick-Reference Guides - All forms revised to include newer equipment and improved with additional information (p. 70).

- Appendix F - Measurement Processing Procedure - Completely revised with expanded discussions for each step (p. 75). 



\section{Contents}

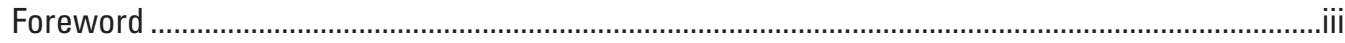

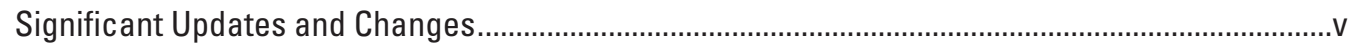

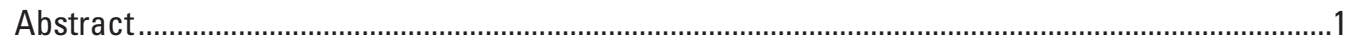

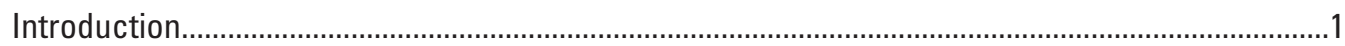

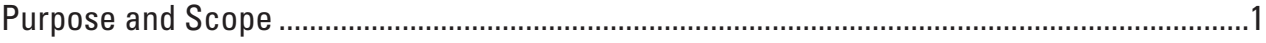

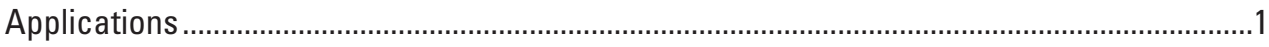

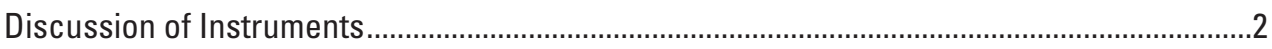

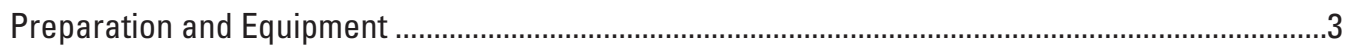

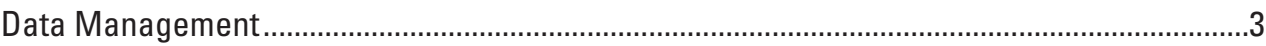

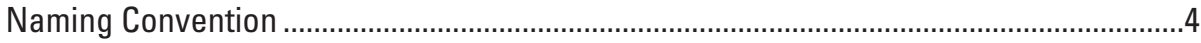

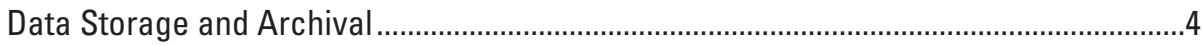

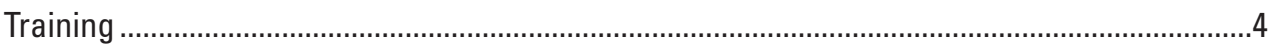

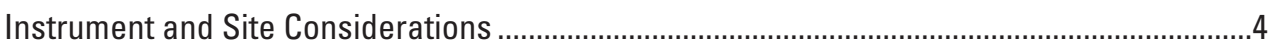

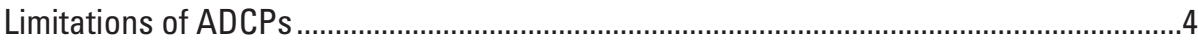

Effect of Sediment .................................................................................................... 4

Unmeasured Areas in a Profile ..............................................................................6

Configuration and Characteristics ..........................................................................

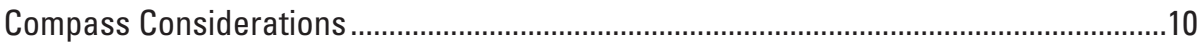

Instrument Quality Assurance .........................................................................................

Software and Firmware ..................................................................................................

Testing Requirements and Procedures...................................................................... 10

Beam-Alignment Test.......................................................................................... 10

Transformation Matrix Check .............................................................................11

Comparison Measurement..................................................................................... 11

Instrument History Log ............................................................................................... 12

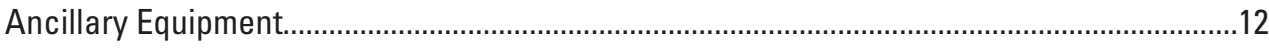

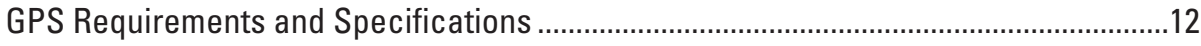

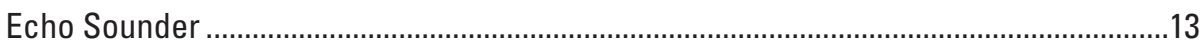

Instrument Deployments and Mounts ..........................................................................13

Manned Boats ....................................................................................................... 13

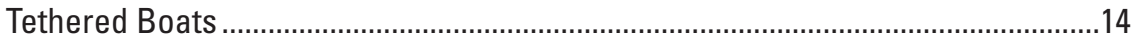

Remote-Controlled Boats ........................................................................................ 18

Other Equipment ............................................................................................................. 18

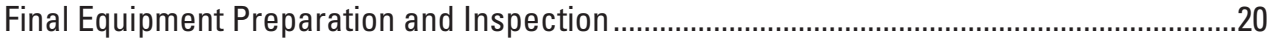

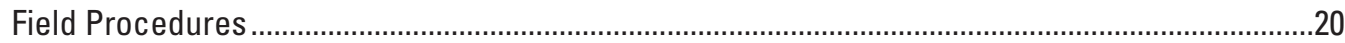

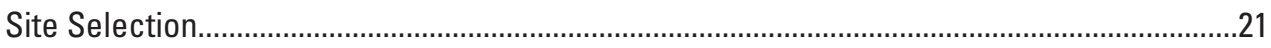

Pre-Measurement Field Procedures .................................................................................2

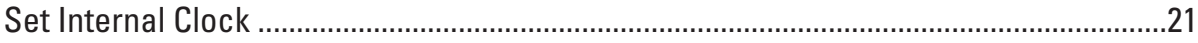

Instrument Diagnostic Checks ....................................................................................22

Variation in Speed of Sound with Depth .........................................................................22

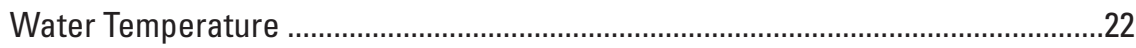

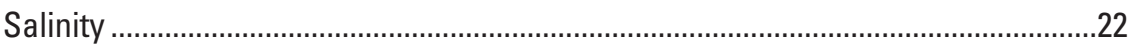

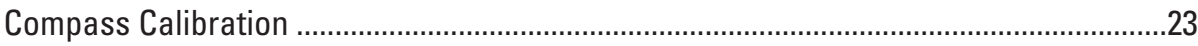

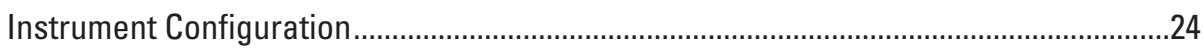




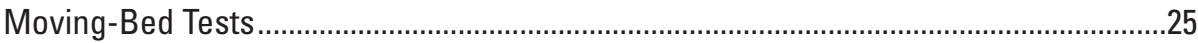

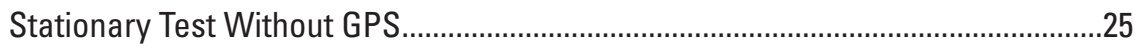

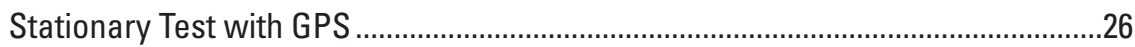

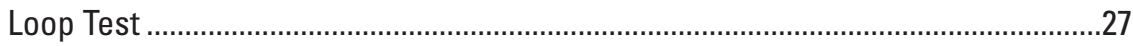

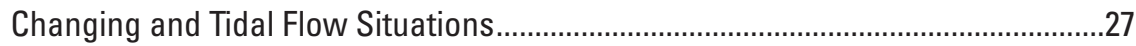

Selecting the Measurement Method Based on Moving-Bed Test Results.............28

Discharge-Measurement Procedures ………………….....................................................28

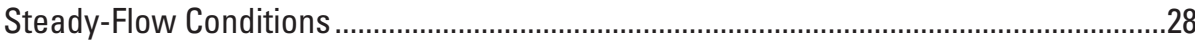

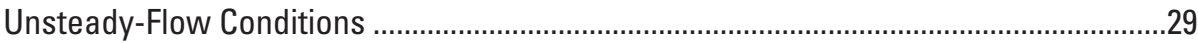

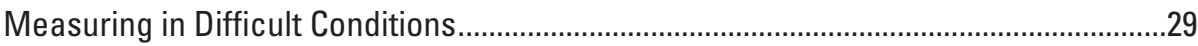

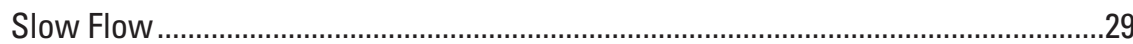

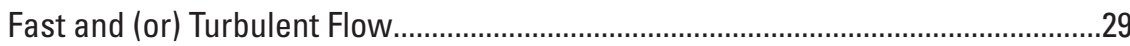

Vertically Stratified Bi-Directional Flow...................................................................30

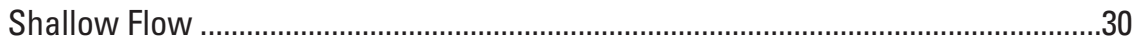

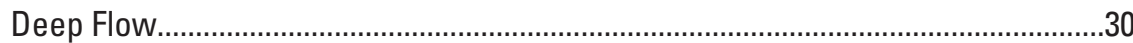

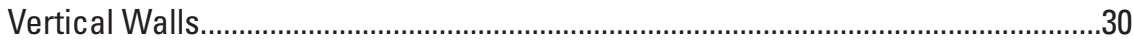

Rough and Irregular Streambeds or Vegetation on the Streambed.........................30

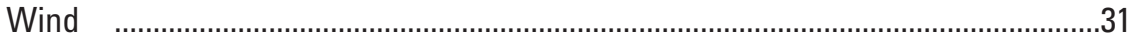

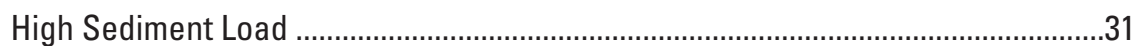

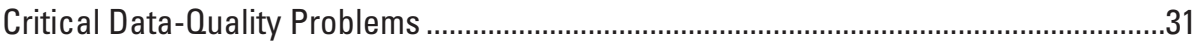

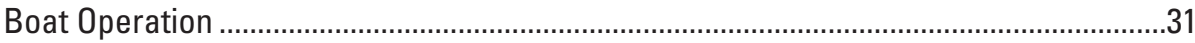

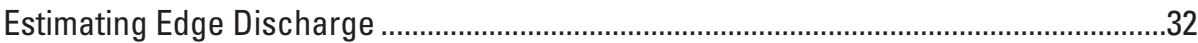

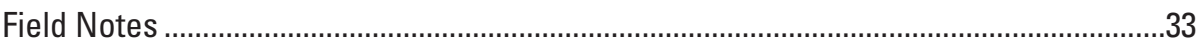

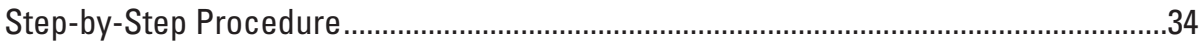

Post-Measurement Field Procedures ....................................................................................

Steps to be Completed before Leaving Measurement Site .............................................35

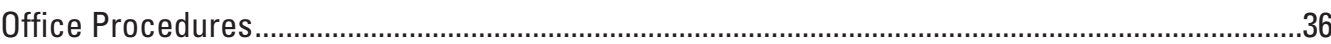

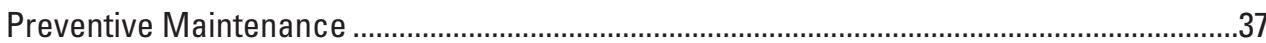

Verify Field Procedures and Finalize Measurement ................................................................37

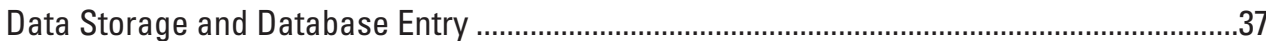

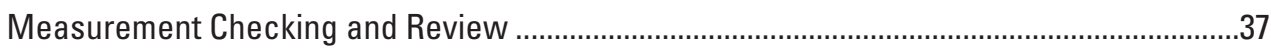

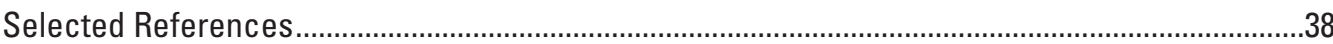

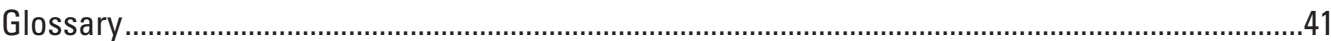

Appendix A - Basic ADCP Operational Concepts ..........................................................................44

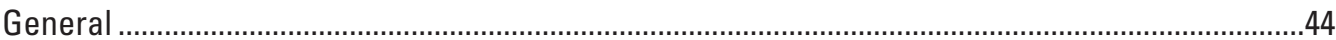

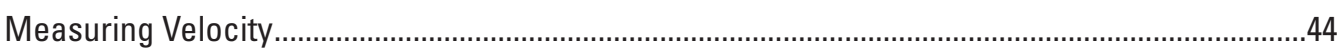

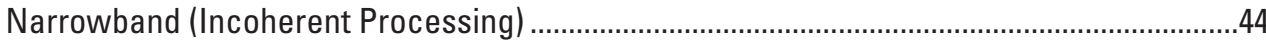

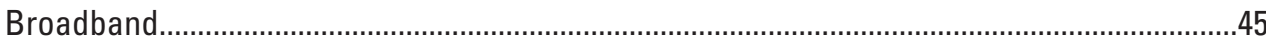

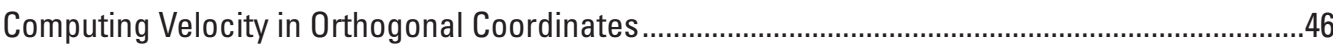

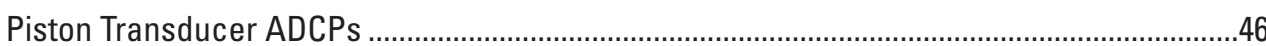

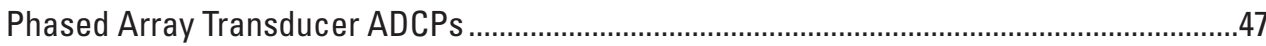

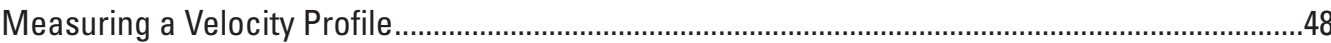

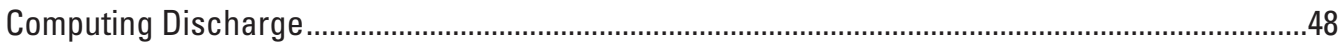

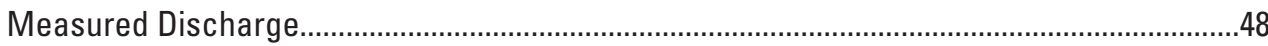

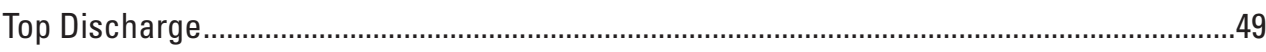

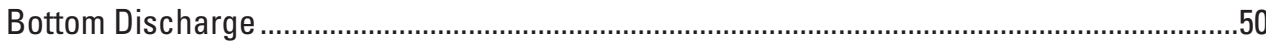

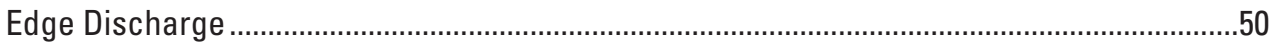




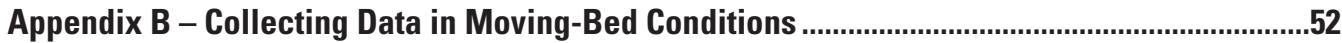

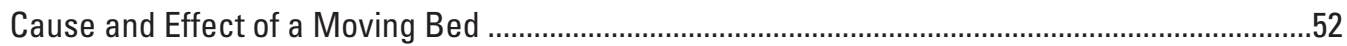

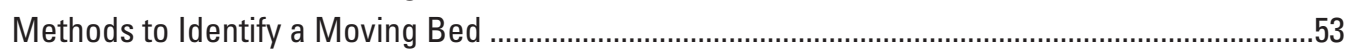

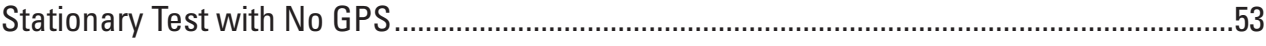

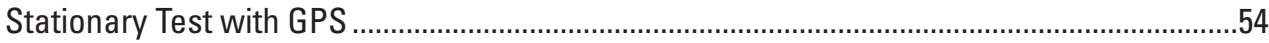

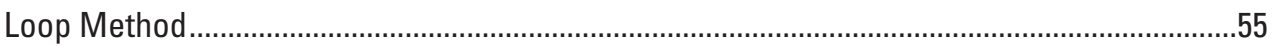

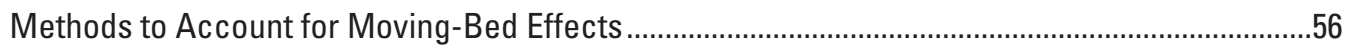

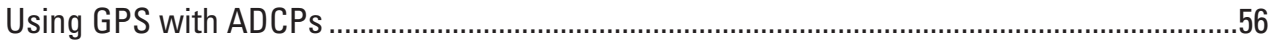

Alternatives to Using a GPS ................................................................................................

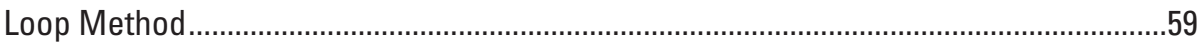

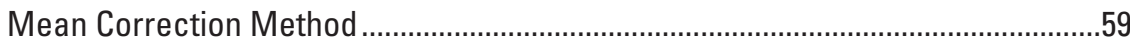

Distributed Correction Method ............................................................................60

Multiple Moving-Bed Test Method ...............................................................................60

Field Procedures .......................................................................................................

Processing Procedures ......................................................................................61

Mid-Section Method .................................................................................................

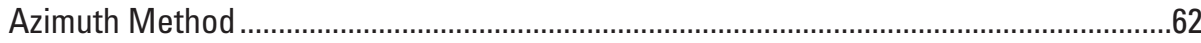

Field Procedures ……………………………………..........................................63

Processing Procedures ..........................................................................................63

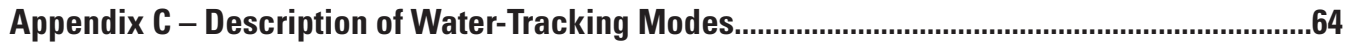

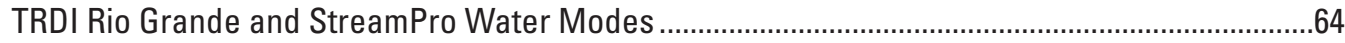

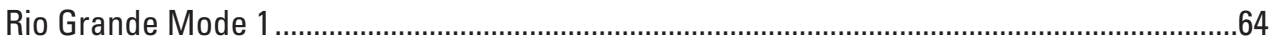

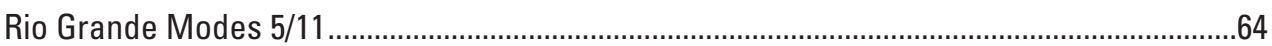

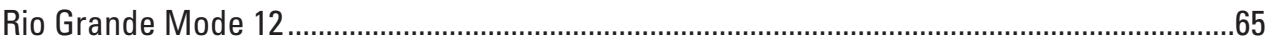

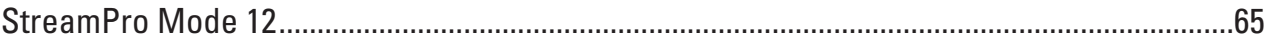

StreamPro Mode 13, Water Mode C, Low Noise Mode .......................................................65

TRDI RiverRay Auto-Adaptive Configurations .......................................................................66

SonTek RiverSurveyor Auto-Adaptive Configuration............................................................66

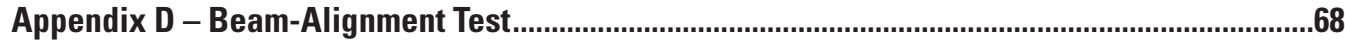

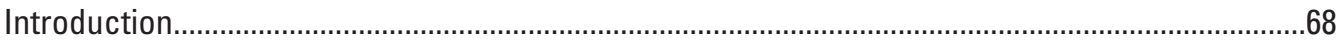

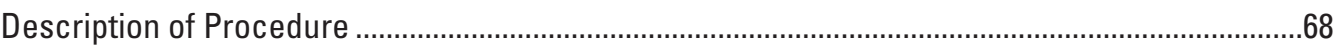

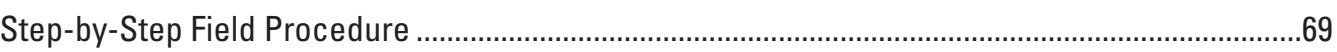

Appendix E - Forms and Quick-Reference Guides ....................................................................70

Appendix F - Measurement Processing Procedures ...................................................................75

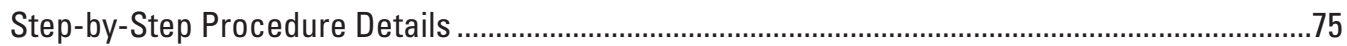

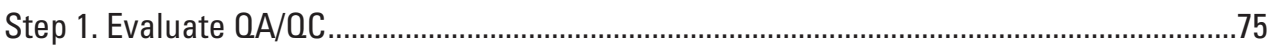

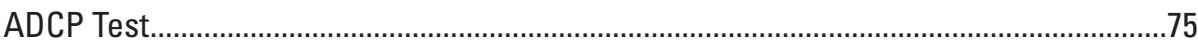

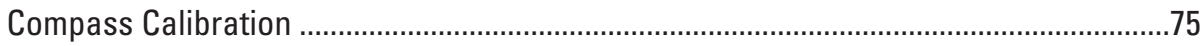

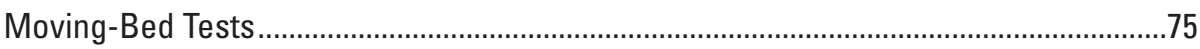

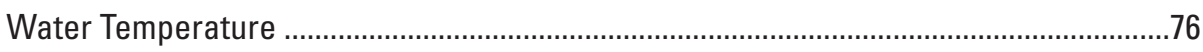

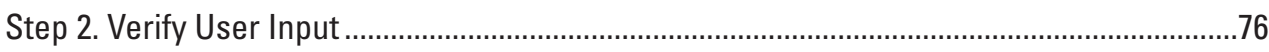

Depth of Transducer (Draft) ......................................................................................

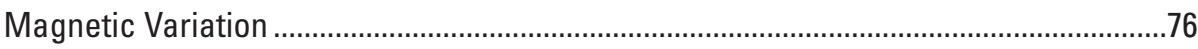

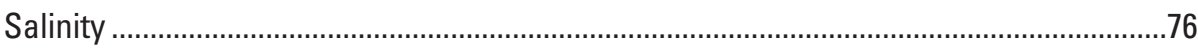

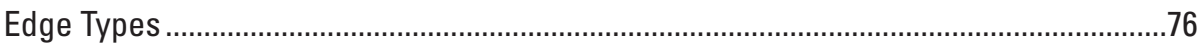

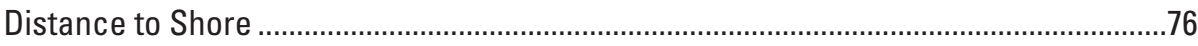

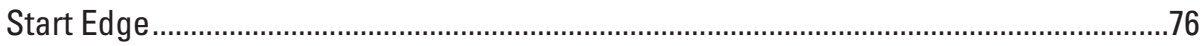


Step 3. Evaluate Tabular Data .............................................................................................76

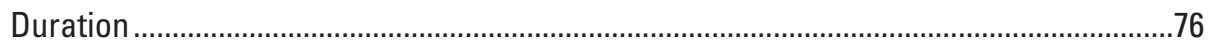

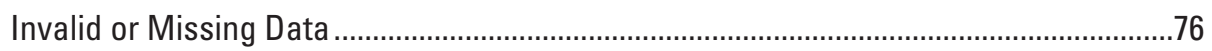

Step 4. Evaluate Ship Track and Velocity Vector Plot...............................................................

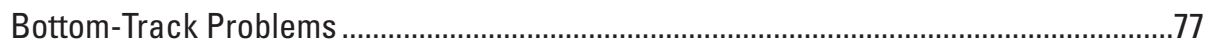

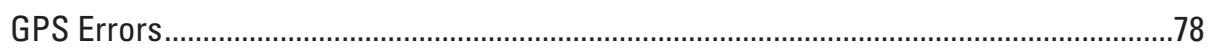

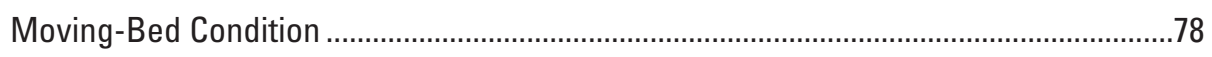

Incorrect Magnetic Variation or Inaccurate Compass Calibration ...................................78

Magnetic Interference on Compass.......................................................................... 81

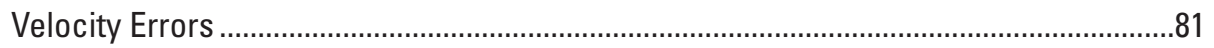

Composite Track Used Improperly (SonTek Only) ......................................................81

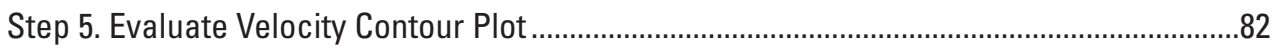

Step 6. Evaluate Echo Intensity Profile Plot ...................................................................... 84

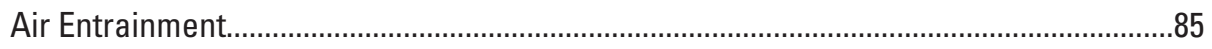

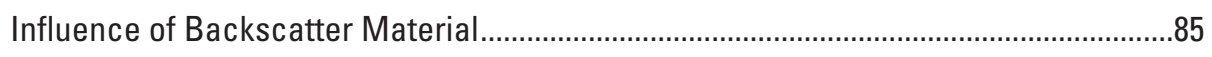

Objects in the Water Column .................................................................................

Step 7. Select Proper Extrapolation Methods .....................................................................

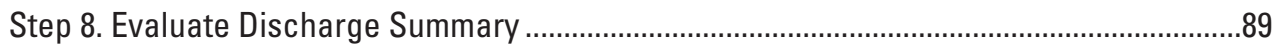

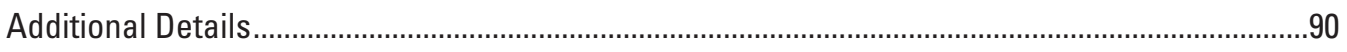

Identifying Magnetic Compass Heading Errors....................................................................90

Identifying Poor GPS Quality.................................................................................... 90

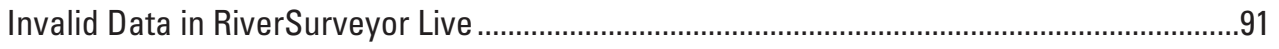

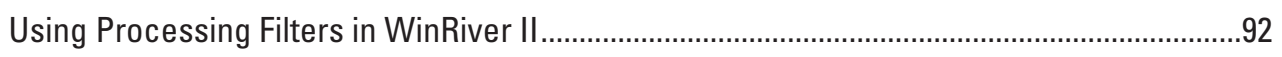

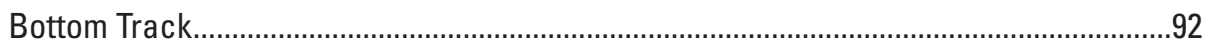

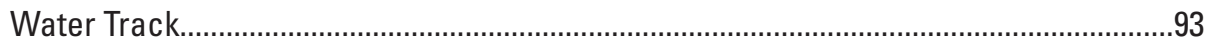

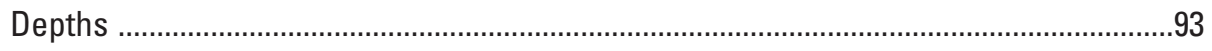

Adjusting Magnetic Variation ......................................................................................99

Subsectioning Transects in WinRiver II.........................................................................95

\section{Figures}

1. Boat-mounted acoustic Doppler current profiler (ADCP) measuring discharge using the moving-boat technique

2. Examples of different ADCP designs. A, TRDI Rio Grande, piston transducers single frequency. B, SonTek M9, piston transducers multifrequency. C, TRDI RiverRay, phased array transducer.

3. Examples of (A) excessive backscatter and (B) excessive attenuation due to sediment in the water as displayed in intensity-profile graphs from WinRiver II..............5

4. Acoustic Doppler current profiler beam pattern and locations of unmeasured areas in each profile.

5. Examples of tethered acoustic Doppler current profiler (ADCP) boats used for making discharge measurements.

6. Temporary bank-operated cableway for making acoustic Doppler current profiler (ADCP) measurements with a tethered ADCP boat. 
7. (A) Manual operated and (B) portable motorized cableway rover for deploying tethered acoustic Doppler current profilers ..

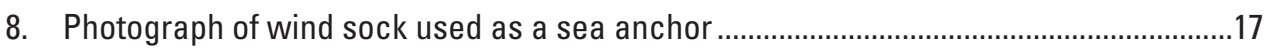

9. Examples of commercially available remote-controlled boats.......................................18

10. Example toolkit of ancillary equipment for use with acoustic Doppler current profilers (ADCPs) when making streamflow measurements

11. Example of a moving bed measured with a 1,200-kilohertz acoustic Doppler current profiler (ADCP) on the Mississippi River at Chester, Illinois.............................................25

12. A distorted ship track in a loop caused by a moving bed ..............................................27

13. Edge distances needed when using a tethered acoustic Doppler current profiler boat for discharge measurements.....................................................................................32

14. Use of a binder to sight perpendicular to the bridge ......................................................3

15. Illustration of proper start or end location in eddy at edge of stream..............................33

16. Example of flood flow where floodplain represents a panhandle-shaped edge because the ADCP could not be maneuvered through the vegetation on the floodplain

17. Example of completed acoustic Doppler current profiler discharge-measurement field note form .34

A-1. Freeway strobe-light system used to measure vehicle speed ..........................................4

A-2. Acoustic pulses for narrowband and broadband ADCP technologies.............................45

A-3. The horizontal $\left(\mathrm{V}_{\mathrm{H}}\right)$ and vertical velocity $\left(\mathrm{V}_{\mathrm{v}}\right)$ components computed from the velocity measured parallel to the acoustic path $\left(\mathrm{V}_{\mathrm{B}}\right)$

A-4. Acoustic Doppler current profiler beam pattern and locations of unmeasured areas in each profile

A-5. Boat-velocity $\left(V_{b}\right)$ and water-velocity $\left(V_{w}\right)$ vectors for a single depth cell in an ADCP ensemble

A-6. Components used to calculate estimates of discharge in the unmeasured edges of cross sections.

B-1. An example of short and long bottom-track pulses.

B-2. An example of the potential for water bias (moving bed) for short and long bottomtrack pulses

B-3. A moving bed measured with a 1,200-kilohertz acoustic Doppler current profiler (ADCP) on the Mississippi River at Chester, Illinois

B-4. Method for verifying that upstream/downstream boat movement is minimized during an acoustic Doppler current profiler moving-bed test ..........................................54

B-5. A distorted ship track in a loop caused by a moving bed ................................................5

B-6. Example of parameters used to compute the mean correction for data collected with an ADCP and displayed with (A) WinRiver and (B) RiverSurveyor

B-7. Boat-velocity vectors referenced by (A) bottom tracking and (B) global positioning system.

B-8. The azimuth method .............................................................................................62

C-1. Illustration of variable number of surface depth cells used to maintain consistent depth-cell boundaries as the standard depth-cell size change .......................................66

D-1. Acoustic Doppler current profiler (ADCP) beam-alignment test form..............................69

F-1. Examples of irregular ship track caused by errors in the bottom track ............................77

F-2. Example of multipath errors in GGA data ...............................................................78 
F-3. Examples of moving-bed condition comparing bottom track to GPS referenced ship tracks with bottom track skewed upstream for reciprocal transects, (A) Win River II,

(B) RiverSurveyor Live

F-4. Example of inconsistent deviations between bottom track and GPS referenced ship tracks for reciprocal headings (A) Win River II, (B) RiverSurveyor Live. .80

F-5. Example of magnetic interference affecting the bottom-track referenced ship track...81

F-6. Example of ambiguity velocities in stick ship track plot from WinRiver II .......................81

F-7. Example showing GGA ship track with composite tracks turned (A) on and (B) off when no GPS data were collected....

F-8. Example of a color contour plot showing a typical distribution of water velocities .......82

F-9. Example of ADCP positioned too close to a vertical wall causing the side-lobe cutoff to be high in the water column and the total depth to be biased low..............................83

F-10. Example of color contour plot showing spikes in the streambed.....................................83

F-11. Example of RiverSurveyor Live holding depth constant due to invalid depths being

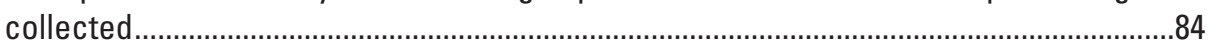

F-12. Example of color contour plot from WinRiver II showing invalid and missing data........84

F-13. Examples of typical intensity profile from WinRiver II (including data below the sidelobe cutoff and streambed) and signal to noise ratio profile from RiverSurveyor Live ...85

F-14. Example of air entrainment degrading the intensity of the acoustic signal in beams 1, 2, and 4 from WinRiver II (including data below the side-lobe cutoff and streambed)

F-15. Example of air entrainment partially blocking the acoustic signal in beam 1 from RiverSurveyor Live.

F-16. Example of intensity profiles when there is insufficient backscatter material in the water column.

F-17. Example of intensity when there is too much backscatter material in water column....87

F-18. Example of spike in intensity profile due to one beam hitting something in the water column

F-19. Extrap user interface............................................................................................8

F-20. Examples of discharge summaries from (A) RiverSurveyor Live and (B) WinRiver II.....89

$\mathrm{F}-21$. Example of directional bias in GGA referenced discharges caused by an incorrect magnetic variation

F-22. Example of discharge summary showing difference in flow direction for reciprocal transects .

F-23. Example of time series plot in RiverSurveyor Live illustrating invalid bottom track........91

F-24. Example of time series plot in RiverSurveyor Live illustrating the changing of the track reference with Composite Tracks turned on

F-25. Example of spikes in boat velocity in the boat speed time series from WinRiver II........92

F-26. Example of color contour plot from WinRiver II showing patterns in the velocity magnitudes

F-27. Example of patterns in the color contour plot of water track error and up velocities in WinRiver II

F-28. Example of using distance made good for the original and subsectioned transect to compute the distance to add to the subsectioned edge. 


\section{Tables}

1. Characteristics of SonTek/YSI RiverSurveyor M9/S5 acoustic Doppler current

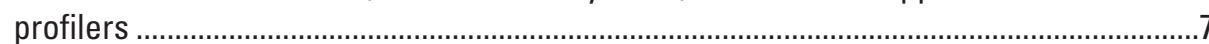

2. Characteristics of Teledyne RD Instruments Rio Grande water-profiling modes for 1,200- and 600-kilohertz acoustic Doppler current profilers ...........................................8

3. Characteristics of Teledyne RD Instruments StreamPro acoustic Doppler current profiler water profiling modes.

4. Characteristics of Teledyne RD Instrument RiverRay acoustic Doppler current profiler auto-adaptive configuration

5. Quality-assurance test requirements for acoustic Doppler current profilers (ADCPs)..11

6. Advantages and disadvantages of acoustic Doppler current profiler (ADCP) mounting locations on manned boats.

7. List of ancillary equipment to be used with acoustic Doppler current profilers when making streamflow measurements

8. Methods for identifying a moving-bed condition, criteria for correction, and minimum durations

9. Methods to account for moving-bed conditions in priority order

C-1. Characteristics of Teledyne RD Instrument RiverRay acoustic Doppler current profiler auto-adaptive configuration

C-2. Summary of water-tracking frequency, depth-cell size, and ping type for RiverSurveyor M9

\section{Conversion Factors}

Inch/Pound to SI

\begin{tabular}{lll}
\hline \multicolumn{1}{c}{ Multiply } & \multicolumn{1}{c|}{ By } & \multicolumn{1}{c}{ To obtain } \\
\hline & Length & \\
\hline foot $(\mathrm{ft})$ & 0.3048 & meter $(\mathrm{m})$ \\
mile $(\mathrm{mi})$ & 1.609 & kilometer $(\mathrm{km})$ \\
& Flow rate & \\
\hline foot per second (ft/s) & 0.3048 & meter per second $(\mathrm{m} / \mathrm{s})$ \\
cubic foot per second $\left(\mathrm{ft}^{3} / \mathrm{s}\right)$ & 0.02832 & cubic meter per second $\left(\mathrm{m}^{3} / \mathrm{s}\right)$ \\
\hline
\end{tabular}

SI to Inch/Pound

\begin{tabular}{lll|}
\hline \multicolumn{1}{r}{ Multiply } & \multicolumn{1}{c|}{ By } & \multicolumn{1}{c|}{ To obtain } \\
& Length & \\
\hline centimeter $(\mathrm{cm})$ & 0.3937 & inch (in.) \\
millimeter (mm) & 0.03937 & inch (in.) \\
meter (m) & 3.281 & foot (ft) \\
\hline
\end{tabular}

Temperature may be converted as follows:

${ }^{\circ} \mathrm{F}=\left(1.8 \times{ }^{\circ} \mathrm{C}\right)+32$

${ }^{\circ} \mathrm{C}=\left({ }^{\circ} \mathrm{F}-32\right) / 1.8$ 


\section{Abbreviations:}

\begin{tabular}{|c|c|}
\hline ABS & acoustic backscatter \\
\hline $\mathrm{ADCP}$ & acoustic Doppler current profiler \\
\hline ADP & acoustic Doppler profiler \\
\hline ADV & acoustic Doppler velocimeter \\
\hline $\mathrm{BB}$ & broadband \\
\hline CD-ROM & compact disc-read-only memory \\
\hline CMG & course made good \\
\hline DBT & depth below transducer \\
\hline $\mathrm{DC}$ & direct current \\
\hline DGPS & differentially corrected global positioning system \\
\hline DMG & distance made good \\
\hline DOP & dilution of precision \\
\hline EMF & electromagnetic field \\
\hline FAA & Federal Aviation Administration \\
\hline GPS & global positioning system \\
\hline HDOP & horizontal dilution of precision \\
\hline $\mathrm{Hz}$ & hertz \\
\hline $\mathrm{kHz}$ & kilohertz \\
\hline LAN & local area network \\
\hline $\mathrm{LC}$ & Loop Correction \\
\hline $\mathrm{MHz}$ & megahertz \\
\hline NMEA & National Marine Electronics Association \\
\hline NWIS & National Water Information System \\
\hline PCMCIA & Personal Computer Memory Card International Association \\
\hline PDA & portable digital assistant \\
\hline ppt & parts per thousand \\
\hline RTK & real-time kinematic \\
\hline SMBA & Stationary Moving-Bed Analysis \\
\hline SNR & signal to noise ratio \\
\hline SWAMI & Surface WAter Measurement and Inspection \\
\hline TRDI & Teledyne RD Instruments \\
\hline USB & Universal Serial Bus \\
\hline USGS & U.S. Geological Survey \\
\hline VRS & virtual reference station \\
\hline WAAS & Wide Area Augmentation System \\
\hline WM & water mode \\
\hline WM12sp & water mode 12 in StreamPro \\
\hline WP & water ping \\
\hline WV340 & ambiguity velocity of 340 millimeters per second \\
\hline YSI & Yellow Springs Instruments \\
\hline
\end{tabular}




\title{
Measuring Discharge with Acoustic Doppler Current Profilers from a Moving Boat
}

\author{
By David S. Mueller, Chad R. Wagner, Michael S. Rehmel, Kevin A. Oberg, and Francois Rainville
}

\begin{abstract}
The use of acoustic Doppler current profilers (ADCPs) from a moving boat is now a commonly used method for measuring streamflow. The technology and methods for making ADCP-based discharge measurements are different from the technology and methods used to make traditional discharge measurements with mechanical meters. Although the ADCP is a valuable tool for measuring streamflow, it is only accurate when used with appropriate techniques. This report presents guidance on the use of ADCPs for measuring streamflow; this guidance is based on the experience of U.S. Geological Survey employees and published reports, papers, and memorandums of the U.S. Geological Survey. The guidance is presented in a logical progression, from predeployment planning, to field data collection, and finally to post processing of the collected data. Acoustic Doppler technology and the instruments currently (2013) available also are discussed to highlight the advantages and limitations of the technology. More in-depth, technical explanations of how an ADCP measures streamflow and what to do when measuring in moving-bed conditions are presented in the appendixes. ADCP users need to know the proper procedures for measuring discharge from a moving boat and why those procedures are required, so that when the user encounters unusual field conditions, the procedures can be adapted without sacrificing the accuracy of the streamflowmeasurement data.
\end{abstract}

\section{Introduction}

The acoustic Doppler current profiler (ADCP) has evolved during the last 25 years from an experimental instrument capable of measuring velocity and computing discharge in deep water (greater than 11 feet (ft)) to an instrument that is commonly used to measure water velocity and discharge in streams as shallow as $1.0 \mathrm{ft}$ deep (Christensen and Herrick, 1982; Simpson and Oltmann, 1993; Oberg and Mueller, 2007b). The development of the ADCP has provided hydrographers and hydrologists with a tool that can substantially reduce the time for making discharge measurements and can measure water velocities at a spatial and temporal scale that was previously unattainable. These instruments are used regularly to measure riverine and estuarine water discharge, to collect data for hydrodynamic model calibration and verification, to assess aquatic habitat, and to study sediment transport processes. Although the use of the ADCP has become common, proper instrument configuration and data-collection and post-processing procedures are required to collect accurate and reliable data.

\section{Purpose and Scope}

The purpose of this report is to present the procedures that should be followed when using an ADCP from a moving boat to make surface-water discharge measurements. The procedures for predeployment preparation, field data collection, and processing of collected data are discussed. A detailed description of how an ADCP measures velocity and computes discharge and additional details on selected topics are presented in appendixes.

\section{Applications}

The measurement of unsteady, bidirectional, and other flows with nonlogarithmic velocity distributions has been a problem faced by hydrographers and hydrologists for many years. Dynamic discharge conditions impose an unreasonable time constraint on conventional current-meter dischargemeasurement methods, which typically take at least 1 hour to complete. Tidally affected discharge can change more than 100 percent during a 10-minute period. In addition, bidirectional flows caused by density currents are common in tidally affected areas and have been increasingly observed in freshwater environments where a significant temperature gradient causes a density current (García and others, 2007). Nearly all discharge measurements made using point-velocity meters have an assumed standard logarithmic distribution of the horizontal velocity in the water column; however, wind-driven currents and very rough bottoms in shallow water may produce nonstandard profiles. The introduction of the ADCP into the coastal and riverine environments has enabled the development of a discharge-measurement system capable of more efficiently and more accurately measuring 
flow in unsteady, bidirectional, and nonstandard conditions. In most cases, an ADCP discharge-measurement system is faster than conventional discharge-measurement systems and has comparable or better accuracy because ADCPs measure a much larger portion of the water column than conventional discharge-measurement systems. More efficient discharge measurements improve safety by reducing the amount of time a hydrographer is on a bridge, on a boat, or in the water. The reduction in measurement time realized by using an ADCP is especially beneficial when trying to develop an index-velocity rating (Morlock and others, 2002; Ruhl and Simpson, 2005) at sites with rapidly changing flow conditions. An ADCP can define the rating in the transitional range of flow that was otherwise indefinable with conventional discharge methods. In addition to measuring streamflow, ADCPs are used in a variety of other applications, including

- measurement of velocity fields for calibration of numerical models, hydraulic studies (for example, safety zones near dams), and habitat assessments;

- in situ deployments for current measurements and for aiding navigation;

- hydrographic surveys to measure channel bathymetry for use in hydrodynamic and habitat modeling applications; and

- estimation of sediment concentration from acoustic backscatter (ABS).

The application of acoustic technology in rivers and lakes has provided data that prior to the mid-1990s would have been unavailable or extremely expensive and impractical to collect.

\section{Discussion of Instruments}

The ADCP uses sound to measure water velocity. The sound transmitted by the ADCP is in the ultrasonic range (above the range heard by the human ear). The lowest frequency used by commercial ADCPs is about 30 kilohertz $(\mathrm{kHz})$, and the common range for riverine measurements is between 300 and $3,000 \mathrm{kHz}$. The ADCP measures water velocity using a principle of physics discovered by Christian Johann Doppler (1842). Doppler's principle relates the change in frequency of a source to the relative velocities between the source and the observer. An ADCP applies the Doppler principle by reflecting an acoustic signal off small particles of sediment and other material (collectively referred to as scatterers) that are present in water. The velocity measured by the Doppler principle is parallel to the direction of the transducer emitting the signal and receiving the backscattered acoustic energy. Typical boat-mounted ADCPs have three or four beams pointing between 20 and 30 degrees from the vertical. Three beams are required to obtain a three-dimensional velocity measurement. If a fourth beam is present, an additional quality check can be measured (Appendix A).

In a boat-mounted system, the transducers are deployed beneath the water surface and aimed downward (fig. 1). Measurement of water velocity from a moving boat will yield the velocity of the water relative to the boat. ADCPs used in this manner account for the velocity of the boat by bottom tracking or through the use of a global positioning system (GPS). Bottom tracking determines the velocity of the boat by measuring the Doppler shift of acoustic signals reflected from the streambed; therefore, the water velocity relative to a fixed reference is computed by correcting the measured water velocity with the measured boat velocity.

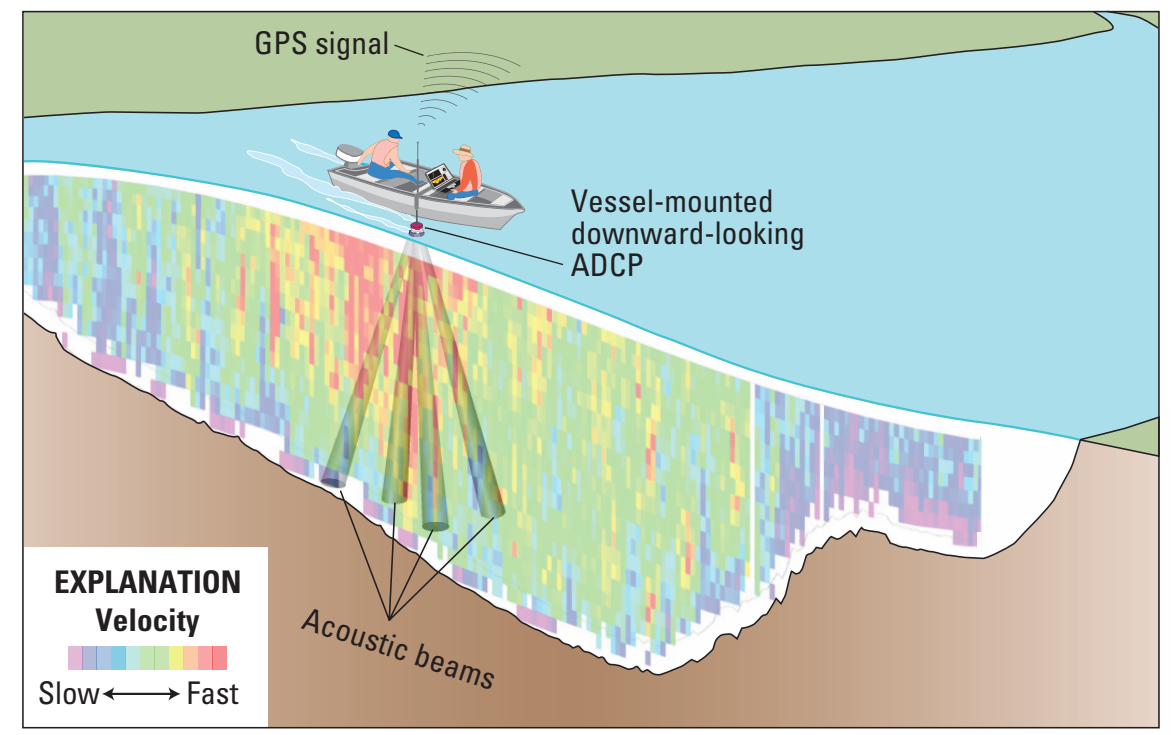

Figure 1. Illustration of a boat-mounted acoustic Doppler current profiler (ADCP) measuring discharge using the moving-boat technique. 

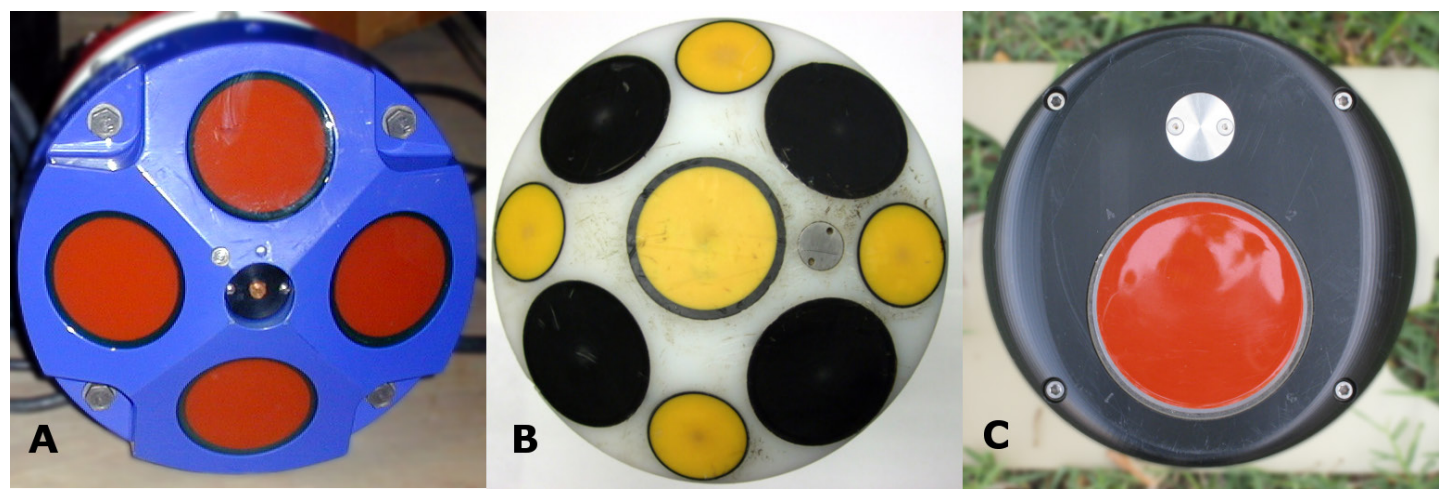

Figure 2. Examples of different ADCP designs. A, TRDI Rio Grande, piston transducers single frequency. B, SonTek M9, piston transducers multifrequency. C, TRDI RiverRay, phased array transducer.

Technological advances have resulted in new ADCP designs and features. Currently (2013) available ADCPs (fig. 2) vary by the type of signal processing, acoustic frequency, transducer design, number of transducers, and ping configuration algorithms. Traditionally, the type of signal processing has been classified into two groups - narrowband and broadband. Narrowband typically is used in the hydroacoustic industry to describe a pulse-to-pulse incoherent ADCP; however, the narrowband ADCPs also can operate in a pulse-to-pulse coherent mode for short ranges. This means that in a narrowband ADCP, only one simple pulse is transmitted into the water, per beam per measurement (ping), and the resolution of Doppler shift takes place during the duration of the received pulse. This characteristic results in a system that is simple to configure and operate, but the velocity measurements made using the narrowband technology are noisy (have a relatively large random error). Narrowband systems compensate for the large random error by pinging fast (up to 70 hertz $(\mathrm{Hz})$ ) and averaging many pings together before reporting a velocity. Broadband systems use a ping consisting of two or more synchronized acoustic pulses that are encoded with a pseudo-random code. The encoded pulse allows multiple velocity measurements to be made with a single ping, thus reducing the random noise associated in the measured velocity.

ADCPs designed for riverine measurements typically have operating frequencies of 300 to $3,000 \mathrm{kHz}$. Until recently, ADCPs have operated at a fixed frequency; however, since 2008 ADCPs have been developed that operate at multiple frequencies.

Piston transducers are used in the majority of ADCPs. The use of piston transducers requires a transducer oriented from the vertical at the predetermined beam angle. For a single frequency ADCP using piston transducers, a minimum of three transducers is required, although most ADCPs are designed with four transducers. Currently (2013), multifrequency designs require separate transducers for each frequency, so a dual frequency system based on piston transducer may have eight transducers.

The use of phased array transducers has recently been introduced. The phased array transducer is composed of many elements that can be used to form multiple beams at various angles, depending on the transducer design. Thus, only a single phased array transducer mounted parallel with the bottom of the ADCP is required to form the three or four beams needed for an ADCP.

Another development since 2008 is auto-adaptive configurations. Prior to auto-adaptive configurations, a fixed configuration was set at the beginning of the transect, and the entire cross section was measured with that configuration. Auto-adaptive configurations change the configuration of the water and (or) bottom-tracking algorithms to obtain the best possible data as depths and water velocities change across the cross section. These configuration changes may include but are not limited to (1) depth-cell size, (2) acoustic frequency, (3) type of signal processing, and (4) ping configuration.

\section{Preparation and Equipment}

Prior to collecting data with an ADCP, it is important to establish standard procedures to ensure that the data collected will be stored in an efficient and consistent manner, the ADCP is in proper working order, and the ADCP is the appropriate equipment for making the measurement. Proper preparation will help avoid delays in the field, ensure complete and accurate data collection, and produce data that are documented and retrievable for future use.

\section{Data Management}

The ADCP and associated software can produce a large number of files. It is important that these files are stored in a manner that allows users to easily identify the location, date, and type of data stored in the files. Because of the volatility of digital data, appropriate backup and archival procedures should also be implemented. All aspects of data management must follow agency policy and be documented in the office's surface-water quality-assurance plan. 


\section{Naming Convention}

Each office should establish and document a consistent naming convention for data files. Names of files should be unique and should be descriptive of the data contained. Site number, site name, measurement number, project name, project number, and date are some of the descriptive terms that could be used in a filename. Typically, ADCP data-collection software will add a suffix to the user-defined name to identify the type of data file (configuration, raw data, ASCII data, etc.) and to ensure that each file has a unique name.

\section{Data Storage and Archival}

Each office collecting electronic discharge-measurement data must have a written policy about permanent file storage and archiving procedures. This policy must reference and document any additions to, or deviations from, applicable agency policy. Procedures outlined herein are based on the assumption that an office has existing systems and procedures for performing routine backups and permanent archival for electronic information stored on servers. This policy should detail file and directory naming conventions, server directory structure, how soon data must be placed on the server after it is collected, and how, when, and where server data will be archived on stable archival media. USGS, Office of Surface Water Technical Memorandum 2005.08 (U.S. Geological Survey, 2005a) provides specific archival guidance. Offices are encouraged to scan paper measurement notes to an electronic file and store them with the electronic data files for the measurement. Paper measurement notes associated with an electronic discharge measurement should be filed and archived with other paper discharge-measurement notes in accordance with current office policies and procedures. Each discharge measurement with electronic data files should have its own directory that contains all of the files collected or created as part of the measurement. These files include, but are not limited to, raw data, configuration information, moving-bed tests, instrument checks, and compass calibration information. The naming convention for the directories in the archival directory structure should include some combination of measurement number, measurement dates, water year, location, and (or) instrument types unless otherwise specified by agency policy.

\section{Training}

The operation of ADCP systems is becoming more automated; however, some basic understanding of acoustical physics, ADCP operation, and the manufacturers' dischargemeasurement software is necessary to ensure the best possible data are collected. ADCP users must comply with the agency required training standards. Trained ADCP users are highly encouraged to attend additional training classes, short courses, and webinars to stay current on enhancements and developments in hydroacoustic instruments and software. The USGS hydroacoustics Web pages (http://hydroacoustics.usgs.gov) provide information on training, webinars, short courses, and current information on the latest hydroacoustic instruments, software, and procedures.

\section{Instrument and Site Considerations}

Any site-specific information, such as maximum water depths and velocities from previous measurements, can be used as a guide for selecting and (or) configuring an ADCP for the measurement site. Notes about conditions and locations from previous ADCP discharge measurements should be reviewed prior to the field trip.

\section{Limitations of ADCPs}

The physics associated with sound generation from a transducer and then propagation, absorption, attenuation, and backscatter in the water column result in specific limitations and characteristics of ADCPs. Limitations that will be discussed in this report include the effect of sediment on backscattered acoustic energy and bottom tracking, and unmeasured areas of a profile associated with transducer draft and ringing and side-lobe interference. Additional limitations are imposed on ADCP measurements by the techniques used to configure and process the acoustic signal, which vary based on specific configuration of the instrument.

\section{Effect of Sediment}

The quantity and characteristics of the particulate matter (such as sediment and aquatic life) in the water column can substantially affect the ability of the ADCP to make an accurate velocity measurement. Pure water is acoustically 


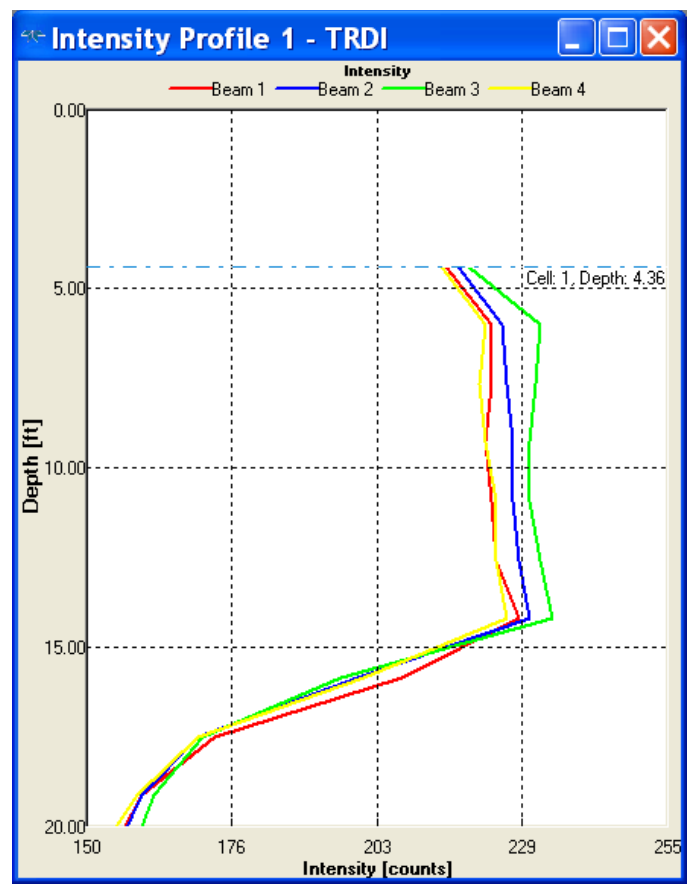

A) Excessive Backscatter

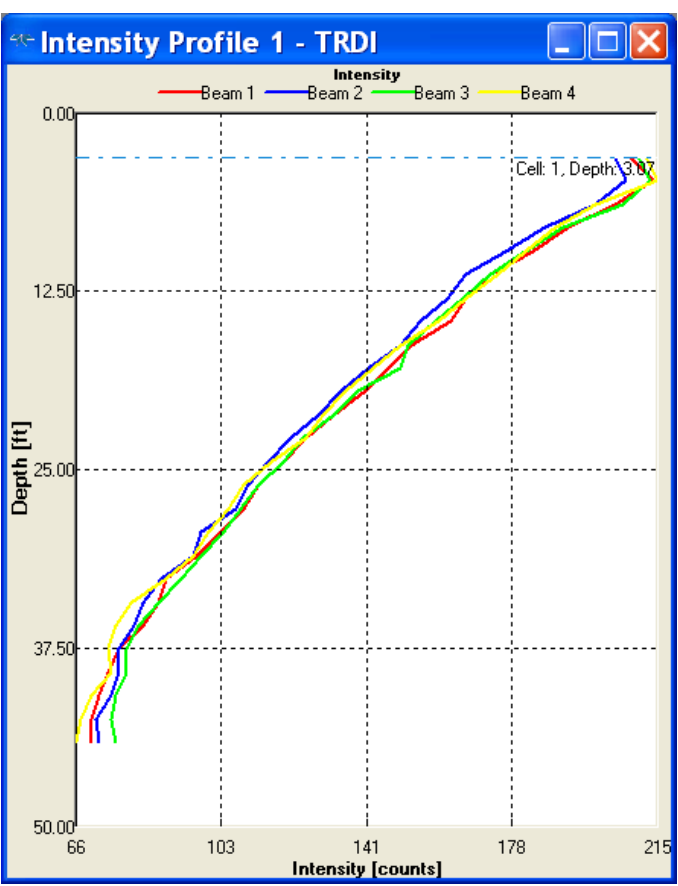

B) Excessive Attenuation

Figure 3. Examples of $(A)$ excessive backscatter and $(B)$ excessive attenuation due to sediment in the water as displayed in intensity-profile graphs from WinRiver II.

transparent because it has no suspended particulate matter to reflect acoustic energy. For a velocity measurement to be made, water must contain enough particulate matter for sufficient acoustic energy to be returned to the ADCP. Therefore, in very clear streams it is possible to have insufficient material in the water column to allow an ADCP to measure water velocity. High sediment loads, which are often present during high-flow conditions, can have the opposite effect. High sediment concentrations near the streambed can cause the ADCP to have trouble discriminating the streambed from the suspended-sediment concentration near the streambed, resulting in inaccurate water depth and (or) invalid boatvelocity measurements (fig. 3A). In addition, high sediment concentrations in the water column can cause the acoustic signal to be attenuated before it can travel through the water column and back to the transducer, thus preventing the ADCP from making a measurement (fig. 3B). The sediment concentrations that trigger these limitations on ADCP operation have been observed but not quantified; these limitations depend on the sediment characteristics, water depth, and instrument frequency. In general, lower frequency acoustic instruments transmit more energy into the water and, therefore, are more capable of penetrating high sediment concentrations than higher frequency instruments.
During high flows, sediment transport near and along the streambed can cause a bias in the boat velocity determined from bottom tracking. Bottom tracking is used to determine the boat velocity and assumes that the streambed is stationary. Sediment transport near and along the streambed can cause a Doppler shift in the bottom-tracking ping and can result in the boat-velocity measurement being biased in the upstream direction. This phenomenon is commonly referred to as a moving bed. If an ADCP is held stationary in a stream with a moving bed, a trace of the instrument motion based on bottom tracking shows the instrument moving upstream rather than being stationary. The result of a moving bed is that measured velocities and discharges will be biased low. Higher frequency instruments are more susceptible to moving-bed problems than are lower frequency instruments. Currently, there is no quantitative guidance for when a moving bed will be detected by an instrument, but tests to detect a moving bed are available and are discussed later in this report. If a moving bed is detected and the instrument is equipped with a compass, the use of GPS for measuring boat velocity is recommended. If the use of a GPS is not possible because site conditions are unfavorable, the instrument does not have a compass, or an accurate heading cannot be achieved throughout the cross section, other means to correct the discharge for the bias caused by the moving bed are available (Appendix B). 


\section{Unmeasured Areas in a Profile}

ADCPs are called profilers because they provide measurements of velocity throughout the water column. The ADCP divides the water column into depth cells (also referred to by some software and references as bins) and reports a velocity for each depth cell; however, an ADCP cannot measure velocities at the water surface due to the draft of the instrument and the required blanking distance, nor can it measure near the bed due to side-lobe interference (fig. 4).

The length of the unmeasured area at the water surface is due to the draft of the instrument deployment, the effect of the transducer mechanics, and the flow disturbance around the instrument. The ADCP must be deployed below the water surface and, thus, cannot measure the water velocity above the transducers. The required instrument draft is controlled by the need to prevent the instrument from coming out of the water and to prevent entrained air from traveling under the instrument; therefore, the required instrument draft depends on the shape of the instrument mount, the boat, and the relative water velocity (water velocity past the instrument).

ADCPs use the same transducers to transmit and receive sound. When a transducer is energized to transmit sound, it vibrates to produce the sound waves. When the energy to the transducer is stopped, the transducer does not stop vibrating immediately; rather, the vibrations dampen with time. The continued vibration of the transducer is called ringing and may be affected by the transducer housing and the ADCP mount. A good analogy of this effect is a large gong. The vibrations from a gong sometimes take several minutes to die out. The vibrations in a transducer die out much quicker than a gong, but sound travels some distance during the time it takes for

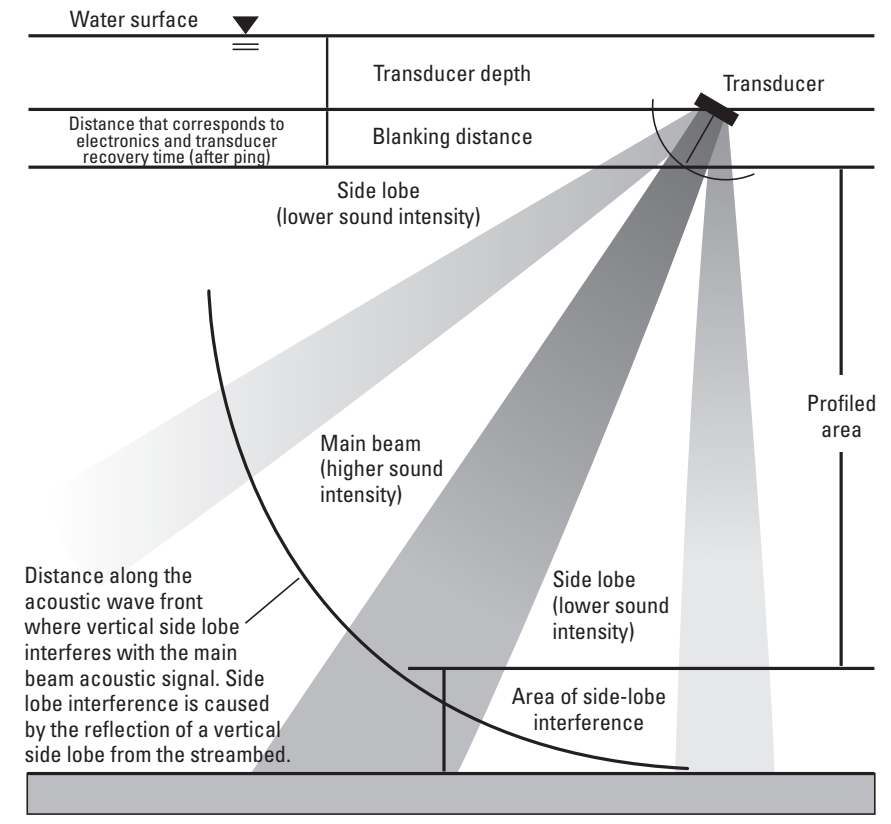

Figure 4. Acoustic Doppler current profiler beam pattern and locations of unmeasured areas in each profile (from Simpson, 2002). the ringing to be reduced to a level where the transducer can accurately record backscattered acoustic signals. The distance that sound travels during the time it takes the ringing to be reduced is the minimum blanking distance. Depending on the frequency (typically lower frequency instruments have longer blanking distances) and the transducer housing, the blanking distance can vary from 0.06 to $3.3 \mathrm{ft}$.

The flow disturbance caused by the instrument and its mount may also be a limiting factor of how close to the instrument an unbiased measurement of velocity can be made. Results from field data and numerical modeling suggest that for typical deployments, a blank of $0.82 \mathrm{ft}$ ( 25 centimeters (cm)) for Teledyne RD Instruments (TRDI) Rio Grandes (Mueller and others, 2007) and $0.1 \mathrm{ft}(3 \mathrm{~cm})$ for TRDI

StreamPros is acceptable. In the standard auto-adaptive mode, the TRDI RiverRay adjusts the blanking distance so that the range to the center of the first depth cell is always $0.82 \mathrm{ft}$ $(25 \mathrm{~cm})$ from the transducer, which is acceptable for flow disturbance considerations. Numerical modeling and analysis of field data to date (2013) suggest that flow disturbance may affect the measured profile to a range of about $0.66 \mathrm{ft}(20 \mathrm{~cm})$ from the bottom of SonTek/YSI RiverSurveyor M9s. This is particularly important when the 3-MHz beams are used in SmartPulse ${ }^{\mathrm{HD}}$ mode because several depth cells are collected in this range. In shallow water $(<3 \mathrm{ft})$, the extent of the bias has been shown to be reduced to about $0.52 \mathrm{ft}$ because of the effect of the streambed on the flow beneath the ADCP. Data collected within $0.52 \mathrm{ft}$ of the bottom of M9s should be considered to be biased low. These biased data can be removed from the measurement using "screening distance" in System Settings of RiverSurveyor Live (Note: Currently RiverSurveyor Live documentation indicates that the "screening distance" is below the transducer, but the software actually measures it from the water surface, so implemented in the software you must set screening distance to the draft plus 0.52 $\mathrm{ft}$ to eliminate data within $0.52 \mathrm{ft}$ of the transducers). Although no modeling has been completed on the RiverSurveyor S5, limited field data have not indicated a bias in the velocity profiles. The criteria provided above are based on typical deployments; the deployment method and mount can influence the extent of the flow disturbance (Mueller and others, 2007).

ADCPs cannot measure the water velocity near the streambed due to side-lobe interference (fig. 4). Most transducers that are developed using current (2013) technology emit parasitic side lobes off of the main acoustic beam. The acoustic energy in the side lobes is much less than in the main beam. The amount of acoustic energy backscattered from scatterers in the water column in the main beam is very small compared to the energy transmitted. The streambed reflects a much higher percentage of the acoustic energy than the scatterers in the water column. The magnitude of the energy in a side-lobe reflection from the streambed is sufficiently close to the energy reflected from scatterers in the main beam to cause potential errors in the measured Doppler shift. The water column affected by this side-lobe interference varies from 
6 percent for a 20-degree system to 13 percent for a 30-degree system and can be computed as

$$
D_{S L}=D *(1-\cos (\theta))
$$

where

$D_{S L}$ is the distance from the streambed affected by side-lobe interference;

$D \quad$ is the distance from the transducer to the streambed (typically the distance associated with the shallowest beam depth for each ensemble); and

$\theta \quad$ is the angle of the transducers from the vertical.

The frequency and the techniques used to configure and process the acoustic signal are important in determining the maximum and minimum water depths that can be measured. Lower frequency ADCPs typically can measure deeper than higher frequency ADCPs but also require larger depth cells and a longer blanking distance. The operational mode of some ADCPs determines the location of the first and last valid depth cells and the acceptable size of the depth cells. The ADCP cannot measure the velocity in the upper and lower portions of the water column because of the draft, blanking distance, and side-lobe interference; therefore, the discharge in these areas must be estimated from data collected in the measured portion of the water column. For this reason, it is recommended that a minimum of two depth cells be measured in the water column. The shallow-water limitation of an instrument is, therefore, the summation of the draft, blanking distance, location of the first depth cell, location of the last depth cell, the depth-cell size, and the range of the side-lobe interference.

\section{Configuration and Characteristics}

Site conditions, such as stream depth, water velocity, and bed material, ultimately dictate which instrument and instrument setup will provide the most accurate discharge measurement. Each of the currently (2013) available instruments have specific characteristics and configuration options. A brief summary of these characteristics and configuration options is provided herein, but due to continuous technical advances the user should seek the latest information from USGS Office of Surface Water Technical Memorandums and Informational and Technical Notes as well as the manufacturers' technical documentation.

The SonTek RiverSurveyor M9 and S5 ADCPs (SonTek, 2012) are multifrequency ADCPs with a low frequency vertical beam and auto-adaptive configuration algorithms. The S5 is a $3-\mathrm{MHz}$ five-beam ADCP with the fifth beam being a 1-MHz vertical beam for additional depth measurements. The M9 is a nine-beam system with four $1-\mathrm{MHz}$ and four $3-\mathrm{MHz}$ beams for water and bottom tracking and a $500-\mathrm{kHz}$ vertical beam for additional depth measurements. The auto-adaptive configuration algorithm allows changing frequency for water and bottom tracking (M9 only), variable depth-cell sizes, and incoherent or pulse coherent ping configuration and processing depending on water depth and velocity. Incoherent ping configuration and processing provides a robust method of measuring the Doppler shift, but the random noise associated with this approach is high. The random noise is reduced by pinging fast and averaging multiple pings, typically for about 1 second, before reporting a measured velocity. The pulse coherent ping configuration and processing are designed for shallow-water and low-velocity situations and have low random errors and allow for small depth-cell sizes. A more detailed discussion of ping configuration and processing is presented in Appendixes A and C. A summary of the characteristics of the $1-\mathrm{MHz}$ and $3-\mathrm{MHz}$ water profiling beams is provided in table 1 .

Table 1. Characteristics of SonTek/YSI RiverSurveyor M9/S5 acoustic Doppler current profilers.

$[\mathrm{kHz}$, kilohertz; ft, foot; ft/s, foot per second; IC, incoherent; HD, high definition pulse coherent; cm, centimeter; NA, not available]

\begin{tabular}{ccccc}
\hline $\begin{array}{c}\text { Frequency, in kHz } \\
\text { (Mode) }\end{array}$ & $\begin{array}{c}\text { Typical maximum } \\
\text { profiling depth, } \\
\text { in ft }\end{array}$ & $\begin{array}{c}\text { Typical maximum } \\
\text { relative velocity, } \\
\text { in ft/s }\end{array}$ & $\begin{array}{c}\text { Minimum recom- } \\
\text { mended depth-cell } \\
\text { size, in ft }\end{array}$ & $\begin{array}{c}\text { 1-second standard } \\
\text { deviation, }{ }^{\text {d in ft/s }}\end{array}$ \\
\hline 1,000 (IC) & 131 & 65 & $1.6(50 \mathrm{~cm})$ & 0.3 \\
1,000 (HD) & 16 & 1.3 & $0.2(6 \mathrm{~cm})$ & N/A \\
3,000 (IC) & 16 & 65 & $0.32(10 \mathrm{~cm})$ & 0.3 \\
3,000 (HD) & 5 & 1.3 & $0.07(2 \mathrm{~cm})$ & $\mathrm{N}^{\mathrm{e}} / \mathrm{A}^{\mathrm{e}}$
\end{tabular}

aC refers to pulse incoherent mode, and HD refers to SonTek's SmartPulse HD pulse coherent mode.

${ }^{b}$ The actual maximum depth that can be profiled depends on the water temperature and sediment in suspension.

'The maximum velocity measured by the acoustic Doppler current profiler, which includes the boat and water speeds.

${ }^{\mathrm{d} A p p r o x i m a t e}$ values. Assumes minimum recommended depth-cells size. Actual value may vary with depth, number, and frequency of bottom track pings and hydraulic conditions.

${ }^{e}$ Values for the standard deviation are not available from the manufacturer, but they are at least an order of magnitude less than the incoherent mode given the same frequency, cell size, and profiling range (David Velasco, SonTek, written commun., January 2013). 
The ADCPs manufactured by TRDI are all single frequency with broadband technology for ping configuration and offer multiple water and bottom modes. The Rio Grande and StreamPro (Teledyne RD Instruments 2007b, 2008b) are piston transducer systems that require the configuration be set prior to data collection. The RiverRay (Teledyne RD Instruments, 2012) is a phased array transducer system with an auto-adaptive configuration algorithm. Data-collection software for the Rio Grande and StreamPro (Teledyne RD Instruments, 2003, 2007a) has a configuration wizard that optimizes the instrument setup on the basis of the maximum expected velocity, boat speed, water depth, and bed material type.

Water modes offered in Rio Grande ADCPs allow the instrument to be optimized for the water velocity, depth, and bed material present at the time of the measurement. Each water mode has associated advantages and disadvantages. Water mode 1 is a robust multipurpose mode that can work in nearly all conditions, but the random errors (noise) associated with this mode limits the practical application in shallow, low-velocity situations. Water modes 5 and 11 are designed for low-velocity (less than 2.3 to 3.3 feet per second (ft/s), depending on frequency), shallow-water (less than 13 to $26 \mathrm{ft}$, depending on frequency) situations and have specific velocity and depth limitations. The advantages of water modes 5 and 11 are very low random errors and small depth-cell sizes. Water mode 12 is a fast ping-rate mode that is similar to water mode 1 , but uses a faster ping rate and an internal averaging technique of multiple pings per ensemble to reduce the random error associated with normal mode 1 measurements. (Note: Samples and ensembles are terms that have been used interchangeably in literature and manufacturer documentation. The term ensemble will be used in this report to generally refer to any combination of pings and data averaging that results in a measurement of the velocity profile that could be communicated to the data-collection software and viewed by the user. However, when referring to manufacturer specific software the manufacturer specific term will be used to avoid confusion with terminology in the software.) This reduction in random error by mode 12 allows smaller depth cells to be used or lower velocities to be measured with greater accuracy. The heading, pitch, and roll sensors are only measured at the beginning of the averaging interval, and bottom-track measurements do not occur during the averaging interval; therefore, random instrument movements caused by poor boat operation or turbulent water-surface conditions are unaccounted for in mode 12 and can cause significant errors if the averaging interval is too long. A maximum averaging interval of 1 second is recommended, and this interval may need to be further reduced in fast, turbulent conditions. The maximum profiling depth, the maximum relative velocity, recommended minimum depth-cell size, and random error for the various water modes available in TRDI Rio Grande ADCPs are summarized in table 2. It is possible to collect valid data when the maximum relative velocity is greater than the values given in table 2 for modes 5 and 11; however, this is not necessarily predictable. These values should be used as a guideline to help users decide whether to use water mode 5 or 11. The high-resolution pulse coherent water modes 5 or 11 should be used wherever possible. It is important to note that not every Rio Grande ADCP has water mode 12; it must be purchased separately and enabled in the ADCP. Users should check their instruments to determine the available water modes by connecting to the ADCP with a terminal program (such as BBTalk; Teledyne RD Instruments, 2006) and issuing a "WM?" command. An in-depth discussion of the various water modes and their applicability to various site conditions can be found in Appendix C.

The Rio Grande also has two bottom modes available. Bottom mode 5 is the general purpose and default water mode, but it does not work well in depths of less than approximately $2.6 \mathrm{ft}$ below the transducer. Bottom mode 7 uses multiple lags to function in depths as shallow as $1.0 \mathrm{ft}$ below the transducer and can function to the full maximum depth of the profiler. The bottom mode 7 multiple lag technique is slower, resulting in less data collected in a fixed time; therefore, bottom mode 7 typically is used only when bottom mode 5 fails to bottom track. Bottom mode 7 is an optional mode that may not be enabled on all Rio Grandes.

Table 2. Characteristics of Teledyne RD Instruments Rio Grande water-profiling modes for 1,200- and 600-kilohertz acoustic Doppler current profilers.

[ft, foot; ft/s, foot per second; cm, centimeter; <, less than; 600-kilohertz values are in brackets]

\begin{tabular}{ccccc}
\hline $\begin{array}{c}\text { Water } \\
\text { mode }\end{array}$ & $\begin{array}{c}\text { Typical } \\
\text { maximum } \\
\text { depth, }^{\text {a }} \text { in ft }\end{array}$ & $\begin{array}{c}\text { Typical } \\
\text { maximum } \\
\text { relative } \\
\text { velocity, } \\
\text { in ft/s }\end{array}$ & $\begin{array}{c}\text { Minimum } \\
\text { recommended } \\
\text { depth-cell } \\
\text { size, in ft }\end{array}$ & $\begin{array}{c}\text { 1-second } \\
\text { standard } \\
\text { deviation, } \\
\text { in ft/s }\end{array}$ \\
\hline 1 & $65[230]$ & $32[32]$ & $\begin{array}{c}0.82[1.64] \\
(25[50] \mathrm{cm})\end{array}$ & $0.31[0.31]^{\mathrm{c}}$ \\
\hline $5^{\mathrm{d}}$ & $13[26]^{\mathrm{e}}$ & $2.3[3.3]^{\mathrm{f}}$ & $\begin{array}{c}0.16[0.33] \\
(5[10] \mathrm{cm})\end{array}$ & $<0.03[<0.03]^{\mathrm{c}}$ \\
\hline $11^{\mathrm{d}}$ & $13[26]^{\mathrm{e}}$ & $2.3[3.3]^{\mathrm{f}}$ & $\begin{array}{c}0.16[0.33] \\
(5[10] \mathrm{cm})\end{array}$ & $<0.03[<0.03]^{\mathrm{c}}$ \\
\hline 12 & $65[230]$ & $32[32]$ & $0.16[0.33]$ & $0.59[0.59]^{\mathrm{g}}$ \\
& & & $(5[10] \mathrm{cm})$ & \\
\hline
\end{tabular}

\footnotetext{
${ }^{a}$ The actual maximum depth that can be profiled depends on the water temperature and sediment in suspension.

${ }^{b}$ The maximum velocity measured by the acoustic Doppler current profiler, which includes the boat and water speeds.
}

${ }^{\mathrm{c} A s s u m e s}$ a 2-hertz ping rate.

${ }^{\mathrm{d}}$ All values for these water modes are approximate.

eIt is possible to profile deeper by decreasing the ambiguity velocity to $0.01 \mathrm{ft} / \mathrm{s}$ (WZ03), but this change reduces the maximum velocity. The WZ03 should be used with caution.

${ }^{\mathrm{f}}$ The maximum velocity for modes 5 and 11 are highly dependent on depth and turbulence.

${ }^{\mathrm{g}}$ Assumes 100 depth cells and an ambiguity velocity of $5.75 \mathrm{ft} / \mathrm{s}$ (WV175). 
Two water modes are available for the TRDI StreamPro ADCP (table 3), which operates in shallow water (less than 6.6 $\mathrm{ft}$ ) with velocities less than $6.6 \mathrm{ft} / \mathrm{s}$, in the standard configuration and float (the instrument can physically measure up to $16 \mathrm{ft} / \mathrm{s})$. In the default configuration, the StreamPro ADCP is limited to twenty $0.33-\mathrm{ft}(10-\mathrm{cm})$ depth cells for a maximum profiling depth of $6.6 \mathrm{ft}$. A long-range upgrade is available for the StreamPro ADCP that increases the maximum depthcell size to $0.66 \mathrm{ft}(20 \mathrm{~cm})$ and maximum number of depth cells to 30 , extending the maximum water depth to $19.7 \mathrm{ft}$. The default mode is similar to water mode 12 , which was explained previously. The StreamPro ADCP, however, does not actually use water mode 12 as implemented in the Rio Grande ADCP; rather, water mode 12 in the StreamPro ADCP (referred hereafter as WM12sp) is a modified multi-ping water mode 1 , which pings fast. An ambiguity velocity of $11 \mathrm{ft} / \mathrm{s}$ (WV340) is used, making an ambiguity error unlikely for typical StreamPro ADCP applications. The StreamPro ADCP has a second water mode (water mode 13 (WM13)) that has less random error than WM12sp and can be used to measure water velocities less than about $0.82 \mathrm{ft} / \mathrm{s}$ in water less than $3.3 \mathrm{ft}$ deep. WM13 is a long-lag pulse coherent mode. WM13 only becomes a selectable alternative for the user when the site conditions meet the criteria for maximum depth (less than $3.3 \mathrm{ft}$ ) and maximum velocity (less than $0.82 \mathrm{ft} / \mathrm{s}$ ).

The bottom-tracking algorithm for the StreamPro ADCP is different than the algorithms used for the Rio Grande ADCP. Each StreamPro ensemble contains two bottom-track pingsone at the beginning of the ensemble and one at the end of the ensemble. The placement of the pings cannot be changed by the user. Field experience has shown that boat speeds greater than about $4.5 \mathrm{ft} / \mathrm{s}$ may result in ambiguity errors in the bottom-track data.

The TRDI RiverRay is a $600-\mathrm{kHz}$ ADCP with a phased array transducer, 30-degree beam angles, and an auto-adaptive configuration algorithm. The phased array transducer is flat,
Table 3. Characteristics of Teledyne RD Instruments StreamPro acoustic Doppler current profiler water profiling modes.

[ft, foot; ft/s, foot per second; cm, centimeter]

\begin{tabular}{lcccc}
\hline $\begin{array}{l}\text { Water } \\
\text { mode }\end{array}$ & $\begin{array}{c}\text { Typical } \\
\text { maximum } \\
\text { depth, } \\
\text { in ft }\end{array}$ & $\begin{array}{c}\text { Typical } \\
\text { maximum } \\
\text { relative } \\
\text { velocity, } \\
\text { in ft/s }\end{array}$ & $\begin{array}{c}\text { Minimum } \\
\text { recommended } \\
\text { bin size, } \\
\text { in ft }\end{array}$ & $\begin{array}{c}\text { 1-second } \\
\text { standard } \\
\text { deviation, } \\
\text { in ft/s }\end{array}$ \\
\hline $12 \mathrm{sp}$ & $6.6(19.7)^{\mathrm{a}}$ & $16(6.6)^{\mathrm{b}}$ & 0.06 & $0.66^{\mathrm{c}}$ \\
13 & 3.3 & 0.82 & 0.06 & $0.006-0.066^{\mathrm{d}}$ \\
\hline
\end{tabular}

${ }^{\text {a }}$ Maximum depth of $19.7 \mathrm{ft}$ requires purchase of extended range mode.

binstrument should measure velocities of $16 \mathrm{ft} / \mathrm{s}$, but the integrated float was designed for velocities less than $6.6 \mathrm{ft} / \mathrm{s}$ with a flat water surface; however, a boat designed for faster water is available.

'Standard deviation is for $0.07 \mathrm{ft}(2 \mathrm{~cm})$ depth-cell size. For $0.66 \mathrm{ft}$ $(20 \mathrm{~cm})$ depth-cell size, the standard deviation is approximately $0.1 \mathrm{ft} / \mathrm{s}$.

${ }^{\mathrm{d}}$ Standard deviation depends on signal correlation, velocity, and depth.

and the angle of the beam is controlled by a phase delay that is produced by fixed circuitry (Teledyne RD Instruments, 2012). The flat transducer phased array design results in less flow disturbance than a multibeam piston array of the same size. In addition, changes in the speed of sound change the angle of the beams in such a manner that the horizontal velocity measurements are independent of the speed of sound. The auto-adaptive configuration algorithm varies the depth-cell size, ping configuration, and use of surface depth cells depending on depth and velocity (table 4). Surface depth cells are used to measure closer to the transducer face than would be possible with the regular depth cells. For a combination of shallow depths and slow water velocities (typically depth times velocity $<4.9$ square feet per second $\left.\left(\mathrm{ft}^{2} / \mathrm{s}\right)\right)$, the regular depth cells may be configured for pulse coherent processing,

Table 4. Characteristics of Teledyne RD Instrument RiverRay acoustic Doppler current profiler auto-adaptive configuration.

[ft, foot; ft/s, foot per second; cm, centimeter; N/A, not applicable; >, greater than]

\begin{tabular}{ccc|ccc}
\hline \multirow{2}{*}{$\begin{array}{c}\text { Range to bottom, } \\
\text { in ft }\end{array}$} & \multicolumn{2}{c|}{ Deep depth cell } & \multicolumn{3}{c}{ Surface depth cell } \\
\cline { 2 - 6 } & $\begin{array}{c}\text { Depth cell size, } \\
\text { in ft }\end{array}$ & $\begin{array}{c}\text { 1-second standard } \\
\text { deviation, }{ }^{\text {in }} \mathbf{f t} / \mathbf{s}\end{array}$ & $\begin{array}{c}\text { Number of } \\
\text { surface cells }\end{array}$ & $\begin{array}{c}\text { 1-second standard } \\
\text { deviation, }{ }^{\text {in }} \mathbf{f t} / \mathbf{s}\end{array}$ & $\begin{array}{c}\text { Depth cell size, } \\
\text { in ft }\end{array}$ \\
\hline $\begin{array}{c}1.5-6.6 \\
(\text { Pulse coherent })\end{array}$ & $0.33(10 \mathrm{~cm})$ & $0.11-0.15$ & 0 & N/A & N/A \\
\hline $2.3-6.6$ & $0.33(10 \mathrm{~cm})$ & $0.37-0.48$ & $0-2$ & $0.11-0.15$ & $0.33(10 \mathrm{~cm})$ \\
\hline $\begin{array}{c}6.6-16.4 \\
(P u l s e ~ c o h e r e n t)\end{array}$ & $0.66(20 \mathrm{~cm})$ & $0.03-0.07$ & 3 & 0.11 & $0.33(10 \mathrm{~cm})$ \\
\hline $6.6-16.4$ & $0.66(20 \mathrm{~cm})$ & 0.09 & 3 & 0.11 & $0.33(10 \mathrm{~cm})$ \\
\hline $16.4-32.8$ & $1.31(40 \mathrm{~cm})$ & 0.21 & 5 & 0.11 & $0.33(10 \mathrm{~cm})$ \\
\hline$>32.8$ & $2.62(80 \mathrm{~cm})$ & 0.16 & 5 & 0.11 & $0.33(10 \mathrm{~cm})$ \\
\hline
\end{tabular}

${ }^{a}$ Approximate values; may vary with hydraulic conditions. 
resulting in lower 1-second standard deviations. If a pulse coherent ping configuration is not possible, then a multi-ping mode 1 type ping configuration is used for the regular depth cells.

\section{Compass Considerations}

Most ADCPs reference the water and boat velocity to magnetic north using an internal fluxgate compass to measure the heading of the ADCP. The effect of heading errors on measurements made with an ADCP is different for watervelocity and discharge data depending on the boat-velocity reference. When bottom tracking is used for the boat-velocity reference, a heading error will cause a rotational error in the measured water velocity, but the magnitude of the velocity is unaffected. The compass has no effect on measured discharge using bottom tracking as the boat-velocity reference; however, when an external boat-velocity reference such as GPS is used, the effect of heading inaccuracies is substantial. The loop moving-bed test is also dependent on an accurate heading. Heading errors during a loop moving-bed test will cause inaccurate closure errors in the loop that could result in more or less moving bed being identified than is actually present. Potential errors include errors in the heading caused by distortion of the Earth's magnetic field due to objects on the boat or at the measurement location, displacement of the compass out of the horizontal position (for example, sudden acceleration or deceleration), poor compass calibration, and errors in determining the magnetic variation for a specific location. A local magnetic variation can be estimated from available computer models if the latitude and longitude of the site(s) are known. The magnetic variation also can be determined in the field using techniques described in the WinRiver User's Guide (Teledyne RD Instruments, 2003). When using an external boat-velocity reference (such as GPS), heading errors will affect both measured water velocity and discharge. StreamPro ADCPs do not have an internal compass in their standard configuration, but a compass option is available. The compass option is required if they are to be used with GPS or with the loop moving-bed test method. Analytical assessment of the heading errors shows that the effect of these errors on velocity and discharge is directly proportional to the speed of the boat. Therefore, maintaining a boat speed that is slow, steady, and practical for the site conditions is imperative to accurately measuring water velocity and discharge when using an external boat-velocity reference.

The accuracy of internal compasses in commercially available ADCPs is typically about $+/-1$ to 2 degrees when properly and accurately calibrated. Fluxgate compasses can be unusable when deployed with mounts or boats constructed of ferrous metals or substantial electrical fields. Use of external heading references can improve the accuracy of the heading measurement and eliminate problems associated with ferrous metals and electrical fields. Traditionally, an external heading reference was a gyroscope; however, improvements in GPS technology have made GPS-based heading measurements a cost-effective and accurate alternative.

\section{Instrument Quality Assurance}

Although ADCPs have no moving parts and typically require no calibration, the instruments and associated software and firmware are complex. Quality-assurance procedures will help identify potential instrument problems. The procedures discussed do not check all components of the ADCP.

\section{Software and Firmware}

Upgrades to both software and firmware associated with ADCPs are common. Many of these upgrades result in minor improvements to the software or firmware and do not substantially affect the quality of discharge measurements made using the instrument. Nevertheless, some software and firmware changes can be major and can appreciably affect discharge-measurement results. Firmware and software revisions should be tested before being used for routine data collection. Testing of software and firmware often requires data collection in a variety of conditions with a variety of ancillary equipment. This can be difficult and time consuming and often requires coordination between select groups of users. ADCP users, therefore, must ensure that the most recent Office of Surface Water-approved software and firmware are used for data collection and processing. In addition to information available from instrument manufacturers, the USGS provides information regarding software and firmware in technical memorandums, a mailing list, forum posts, and the Office of Surface Water hydroacoustics Web page at http:// hydroacoustics.usgs.gov/(U.S. Geological Survey, 2011a).

\section{Testing Requirements and Procedures}

The purpose of instrument quality assurance testing is to verify that the ADCP is working properly. Each ADCP used must be tested prior to use for data collection (1) when the ADCP is first acquired, (2) after hardware repair or upgrade, and (3) after firmware upgrades. In addition, a comparison measurement should be made with each ADCP at least once during a 3 -year period. The limitations of various methods for testing ADCPs are discussed in Oberg (2002). Table 5 provides a matrix of the quality-assurance tests required for various instrument conditions. A description of the procedures for each test is provided in the following sections.

\section{Beam-Alignment Test}

The accuracy of the bottom-track and water-track velocities used in the computation of discharge is dependent on the conversion of the velocities measured along the beam (beam velocities) into orthogonal coordinates ( $\mathrm{x}, \mathrm{y}$, and $\mathrm{z}$ ). This conversion is accomplished by multiplying the beam velocities with a transformation matrix that accounts for the threedimensional orientation of the beams. The beam-alignment test checks the accuracy of the transformation matrix by comparing the straight-line distance (commonly called the distance made good) measured by bottom tracking to a known 
Table 5. Quality-assurance test requirements for acoustic Doppler current profilers (ADCPs).

\begin{tabular}{lccc}
\hline \multicolumn{1}{c}{ Instrument situation } & \multicolumn{2}{c}{ Quality-assurance test } \\
\cline { 2 - 3 } & $\begin{array}{c}\text { Beam } \\
\text { alignment } \\
\text { test }\end{array}$ & $\begin{array}{c}\text { Transformation } \\
\text { matrix } \\
\text { check }\end{array}$ & $\begin{array}{c}\text { Comparison } \\
\text { measurement }\end{array}$ \\
\hline New & Required & Required \\
\hline $\begin{array}{l}\text { Transducer repair or } \\
\text { replacement }\end{array}$ & Required & Required \\
\hline $\begin{array}{l}\text { Non-transducer hardware repair or } \\
\text { upgrade }\end{array}$ & Required & Required \\
\hline $\begin{array}{l}\text { Required, recommended, or allowed } \\
\text { firmware change }\end{array}$ & Required & \\
\hline Unapproved or testing firmware change & Required & Required \\
\hline At least once within a 3-year period & & Required \\
\hline
\end{tabular}

${ }^{\text {aS }}$ See detailed description of beam alignment for applicability to specific ADCPs.

distance in the laboratory or to a distance measured by GPS in the field. Detailed procedures for field beam-alignment tests are provided in Appendix D. However, not all ADCPs are easily evaluated in the field. The StreamPro and the $3-\mathrm{MHz}$ beams of the M9 are difficult to test in field conditions, and field testing of beam alignments for these ADCPs is not currently (2013) required. Bottom tracking is known to have a small bias caused by terrain effects, but this bias typically is less than 0.2 percent. On the basis of discussions with staff at TRDI, the USGS has used the ratio of bottom-track distance made good to the GPS distance made good of between 0.995 and 1.003 as the recommended criterion for the Rio Grande ADCP beam alignment to be acceptable. The manufacturer's specifications, however, define the criteria that each instrument must meet (see Appendix D for additional details). If the instrument does not meet the applicable beam-alignment criterion, the ADCP can be returned to the manufacturer for a custom transformation matrix.

\section{Transformation Matrix Check}

When changes to the system are made that should not affect the physical beam configuration, such as but not limited to firmware upgrades, a transformation check can be made in lieu of a beam-alignment test. Once the beam alignment has been tested and shown to meet the prescribed standard, the transformation matrix can be read from the instrument and stored in the instrument history log. The transformation matrix can be obtained from Teledyne RD Instrument-manufactured ADCPs by using the PS3 command from a terminal emulator, such as BB-Talk. The transformation matrix for Teledyne RD Instrument-manufactured ADCPs is included in the ADCP test completed from within WinRiver II. To obtain the transformation matrix from SonTek RiverSurveyor M9 or S5 ADCPs, a data file must be loaded into RiverSurveyor Live and a Matlab export file must be created. The transformation matrix is in the variable "Tranformation_Matrices.Matrix." A USGS utility, RSMatrix, can be used to obtain the transformation matrix from the exported Matlab file (RSMatrix is available from http://hydroacoustics.usgs.gov). After a change is made to the instrument, the transformation matrix can be retrieved and compared to the matrix saved in the instrument history $\log$. If the matrices agree, the instrument can be used for data collection. However, if there are differences, the justification for any changes must be verified with the manufacturer and a beam-alignment test completed.

\section{Comparison Measurement}

Comparison measurements help ensure consistency among instruments and discharge-measurement techniques. A comparison measurement may be made at a site where the ADCP-measured discharge can be compared with a known discharge derived from some other source, such as the rated discharge from a site with a stable stage-discharge rating or a concurrent measurement made using an independent technique. If the $\mathrm{ADCP}$ is equipped with more than one water- or bottom-tracking mode, it is desirable, though not required, to periodically conduct instrument checks by using the different modes. Periodic comparison measurements should be performed at different sites, so that a range of hydrologic conditions are reflected in the tests and so that any inherent biases associated with a particular site are minimized. The discharge obtained from the ADCP should be within 5 percent of the known discharge, but a consistent bias should be investigated. If the comparison reference is a stable stage-discharge rating and the ADCP measurement departs from the discharge rating by more than 5 percent, it is possible that a rating may have shifted. Another measurement with a second ADCP or conventional discharge measurement should be made to check the validity of the rating before drawing definitive conclusions regarding the ADCP instrument test. The comparison measurement data should be permanently stored according to agency and local office policy. A brief summary of the test results should be stored in the instrument history log, discussed below. 


\section{Instrument History Log}

Documentation of instrument quality-assurance tests, as discussed above, and both hardware and firmware upgrades to an ADCP is important to prove the instrument has been maintained in proper working order. This log can be either electronic or paper but should contain the original documents obtained when the instrument was purchased and the date, results, and location of supporting data for any tests or changes made to the instrument. This log is not intended to include the instrument self-tests collected as part of a discharge measurement.

\section{Ancillary Equipment}

Although the ADCP and computer are the primary equipment, the ancillary equipment discussed in this section will help achieve an accurate measurement in a variety of conditions. Not all of the equipment discussed is necessary for every measurement; depending on the site conditions encountered, the appropriate equipment should be used.

\section{GPS Requirements and Specifications}

Using a GPS to measure the boat velocity is the preferred method of data collection when moving-bed conditions are present. (See Appendix B for a detailed discussion of methods for collecting data in moving-bed conditions.) GPS provides two options for determining boat velocity: differentiated position using the GGA National Marine Electronics Association (NMEA)-0183 sentence or the velocity reported in the VTG NMEA-0183 sentence (National Marine Electronics Association, 2002). In addition to positions, the GGA sentence provides time, elevation, and information about the satellite constellation used to reach the position solutions. The GPS receiver should be configured to output both GGA and VTG sentences.

The boat velocity is determined from the positions in the GGA sentence by dividing the distance between successive positions by the time elapsed between these position solutions (differentiated position). Use of differentiated position requires accurate position solutions and, thus, differential correction. Differential correction compensates for satellite and receiver clock drift, ephemeris inaccuracies, and tropospheric and ionospheric errors associated with the coded signal being broadcast by the GPS satellites. The two common methods of differentially correcting a GPS signal are (1) real-time kinematic (RTK) systems, which require a user-operated base station or correction signal from virtual reference station (VRS) and separate rover receiver, both of which can receive dual frequency code-phase and carrier-phase satellite signals, and (2) code-phase differential corrections. RTK systems typically cost more than $\$ 10,000$ and deliver accuracies in the centimeter range. These systems are used most frequently where satellite-based code-phase corrections are not available or where high-accuracy positions are required. Code-phase differential corrections can be obtained from user-operated base stations but are more commonly obtained from differential correction services. Two free sources of differential correction services are provided by the U.S. Government. The first source is the Wide Area Augmentation System (WAAS), which has been developed for the Federal Aviation Administration (FAA) to provide precision guidance to aircraft at airports and airstrips. The WAAS uses a system of satellites and ground stations that provide GPS signal corrections (Federal Aviation Administration, 2006). The second source is U.S. Coast Guard radio beacons, which are part of a large network that provides differential correction to coastal areas, navigable rivers, and, more recently, inland agricultural areas. Some commercial satellite differential service providers offer differential corrections with various levels of accuracy for a fee. These corrections typically are broadcast using a communications satellite. The accuracy of code-phase differential corrections varies according to the correction source used and the characteristics of the GPS receiver. Many commercial receivers claim submeter accuracy using WAAS as the differential correction source. These receivers are currently (2013) the most common type of receiver used for ADCP data collection and range in cost from about $\$ 800$ to $\$ 3,000$. Handheld and some low-cost marine GPS receivers use the WAAS differential corrections but do not provide the output resolution required for ADCP streamflow measurements. The GPS receiver must be capable of outputting the latitude and longitude in the GGA sentence to at least five decimal minute resolution and the velocity in the VTG sentence to two decimal resolution. The receiver should be able to provide these data two times per second $(2 \mathrm{~Hz})$ or faster (U.S. Geological Survey, 2012). If the update rate is too slow, each $\mathrm{ADCP}$ ensemble will not have a unique position or speed, but if the update rate is too fast, the communications and computer may cause a lag between the GPS and ADCP data.

The velocity reported in the VTG sentence typically is based on measured Doppler shifts in the satellite signals, but some receivers may use differentiation of successive positions to compute the reported velocity. Wagner and Mueller (2011) concluded that VTG can be a valid alternative for measuring discharge with an ADCP in moving-bed environments without the assistance of differential corrections, but more inaccuracies in VTG-based discharges may occur, particularly for boat speeds less than about $0.8 \mathrm{ft} / \mathrm{s}$. Use of the Doppler shift to determine velocity does not require and is unaffected by differential corrections. This velocity measurement can be robust because it is resistant to some of the errors that are problematic for position determination, such as multipath errors and ionospheric and atmospheric distortions. Some receivers, particularly low-cost GPS receivers, may apply filters to smooth out the velocity or display a zero velocity when the velocity drops below a specified threshold. These types of filters and thresholds are unacceptable for using the GPS receiver with an ADCP. 
Experience using GPS with ADCPs has shown that the two most common problems are filters in the receiver and multipath errors caused by site conditions. The GPS receiver should allow all filters to be turned off. Multipath errors are caused by the satellite signal reflecting off of bridges, trees, and buildings before arriving at the antenna. Multipath errors affect only the position solutions; they do not affect Dopplerbased GPS velocity data. Some receivers contain special antennas or software to reduce multipath errors. If multipath errors are a problem during measurements, the use of VTG often is the best solution. (For additional details about the use of GPS with ADCPs, see Appendix B.)

\section{Echo Sounder}

Streams with high sediment concentrations of fine material and sand being transported on or near the streambed also may cause inaccuracies in ADCP water-depth measurements and, therefore, may cause an inaccurate discharge measurement. In such conditions, using a lower frequency echo sounder (approximately $200 \mathrm{kHz}$ ) to measure the water depth may be necessary. The echo sounder must support the NMEA 0183 depth below transducer (DBT) data string to be compatible with ADCP data-collection software. If a depth sounder is used, the echo sounder needs to be properly calibrated as part of the pre-measurement field procedures. For proper calibration techniques, the user is referred to the bar check procedures in the U.S. Army Corps of Engineers Engineering Design Manual on hydrographic surveying (U.S. Army Corps of Engineers, 2002). The bed-load transport rate and sediment concentration that make the use of a depth sounder necessary have not been quantified, and user judgment is required.

\section{Instrument Deployments and Mounts}

Every measurement site has unique features that may determine the best type of ADCP deployment platform. Site features may include hydraulic characteristics, such as water velocity and surface waves, and access considerations, such as the presence of boat ramps, bridges, or cableways. Three common types of ADCP deployment platforms are manned boats, tethered boats, and remote-controlled boats.

\section{Manned Boats}

An ADCP can be mounted on either side, off the bow, or in a well through the hull of a manned boat. Advantages and disadvantages for mounting locations on manned boats are listed in table 6. To minimize ADCP compass errors, the ADCP should not be mounted close to any object containing ferrous metal or sources of strong electromagnetic fields, such as generators, batteries, and boat engines. A good rule of

Table 6. Advantages and disadvantages of acoustic Doppler current profiler (ADCP) mounting locations on manned boats (adapted from Oberg and others, 2005).

\begin{tabular}{|c|c|c|}
\hline Mounting location & Advantages & Disadvantages \\
\hline \multirow{4}{*}{ Side of boat } & Easy to deploy & $\begin{array}{l}\text { Moderate chance of directional bias in mea- } \\
\text { sured discharges with some boats and flows }\end{array}$ \\
\hline & $\begin{array}{l}\text { Mounts are easy to construct and are } \\
\text { adaptable to a variety of boats }\end{array}$ & $\begin{array}{l}\text { Possibly closer to ferrous metal (engines) } \\
\text { or other sources of electromagnetic fields } \\
\text { (EMF) }\end{array}$ \\
\hline & $\begin{array}{l}\text { ADCP draft measurement can be } \\
\text { easily obtained }\end{array}$ & $\begin{array}{l}\text { Moderate-low risk of damage to ADCP from } \\
\text { debris or obstructions in the water }\end{array}$ \\
\hline & & Susceptible to roll-induced bias in ADCP depths \\
\hline \multirow{3}{*}{ Bow of boat } & $\begin{array}{l}\text { Minimizes chance of directional bias } \\
\text { in measured discharges }\end{array}$ & $\begin{array}{l}\text { Increased risk of damage to ADCP from debris } \\
\text { or obstructions in the water }\end{array}$ \\
\hline & Mounts are relatively easy to construct & More difficult to measure ADCP depth \\
\hline & $\begin{array}{l}\text { Usually far from ferrous metal or } \\
\text { electromagnetic fields }\end{array}$ & $\begin{array}{l}\text { Susceptible to pitch-induced bias in ADCP } \\
\text { depths, particularly at high speeds or during } \\
\text { rough conditions (waves) }\end{array}$ \\
\hline \multirow{3}{*}{ Well in center of boat } & Protected from debris and obstructions & \\
\hline & Accurate depth measurements possible & Often requires special modifications to boat \\
\hline & $\begin{array}{l}\text { Least susceptible to pitch-and-roll- } \\
\text { induced bias in ADCP depths }\end{array}$ & \\
\hline \multirow{3}{*}{ Tethered boat } & Consistent draft & $\begin{array}{l}\text { ADCP may rotate independent of manned boat } \\
\text { changing the magnetic field }\end{array}$ \\
\hline & No need for custom mount & $\begin{array}{l}\text { More susceptible to heave, pitch, and roll in } \\
\text { turbulent and choppy conditions }\end{array}$ \\
\hline & Can leave ADCP in tethered boat & Boat operation can be more difficult \\
\hline
\end{tabular}


thumb is that an ADCP should not be mounted any closer to a ferrous object than the largest dimension of that object. This is a general rule, however, and large variations in the magnetic fields are generated by different metals. Even stainless steel varies appreciably in the amount of ferrous material contained in the steel.

ADCPs may be deployed from a manned boat using a rigid mount attached to the manned boat or by deploying a tethered boat from the manned boat. The ADCP should not be placed in a location were the flow past the unit may be affected by the boat's propulsion or wake. When both the wake created by the boat and potential propulsion effects are minimal, such as when using a kayak, towing a tethered boat may be acceptable.

\section{Rigid ADCP mounts for manned boats should}

- allow the ADCP transducers to be positioned free and clear of the boat hull and mount,

- hold the ADCP in a fixed, vertical position so that the transducers are submerged at all times while minimizing air entrainment under the transducers,

- allow the user to adjust the ADCP depth easily,

- be rigid enough to withstand the force of water caused by the combined water and boat velocity without changing the orientation of the ADCP,

- be constructed of nonferrous materials (including all nuts, bolts, and washers; use a magnet to check for ferrous materials),

- be adjustable for boat pitch-and-roll, and

- be equipped with a safety cable to hold the ADCP in the event of a mount failure.

Tethered boats deployed from a manned boat should

- allow the ADCP transducers to be positioned free and clear of the boat hull,

- be in a position free from velocity and water-surface distortions caused by the manned boat, and

- be tethered such that rotation of the tethered boat relative to the manned boat is minimized, so that the tethered boat rotates with, not separate from, the manned boat.

Photographs of a variety of ADCP mounts are available in USGS Open-File Report 01-01 (Simpson, 2002, p. 58-69) or at the USGS hydroacoustics Web page (http://hydroacoustics. usgs.gov/).

\section{Tethered Boats}

A tethered boat can be defined as a small boat (usually less than $6.5 \mathrm{ft}$ long) attached to a rope, or tether, that can be deployed from a bridge, a manned boat, a fixed cableway, or a temporary bank-operated cableway. The tethered boat should be equipped with an ADCP mount that meets all of the specifications outlined in the previous section on manned boats. The tethered boat also should contain a waterproof enclosure capable of housing a power supply and wireless radio modem for data telemetry. A second wireless radio modem attached to the field computer enables communication between the ADCP and field computer without requiring a direct cable connection. The radio modems should reliably communicate with the ADCP using the ADCP data-acquisition software; have a rugged, waterproof housing; and have sufficient data-communication capability to maximize ADCP data throughput. Rehmel and others (2002) describe the development of a prototype tethered platform, a project to refine the platform into a commercially available product, and tethered-platform measurement procedures.

The StreamPro ADCP comes standard with a tethered boat designed specifically for the StreamPro. The standard StreamPro tethered boat has two options for mounting the transducer. The in-hull position is the generally recommended deployment as it reduces drag and lessens the effect of pitch. The extended position may be used in very shallow water as it allows a smaller transducer draft, but model simulations have indicated a potential for increase in flow disturbance. Boat movement must be very smooth, with little pitch or roll, in order to take advantage of smaller drafts when the transducer is placed in the extended position, or the transducer is likely to come out of the water. The standard StreamPro boat has a rigid tow harness that can be fixed at various angles. If the front of the boat is pitching up, the tow harness angle may be set higher, which will tend to minimize the pitch. However, when using the StreamPro on the standard float in higher velocities ( $>3 \mathrm{ft} / \mathrm{s}$ ) care must be taken in setting the angle of the harness as it may cause the float to flip or dive unexpectedly. The larger the angle of the harness to the water surface, the more likely the float will dive. If a tethered boat begins to dive, the best action is to let out as much rope as practical. Pulling on the rope when a tethered boat is diving will tend to cause the boat to dive at a faster rate. Tethered boats for other ADCPs, including boats designed to deploy the StreamPro in velocities greater than $5 \mathrm{ft} / \mathrm{s}$, can be purchased commercially from the ADCP manufacturers or third-party vendors.

Tethered boats have become a common deployment method (fig. 5). Certain considerations need to be made when making tethered boat measurements. Tethered boats are used in a variety of settings, but primarily they are used from the downstream side of bridges for convenience. Bridge piers can cause excessive turbulence during high streamflow, especially if debris accumulations are present on the piers and the piers are skewed to the flow. The effect of bridge-pier-induced turbulence may be reduced by lengthening the tether to increase the distance between the bridge and the tethered boat; however, control of the boat on a long tether can be difficult. Attention should be paid to the cross section to minimize the effect of large eddies on the measurement. Possible alternatives to measuring from the downstream side of bridges include using bank-operated cableways or having personnel on 


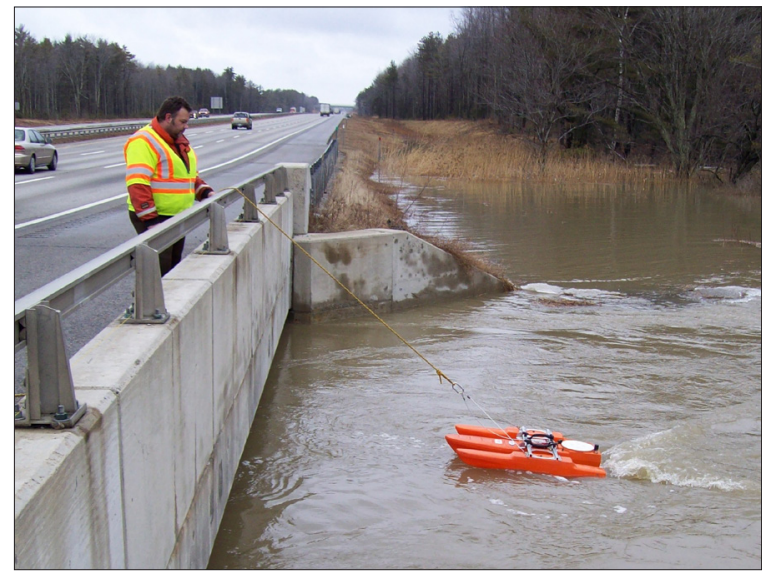

(A) OceanScience Riverboat

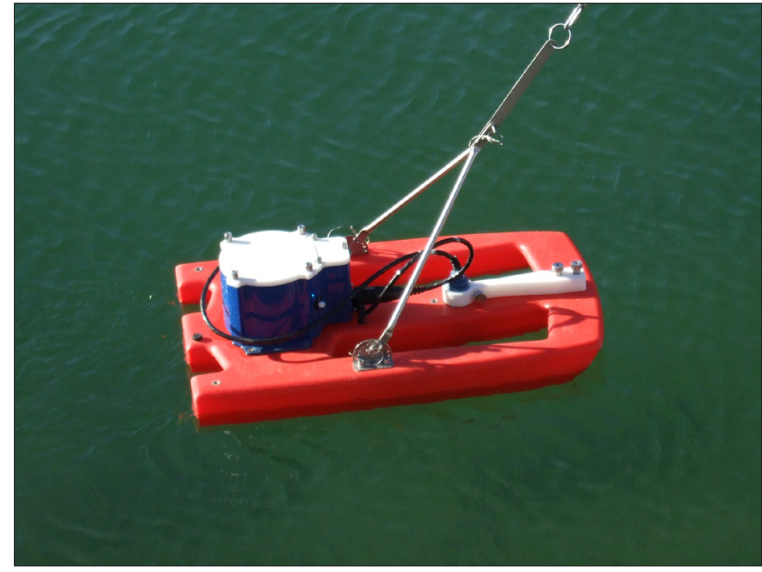

(C) StreamPro in included float

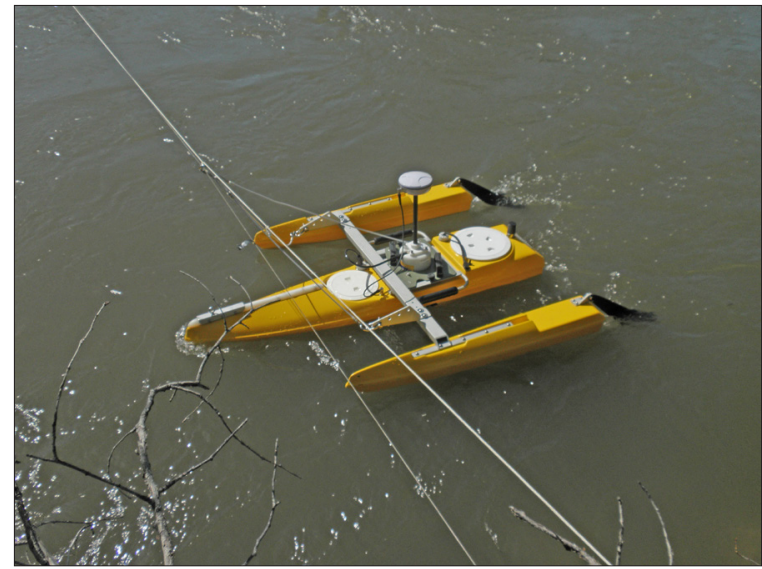

(E) OceanScience High-Speed Riverboat

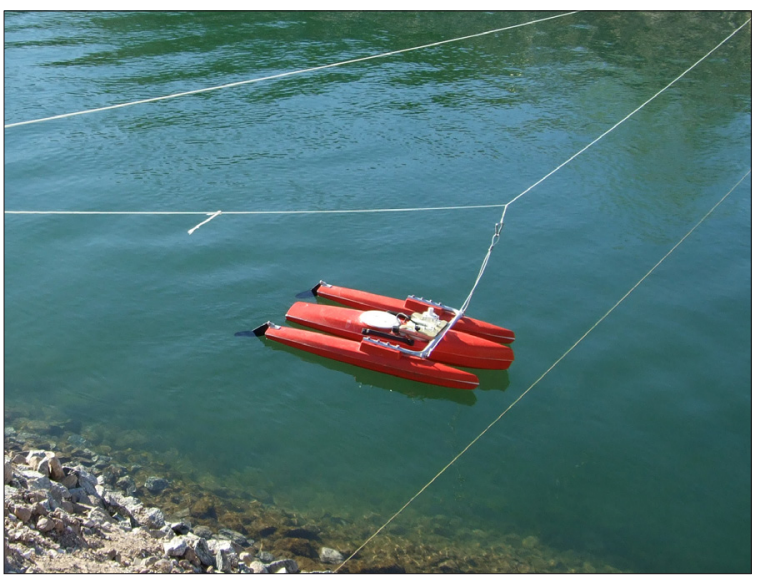

(B) RiverRay in included trimaran

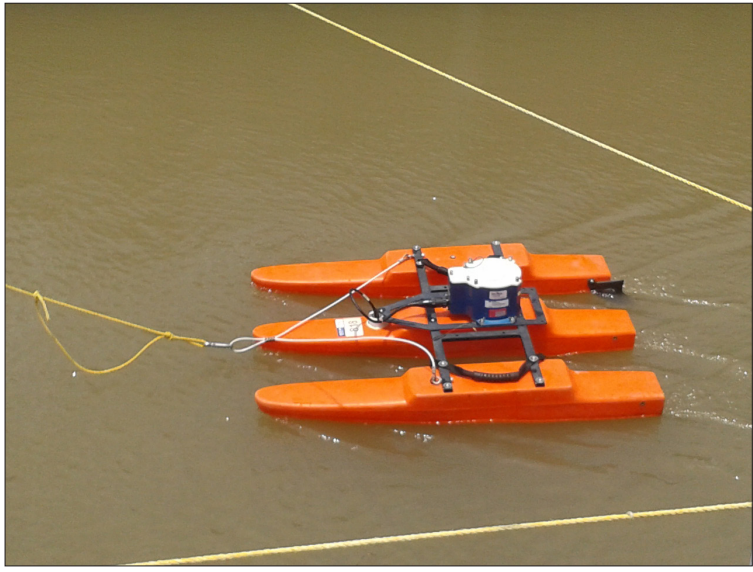

(D) StreamPro in OceanScience Riverboat SP

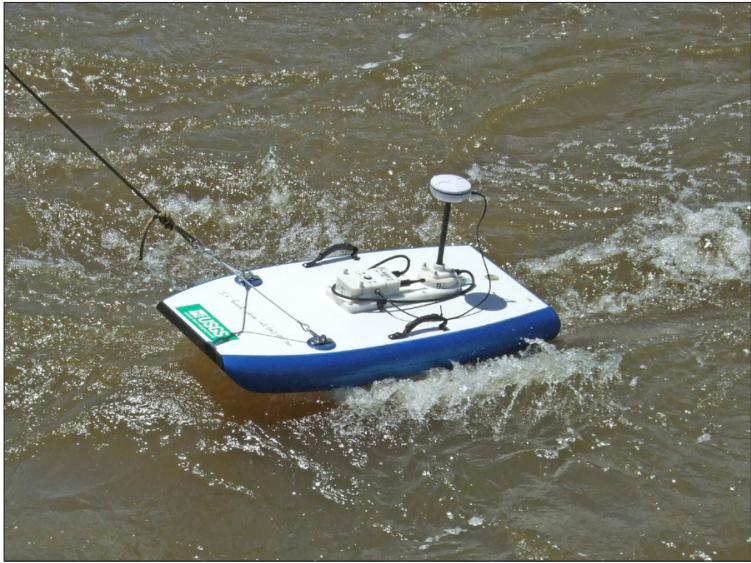

(F) SonTek M9 in Hydroboard

Figure 5. Examples of tethered acoustic Doppler current profiler (ADCP) boats used for making discharge measurements. 
each bank hold a rope attached to the platform to pull the platform back and forth across the river. Bank-operated cableways may be as simple as a temporary "rope and pulley" apparatus (fig. 6) or may involve the use of a permanent unmanned cableway with manual cranks or a motorized drive for towing the tethered boat back and forth across the stream (fig. 7). In 2004, remote-controlled rovers were developed for cableways (Oberg and others, 2005). These rovers can be carried from one streamflow-gaging station to another and, once mounted on the cableway, can be used to winch up the tethered boat and drive the boat back and forth at a user-controlled speed. One method that has been employed but should be avoided is wading with the tethered boat. Several issues have been observed when attempting to wade the boat across the stream:

1. the boat does not move smoothly across the stream but rather moves sporadically with more pitch-and-roll than is typical of bank-operated cableways;

2. the hydrographer in the stream may interfere with the acoustic beams if they are too close to the boat; and

3. the hydrographer may change the flow pattern measured by the ADCP if they are too close to the boat or moving upstream.

Therefore, a temporary bank-operated cableway should be used instead of wading.

When the water velocity is slow (usually less than $0.5 \mathrm{ft} / \mathrm{s}$ ), controlling the tethered boat may become difficult. This lack of control may be exacerbated by wind, which may push the boat in an undesired direction. Boat handling can be improved by attaching a sea anchor (fig. 8) to the back side of the boat to increase the effect of the current and its pull on the tether. Make sure that the anchor is far enough behind the boat so as not to disturb the flow and potentially bias the velocity measurements. Maintain a smooth boat speed that is fast enough to keep the boat moving consistently in one direction and prevent it from wandering back and forth.

When the water velocity is fast (usually greater than $5 \mathrm{ft} / \mathrm{s}$ ) or when the boat is deployed from a high bridge, it is not uncommon for a tethered boat to be pitched upward at the bow. This increased pitch is caused by increased vertical tension on the tether in faster flows, hull dynamics, and an incorrect setting of the angle for the bail for those boats equipped with a rigid bail. The bail connects the tether to the boat and can be either a rigid design or a flexible rope bail. Large pitch angles may introduce some bias in depth measurements and should be minimized as much as practical. Adding a sounding weight on the tether near the location where the tether is tied to the boat will help decrease the pitch angle. In addition, increasing the length of the tether helps reduce the pitch angle. Depending on the design of the boat, the boat may dive in high velocity conditions with surface waves, which can result in loss or damage of equipment and become a safety hazard to the operator. If a tethered boat begins to dive, the best action is to let out as much rope as practical. Pulling on the rope when a tethered boat is diving will tend to cause the

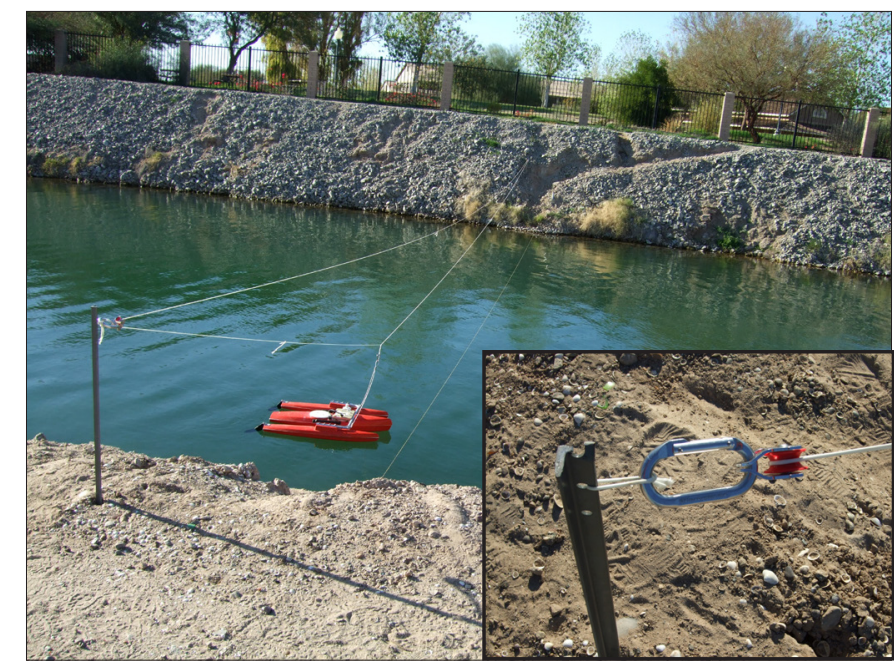

Figure 6. Temporary bank-operated cableway for making acoustic Doppler current profiler (ADCP) measurements with a tethered ADCP boat.

boat to dive at a faster rate. It is important to ensure that the performance specifications of the tethered boat are appropriate for the conditions being measured.

Although tethered boats reduce the exposure time of the hydrographer to traffic and the amount of equipment deployed on a bridge, there are important safety considerations when using a tethered boat. The tether line should be visible from the water surface to minimize the risk of collision with boat traffic. Orange plastic flags tied along the tether will enhance its visibility. The operator should also be capable of releasing the tether quickly in case the boat becomes entangled in debris or collides with boat traffic. The user may also consider having an air horn or hand flags to signal to boat traffic. DO NOT wrap the tether around your hand to hold the boat, have excess tether line around your feet or behind your body, or tie the end of the tether to yourself. DO wear gloves and always keep the line between you and the boat. Standard safety practices, site-specific traffic safety plans, and local highway traffic regulations should be followed.

It is possible to lose control of a tethered boat because of a system-component failure. For example, a boat tether or tether attachment point could break. ADCP operators using tethered-boat deployments should have redundant attachment points for the tether on the boat and have a contingency plan for retrieving the boat in the event of a failure that causes a loss of boat control. An example of a contingency plan would be to carry a small manned boat that could be quickly and safely launched to retrieve the tethered boat (Oberg and others, 2005). Contact information for the office should be affixed to the ADCP and boat to facilitate return of a lost ADCP and boat. The use of a commercially available GPS personal locator tracking device attached to the ADCP could be considered in conditions where retrieving an ADCP may not be practical, such as high velocity flood conditions or areas where safe access to the river is limited. 

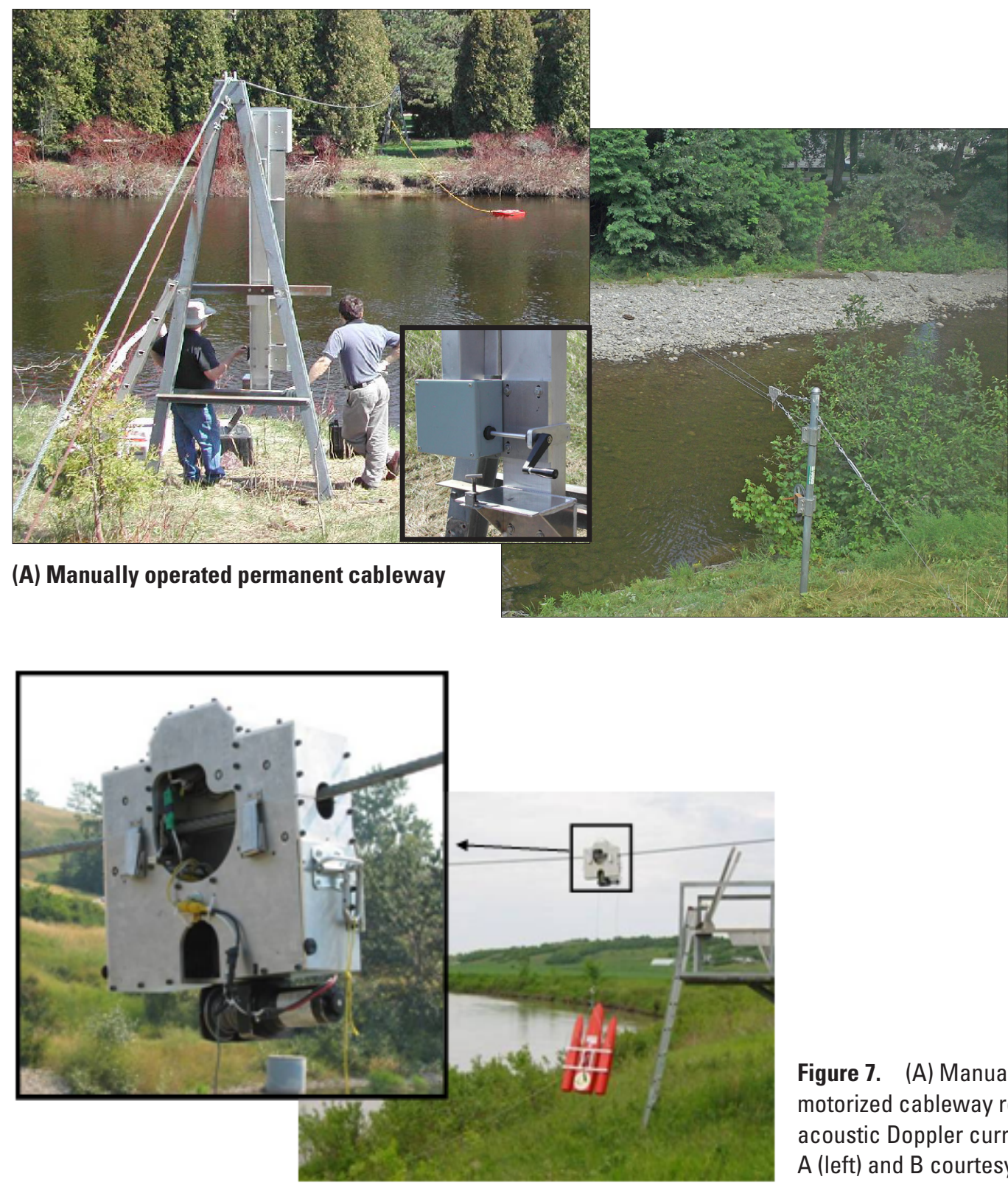

Figure 7. (A) Manually operated and (B) portable motorized cableway rover for deploying tethered acoustic Doppler current profilers. (Photographs A (left) and B courtesy of Water Survey of Canada.)

\section{(B) Portable motorized drive for permanent cableway}

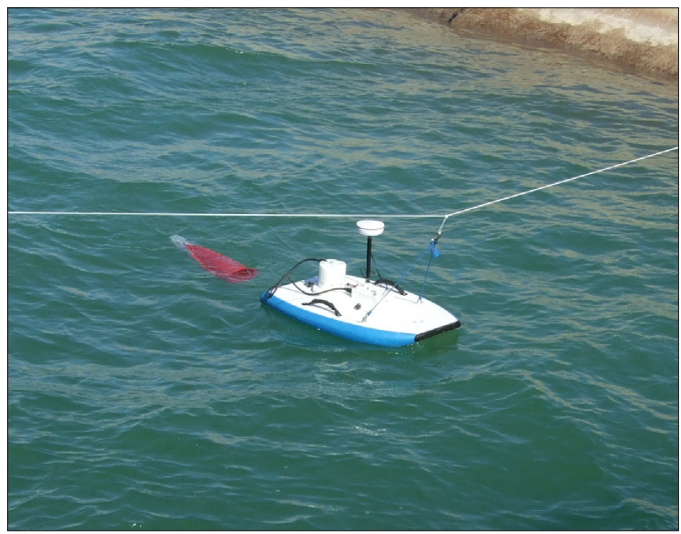

Figure 8. Wind sock used as a sea anchor. 


\section{Remote-Controlled Boats}

Unmanned, remote-controlled boats allow the deployment of ADCPs where deployment with a manned boat or tethered boat may not be feasible or ideal. Similar to (but smaller than) manned boats, a remote-controlled boat has self-contained motors and a remote-controlled system for maneuvering the boat across the river. Unlike the tethered boat, the remote-controlled boat has no rope (tether) restraints. Although remote-controlled boats have an increased risk of equipment loss because of potential loss of boat control, they provide the ability to launch a boat without a boat ramp and to collect data away from bridge effects (for example, upstream from a bridge) or at sites where no bridge or cableway is present. Currently (2013) remote-controlled boats are commercially available (fig. 9). An ADCP mount for a remote-controlled boat should meet all mount specifications previously listed for manned boats. Of particular concern is the potential effect of the motors and batteries on the compass of a remote-control boat. If the boat is not properly designed, magnetic interference from electric motors and batteries can be substantial. The remote-controlled boat also should contain a waterproof enclosure capable of housing a power supply, a radio modem, and the control radio. Radio modems are used for data telemetry between the remote-controlled boat and field computer; the radio modems should have the capabilities previously described for tethered-boat deployments.

The same operational guidelines regarding speed and maneuvering for manned boats also apply to remote-controlled boats. The selection of the remote-control boat should consider its operational limitations compared to the site conditions being measured. Proper control of a remote-controlled boat requires practice. The operator should be familiar with remote-controlled boat operation prior to using this deployment technique in high flows. Regular maintenance of the boat and control radios is critical to ensure reliable operation.

For remote-controlled boats, it is possible to lose control of the boat because of a system component failure. ADCP operators using remote-controlled boat deployments should have a contingency plan for retrieving the ADCP similar to that discussed in the tethered boat section.

\section{Other Equipment}

A DB9 serial port on a laptop computer may be required for communication with the ADCP, and a second DB9 serial port may be required if a GPS is used. Laptop computers (2013) typically do not contain a serial port. Use of Universal Serial Bus (USB) or Personal Computer Memory Card International Association (PCMCIA) serial ports is often required. USB serial ports are virtual serial ports, and some brands do not work well with ADCPs and (or) GPS receivers. StreamPro, RiverRays, and RiverSurveyor ADCPs communicate with computers, portable digital assistants (PDAs), or phones, through a wireless Bluetooth connection. An external Bluetooth radio is required for computers that do not have built-in Bluetooth or that need extra range. Prior to going to the field, all ports should be checked for compatibility with the instruments to be used. A list of some USB, PCMCIA, and Bluetooth serial ports that have been shown to work well with ADCPs can be found at the USGS hydroacoustics Web site (http://hydroacoustics.usgs.gov/).

In addition to the ADCP and computer, the following additional equipment is necessary to achieve a high-quality discharge measurement (table 7).

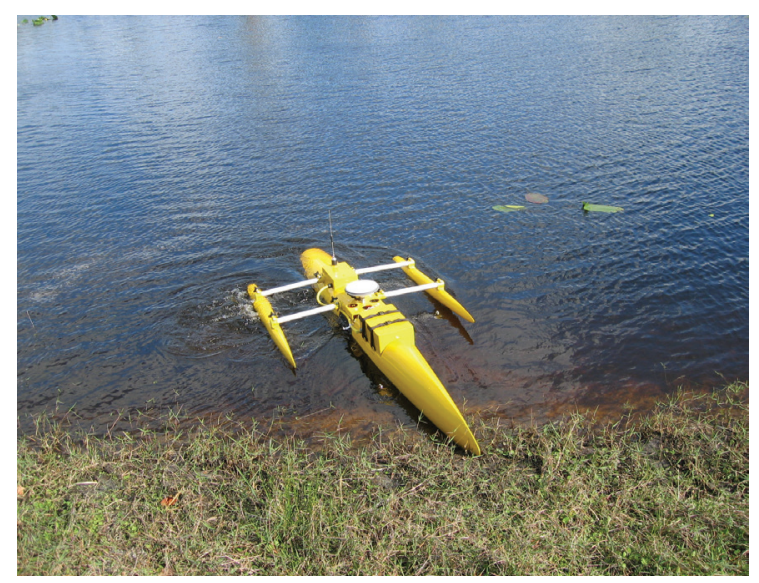

(A) SeaRobotics, Inc.

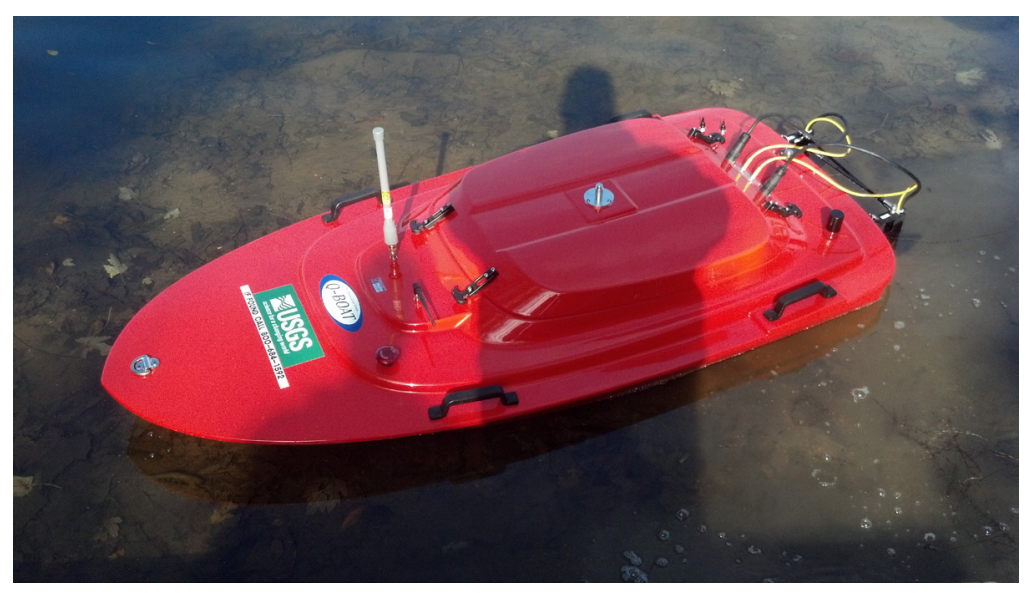

(B) OceanScience Group

Figure 9. Examples of commercially available remote-controlled boats (photographs courtesy of SeaRobotics, Inc., and OceanScience Group). 
- A toolkit (fig. 10) should be assembled for the ADCP with tools, multimeter, and any spare parts that may be difficult to obtain in the field (such as fuses, o-rings, and special wrenches). The toolkit should always be kept with the ADCP.

- An adequate supply of the Office of Surface Waterapproved ADCP discharge-measurement field forms or devices and software for taking electronic field notes should be taken to the field. The USGS discharge-measurement form (9-275-I) and information on and links to software for electronic field notes are available from the USGS hydroacoustics Web site (http://hydroacoustics.usgs.gov/). The USGS discharge-measurement form (9-275-I) is shown in Appendix E.

- Computer data-storage media (such as a flash-memory card or USB memory stick) should be available with

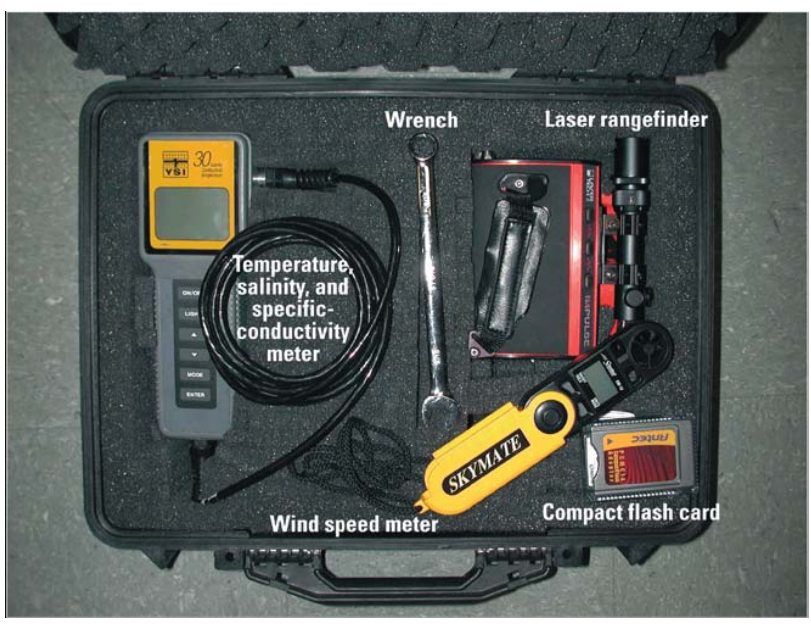

Figure 10. Example toolkit of ancillary equipment for use with acoustic Doppler current profilers (ADCPs) when making streamflow measurements.

Table 7. List of ancillary equipment to be used with acoustic Doppler current profilers when making streamflow measurements.

[USB, Universal Serial Bus; PCMCIA, Personal Computer Memory Card International Association; ADCP, acoustic Doppler current profiler; DGPS, differentially corrected global positioning system]

\begin{tabular}{|c|c|c|}
\hline Equipment & Function & $\begin{array}{l}\text { Optional or } \\
\text { required }\end{array}$ \\
\hline USB or PCMCIA serial port(s) & $\begin{array}{l}\text { Computer connection to ADCP and } \\
\text { (or) DGPS }\end{array}$ & Optional $^{1}$ \\
\hline External Bluetooth radio & Computer connection to StreamPro & Optional $^{2}$ \\
\hline Toolkit & Field troubleshooting and repairs & Required \\
\hline ADCP field notes & Note keeping & Required \\
\hline Computer data-storage media & Field backups of data & Required \\
\hline Thermometer & Measure water and air temperatures & Required \\
\hline $\begin{array}{l}\text { Measuring tape, or mount with graduated } \\
\text { markings, or folding rule }\end{array}$ & Measure ADCP depth & Required \\
\hline $\begin{array}{l}\text { Laser rangefinder or other distance- } \\
\text { measurement tool }\end{array}$ & Measure shore distances & Required \\
\hline Salinity/conductivity meter & Measure salinity & Optional $^{3}$ \\
\hline Handheld anemometer & Obtain estimate of wind speed & Optional \\
\hline ADCP cable ${ }^{4}$ & Direct communication & Required \\
\hline Trolling motor or tagline & Slow boat speed & Optional \\
\hline Hand-held radios & $\begin{array}{l}\text { Communication during tethered or } \\
\text { remote-control boat measurements }\end{array}$ & Optional \\
\hline Shade/rain cover for computer & $\begin{array}{l}\text { Improves view of computer screen/ } \\
\text { protects screen }\end{array}$ & Optional \\
\hline Batteries & Power for ADCP and other equipment & Required \\
\hline
\end{tabular}

${ }^{1}$ Required if computer does not support sufficient internal serial ports.

${ }^{2}$ Required if computer does not support internal Bluetooth communication.

${ }^{3}$ Required for ADCP measurements in estuaries and coastal streams.

${ }^{4}$ For those instruments that provide direct or hardwire communication. 
sufficient storage space for making temporary backup copies of all field data files.

- A thermometer is needed to check the accuracy of the water-temperature measurement of the ADCP because an incorrect temperature will bias the velocity and discharge measurements (see section on Water Temperature for accuracy specifications).

- If the ADCP mount does not have graduated markings, a measuring tape or folding rule is needed to measure the depth of the ADCPtransducers below the water surface.

- The distances from the beginning and end of a transect to the nearest edge of water must be measured and input to the software for computation of the discharge in the unmeasured areas. Typically visual estimates underestimate the distance over water; therefore, a laser rangefinder or some other means of measuring the distance to shore is required. The calibration of distance-measurement devices should be checked periodically by measuring the distance to targets at a known distance; the results of these calibration tests should be recorded in the instrument history log. Various types of laser and optical rangefinders, accuracy and limitations, and test results can be found at the USGS hydroacoustics Web site (http://hydroacoustics. usgs.gov/).

- A conductivity or salinity meter is required to determine the salinity at the transducer face for measurement in saline environments.

- If the surface velocities are affected by wind, the speed and direction of the wind is important. A hand-held anemometer will allow direct measurement of the wind speed.

- If radio modems are used for ADCP communications, the cable for connecting directly to the ADCP, where applicable, should be taken to the field. An ADCP connected through radio modems occasionally will not communicate with the field computer. The problem is often resolved by using a direct cable to establish communications and then reconnecting the radio modems. If available, a second pair of radio modems should be taken to the field as a backup.

- If low-velocity conditions are expected (generally velocities less than $0.5 \mathrm{ft} / \mathrm{s}$ ), a trolling motor or tagline may be necessary to keep boat speed slow and consistent (Oberg and others, 2005). If it is not possible to maintain a slow boat speed, maintain the slowest speed that allows smooth boat operation.

- If a remote-control or tethered boat deployment is used, hand-held radios are helpful for communications between the boat operator and the computer operator.
- If the data-collection computer will be used in bright sunlight, a shade for the computer screen may be necessary to improve the readability of the screen. In potentially rainy conditions, a rain cover is required to keep nonruggedized computers dry.

- Batteries to power ADCP and other electronic equipment and computer(s).

\section{Final Equipment Preparation and Inspection}

A pre-field inspection checklist is recommended to ensure that all procedures are followed and that all necessary equipment is available and functioning for the field trip. An example of a pre-field inspection checklist is shown in Appendix E; however, the checklist should only be used as a guideline for field preparation. Other equipment may be necessary for the sites and conditions that may be encountered in the field. The ADCP, cables, connectors, batteries, mounts, and GPS or echo sounders that will be integrated with the ADCP in the field should be inspected for any irregularities. The ADCP should be connected to the field computer, and communications with the ADCP should be established using the ADCP datacollection software and computer to be used in the field. The ADCP clock should then be set to the appropriate reference time. If radio modems are to be used for communications with a tethered or remote-controlled boat, the communications should be established using the radio modems. If a GPS or echo sounder will be connected to the ADCP in the field, then the GPS or echo sounder should be connected with the ADCP to the computer to ensure that they properly function with the $\mathrm{ADCP}$ and the ADCP data-collection software. If problems are encountered during any system check, the problems should be resolved by (1) consulting the necessary technical documentation, (2) calling a qualified agency staff member familiar with ADCPs, (3) calling the vendor technical support unit, or (4) some combination of these three options.

Tethered and remote-controlled boat hulls, fins, structural members and compartments/hatches should be inspected. The tether line(s) and connectors for a tethered boat should be inspected for wear and to ensure that they are suitable to withstand expected field conditions. When deployed in streams and rivers with high velocities or turbulence, redundant attachment points for the tether on the boat should be used to allow the tethered boat to be recovered should the primary attachment point fail. Remote-control boat motors, servos, and the radio controls should be inspected and tested before going into the field (Oberg and others, 2005).

\section{Field Procedures}

Proper field procedures are critical to obtaining highquality discharge measurements using ADCPs. Although stepby-step procedures are an important aspect of high-quality 
data collection, nothing can substitute for field personnel who understand both the instrument and effect of hydraulic and sediment transport conditions. The following sections provide guidance on proper site selection, pre-measurement field procedures, discharge-measurement procedures, and post-measurement field procedures.

\section{Site Selection}

One of the most important steps in collecting highquality streamflow measurements is site selection. Many ADCP measurement problems can be solved by moving to a better measurement site. The guidelines provided in USGS Water-Supply Paper 2175 (Rantz and others, 1982, p. 139) for making traditional current-meter measurements also are excellent guidelines when using an ADCP, except for those guidelines that relate to depth and velocity requirements for specific meters. General guidelines for selection of an ADCP measurement site can be categorized by location, shape, flow velocity, and other factors.

1. Location:

a. The cross section of a stream lies within a straight reach, and streamlines are parallel to each other. Flow is relatively uniform and free of eddies, slack water, and excessive turbulence (Rantz and others, 1982).

b. The measurement section is relatively close to the gaging station control to avoid the effect of tributary inflow between the measurement section and control as well as to avoid the effect of storage between the measurement section and control during periods of rapidly changing stage (Rantz and others, 1982).

2. Shape:

a. Desirable measurement sections are roughly parabolic, trapezoidal, or rectangular. Asymmetric channel geometries (for example, deep on one side and shallow on the other) should be avoided if possible (Simpson, 2002) as should cross sections with abrupt changes in channel-bottom slope.

b. The streambed cross section should be as uniform as possible and free from debris and vegetation or plant growth.

c. Depth at the measurement site should allow for the measurement of velocity in two or more depth cells at the start and stop points near the left and right edges of the measurement section and result in less than 5 percent of the discharge in each edge.

3. Flow velocity:

a. Measurement sections with mean velocities less than $0.3 \mathrm{ft} / \mathrm{s}$ should be avoided if an alternative mea- surement location is available (Oberg and others, 2005). Although measurements can be made in low velocities, boat operation must be slow and smooth, often requiring special techniques for boat control (Simpson, 2002). If maintaining a slow boat speed is not possible, maintain the slowest speed that allows smooth boat operation. (Additional transects may be necessary to average turbulence and instrument noise.)

b. Sites with very turbulent flow, such as standing waves, large eddies, and nonuniform flow lines, should be avoided. This condition is often indicative of nonhomogenous flow, which is a condition that violates one of the assumptions required for accurate ADCP velocity and discharge measurements.

4. Other factors:

a. Measurement sections having local magnetic fields that are relatively large as compared to the Earth's magnetic field should be avoided. Large steel structures, such as overhead truss bridges, are a common source for these large local magnetic fields and may result in ADCP heading errors.

b. When using GPS, avoid locations where multipath interference is possible, such as where signals from the satellites bounce off structures and objects such as trees along the bank or nearby bridges or buildings. Also avoid locations where reception of signals from GPS satellites is blocked. It may be possible to make valid measurements in sections that violate one or more of the above guidelines, but whenever possible, locate and use a better measurement section (Oberg and others, 2005)

Sometimes measurements need to be made where conditions do not satisfy the suggested guidelines. In such situations, the quality of the measurement can be greatly diminished; therefore, the field personnel must use their best judgment in selecting a measurement section.

\section{Pre-Measurement Field Procedures}

Pre-measurement tests and proper configuration of the ADCP help to ensure a high-quality measurement. The following sections describe the field procedures that should be completed prior to making ADCP measurements.

\section{Set Internal Clock}

Prior to the start of the discharge measurement, the ADCP's internal clock should be checked, set to the correct time, and noted in the ADCP measurement field notes. This should be done prior to any diagnostic tests, calibrations, or configuration so that time stamps on all data will be consistent. 
In most cases, the ADCP's clock should be set to agree with the recorder time at the streamflow-gaging station. Checking and setting the correct time is of particular importance when using the discharge measurements to calibrate or check the calibration of fixed acoustic current meters installed at streamflow-gaging stations or when measuring at sites where the flow is unsteady (Oberg and others, 2005).

\section{Instrument Diagnostic Checks}

After the ADCP is mounted and communication between the ADCP and field computer is established, the ADCP must be checked to ensure all components are operating properly. Diagnostic tests should be performed and the results electronically stored on the field computer. Diagnostic tests may include system serial number, firmware and hardware configuration versions, the beam transformation matrix, electronics diagnostic tests, internal system tests, and sensor verification tests.

If diagnostic-test information is not available for a specific instrument, the user should contact the manufacturer for guidance. The results of diagnostic tests should be backed up in the field and archived in the office with the associated discharge-measurement files. Diagnostics tests should be documented in the field notes. Complete diagnostic tests must be made prior to every discharge measurement. If possible, conduct the test from a stationary boat in relatively still water, for example, near the shore. Some of the tests require little or no water motion relative to the ADCP.

\section{Variation in Speed of Sound with Depth}

Variation in the speed of sound with depth does not affect the measurement of horizontal currents (Teledyne RD Instruments, 1996); however, it does affect the measurement of vertical currents and depth (range from the transducer). Regarding horizontal velocity measurements, Snell's law states that the horizontal wave number is conserved when sound passes through horizontal interfaces. Because the frequency of the sound wave remains constant, the change in the speed of sound with depth does not affect the horizontal component of the sound velocity and hence the horizontal velocity measurement. The measurement of the vertical velocity component and the depth is proportional to the change in speed of sound. Currently (2013), some commercially available data-collection and processing software have instrument specific capabilities for correcting the vertical velocity or the depth for changes in the speed of sound (SonTek, 2012). The horizontal velocities of phased array ADCPs are unaffected by the speed of sound, but the vertical velocity and depth are still dependent on the correct speed of sound. Temperature and salinity are the two most important variables for determining the speed of sound for boat-mounted ADCPs.

\section{Water Temperature}

ADCPs have built-in temperature sensors to measure water temperature at the transducer face. Temperature is the most important variable in the equation used to compute the speed of sound (Urick, 1983, p. 113). The ADCP must compute the speed of sound correctly to accurately measure velocities, depths, and compute discharge. An error of 5 degrees Celsius $\left({ }^{\circ} \mathrm{C}\right)$ in the temperature measurement at a water temperature of $20^{\circ} \mathrm{C}$ will cause about a 3-percent bias error in the measured discharge for piston transducer ADCPs (colder temperatures result in larger errors). Thus, the temperature measured by the ADCP must be read and compared with an independent simultaneous temperature measurement made adjacent to the ADCP (U.S. Geological Survey, 2010) prior to every discharge measurement and the results recorded on the field notes. If the temperature measured by the ADCP temperature sensor differs from the independent temperature measurement by $2{ }^{\circ} \mathrm{C}$ or more, verify the independent temperature measurement and ensure the ADCP has been given sufficient time to equilibrate to the water temperature. Depending on the ADCP, the initial temperature of the ADCP, and the water temperature, equilibration can take up to 30 minutes or more. If a difference of $2{ }^{\circ} \mathrm{C}$ or more is consistently observed from multiple deployments, or if the ADCP temperature sensor has failed, the ADCP should not be used to make discharge measurements until the temperature sensor is repaired and checked. In the event that a discharge measurement is necessary and another ADCP is not readily available, it may be possible to enter a temperature manually for use in the speed-of-sound calculations. This action is not recommended as standard practice, however, and it may decrease the accuracy of the discharge measurement.

These water temperature measurements are being made to help ensure that there are no gross errors in the temperature readings made by the hydroacoustic instruments; therefore, it is not necessary to use a thermometer that meets USGS Office of Water Quality standards for field measurement of water temperature as presented in Wilde (variously dated). Any comparison temperature data measured with a thermometer that does not meet USGS Office of Water Quality standards should be used for internal quality-assurance purposes only and should not be released to the public.

\section{Salinity}

Salinity is another important variable in the speed of sound equation. Salinity values generally range from zero parts per thousand (ppt) for freshwater to $35 \mathrm{ppt}$ for water from the open ocean. A change in salinity from 0 to $5 \mathrm{ppt}$ at a water temperature of $20^{\circ} \mathrm{C}$ will result in about a 1 percent change in discharge. Therefore, when measuring in waters where the salinity is expected to be greater than $5 \mathrm{ppt}$, the salinity should be measured near the transducer face and 
recorded in the field notes. The salinity value may then be entered into the ADCP data-collection software prior to data collection and adjusted as necessary during measurement playback and processing. Salinity should be measured for each transect in locations where salinity varies over time. Salinity may also vary from bank to bank. It should be noted that the salinity value used for a transect should reflect an average salinity for the section to be measured at the approximate depth of the ADCP transducers.

\section{Compass Calibration}

Calibrating the internal magnetic compass of instruments with an internal compass is encouraged prior to all ADCP measurements, but is mandatory when using GPS as the navigation reference, using the loop moving-bed test, using the loop method for correcting discharge for bias caused by a moving bed (Mueller and Wagner, 2006), or when the velocity direction is important. The instrument-specific procedures available from the manufacturer and (or) guidance from the USGS hydroacoustics Web site (http://hydroacoustics.usgs. gov/) for calibrating the compass of the ADCP being used should be followed. The following guidelines should be followed for successful compass calibrations:

1. Minimize ferrous material and electromagnetic field (EMF) interference located in the vicinity of the ADCP (on the boat and at the measurement site). EMF and ferrous material may adversely affect the performance of the internal magnetic compass.

2. If the instrument calibration or evaluation process reports a total compass error, this error should be less than 1 degree when evaluated after calibration. If the error reported by the compass evaluation exceeds 1 degree, the calibration procedure should be repeated. If after several attempts, the total compass error cannot be reduced to less than 1 degree, the compass error should be noted on the field sheet. The discharge measurement then can be made, but special attention should be paid to potential heading errors, such as directional bias and irregular ship track. If the instrument does not report a numerical error, manufacturer's manuals and supplemental USGS guidance should be consulted as to what criteria can be used to determine an acceptable compass calibration.

3. The rotation and any pitch-and-roll of the ADCP during compass calibration should be smooth and slow. Pitchand-roll changes must be minimized with Rio Grande ADCPs because they are equipped only for a single-tilt calibration process. In such situations, the standard deviation of the pitch-and-roll should be less than 1 degree and, ideally, 0.5 degree or less during the calibration and evaluation process. For RiverRay and StreamPro ADCPs, the flat calibration procedure is recommended for typi- cal field use. If pitch-and-roll is consistently greater than 10 degrees, consider using the compass calibration that accounts for pitch-and-roll. Note: The calibration that accounts for pitch-and-roll is more time consuming to complete. For RiverSurveyor ADCPs, it is important to pitch-and-roll the instrument smoothly during calibration about 5-10 degrees more than the pitch-and-roll expected during data collection. It is important that the pitch-androll of a RiverSurveyor during data collection does not exceed the maximum pitch-and-roll during the compass calibration. Compass calibration procedures may change as the USGS works with manufacturers to improve the field performance of the compass. The most recent recommendations on compass calibration procedures are available on the USGS hydroacoustics Web site (http:// hydroacoustics.usgs.gov).

4. Compass calibration should be done as close to the measurement site as possible with the ADCP mounted in the same manner as it will be deployed for the measurement. The entire deployment platform, anything that will move with the ADCP across the channel, should be rotated through the calibration procedure.

5. For best results, the maximum rotation velocity should be 5 degrees per second or less.

A tethered boat deployed from a bridge or cableway often presents a problem for compass calibrations. The best location to calibrate the compass is at the water's edge, preferably close to where the measurement will take place. If access to the water from the bank is not possible or safe, then the compass should be calibrated on land, but not on the bridge or near the A-frame of the cableway. A suitable location for the compass calibration is away from the bridge, guardrails, A-frame, field vehicle, and any other object that could strongly influence the compass reading.

For manned boat deployments, it is important that the boat and ADCP are rotated and, if necessary, pitch-and-rolled together. Rotating, pitching, and rolling the ADCP independent of the manned boat creates changes in the magnetic field that are not representative of the magnetic field that will be experienced during data collection. The objective is to calibrate the compass in the conditions that it will experience during data collection. If a tethered boat is deployed from the manned boat, the tethered boat should not be rotated independent of rotating the manned boat. Rather, the tethered boat must be rotated with the manned boat while minimizing rotation of the tethered boat relative to the manned boat (see section on Manned Boats deployment). Any movement of the tethered boat independent of the manned boat (rotation, floating away from or toward the manned boat, etc.) during compass calibration or data collection will change the effect of the manned boat on the magnetic field experienced by the compass on the tethered boat and may result in inaccuracies in the measured headings that cannot be corrected by calibration. 


\section{Instrument Configuration}

The ADCP should be configured, as necessary, by a trained user to reflect the hydrologic conditions at the site and to optimize the data quality (Lipscomb, 1995). Some ADCPs employ auto-adaptive features that automatically set and adjust the configuration during data collection. Other ADCPs use a fixed configuration that is set prior to the start of data collection. ADCP configuration parameters that may need to be set prior to starting data collection include the blanking distance, water mode, bottom mode, depth-cell size, and profiling range. Other parameters that should be set prior to data collection but can be modified during postprocessing include the instrument draft, edge shape, top and bottom extrapolation method, and magnetic variation. Configuration parameters are specific to the model of the ADCP being used. For a detailed description of all configuration parameters, refer to the technical documentation for the specific ADCP.

General recommendations for configuration parameters are given below.

1. File names for the data files collected should follow a uniform, documented convention developed by each office involved in ADCP operation if the file names are user configurable (U.S. Geological Survey, 2005a).

2. The depth of the ADCP (vertical distance from the water surface to the zero point on the ADCP, often the center of the transducer face) must be measured accurately, recorded in the ADCP discharge-measurement notes, and entered into the data-collection software. The pitch-androll of the boat when the depth is measured should be similar to the pitch-and-roll during the discharge measurement. If the depth of the ADCP changes during the measurement, the depth must be measured again, noted, and the value in the software modified with the new depth (for diagrams see Appendix E).

3. Data-collection software for ADCPs that does not operate in an auto-adaptive mode often contains an automated pre-measurement user dialog to configure the ADCP. The automated pre-measurement user dialog is dependent on user-supplied information about site characteristics, such as maximum water depth, bed-material characteristics, and expected maximum water and boat speeds. If these user dialogs are available in ADCP data-collection software, they should be used to configure the ADCP for discharge measurements (U.S. Geological Survey, 2003).

4. Any changes made to the ADCP configuration during a measurement should be documented in the measurement field notes, so it is clear that changes were made and to which transects these changes apply.

5. Many of the operational modes available in the various ADCPs average multiple pings before reporting and recording the measured data. The averaging in these operational modes has been optimized on the basis of typical water and boat dynamics and how often the heading, pitch, and roll sensors are recorded and how often water depth and boat velocity are measured. Use of the default data rate of these modes allows possible data-quality problems to be more easily identified than problems with data that have been averaged beyond the default values. The flexibility provided by water mode 12 in the Rio Grande ADCP allows the user to set a configuration that may not be optimal for moving-boat deployments. If the averaging interval is too long for the boat stability and water turbulence, errors can be introduced into the measurement. Unless there is a specific reason and the user understands the sampling frequency of the various sensors and the potential effect of longer averaging times, the user should not deviate from the settings configured automatically by the ADCP or the automated pre-measurement dialog. The most up-to-date agency-specific guidelines for the instrument should be consulted before attempting a manual configuration. If guidelines are not available, the user should use manufacturer recommendations for the unit or, seek advice from USGS ADCP experts.

6. The extrapolation method for the top and bottom unmeasured zones can be specified unless data are collected with a StreamPro ADCP on a PDA, in which case the extrapolation methods default to the one-sixth $(0.1667$ power coefficient) power law on the top and bottom for data collection. Often, the appropriate extrapolation method cannot be determined until after the measurement. Previous data collected at a site may be used to guide the selection of the extrapolation method. In the absence of any other information, the one-sixth power-law extrapolation method is a good technique for most open-water discharge measurements made during steady-flow conditions. Evaluate the extrapolation methods and, if necessary, change the methods during postprocessing.

7. Wind speed can be important, especially for sites with low velocities where wind can greatly affect the surface velocities and influence the top extrapolation. Overall wind speed and direction, as well as changes between transects, should be noted on measurement field notes to assist with accurate processing and reviewing of measurements.

8. If the user is unfamiliar with the measurement section, a trial transect, which may or may not be recorded, should be made across the river to determine if the site is appropriate for an ADCP measurement and, if so, to determine site characteristics that will be useful in configuring the instrument, if required. A trial transect is useful for determining the following characteristics for the proposed measurement:
a. maximum water depth;
b. overall cross-section shape;
c. maximum water velocity; 
d. location of the maximum water velocity in the cross section;

e. flow uniformity;

f. effects of hydraulic structures, such as bridges, piers, and islands, on the flow;

g. unusual flow conditions, such as reverse or bi-directional flow;

h. bank shapes; and

i. approximate start-and-stop locations on the left and right banks, where a minimum of two depth cells with valid velocity measurements can be measured. (To obtain consistent edge estimates, buoys can be used to mark the start-and-stop locations.)

\section{Moving-Bed Tests}

ADCPs can measure boat velocity by using a technique called bottom tracking, which computes the Doppler shift of acoustic pulses reflected from the streambed. This technique assumes that the streambed is stationary; however, sediment transport on or near the streambed can affect the Doppler shift of the bottom-tracking pulses. In such situations, reflections of bottom-tracking pulses from highly concentrated near-bed sediments contaminate the reflections from the bed. These near-bed sediments typically are being transported in the downstream direction. If bottom tracking is affected by sediment transport, the measured boat velocity will be biased in the opposite direction of the sediment movement. A stationary boat in the stream would appear to be moving upstream (fig. 11). This bias in the boat velocity will result in measured water velocities and discharge that are less than the true water velocities and discharge (negative bias).

Field experience has shown that sediment transport characteristics can vary greatly for the same discharge, depending on the hydrograph shape, source of runoff, and season of the year. Thus, a moving bed may be detected at a location and discharge where one was not previously detected, or a moving bed may no longer exist at a location and discharge where one was previously detected. Movingbed conditions also have been reported in low-velocity environments (less than $1 \mathrm{ft} / \mathrm{s}$ ). Therefore, to ensure the quality of the data collected, every moving-boat measurement made with an ADCP must have a recorded moving-bed test.

A moving-bed test must be conducted prior to making a discharge measurement. This requirement supersedes Oberg and others (2005) and various USGS training materials. If a site routinely has a moving bed and GPS is always used with the ADCP, a moving-bed test is still required. If multiple discharge measurements are obtained during a single deployment, a moving-bed test is not required for each set of transects used as a discharge measurement, but appropriate procedures must be followed to identify and account for the possibility of a moving-bed during changing flow conditions (see Changing and Tidal Flow Situations).

A moving-bed test is only useful if proper techniques are followed in conducting the test and analyzing the results. The three acceptable methods for performing a moving-bed test are (1) stationary test with no GPS, (2) stationary test with GPS, and (3) the loop method (table 8). The stationary moving-bed test must be made at the location in the measurement section expected to have the highest potential for a moving bed. Additional stationary moving-bed tests provide a better characterization of the moving-bed conditions in the measurement section, but multiple stationary moving-bed tests are required only if the tests are going to be used to correct the measured discharge for moving-bed conditions (see Appendix B). A brief summary of each method is provided here, and detailed descriptions of these methods are provided in Appendix B along with data-collection and processing methods that can be used to obtain an unbiased discharge measurement if a moving bed is present.

\section{Stationary Test Without GPS}

The stationary test with no GPS requires that the boat with the ADCP be held in a stationary position while recording ADCP data, using bottom tracking as the boat-velocity reference. If the stationary position is maintained by a tether or anchor so that upstream or downstream movement of the ADCP is not possible, the moving-bed test should be recorded for no less than 5 minutes; however, if the ADCP can move either upstream or downstream, such as when the boat

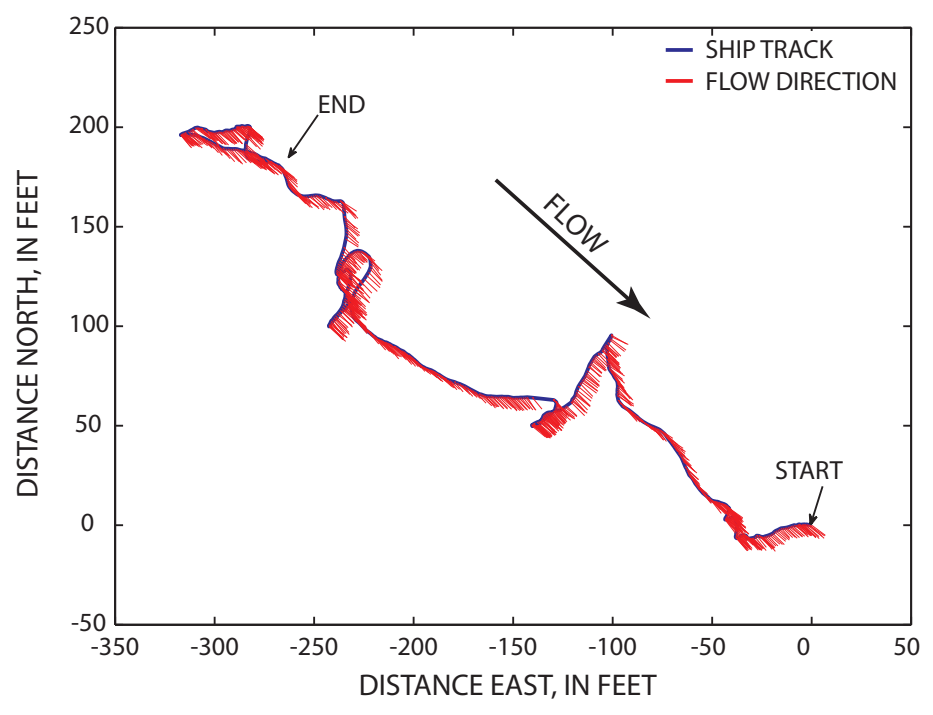

Figure 11. Example of a moving bed measured with a 1,200-kilohertz acoustic Doppler current profiler (ADCP) on the Mississippi River at Chester, Illinois. 
operator is trying to maintain the position of the boat, the test should be recorded for no less than 10 minutes (table 8). These criteria supersede the guidance on stationary moving-bed tests that have been published previously in U.S. Geological Survey (2002b) and Oberg and others (2005). When a moving-bed condition is present, a stationary boat will appear to have moved upstream (fig. 11). The error caused by the moving bed can be estimated by dividing the distance of the apparent boat motion in the upstream direction by the duration of the test in seconds. This computation will provide an estimate of the moving bed detected by the bottom-tracking technique. This moving-bed velocity can then be divided by the average water velocity from the moving-bed test and multiplied by 100 to yield the percent bias error for a water-velocity measurement at this stream location. If the moving-bed test was completed with a fixed tethered deployment, an anchored manned boat, or a manned boat where little movement of the boat was ensured, a moving bed is determined to be present when the measured moving-bed velocity is greater than 1 percent of the mean water velocity at the test location. If the moving-bed test was conducted using a manned boat that was not anchored and may have moved either upstream or downstream, a criteria of 2 percent instead of 1 percent is used because uncertainty has been introduced into the test by the boat's movement. Stationary moving-bed tests collected with a StreamPro ADCP with no compass can result in a false upstream ship track. Special techniques and software to account for this upstream movement are discussed in Appendix B. Dischargemeasurement techniques that are not affected by a moving bed, or that correct for the effect of a moving bed, should be used if a moving bed has been detected (Appendix B).

\section{Stationary Test with GPS}

A more accurate method for estimating the errors introduced by a moving bed can be determined if a GPS is available for use and is interfaced with the ADCP and the data-collection software. This second method also requires that the ADCP boat be held in a stationary position and a data file recorded for at least 5 minutes if quality GPS data are being recorded (table 8 ). The error caused by the moving bed can be computed in the same manner as previously described for the first method, except that the distance in the upstream direction indicated by bottom tracking should be corrected by the distance actually traveled in that direction, as indicated by GPS (Oberg and others, 2005). In the WinRiver and RiverSurveyor Live software, this distance can be found in the "compass calibration" tabular window and GPS tabular display, respectively, and is labeled "BMG-GMG mag" and "BMG-GMG dir." The direction of the "BMG-GMG dir" should be in the upstream direction. If the measured moving-bed velocity is greater than 1 percent of the mean water velocity at the test location, GPS should be used as the navigation reference (Appendix B).

Table 8. Methods for identifying a moving-bed condition, criteria for correction, and minimum durations.

[s, seconds; ft/s, foot per second]

\begin{tabular}{|c|c|c|c|}
\hline $\begin{array}{l}\text { Moving-bed detection } \\
\text { method }\end{array}$ & Requires & Detection threshold ${ }^{1}$ & Minimum duration \\
\hline \multirow[t]{2}{*}{ Stationary with no GPS ${ }^{2}$} & $\begin{array}{l}\text { Anchor or fixed tether with } \\
\text { minimal upstream and } \\
\text { downstream movement }\end{array}$ & $\begin{array}{l}\text { Moving bed velocity }>1 \% \text { of } \\
\text { mean water velocity }\end{array}$ & 5 minutes $(300 \mathrm{~s})$ \\
\hline & $\begin{array}{l}\text { Manned boat with no anchor } \\
\text { or GPS }\end{array}$ & $\begin{array}{l}\text { Moving bed velocity }>2 \% \text { of } \\
\text { mean water velocity }\end{array}$ & 10 minutes $(600 \mathrm{~s})$ \\
\hline Stationary $^{2}$ with GPS & $\begin{array}{l}\text { GPS integrated with ADCP } \\
\text { data }\end{array}$ & $\begin{array}{l}\text { Moving bed velocity }>1 \% \text { of } \\
\text { mean water velocity }\end{array}$ & 5 minutes $(300 \mathrm{~s})$ \\
\hline Loop & $\begin{array}{l}\text { Precisely start and end at same } \\
\text { location } \\
\text { Accurate heading } \\
\text { Mean water velocity }>0.8 \mathrm{ft} / \mathrm{s} \\
\text { Consistent boat speed }\end{array}$ & $\begin{array}{l}\text { Moving bed velocity } \\
>0.04 \mathrm{ft} / \mathrm{s} \text { and }>1 \% \text { of } \\
\text { mean water velocity }\end{array}$ & 3 minutes $(180 \mathrm{~s})^{3}$ \\
\hline
\end{tabular}

\footnotetext{
${ }^{1}$ The detection threshold is the limit at which either GPS should be used for reference or a correction should be applied to bottom-track reference. These thresholds are based on the accuracy limits of the moving-bed detection method.

${ }^{2}$ The stationary moving-bed detection method only determines moving bed at a single location in the cross section and should be completed in a location where moving bed is likely the greatest. If the location of greatest potential of moving bed is uncertain, multiple stationary moving-bed tests should be completed.

${ }^{3}$ Longer durations may help minimize potential effects of some compass errors.
} 


\section{Loop Test}

If the ADCP can be held stationary, stationary movingbed tests are a good measure of the magnitude of an apparent moving bed; however, these tests represent the moving-bed condition only at the location in the cross section where the test is completed. An alternative to the stationary moving-bed test is the loop method, which is based on the fact that as an ADCP is moved across the stream, a moving bed will cause the bottom-track-based ship track to be distorted in the upstream direction. Therefore, if an ADCP makes a two-way crossing of a stream (loop) with a moving bed and returns to the exact starting position, the bottom-track-based ship track will show that the ADCP appears to have returned to a position upstream from the original starting position (fig. 12). The mean moving-bed velocity can be computed from the distance the ADCP appeared to have moved upstream from the starting position (loop-closure error) and the time required to complete the loop. If the moving-bed velocity measured by the loop method is greater than $0.04 \mathrm{ft} / \mathrm{s}$ and greater than 1 percent of the mean water velocity, a moving bed is present (table 8). The accuracy of the loop method may not be adequate for mean velocities less than $0.8 \mathrm{ft} / \mathrm{s}$. If the mean velocity is less than $0.8 \mathrm{ft} / \mathrm{s}$, a stationary test should provide more reliable results. Discharge-measurement techniques that are not affected by a moving bed, or that correct for the effect of a moving bed, should be used if a moving bed has been detected (Appendix B). The loop method must be applied properly, or it may produce incorrect results. Anyone planning to use the loop method should read and follow USGS Scientific Investigations Report 2006-5079 (Mueller and Wagner, 2006), which describes the procedures, limitations, and uncertainties associated with the loop method. A detailed description of the loop method also is presented in Appendix B.

\section{Changing and Tidal Flow Situations}

When the flow conditions change during a measurement or series of measurements, the moving-bed conditions are also likely to change. A moving-bed test made at the start of the deployment may not be applicable for the entire set of measurements. These changes can occur on inland rivers during periods of rapidly varying flow and more commonly in a coastal environment during a measurement through a tidal cycle. These conditions do not eliminate the requirement for at least one moving-bed test and may require multiple moving-bed tests depending on whether GPS data are integrated with the ADCP.

If the data are being collected with GPS integrated with the ADCP, a single moving-bed test is the minimum requirement.

1. A moving-bed test should be made immediately prior to the start of the discharge transects. The loop test is recommended as it will capture the moving-bed conditions throughout the cross section. The result of the moving-bed test should be consistent with the difference in discharges computed with GPS and bottom track as the navigation references for transects immediately following the moving-bed test. This procedure will verify that the GPS, compass calibration, and magnetic variation are accurate.

2. As flow conditions change, the GPS referenced ship track and discharge can continue to be compared to the bottom-track referenced ship track and discharge. The final discharges should be referenced to bottom track unless (a) the bottom-track referenced ship track plots upstream from the GPS referenced ship track and (b) the bottom-track discharge is consistently less than the GPS referenced discharge by 1 percent or more.

If the data are being collected without the benefit of having GPS, bottom track must be used as the reference for all transects. In this situation, multiple moving-bed tests may be required. At least two moving-bed tests should be made: one at the beginning of the measurement series and one in the condition expected to have the greatest potential for a moving bed.

1. If both tests indicate no moving bed, it could reasonably be assumed that a moving bed does not exist for the full range of conditions, although additional tests would provide better support for this assumption.

2. If either moving-bed test indicates a moving bed, then additional moving-bed tests need to be made to fully characterize the change in moving-bed conditions until no moving-bed condition exists. Corrections to measured discharges between moving-bed tests need to be interpolated from the moving-bed tests that bracket the measurement. These interpolations and corrections may be made manually if available software does not support such computations.

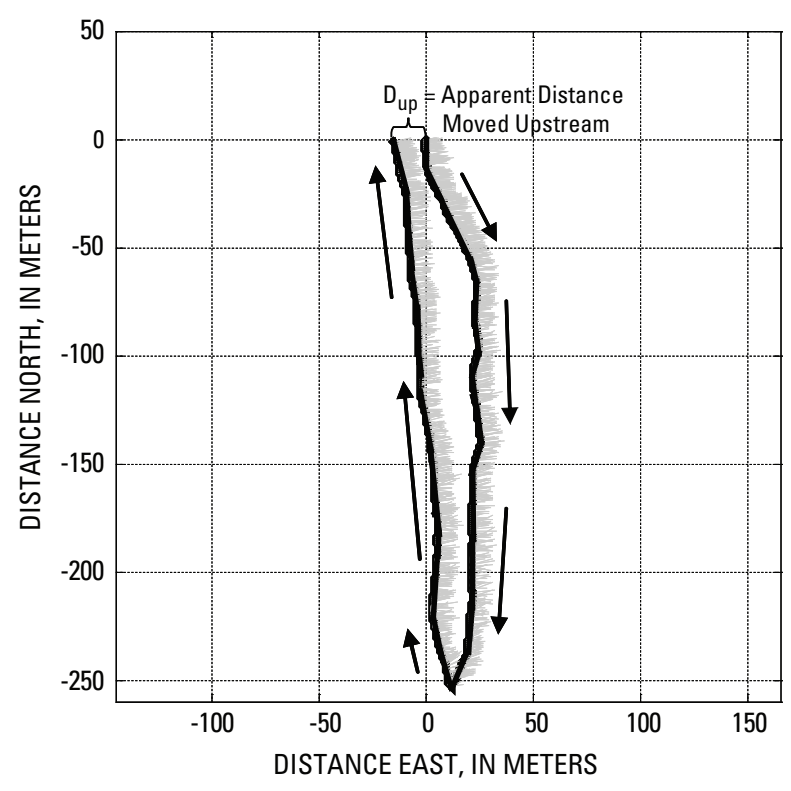

Figure 12. A distorted ship track in a loop caused by a moving bed. 


\section{Selecting the Measurement Method Based on Moving- Bed Test Results}

When the moving-bed test indicates no moving bed, bottom track is the preferred navigation reference because it minimizes the potential error sources in the measurement. If the moving-bed test indicates a moving bed, then a GPS should be used with the ADCP and either GGA or VTG selected as the navigation reference. If GPS cannot be used because of insufficient satellite coverage or unreliable headings due to compass interference at the site, then a method of correcting the bottom-track referenced discharge should be used or the measurement made using the mid-section technique. The recommended approaches for measuring discharge with an ADCP in moving-bed conditions are presented in priority order in table 9 . Correcting the bottom-track referenced discharge using the loop method or multiple stationary tests is not an alternative to using GPS and should only be used when GPS cannot be used because of site conditions or heading inaccuracies. The details of collecting and processing data in moving-bed conditions are presented in Appendix B.

\section{Discharge-Measurement Procedures}

The procedures to be followed to make quality discharge measurements vary depending on the flow conditions being measured. The procedures for measuring steady-flow conditions are different from the procedures used to measure unsteady-flow conditions. Although the procedures may be different for the various flow conditions, the data-quality indicators for both conditions are consistent. The following sections provide details on the recommended procedures for measuring discharge in steady- and unsteady-flow conditions as well as data-quality problems to monitor in the field when making discharge measurements.

\section{Steady-Flow Conditions}

Discharge measurements made from a moving boat under approximately steady-flow conditions will consist of reciprocal transects (at least two transects) having a total exposure time of 720 seconds or greater. Exposure time refers to the total amount of time spent sampling (or measuring) the flow during a discharge measurement and does not include

Table 9. Methods to account for moving-bed conditions in priority order.

[DGPS, differentially corrected global positioning system; GPS, global positioning system: Hz, hertz; NMEA, National Marine Electronics Association; $<$, less than; ft/s, foot per second; >, greater than; SMBA, Stationary Moving-Bed Analysis]

\begin{tabular}{|c|c|c|}
\hline Method & Requires & Potential issues \\
\hline DGPS (GGA) as navigation reference & $\begin{array}{l}\text { - Differentially corrected } \\
\text { - Five decimal minute precision GGA } \\
\text { - GGA NMEA sentence } \\
\text { - Accurate compass headings } \\
\text { - Accurate magnetic declination } \\
\text { - Valid depths }\end{array}$ & $\begin{array}{l}\text { - Source of compass interference that varies } \\
\text { in the cross section } \\
\text { - Slow GPS update rate }(<2 \mathrm{~Hz}) \\
\text { - Multi-path errors }\end{array}$ \\
\hline GPS (VTG) as navigation reference & $\begin{array}{l}\text { - VTG string based on Doppler shift of } \\
\text { satellite signals } \\
\text { - Two decimal precision for speed } \\
\text { - VTG NMEA sentence } \\
\text { - Accurate compass headings } \\
\text { - Accurate magnetic declination } \\
\text { - Valid depths }\end{array}$ & $\begin{array}{l}\text { - Source of compass interference that varies } \\
\text { in the cross section } \\
\text { - Subject to inaccuracies when boat speeds } \\
\text { are }<0.8 \mathrm{ft} / \mathrm{s} \\
\text { - Slow GPS update rate }(<2 \mathrm{~Hz})\end{array}$ \\
\hline Loop $^{1,2}$ & $\begin{array}{l}\text { - Precisely start and end at same location } \\
\text { - Accurate compass heading } \\
\text { - Mean water velocity }>0.8 \mathrm{ft} / \mathrm{s} \\
\text { - Consistent boat speed, }<1.5 \text { times the mean } \\
\text { water speed } \\
\text { - Valid but potentially biased bottom track } \\
\quad \text { data (during loop and transects) }\end{array}$ & $\begin{array}{l}\text { - Any invalid bottom track while during } \\
\text { changes in speed or direction } \\
\text { - Poor compass calibration } \\
\text { - Source of compass interference that varies } \\
\text { in the cross section } \\
\text { - Assumes moving-bed velocity is propor- } \\
\text { tional to near-bed velocity }\end{array}$ \\
\hline Multiple $^{1,2}$ stationary moving-bed tests & $\begin{array}{l}\text { - Only minor upstream or downstream boat } \\
\text { movement } \\
\text { - Valid but potentially biased bottom track } \\
\text { data during measurement transects }\end{array}$ & $\begin{array}{l}\text { - Instrument configurations with relatively } \\
\text { high random uncertainty in water ve- } \\
\text { locities may introduce error in the SMBA } \\
\text { computed upstream distance } \\
\text { - Assumes moving-bed velocity is propor- } \\
\text { tional to near-bed velocity }\end{array}$ \\
\hline
\end{tabular}

${ }^{1}$ Correcting the bottom track referenced discharge using the loop method or multiple stationary tests is not an alternative to using GPS and should only be used when GPS cannot be used because of site conditions.

${ }^{2}$ Corrections to discharge using the loop or multiple moving-bed tests should be accomplished with U.S. Geological Survey utility programs Loop Correction (LC) and Stationary Moving-Bed Analysis (SMBA) or equivalent. Hand computations should not be used. 
time between transects nor time spent doing moving-bed tests or other tasks. An even number of transects with reciprocal courses is required to minimize directional biases in measured discharges. Directional biases occur when the discharges measured for transects made when traveling from the left bank to the right bank are consistently either greater than or less than discharges measured for transects made when traveling from the right bank to the left bank. The minimum exposure time for the discharge measurement should be at least 720 seconds (12 minutes), even if that requires the hydrographer to collect more than four transects (U.S. Geological Survey, 2011b). The transects should be collected using a reasonably uniform boat speed across the cross section and consistent boat speeds among the transects. If a critical data-quality problem can be identified and documented (for example, a tow boat approaching the section, a sudden change in discharge because of a lockage, communication problems between the computer and ADCP, or other factors), that transect may be replaced with an additional transect collected in the same direction and the reason for this action documented in the field notes.

\section{Unsteady-Flow Conditions}

At times, flow changes rapidly enough that discharge measurements with a duration of 720 seconds may not properly characterize the streamflow being measured. Unsteady flows can be caused by upstream dam or lock regulation, tidal effects, downstream backwater effects, flood waves, or other conditions. In addition, discharge measurements used in the development of an index velocity rating may need shorter durations to allow better correlation with the measured index velocity. In such situations, it may be necessary to consider individual transects as discrete measurements. If possible, however, reciprocal transects should be averaged together as one measurement of discharge to reduce the potential of directional bias (U.S. Geological Survey, 2002b). The justification for using a single transect or any combination of transects with a total exposure time of less than 720 seconds for discharge measurements should be documented in the field notes and stored with the discharge measurement or applicable station analysis files. Another consideration for unsteady flows, specifically bi-directional flows, is the assignment of a positive or negative sign to the discharge measurement. The ADCP software may or may not assign flow direction correctly, and the positive or negative sign also can change depending on which edge is designated "left" or "right." Thus, the operator should note the direction of flow during measurement for each transect, according to accepted convention for a particular site.

\section{Measuring in Difficult Conditions}

Not all measurements can be made in ideal conditions. Often the situation dictates that a measurement must be made in conditions that make it difficult to measure streamflow accurately. Knowledge of the fundamental principles of ADCP operation and the potential effects of specific conditions on the streamflow measurement can allow the hydrographer to adapt the data-collection and processing procedures to ensure the best possible measurement is made. Selected difficult conditions encountered in hydroacoustic discharge measurements are identified below, and the best procedures for collecting and processing are discussed.

\section{Slow Flow}

Although flood conditions can be the most difficult and dangerous physical conditions for measuring streamflow, slow flow conditions are perhaps the most difficult for making an accurate measurement. Any noise or inaccuracies in the data, even though small in magnitude, are often much larger than expected when viewed as a percentage error, because the velocities are low. Often very slow flow is unsteady and with even mild wind in the upstream or downstream directions may surge or oscillate. Disturbance caused by the boat used to deploy the ADCP can become significant. Even instrument noise in the velocity measurements can become significant and require considerably more averaging to achieve an accurate mean than under normal flow conditions. To minimize instrument noise, use pulse coherent modes, if possible. Use a tagline, cable system, or trolling motor to maintain smooth slow boat operation. Position the ADCP so as to minimize any disturbance by the boat, especially manned boats. Generally for manned boats, locating the ADCP upstream from the bow minimizes the effects of the hull. When using tethered boats, allow the boat to orient itself to the flow and direction of travel; do not fix the tethered boat in an upstream orientation and move it side to side as this will cause major disruptions in the weak flow patterns. Use of a wind sock as a sea anchor (fig. 8) will help steady the orientation of the tethered boat. Collect more transects to ensure an accurate average and to identify any cyclical trends in the flow. The random error associated with the average can be approximated by dividing the coefficient of variation by the square root of the number of transects (Bell, 1999).

\section{Fast and (or) Turbulent Flow}

Fast and (or) turbulent flows can challenge the operating limits of both the deployment platform and the ADCP. The stability of the boat (tethered or manned) is an important consideration for safety of the field crew and quality of the data collected. Safety of field personnel should always be the top priority. Some tethered boats may dive when over topped, creating a large sudden increase in the force on the tether, which is a safety hazard for the operator. Heave, pitch, and roll of the boat due to waves and a turbulent water surface can result in air entrainment under the transducers, which can block the acoustic signals resulting in invalid data. The heave, pitch, and roll can also cause change in the instrument draft, resulting in an increase in the uncertainty associated with the streamflow measurement. When using tethered boats from a bridge, a constant pitch of the boat may be caused by the 
required tension and angle of the tether. Fast and turbulent flow is often associated with sediment transport, which may result in a moving bed and (or) rough streambed composed of cobbles and boulders, all of which can result in loss of bottomtrack data. The flow homogeneity assumption of the ADCP is often violated in turbulent conditions, but generally the averaging of the effects of the turbulence throughout the cross section results in an accurate streamflow measurement. In fast and turbulent flow a deployment method that maximizes safety and stability of the ADCP should be used, such as larger manned boats or tethered boats designed for deployment in fast turbulent water. During data collection the data should be carefully monitored for invalid data caused by air entrainment or invalid bottom track. Adjustments to the deployment, such as increasing the draft of the instrument or changing the location of the measurement section, may be needed to minimize the loss of data. The selected ADCP operating mode should ensure the sensors (heading, pitch, and roll) are read often and apply the latest readings to the velocity measurements.

\section{Vertically Stratified Bi-Directional Flow}

Bi-directional flow is common in estuaries but may occur where there are density currents due to changes in density caused by salinity or temperature, near hydraulic structures where flow is withdrawn or introduced in part of the water column (as opposed to uniformly throughout the full depth), and where wind creates a strong surface current. Vertically stratified bi-directional flow will result in a nonstandard velocity profile. Typically, constant or 3-point extrapolation methods will be required at the top and a no-slip extrapolation method at the bottom (for more information on extrapolation methods see Appendix A). Collecting data as near to the surface as possible, without measuring the effect of flow disturbance from the instrument or deployment platform, is important in accurately representing the surface flow. Wind and hydraulic conditions at the water surface, including the general pattern or trend of the flow, must be carefully considered when evaluating the velocity profile to select the best top extrapolation method. In some instances, another method to directly measure the velocity near the surface could be used. A point-velocity acoustic Doppler velocimeter (ADV) may be used for this purpose; however, there are no software or standard procedures for this type of application.

Temperature and salinity can vary both temporally and spatially. Only the temperature at the transducer face is important for the Doppler shift, but changes in temperature through the water column will affect the measured depth. For more detailed information on the effect of temperature and salinity on ADCP measurements, see the section Variation in Speed of Sound with Depth in this report.

\section{Shallow Flow}

The accuracy with which the flow in the unmeasured areas can be computed from the extrapolation methods is the primary issue with streamflow measurements in shallow flows. The limitations of the ADCP regarding depth-cell size, operating mode, flow disturbance, and blanking distance are important in determining how much of the water column can be measured and how much must be computed on the basis of the extrapolation methods fit to the measured data. The critical question is, "Are the measured data representative of the unmeasured areas such that the extrapolation method can be evaluated and selected so that the resulting discharge is accurate?" The instrument, configuration, and deployment should maximize the percentage of the water column that can be measured without compromising the instrument limitations, including flow disturbance limitations. Rough streambeds in shallow flows can further complicate the measurement. Site and instrument selection are critical for an accurate measurement. A site that has uniform flow both horizontally and vertically and an instrument that provides a small blanking distance, minimal flow disturbance, and small depth cells will result in the best measurement.

\section{Deep Flow}

Measurements in deep flow can be limited by the concentration of backscatter material, the frequency of the ADCP, and the speed of the flow. The range to which the ADCP can measure is a function of the frequency of the instrument and the backscatter material in the water column. Lower frequency ADCPs can typically measure deeper water than higher frequency ADCPs. The depth to which an ADCP can collect data is also dependent on the concentration and composition of the backscatter material (see Limitations of ADCPs, Effect of Sediment for more details). In general a lower frequency ADCP using a nonpulse coherent operating mode can achieve the deepest measurement range.

\section{Vertical Walls}

Although providing a well-defined channel boundary, vertical walls present a potential problem for ADCPs. As an ADCP is positioned near a vertical wall, the angled beams and (or) acoustic side lobes of the beams may reflect off the vertical wall and potentially contaminate the data in the other beams. For an example of the effects of a vertical wall, see Appendix F, Step 5, fig. F-9. To avoid reflections from a vertical wall, a good rule of thumb is to keep the ADCP away from vertical walls a distance equal to the depth of flow at the wall.

\section{Rough and Irregular Streambeds or Vegetation on the Streambed}

Rough and irregular streambeds lead to uncertainty in the bottom extrapolation and a higher potential for invalid bottom track. Vegetation on the streambed causes similar problems but can also result in incorrect, as well as invalid, bottom track. The best solution to this condition is to select a better measurement location, if possible. If a measurement must be made in a cross section with a rough or irregular bed, 
slow smooth boat movement will provide the best opportunity to collect valid bottom-track data. Evaluation of the velocity profile is especially important, because the roughness of the streambed may create more hydraulic drag resulting in a flatter velocity profile requiring a higher exponent for the power or no-slip extrapolation methods.

Wind

Wind can affect the streamflow and shape of the discharge profile near the water surface. The effect of wind is greater in slow flow conditions than in faster flow conditions. The effect of wind may or may not extend deep enough into the water column to be measured by the ADCP. Collecting data as near to the surface as possible, without measuring the effect of flow disturbance from the instrument or deployment platform, is important in accurately measuring the effect of wind. Field notes on the wind speed and direction and its observed effect on surface currents are critical to properly accounting for wind in the streamflow computation. These field notes should be used during the evaluation of the discharge profile in selecting the top extrapolation method. As with vertically stratified flow, another method to directly measure the velocity near the surface could be used. An ADV may be used for this purpose; however, there are no software or standard procedures for this type of application.

\section{High Sediment Load}

The effect of sediment on ADCP measurements is discussed in detail in Limitations of ADCPs, Effect of Sediment earlier in this report. In some situations, it may not be possible to make an ADCP measurement because of high sediment concentrations; however, in other situations use of a lower frequency ADCP and external devices (echo sounder and GPS) may allow data collection that would not be possible with the ADCP alone. Lower frequency ADCPs typically perform better in high sediment conditions. High sediment concentrations typically result in a moving-bed condition. A GPS should be used for measuring the boat velocity in such conditions. When the sediment concentration is such that the ADCP has difficulty bottom tracking and detecting the streambed (depth), use of a low frequency ( $200 \mathrm{kHz}$ or lower) echo sounder to measure depth and GPS to measure boat velocity can allow accurate streamflow measurements to be made. Additional details on the use of echo sounders and GPS can be found in Ancillary Equipment earlier in this report.

\section{Critical Data-Quality Problems}

When making ADCP discharge measurements, the ADCP operator should continuously monitor the data through the ADCP software. If a critical data-quality problem is observed during measurement in a transect, the use of that transect may be terminated. If a transect is not used, the reason should be documented in the ADCP discharge-measurement field notes, and that transect should not be used in the computation of measurement discharge. If the problem was related to undesirable measurement-section characteristics, a new measurement section should be located and noted on the measurement field notes. If the terminated transect was not the first transect in a measurement series, the boat should be returned to the initial starting point to ensure that the transects are measured in reciprocal pairs (Oberg and others, 2005). Potential critical data-quality problems can include, but are not limited to the following:

1. Inappropriate or improperly configured water or bottom mode;

2. Configuration errors, such as an insufficient number of depth cells to profile down to the channel bed;

3. Appreciable or consistent portion of the section with invalid data, data that failed to meet internal and userspecified data-quality criteria, or missing data caused by communication problems between the computer and the ADCP (to identify invalid data in RiverSurveyor Live, it is recommended that the track reference code be displayed in the time series plot and monitored during data collection);

4. Appreciable invalid bottom tracking;

5. Erroneous boat or water velocities, such as ambiguity errors (Appendix A);

6. Excessive boat speed;

7. Poor GPS data attributed to multipath, satellite changes, or high dilution of precision (DOP);

8. Erroneous compass headings due to poor compass calibration or magnetic interference when using GPS for boat speed reference or loop moving-bed detection;

9. Excessive pitch-and-roll or erratic motion of boat and $\mathrm{ADCP}$; and

10. Inadvertent early or late start and (or) termination of the transect.

\section{Boat Operation}

A good rule of thumb is for the average boat speed during each transect to be approximately equal to or less than the average water speed. More important than slow boat speed, however, is smooth boat operation (gradual accelerations and decelerations, maintaining a uniform speed, if possible, and slow turns). At some sites, it may be necessary to move the boat across the channel using a nonferrous tag line. Other methods for moving the boat slowly and smoothly include the use of push poles, paddles, low-speed trolling motors, or tethered boats, which can be moved slowly across the channel when deployed from a hand-operated cableway or a 
bridge. When using a tethered boat, the boat speed should be fast enough to keep the boat moving consistently rather than having the wind or waves move the boat back and forth. Use of a wind sock as a sea anchor or other mechanism (fig. 8) to increase the drag on the back of the float can be helpful in obtaining smooth boat operation in slow velocities and windy conditions. When using GPS, keeping the boat speed as low as practical is especially important because errors in the compass readings are additive and increase with boat speed. Rapid course changes should be avoided; the key element in boat operation during the measurement is to do everything slowly and smoothly. Simpson (2002) discusses proper boat operation for ADCP measurements in detail, and his remarks on boat operation should be heeded (Simpson, 2002, p. 122):

\begin{abstract}
"Be a smooth operator! The BB [broadband]-ADCP discharge-measurement system will give more consistent results if rapid movements and course changes are kept to a minimum. Smooth boat motion is more important than a straight-line course."
\end{abstract}

\section{Estimating Edge Discharge}

Because depths will eventually get too shallow for valid data collection as the ADCP approaches a bank, it is necessary to estimate discharge in the near-shore unmeasured zones using the ADCP discharge-measurement software. If an individual edge discharge is more than 5 percent of the total discharge, an alternate method of measuring/estimating the discharge should be used to check the edge discharge. An alternate method could include measuring and (or) estimating multiple point velocities and depths in the edge and computing a discharge for the edge using the midsection method. If the edge discharge measured with the alternate method agrees with the ADCP software edge discharge, the ADCP software edge discharge should be used. If the discharge from the alternative method does not agree with the ADCP software edge discharge, the more accurate of the two discharges, based on the hydrographer's judgment, should be used. The alternate method must be documented with the measurement (U.S. Geological Survey, 2012).

The distances from the edge of water to the starting and stopping points of each transect must be measured using a distance-measurement device (such as a laser or optical rangefinder), tagline, or some other accurate measurement device. Use of marker buoys at the start and end points of transects will provide more consistent edge estimates. When measuring in channels with vertical walls at the edges, the rule of thumb is that start and stop points for transects should be no closer to the wall than the depth of water at the wall to prevent acoustic interference from the main beam or side lobes impinging on the wall. For example, if the depth at a vertical wall is $10 \mathrm{ft}$, transects should start or stop at least $10 \mathrm{ft}$ away from the wall.

When using a tethered boat, special methods are required to measure edge distances. Distance marks on the bridge handrail or guardrail may be used to measure edge distances, but care must be taken to ensure proper line of sight (fig. 13). Use of a notebook, binder, or other object with perpendicular straight edges can be used to sight perpendicular to the bridge (fig. 14). If the tethered boat is too far away from the bridge to accurately use distance marks for measuring edge distances, laser rangefinders having a compass, an inclinometer, and a "missing-line mode" capability may be used. Missing-line mode calculates a horizontal distance between two points, given a range, heading, and vertical angle measured for each point. Edge distance may be measured by selecting the shore and the transect start or end point while using this mode (Rehmel and others, 2002).

When using a remote-controlled boat or bank-operated cableway at some sites, edge distances may be measured using the same techniques as with tethered boats. At other sites where edge distances cannot be measured using these techniques, it may be necessary to position someone in line with the measurement section to measure the distance from the near-shore edge of water to the starting point and the distance from the ending point to the edge of water on the far shore. For example, the distance to shore can be measured using a laser rangefinder to measure the distance to the bank and the distance to the ADCP at the far edge; then the distance between the shore and the ADCP can be computed.

The velocity used to compute the edge estimate must be representative of the flow in the edge. The formulas used to compute the edge discharge assume a decrease in velocity from the last measured point to the bank (Fulford and Sauer, 1986). In order to obtain an accurate mean velocity for computing the discharge in the near-shore zones, the boat should be kept nearly stationary for at least 10 ensembles at the start and end of each transect. When an eddy or flow reversal is encountered at a channel boundary, the best

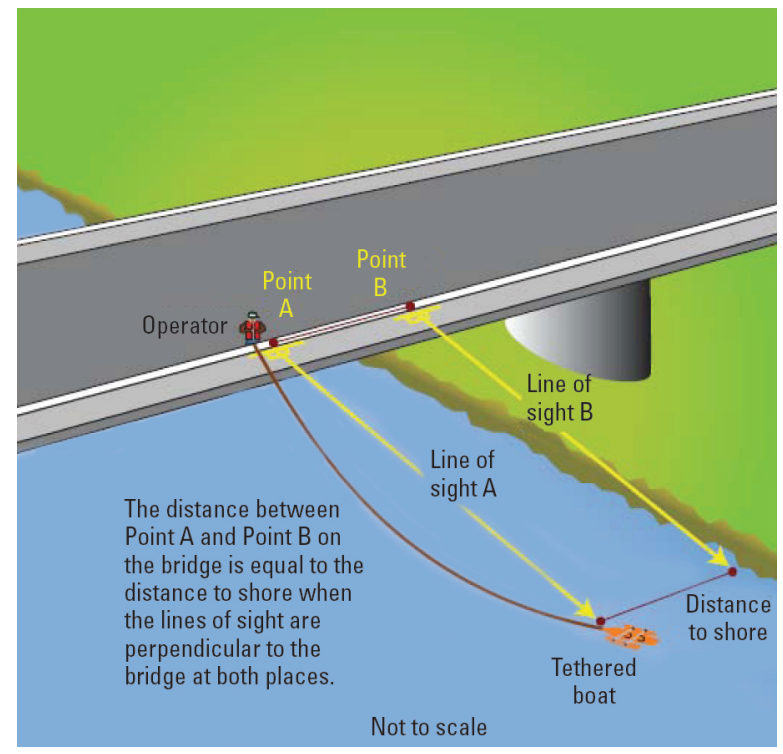

Figure 13. Edge distances needed when using a tethered acoustic Doppler current profiler boat for discharge measurements (modified from Environment Canada, 2004). 


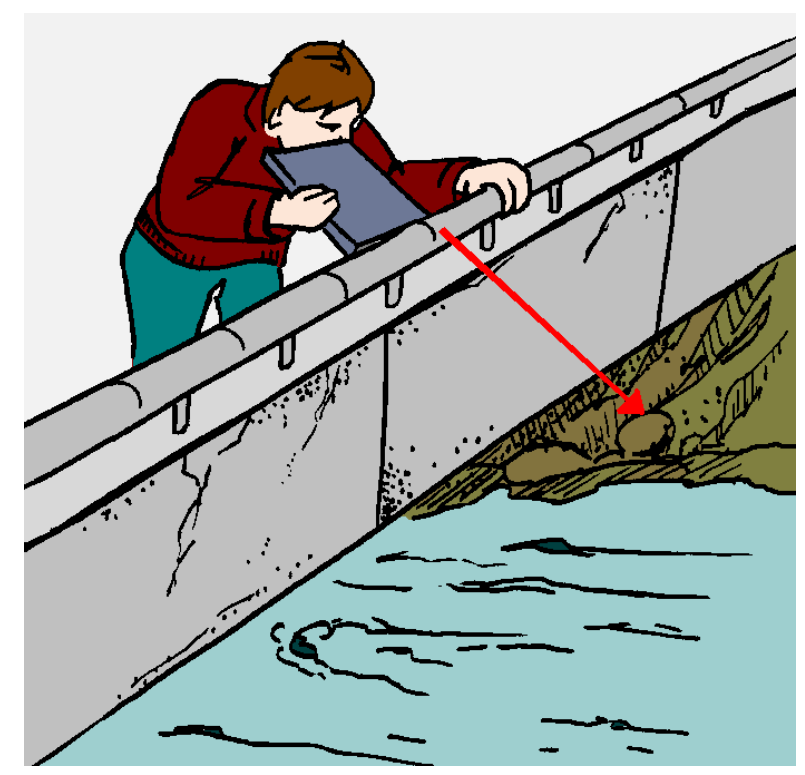

Figure 14. Use of a binder to sight perpendicular to the bridge. (Illustration provided by Francois Rainville, Environment Canada, 2013.)

approach is to select a different measuring section to avoid this situation. However, if a measurement must be made at a location with an eddy or flow reversal on one or both banks, then it is important to capture both the upstream and downstream flow in the eddy and document this condition in the field notes (fig. 15). Typically the eddy will result in downstream flow further from the bank with upstream or negative discharge along the bank. Since the downstream flow includes the flow moving upstream along the bank as it is turned and flows back downstream, it is important to account for this negative flow or the measured discharge will be biased high. Therefore, to account for the negative discharge, the start and end of the transect should be in the upstream velocity portion of the eddy so that the discharge computed in the edge is negative. In an eddy, it may be difficult to keep a tethered boat stationary for 10 ensembles in order to obtain an accurate mean velocity for the edge estimate. The eddy may force the boat into water that is too shallow to measure with the ADCP. Therefore, it is recommended that, at the end of each transect, the user review each edge discharge, adjust the number of ensembles used for the mean velocity (as necessary), and verify that the mean velocity appears reasonable for the given site conditions.

Accurate edge-discharge estimates also require the ADCP operator to select the correct edge-shape coefficient for the type of edge. Currently (2013) the ADCPs manufacturers' software supports two standard edge shapes: (1) sloping or triangular or (2) vertical or rectangular. The coefficient for the vertical or rectangular edge is based on a smooth concrete wall (Oberg and Schmidt, 1994). If these options are not representative of the edge, a user-determined coefficient can be specified in WinRiver II or a manually computed discharge can be entered in RiverSurveyor Live. During flood conditions, it is common to not be able to measure to the edge of the floodplain due to shallow depth and (or) vegetation, which results in a panhandle edge shape (fig. 16). For this and other nonstandard edges, the flow may need to be measured by another means, if possible. If physical measurement of the flow in the edge is not possible, then the hydrographer should consider the effect of roughness and shape to adjust the coefficient from the standard coefficient. Increased vegetation or roughness will decrease the coefficient. Deviations in shape should increase or decrease the coefficient based on an increase or decrease in the cross-sectional area of the edge from the standard shapes. The edge discharge should be estimated in the most accurate way possible. Field notes documenting the flow and vegetation distribution in the unmeasured portion are required to justify nonstandard edge computations. Photographs of the edge can be used to document the site conditions.

\section{Field Notes}

Field notes are important for documenting pre-deployment tests, describing site conditions, verifying data entered into the ADCP software, and justifying various settings, such as extrapolation method or edge shape. Field notes may be recorded on paper using the ADCP discharge-measurement field note form as shown in figure 17 or using an electronic field notes program, such as Surface WAter Measurement and Inspection (SWAMI) (links to these forms are available from http://hydroacoustics.usgs.gov). The ADCP operator should note any conditions that potentially could affect the measurement, including estimated wind speed and direction, bi-directional or unusual flow patterns, excessive waves, or passing boats. Use of an ADCP does not negate long-standing, agency guidelines and policies regarding measurement documentation, such as recording reference gage heights before, after, and, if needed, during the discharge measurement.

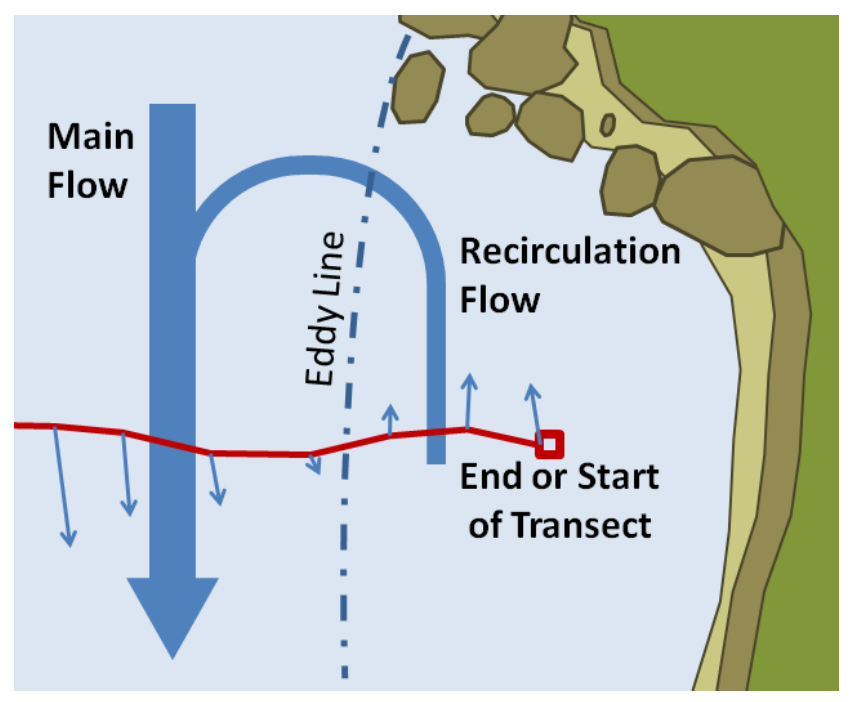

Figure 15. Illustration of proper start or end location in eddy at edge of stream. (Illustration by Francois Rainville, Environment Canada, 2013.). 


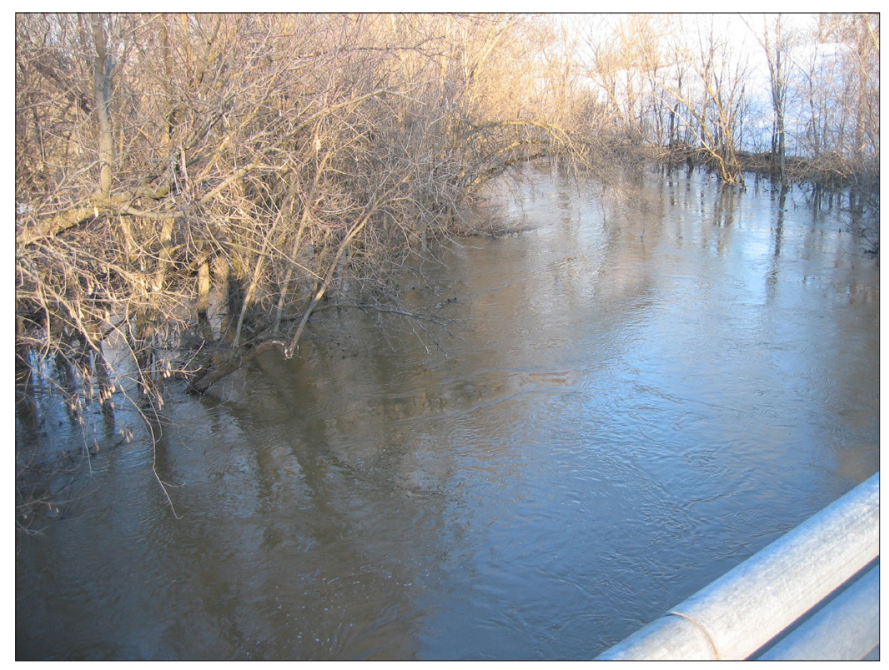

Figure 16. Example of flood flow where floodplain represents a panhandle-shaped edge because the ADCP could not be maneuvered through the vegetation on the floodplain. (Photograph by Francois Rainville, Environment Canada.)

\section{Step-by-Step Procedure}

The steps for making a discharge measurement using an ADCP are not complex, but each step must be completed to ensure quality data. To assist the field hydrographer, quick-reference guides that detail the step-by-step procedure for making ADCP discharge measurements, along with other pertinent information, are presented in Appendix E. These guides can be printed, laminated, and kept with the ADCP for reference.

\section{Post-Measurement Field Procedures}

USGS policy (U.S. Geological Survey, 2012) requires that all discharge measurements be computed on-site to obtain, as nearly as possible, the final discharge. This final discharge is used to determine if a check measurement should be made. If site conditions, safety, or other considerations preclude making a check measurement, the reason for not making the check measurement must be documented. Although there are

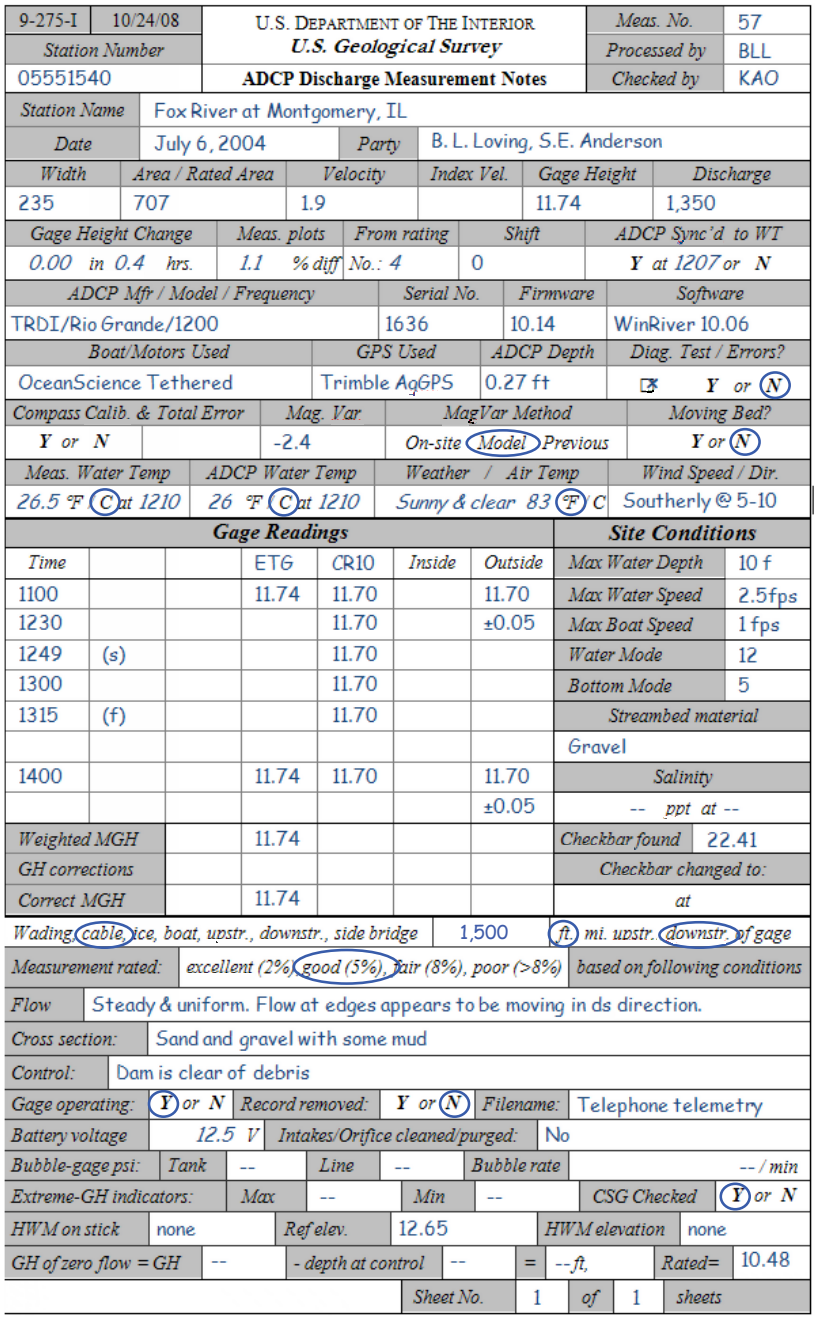

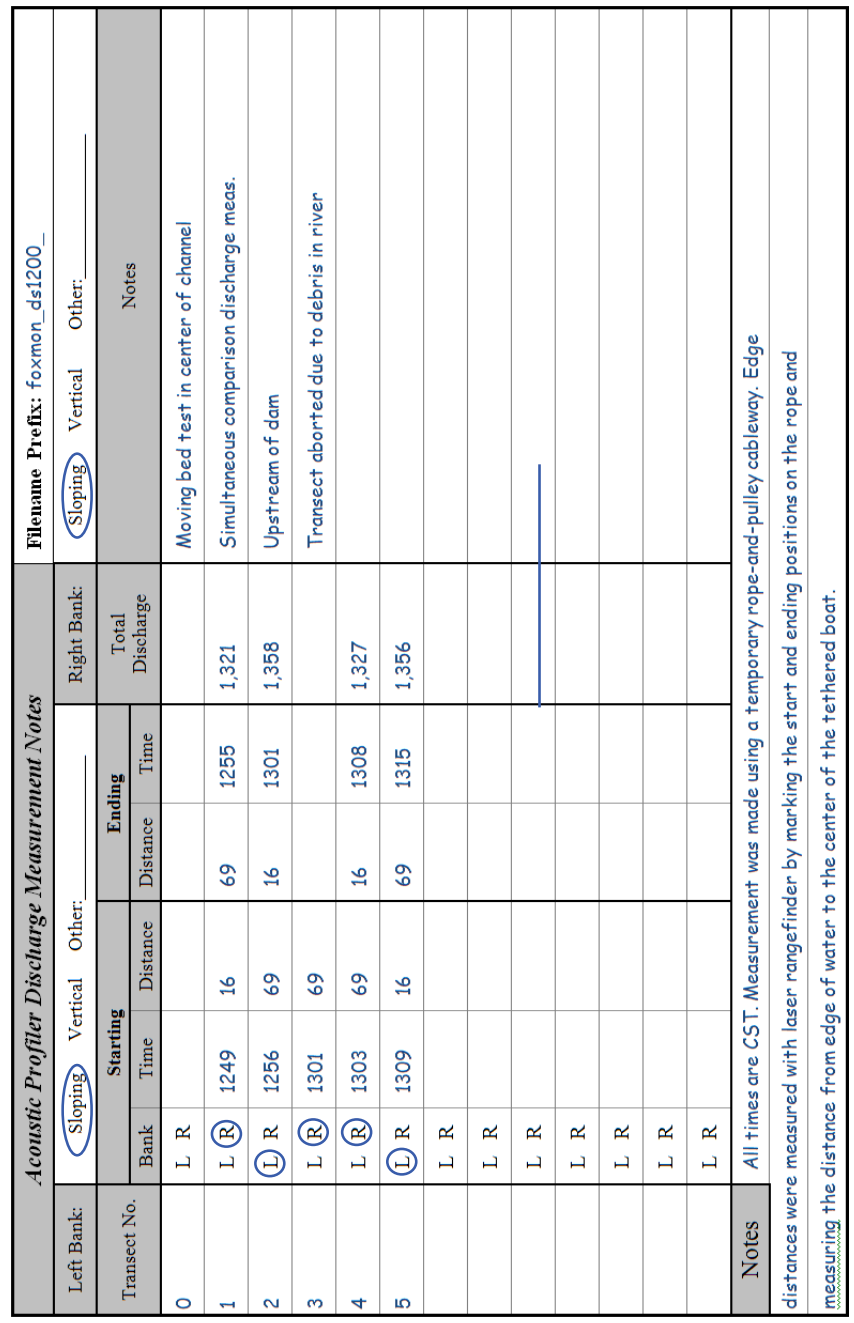

Figure 17. Example of completed acoustic Doppler current profiler discharge-measurement field note form (Oberg and others, 2005). 
many situations when it may be beneficial to use a PDA or mobile phone software for ADCP measurement data collection, the final discharge processing cannot be completed on the currently (2013) available handheld (PDA/mobile phone) software. Before leaving the site, the hydrographer must process the measurement using software that allows quality assessment and complete discharge computation to obtain a final discharge.

\section{Steps to be Completed before Leaving Measurement Site}

Before leaving the site it is important that the measurement be processed and compared to the rating, a backup copy of the data made, and the equipment is properly stored for transport to the next field site or office. Steps 1-8 of the 11 steps discussed below are the steps needed to process the measurement and determine a final discharge. Only a summary of these steps is provided in this section for brevity but a detailed description of each step including example figures and potential solutions identified are included in Appendix F - Measurement Processing Procedures. Note: For a good measurement with no major issues, processing the measurement should not take more than about 15 minutes.

1. Evaluate QA/QC Data - Evaluate the quality-assurance/ quality-control (QA/QC) data to verify that the ADCP is working properly, that the compass has been accurately calibrated, if appropriate, and that the measurement is collected and processed consistent with the moving-bed conditions at the site. An accurate compass calibration is critical if GPS or a loop moving-bed test is used. Moving-bed tests must be valid. Evaluate stationary movingbed tests in Stationary Moving-Bed Analysis (SMBA), loop moving-bed tests in Loop Correction (LC), or equivalent versions of these utilities that have been integrated into the manufacturers' software. If a moving bed is detected, GPS should be used as the reference whenever accurate and reliable GGA or VTG and heading data can be collected. If GPS cannot be used, the bottom-track discharge must be corrected appropriately using the techniques in SMBA, LC, or equivalent. Verify that the water temperature measured by the ADCP is within $2{ }^{\circ} \mathrm{C}$ of the water temperature measured by an independent instrument.

2. Verify User Input - Before processing the collected data, verify that the user inputs have been entered correctly. These include depth of transducer (draft), salinity, edge types, distance to shore, start edge, and magnetic variation.

3. Evaluate Tabular Data - The tabular data typically are presented in a window along one side of the manufacturers' software. The location and data available may vary. Check that the number of ensembles and duration of the transect are appropriate for the water velocity and channel width. During a measurement, it is common for some of the data to be missing or invalid; however, the amount of missing or invalid data should not be excessive. Missing or lost data indicate communication problems between the ADCP and the computer. Invalid or bad data indicate that the ADCP was unable to measure the velocities in a portion of the cross section. The amount of missing or invalid data that will result in a poor measurement is difficult to establish because the location and clustering of the missing or invalid ensembles is important. The location and cluster of invalid or missing data are evaluated in step 5.

4. Evaluate Ship Track and Velocity Vector Plot - The velocity vector plot (referred to as stick ship plot in WinRiver II) provides a plan view of the path made by the ADCP during the transect and the magnitude and direction of the flow throughout the cross section. The objective of this step is to verify that the ship track and velocity magnitudes and directions are consistent with site conditions. If GPS data were collected in addition to bottom track, it is often helpful to compare the different references.

5. Evaluate Velocity Contour Plot - The velocity contour plot provides a cross-section view of the velocity magnitudes (by default). The velocity distribution should be representative of the site conditions with no unusual or unexplainable patterns. Unusual or unexplainable patterns should be further investigated to determine their cause and potential solution. The shape of the cross section should be consistent with site conditions, with few irregularities. The distribution and potential impact on the discharge computation of any invalid or missing data should be assessed. If a substantial amount of data are invalid or missing in one portion of a transect, that transect should not be included in the computation of discharge; however, an even number of reciprocal transects should be maintained.

6. Evaluate Echo Intensity - The intensity profile plot in WinRiver II and the signal to noise ratio (SNR) profile plot in RiverSurveyor Live provide feedback on the magnitude of the acoustic return from the water column. Generally the signal should be high at the transducer and smoothly decrease in magnitude as the distance from the transducer increases. Air entrainment can be identified by a noticeable reduction in the intensity of one or more beams. If air entrainment occurs, the hydrographer should (a) increase ADCP depth, (b) take steps to minimize pitch/roll during data collection, and (or) (c) locate another cross section.

7. Select Proper Extrapolation Methods - Verify that the extrapolation methods used for the top and bottom discharges are valid and sufficiently documented. Use of a method that allows proper development of a mean profile 
for the whole measurement, such as the extrap program (Mueller, 2013; available from http://hydroacoustics. usgs.gov), is recommended. The same extrapolation method should be used for all transects in a measurement, unless field notes indicate a substantial change in conditions that could affect the velocity profile. Although automated methods of selecting the extrapolation method and exponent may be available in some software, the hydrographer is responsible for evaluating the profile and selecting the appropriate extrapolation method and exponent. The selected extrapolation method and exponent must be entered in the software used to process the measurement and the final discharge computed.

8. Evaluate Discharge Summary - The discharge summary provides a summary of each transect and the whole measurement with mean and variability statistics. The following should be evaluated in the discharge summary:

a. Even number of reciprocal transects: A measurement should always consist of reciprocal transects, which helps average and minimize any variation due to directional bias.

b. Directional bias: Heading errors or incorrect magnetic variation commonly cause a directional bias in GPS referenced discharges. Generally these errors are small, and the average of reciprocal transect yields an accurate discharge. If the errors are greater than 5 percent, consider adjusting the magnetic variation (see Appendix F, Incorrect Magnetic Variation or Inaccurate Compass Calibration under step 4).

c. Exposure time greater than 720 seconds: Discharge measurements made from a moving boat under approximately steady-flow conditions will consist of an even number of transects (at least two) having a total exposure time of 720 seconds or greater (U.S. Geological Survey, 2011b).

d. Consistency in measurement characteristics: Unless one or more transects were collected in a different location (which should be documented in the field notes), the characteristics of the measurement and cross section should be similar among the transects. Check for consistency in area, width, boat speed, flow direction, and flow speed. Also verify that the boat speed is appropriate for the water speed and site conditions.

9. Check Measurement - The measured discharge must be compared with the rated discharge, if possible, and a determination of the need for a check measurement made in accordance with USGS policy and the surface-water quality assurance plan. When a check measurement is made, the measurement should be changed as much as is practical while still maintaining the overall quality of the measurement. Ideally a different ADCP or Price meter should be used; however, using a different instrument is not always possible or practical. Other potential changes for the check measurement include (a) measurement method (moving boat or midsection), (b) cross section (c) power (batteries), (d) ADCP depth, (e) ADCP configuration, and (f) operator. Make the check measurement as close in time and gage height to the original measurement as possible. If an ADCP is used for both the original and check measurement, the complete ADCP measurement procedure must be repeated, including diagnostic tests, compass calibration, moving-bed test, water temperature check, and ADCP configuration. Power off all equipment and begin with step 1c of the ADCP MovingBoat Discharge Measurement Procedures in Appendix E and proceed through the remainder of the procedures. If practical, choose a new measurement cross section for the check measurement. The measured discharge from the check measurement should then be plotted on the rating curve, and the percentage of difference from the discharge rating should be computed in the field. During rapidly changing flow, it may not be possible to complete a check measurement in the same segment of the rating. Multiple measurements, however, should still be made to help verify trends in the departure over the changing conditions.

10. Data Backup - Before leaving the field site, all files, including raw data files, configuration files, instrument test files, compass calibration files, and any electronic measurement forms, must be backed up on nonvolatile media, such as flash-memory cards, or USB drives, and stored separately from the field computer (Oberg and others, 2005). The purpose of this backup is to preserve the data in the event of loss or failure of the field computer.

11. ADCP Storage - The ADCP should be dried after use and stored in a manner to protect the transducers from sun light, abrasion, or puncture from sharp objects. When working in estuaries and other saltwater environments, the ADCP must be rinsed off with freshwater and dried prior to storing for transport. Failure to dry the ADCP may result in corrosion of the ADCP connectors, mounting brackets, and any ADCP accessories stored in the protective case (Oberg and others, 2005).

\section{Office Procedures}

Upon returning to the office from field data collection, complete preventative maintenance of equipment, verify completion of all field procedures, finalize the measurement by addressing any data-quality issues not resolved during processing of the measurements in the field, store all data files and notes and update database(s), and have the measurements 
checked and reviewed by another person according to USGS policy (U.S. Geological Survey, 1961; Kennedy, 1983) and the office surface-water quality-assurance plan. Adherence to these procedures will ensure the equipment is ready for the next deployment and that data are processed and stored in the most efficient manner.

\section{Preventive Maintenance}

The ADCP and associated accessories, such as GPS, vertical depth sounders, and electronic rangefinders, should be inspected upon returning from the field to determine their condition. Deployment platforms and mounts also should be inspected. Damage or undue wear to any instrument components, deployment platforms, or mounts should be repaired as soon as possible. The ADCP, all accessories, platforms, mounts, and field computers should be prepared for redeployment and stored in an appropriate location. All batteries should be recharged immediately to facilitate rapid reuse.

\section{Verify Field Procedures and Finalize Measurement}

Although the discharge measurement should be processed completely in the field, there may be situations where questions or problems with the measurement cannot be resolved in the field. In such cases, these issues should be addressed in the office. Appendix F - Measurement Processing Procedures of this document provides a detailed procedure and some solutions for common problems. If further evaluation of the measurement by the hydrographer does not resolve the issues then other hydrographers or hydroacoustic specialists should be consulted to resolve the issues prior to finalizing the measurement.

\section{Data Storage and Database Entry}

All data associated with the measurement must be stored and archived so that the original data and final discharge are preserved. This process includes (a) archiving electronic and (or) paper notes and summaries (b) archiving of data files, and (c) entering measurement information in the National Water Information System (NWIS) database. Specific details associated with the storage and archival of both paper and electronic field notes and associated electronic ADCP data should be documented in the office surface-water quality-assurance plan (U.S. Geological Survey, 2005a).

The following procedures for handling field measurements are considered good practice:

1. All measurement data should be moved from the field computer or field backup media to an office server within 48 hours of returning from the field.
2. Once the measurement has been finalized, it should be permanently stored in a manner that would prevent accidental modification and (or) deletion.

3. All ADCP data, including compass calibration and ADCP test results associated with an individual measurement, should be stored together in a unique folder.

4. When electronic field notes are used-

a. A summary of the final discharge must be stored in NWIS (such as importing the measurement into SiteVisit using SWAMI) and (or) the output from the discharge processing software saved electronically (such as a pdf file) and stored in the folder with the ADCP data.

b. Output from any utility programs used to process the data to a final discharge (examples include LC, SMBA, extrap, etc.) should be stored electronically with the ADCP data.

5. When paper field notes are used-

a. A summary of the final discharge from the discharge processing software should be printed and stored with the field notes and saved electronically (such as a pdf file) and stored with the ADCP data.

b. Output from any utility programs used to process the data to final discharge (examples include LC, SMBA, extrap, etc.) should be printed and stored with the field notes and saved electronically and stored with the other ADCP data.

c. The paper notes should be scanned into a pdf or tiff file format and stored in the folder with the ADCP data.

\section{Measurement Checking and Review}

The USGS policy (U.S. Geological Survey, 1961; Kennedy, 1983) and the office surface-water quality-assurance plan regarding checking and reviewing of measurements after they are finalized by the hydrographer should be followed.

The procedure for processing the measurement in Appendix F may be used as a general guide for checking and reviewing of measurements. It is also a good practice to have measurements checked or reviewed occasionally by someone outside the office. Use of checkers and (or) reviewers outside the local office will provide an objective assessment of the measurements and will help eliminate any perpetuation of poor practices or biases that may develop within an office.

Problems identified during checking and reviewing should be viewed as an opportunity for improving future measurements. If the measurement section had undesirable characteristics (undesirable measurement section 
characteristics are described in the Site Selection section of this report), future measurements should be made at a more appropriate measurement section. If boat operation technique problems are identified, these problems should be discussed with the boat operator so they are not repeated during future measurements. If the ADCP and the data-collection software could have been more accurately configured, this problem also should be discussed with the field crew.

\section{Selected References}

Bell, Stephanie, 1999, A beginner's guide to uncertainty of measurement: Teddington, Middlesex, United Kingdom, National Physical Laboratory, Measurement Good Practice Guide No. 11 (Issue 2), 33 p.

Callede, J., Kosuth, P., Guyot, J.L., and Guimaraes, V.S., 2000, Discharge determination by acoustic Doppler current profilers (ADCP) - A moving bottom error correction method and its application on the River Amazon at Obidos: Hydrological Sciences-Journal-des Sciences Hydrologiques, v. 45, no. 6, p. 911-924.

Chen, Cheng-Lung, 1989, Power law of flow resistance in open channels - Manning's formula revisited: Proceedings of the International Conference on Channel Flow and Catchment Runoff, Centennial of Manning's Formula and Kuichling's Rational Formula, May 22-26, 1989, Charlottesville, Va., v. 8, p. 17-48.

Christensen, J.L., and Herrick, L.E., 1982, Mississippi River test, volume 1. Final report DCP4400/300, prepared for the U.S. Geological Survey by AMETEK/Straza Division, El Cajon, California, under contract No. 14-08-001-19003, p. A5-A10.

Den Herder, J.L., 2011, RiverRay auto adaptive pinging explained: Presentation at ADCPs in Action 2011, Teledyne RD Instruments, San Diego, Calif.

Doppler, J.C., 1842, Über das farbige Licht der Doppelsterne und einiger anderer Gestirne des Himmels: Abn.königl. böhm.Ges.Wiss, v. 2, p. 465-482.

Environment Canada, 2004, Procedures for conducting ADCP discharge measurements: Water Survey of Canada, Hydrometric Operations Division, SOP001-2004.

Federal Aviation Administration, 2006, WAAS and its relation to enabled hand-held GPS receivers, accessed September 22, 2008, at http://gpsinformation.net/exe/waas.html.

Fulford, J.M., and Sauer, V.B., 1986, Comparison of velocity interpolation methods for computing open-channel discharge, in Subitsky, S.Y., ed., Selected papers in the hydrologic sciences: U.S. Geological Survey Water-Supply Paper 2290, 154 p.
García, C.M., Oberg, K., and García, M.H., 2007, ADCP measurements of gravity currents in the Chicago River, Illinois: Journal of Hydraulic Engineering, v. 133, no. 12, p. 1356-1366.

Huang, Hening, 2000, Principle and accuracy analysis of river discharge measurement using SonTek RiverSurveyor System: San Diego, Calif., SonTek/YSI, 11 p.

Kennedy, E.J., 1983, Computation of continuous records of streamflow: U.S. Geological Survey Techniques of WaterResources Investigations, book 3, chap. A13, 52 p.

Lipscomb, S.W., 1995, Quality assurance plan for discharge measurements using broad-band acoustic Doppler profilers: U.S. Geological Survey Open-File Report 95-701, 7 p.

Mathworks, Inc., 2005, Matlab-The language of technical computing: Natick, Mass., Mathworks, Inc., v. 7.1.

Morlock, S.E., Nguyen, H.T., and Ross, J.H., 2002, Feasibility of acoustic Doppler velocity meters for the production of discharge records from the U.S. Geological Survey streamflow-gaging stations: U.S. Geological Survey WaterResources Investigations Report 01-4157, 59 p.

Mueller, D.S., 2002, Use of acoustic Doppler instruments for measuring discharge in streams with appreciable sediment transport, in Proceedings, Conference of Hydraulic Measurements and Experimental Methods, Estes Park, Colo., July 28-August 1, 2002: Environmental and Water Resources Institute of the American Society of Civil Engineers.

Mueller, D.S., 2013, extrap-Software to assist the selection of extrapolation methods for moving-boat ADCP streamflow measurements: Computers \& Geosciences, v. 54, p. 211-218.

Mueller, D.S., Abad, J.D., García, C.M., Gartner, J.W., García, M.H., and Oberg, K.A., 2007, Errors in acoustic Doppler profiler velocity measurements caused by flow disturbance: Journal of Hydraulic Engineering, v. 133, no. 12, p. 14111420 .

Mueller, D.S., and Wagner, C.R., 2006, Application of the loop method for correcting acoustic Doppler current profiler discharge measurements biased by sediment transport: U.S. Geological Survey Scientific Investigations Report 20065079, 26 p.

National Marine Electronics Association, 2002, NMEA 0183 Standard for interfacing marine electronic devices, version 3.01: National Marine Electronics Association. 
Oberg, K.A., 2002, In search of easy-to-use methods for calibrating ADCPs for velocity and discharge methods, in Wahl, T.L., Pugh, C.A., Oberg, K.A., and Vermeyen, T.B., eds., 2002, Hydraulic measurements and experimental methods 2002: Proceedings, Conference of Hydraulic Measurements and Experimental Methods, Estes Park, Colo., July 28August 1, 2002: Environmental and Water Resources Institute of the American Society of Civil Engineers.

Oberg, K.A., Morlock, S.E., and Caldwell, W.S., 2005, Quality-assurance plan for discharge measurements using acoustic Doppler current profilers: U.S. Geological Survey Scientific Investigations Report 2005-5183, 35 p.

Oberg, K.A., and Mueller, D.S., 2007a, Analysis of exposure time on streamflow measurements made with acoustic Doppler current profilers, in Proceedings of the Hydraulic Measurements and Experimental Methods 2007, Reston, Va., American Society of Civil Engineers.

Oberg, K.A., and Mueller, D.S., 2007b, Validation of streamflow measurements made with acoustic Doppler current profilers: Journal of Hydraulic Engineering, v. 133, no. 12, p. 1421-1432.

Oberg, K.A., and Schmidt, A.R., 1994, Measurements of leakage from Lake Michigan through three control structures near Chicago, Illinois, April-October 1993: U.S. Geological Survey Water-Resources Investigations Report 94-4112, $48 \mathrm{p}$.

Ott, Lyman, 1988, An introduction to statistical methods and data analysis: Boston, PWS-KENT Publishing Co., 945 p.

Rantz, S.E., and others, 1982, Measurement and computation of streamflow, volume 1, Measurement of discharge: U.S. Geological Survey Water-Supply Paper 2175, 631 p.

Rehmel, M.S., Stewart, J.A., and Morlock, S.E., 2002, Unmanned, tethered acoustic Doppler current profiler platforms for measuring streamflow: U.S. Geological Survey Open-File Report 03-237, 15 p.

Ruhl, C.A., and Simpson, M.R., 2005, Computation of discharge using the index-velocity method in tidally affected areas: U.S. Geological Survey Scientific Investigations Report 2005-5004, 41 p.

Schlichting, H., 1979, Boundary layer theory (7th ed.): New York, McGraw-Hill.

Simpson, M.R., 2002, Discharge measurements using a broadband acoustic Doppler current profiler: U.S. Geological Survey Open-File Report 01-01, 123 p., accessed June 22, 2007, at http://pubs.usgs.gov/of/2001/ofro101/.

Simpson, M.R., and Oltmann, R.N., 1993, Discharge measurement using an acoustic Doppler current profiler: U.S. Geological Survey Water-Supply Paper 2395, 34 p.
SonTek/YSI, 2000, Acoustic Doppler profiler principles of operation: San Diego, Calif., SonTek/YSI, 28 p.

SonTek/YSI, 2007, RiverSurveyor system manual, software version 4.60: San Diego, Calif., SonTek/YSI, 194 p.

SonTek/YSI, 2012, RiverSurveyor S5/M9 system manual firmware version 3.00: San Diego, Calif., SonTek/YSI, $162 \mathrm{p}$.

Teledyne RD Instruments, 1996, Principals of operation-A practical primer for broadband acoustic Doppler current profilers (2d ed.): San Diego, Calif., Teledyne RD Instruments, $51 \mathrm{p}$.

Teledyne RD Instruments, 2003, WinRiver user's guideUSGS version: San Diego, Calif., Teledyne RD Instruments, P/N 957-6096-00, $156 \mathrm{p}$.

Teledyne RD Instruments, 2006, WinRiver II quick start guide: San Diego, Calif., Teledyne RD Instruments, P/N 957-6230-00, $37 \mathrm{p}$.

Teledyne RD Instruments, 2007a, WinRiver II user's guide: San Diego, Calif., Teledyne RD Instruments, P/N 9576231-00, $166 \mathrm{p}$.

Teledyne RD Instruments, 2007b, Workhorse Rio Grande acoustic Doppler current profiler technical manual: San Diego, Calif., Teledyne RD Instruments, P/N 957-6241-00, $264 \mathrm{p}$.

Teledyne RD Instruments, 2008a, Workhorse Rio Grande ADCP, accessed December 15, 2008, at $h t t p: / / w w w$. rdinstruments.com/datasheets/rio_grande_ds_lr.pdf.

Teledyne RD Instruments, 2008b, StreamPro ADCP operation manual: Teledyne RD Instruments, San Diego, Calif., P/N 95B-6003-00, $118 \mathrm{p}$.

Teledyne RD Instruments, 2009, RiverRay ADCP user's guide: Teledyne RD Instruments, San Diego, Calif., P/N 95B-6064-00, $28 \mathrm{p}$.

Teledyne RD Instrument, 2011, Phased array sound speed effects: Teledyne RD Instruments, San Diego, Calif., FSA-027, 4 p.

Teledyne RD Instruments, 2012, RiverRay operation manual: Teledyne RD Instruments, San Diego, Calif., P/N 95B6063-00, $150 \mathrm{p}$.

Urick, R.J., 1983, Principles of underwater sound (3d ed.): New York, McGraw-Hill, 423 p.

U.S. Army Corps of Engineers, 2002, Engineering design manual on hydrographic surveying (EM 11103-2-1003), accessed July 30, 2013, at http://publications.usace.army. mil/publications/eng-manuals/EM_1110-2-1003_pfl/toc.htm. 
U.S. Geological Survey, 1961, Water, Surface-Checking discharge measurements: U.S. Geological Survey, Surface Water Branch Memorandum No. 61.78, 1 p.

U.S. Geological Survey, 2002a, Configuration of acoustic profilers (RD Instruments) for measurement of streamflow: U.S. Geological Survey, Office of Surface Water Technical Memorandum 2002.01.

U.S. Geological Survey, 2002b, Policy and technical guidance on discharge measurements using acoustic Doppler current profilers: U.S. Geological Survey, Office of Surface Water Technical Memorandum 2002.02.

U.S. Geological Survey, 2003, Release of WinRiver software version 10.05 for computing streamflow from acoustic profiler data: U.S. Geological Survey, Office of Surface Water Technical Memorandum 2003.04.

U.S. Geological Survey, 2005a, Guidelines for archiving electronic discharge measurement data: U.S. Geological Survey, Office of Surface Water Technical Memorandum 2005.08.

U.S. Geological Survey, 2005b, Guidance on the use of RD Instruments StreamPro acoustic Doppler profiler: U.S. Geological Survey, Office of Surface Water Technical Memorandum 2005.05.

U.S. Geological Survey, 2010, Independent water temperature measurement for hydroacoustic measurements: U.S. Geological Survey, Office of Surface Water Technical Memorandum 2010.07.
U.S. Geological Survey, 2011a, Policy on the use of hydroacoustic software and firmware: U.S. Geological Survey, Office of Surface Water Technical Memorandum 2011.04.

U.S. Geological Survey, 2011b, Exposure time for ADCP moving-boat discharge measurements made during steady flow conditions: U.S. Geological Survey, Office of Surface Water Technical Memorandum 2011.08.

U.S. Geological Survey, 2012, Processing ADCP discharge measurements on-site and performing ADCP check measurements: U.S. Geological Survey, Office of Surface Water Technical Memorandum 2012.01.

Wagner, C.R., and Mueller, D.S., 2011, Comparison of bottom-track to global positioning system referenced discharges measured using an acoustic Doppler current profiler: Journal of Hydrology, v. 401, p. 250-258.

Wilde, F.D., ed., variously dated, Field measurements: U.S. Geological Survey Techniques of Water-Resources Investigations, book 9, chap. A6, accessed July 30, 2013, at http:// pubs.water.usgs.gov/twri9A6/. 


\section{Glossary}

Acoustic beam The pattern of acoustic energy transmitted from a transducer as it travels through the water.

ADCP Acoustic Doppler current profiler is used to identify any type of instrument that obtains profiles of water velocity by transmitting sound of known frequency into the water and measuring the Doppler shift of reflections from scatterers, which are assumed to be passively moving with the water.

Ambiguity The use of phase change to determine the Doppler shift results in a multi-valued solution because the phase is periodic. Thus, the solution to the Doppler shift could have multiple values, and, without further information, the solution is ambiguous.

Ambiguity resolution A method to count the number of wavelengths included between two points where phase is measured, thereby removing the ambiguity associated with measuring only phase (Teledyne RD Instruments, 2007b).

Ambiguity velocity The maximum allowable radial velocity that can be measured unambiguously beyond which ambiguity resolution is required.

Backscatter (1) The portion of a sound wave that is reflected by scattering particles directly back toward the source. (2) A qualitative measurement of scattering particle concentration. Backscatter is the intensity of returned energy normalized for sound absorption, beam spreading, water temperature, etc., and provides means of tracking relative concentration of scattering particles (Teledyne RD Instrument, 2007b).

Beam coordinates A coordinate system defined by vectors along the beams. Velocity data reported in beam coordinates refers to the velocity parallel to each beam.

Bin (depth cell) Discrete segments of the vertical water column for which data measured by the ADCP are reported.

Blanking distance The distance from the transducer face traveled by the acoustic pulse during the time allowed for the electronics and transducer (ringing) to recover from the transmission of the pulse. Data collected within the blanking distance may be contaminated by the residual effects of the transmitted pulse and will typically be biased low.

Bottom track The ping and processing algorithm to measure the Doppler shift of a signal returned from the bottom (streambed) for the purpose of determining the velocity of the ADCP (boat). This velocity is used to determine the true water velocity from the measured velocity by removing the velocity of the ADCP (boat). If the bottom is not moving, this measurement is typically a very accurate measurement; however, sediment transport can cause a bias in bottom tracking that results in a false upstream velocity of the ADCP causing a low bias in the measured water velocity and corresponding discharge.

Broadband processing A technique that uses coded pulses to make multiple measurements of the Doppler shift with a single ping. Because random noise is reduced by the square root of the number of samples, this technique reduces the random noise associated with single ping velocity measurements.

Correlation A measurement of how much the particle distribution has changed between phase measurements. The less the distribution has changed, the higher the correlation, and the more precise the velocity measurement (Teledyne RD Instruments, 2007b).

Counts Raw signal amplitude values that have not been normalized. Values often range from 0 to 255 .

Depth cell (bin) Discrete segments of the vertical water column for which data measured by the ADCP are reported.

Distance made good The straight line distance between the current location of the ADCP and the starting point of the transect.

Doppler shift The change in apparent frequency of a wave as observer and source move toward or away from each other. Named for Johann Doppler (1803-1853).

Earth coordinates Profile data are reported in an orthogonal coordinate frame as referenced to the Earth (East, North, and Up). "North" can mean magnetic or true, depending on the heading input (Teledyne RD Instruments, 2007b).

Echo intensity A measure of the signal strength intensity returned to the transducer.

Ensemble (sample) An ensemble or sample is a group of measured data associated with a single vertical profile of the water column as reported to the user by the ADCP. These data may include but are not limited to acoustic properties (correlation, intensity, etc.), water velocity, boat velocity (bottom track and (or) GPS), and sensor readings (heading, pitch, roll, temperature, etc.). The ADCP may average multiple pings or measurements of these data before reporting the ensemble or sample, depending on its mode of operation.

Error velocity The name given by Teledyne RD Instruments to the difference in vertical velocity measured by opposing beams and scaled to be comparable to the variance in the horizontal velocity. If the flow field is homogeneous, the difference between these vertical velocities will average to zero.

Frequency The number of wave crests passing a given point per unit time.

Gage height The height of the water surface of a stream or lake above an established datum plane. Gage height and stage are often used interchangeably; however, gage height is more appropriate when used to indicate a reading on a gage (Rantz and others, 1982).

GGA Shorthand for the \$GPGGA standard output format for GPS data defined by the National Marine Electronics Association (NMEA) 0183 standard that includes time, latitude, longitude, fix quality, number of satellites, horizontal dilution of precision (HDOP), altitude, and other parameters (National Marine Electronics Association, 2002).

Global positioning system (GPS) A space-based satellite navigation system that provides location and time information 
in all weather conditions, anywhere on or near the Earth where there is an unobstructed line of sight to four or more GPS satellites (http://en.wikipedia.org/wiki/Global_

Positioning_System, accessed February 11, 2013). DGPS refers to a positioning solution to which a differential correction is applied. Often used as the navigation reference for ADCP measurements when bottom track is unreliable or is biased by sediment transport.

Heading The orientation of the ADCP relative to magnetic or true North, depending on user input of the magnetic variation.

Homogeneity The assumption that the velocity measured by each beam of the ADCP is identical. This assumption is required by the equations used to transform $\mathrm{ADCP}$ beam velocities into an orthogonal coordinate system.

Instrument noise level The measured echo intensity when no transmitted signal is present. This measured echo intensity is caused by a combination of environmental and electronic noise.

Lag A time delay between pulses.

Length The curvilinear distances measured along the path of the ADCP between the start of the first ensemble and that of the last ensemble.

Main beam The primary beam of acoustic energy transmitted by a transducer. Transducers emit side lobes of acoustic energy at various angles not coincident with the main beam. Typically the main beam is defined as the acoustic energy between $+/-3 \mathrm{~dB}$.

Moving bed (bottom) Describes a condition when the bottom track is biased by sediment transport. Sediment transport on or near the streambed can affect the Doppler shift of the bottomtracking pulses and can cause the bottom track to have a false upstream velocity component.

Narrowband processing Uses a single pulse per ping to measure velocity. The narrowband ping is simple and can be processed quickly. Current (2013) narrowband systems can ping at rates up to $70 \mathrm{~Hz}$ for incoherent pings. By pinging fast and averaging the velocity measurement of each ping, a narrowband ADCP can measure water velocity with random error standard deviations of about $0.3 \mathrm{ft} / \mathrm{s}$ for 1 -second averaging for incoherent pings.

Noise Refers to the random error associated with velocity measurements. Noise is caused by both instrument and environmental factors. "Noisy" velocity data would have a relatively large random error.

Phase The location along a sine wave measured in degrees. Phase is ambiguous in that it is cyclical (e.g., 10 degrees is the same phase as 370 degrees).

Phase change (shift) A phase change represents the amount a wave has shifted horizontally from the original wave and is measured in degrees, where a complete cycle is 360 degrees. It is an engineering measure of the propagation delay caused by radial motion between scatterer and source. This horizontal shift represents a shift in time.

Phased array transducer A single, flat, multi-element transducer that can form multiple beams by changing the timing (phase) of the transmission from each of the elements in the transducer in such a way that the effective pattern of the array is reinforced in the desired direction and suppressed in undesired directions.

Ping The entirety of the sound generated by an ADCP transducer for a single measurement cycle. A broadband ping contains a coded series of pulses and lags, while a narrowband ping contains a single pulse.

Pitch Pitch of an ADCP involves rotation or tilting of the $\mathrm{ADCP}$ in the longitudinal direction (y-axis) about the lateral axis as defined for the ADCP.

Profile The collection of velocity measurements at various depths along a single vertical of the water column.

Profile extrapolation A method used to estimate the unmeasured areas on the top and bottom parts of a velocity profile where the ADCP cannot measure.

Pulse A sound wave generated by a transducer.

Pulse coherent An algorithm for the transmission and processing of a pair of acoustic pulses where the pulses are independent. The ADCP sends the first pulse, receives and collects returning data, then transmits a second pulse and again receives and collects returning data.

Pulse incoherent An ADCP that transmits one pulse into the water per measurement (ping). The Doppler shift is computed as the reflected pulse is received.

Radial velocity The radial velocity represents the component of the scattering particles velocity that is parallel to the main beam of acoustic energy.

Regatta Measurement campaign producing simultaneous discharge observations from many ADCPs at once, for the purpose of comparing the performance of these instruments and their configuration.

Relative velocity Includes the speed of the water moving by the ADCP and the speed of the ADCP itself. To compute the water velocity, the ADCP, or boat, speed must be subtracted from the relative velocity.

Ringing After transmission, the ADCP's electronics, transducer, and immediate surrounding equipment (particularly in vessel-mounted $\mathrm{ADCPs}$ ) all require some finite time to dampen the transmitted energy, during which time any signal return from scattering particles will be contaminated (Teledyne RD Instruments, 2007b).

Roll Roll of an ADCP involves rotation of the ADCP in the lateral direction ( $\mathrm{x}$-axis) about the longitudinal direction (y-axis) as defined for the ADCP.

RTK Real-time kinematic (RTK) satellite navigation is a technique used to enhance the precision of position data 
derived from satellite-based positioning systems. RTK uses measurements of the phase of the signal's carrier wave rather than the information content of the signal, and it relies on a single reference station to provide real-time corrections, providing up to centimeter-level accuracy (http://en.wikipedia. org/wiki/Real_Time_Kinematic, accessed February 11, 2013). This technique requires two GPS receivers - one for a base station and one for a rover-and wireless communications between the two.

Sample (ensemble) An ensemble or sample is a group of measured data associated with a single vertical profile of the water column as reported to the user by the ADCP. These data may include but are not limited to acoustic properties (correlation, intensity, etc.), water velocity, boat velocity (bottom track and (or) GPS), and sensor readings (heading, pitch, roll, temperature, etc.). The ADCP may average multiple pings or measurements of these data before reporting the ensemble or sample, depending on its mode of operation.

Scatterers Small particles such as suspended sediment or organic matter that spread and reflect acoustic energy transmitted by hydroacoustic instruments.

Ship coordinates An orthogonal coordinate frame that is referenced to the ADCP and may correct for pitch-and-roll but does not apply a heading correction.

Ship track Plot of the horizontal path traveled by the ADCP based on the selected navigation reference (bottom track or GPS).

Shore distance Perpendicular distance from the start or end ensemble to the shore.

Side lobe Peaks in sound intensity generated by a transducer found to the side of the main lobe (Teledyne RD Instruments, 2007b).

Side-lobe contamination ADCP transducer beams are angled relative to the vertical, which means that the distance from the ADCP directly to the streambed typically is shorter than the distance along the beams. Because most streambeds will reflect more energy than the scattering particles in the water column, side-lobe energy traveling the shorter path directly between the ADCP and the streambed will contaminate the velocities measured in the beams near the streambed. The size of the area of interference is computed using the cosine of the angle of the beams relative to vertical.
Signal-to-noise ratio (SNR) Often defined as the strength of a returned acoustic signal divided by the instrument noise as measured by an acoustic Doppler velocity meter. The SNR is used to assess the amplitude (strength) of the received acoustic energy used to measure velocity.

Stage The height of the water surface of a stream or lake above an established datum plane. Stage and the term "gage height" are often used interchangeably.

Transducer Transducers used in ADCPs transmit and receive acoustic energy. The transducer consists of a ceramic element protected with a urethane coating, which when energized by an electrical pulse vibrates to transmit sound waves which travel through water and are reflected back to the transducer. The reflected sound waves cause the quiescent ceramic to vibrate, generating an electrical signal which is read by the ADCP.

Transect A single pass across a river cross section, beginning and ending as close to each bank as possible, while still collecting valid data. A transect is not necessarily a straight line from one bank to the other, but rather an arbitrary surface depending on the path of the ADCP. Transects consist of multiple ensembles, each with depth, distance, and velocity data, allowing the ADCP's software to compute discharge. A discharge measurement typically consists of multiple transects averaged together.

Update rate The number of data samples per unit time provided by an instrument.

VTG Shorthand for the \$GPVTG standard output format for GPS data defined by the National Marine Electronics Association (NMEA) 0183 standard that includes information on the ADCP heading and ground speed (National Marine Electronics Association, 2002).

Water mode A set configuration of ADCP pings and processing algorithms that can be changed either manually or automatically for different river conditions.

Wave crest The section of a wave with maximum rise above the undisturbed position. Wave crests correspond to areas of high pressure in the water.

Wave trough The section of a wave with maximum depression below the undisturbed position. Wave troughs correspond to areas of low pressure in the water. 


\section{Appendix A - Basic ADCP Operational Concepts}

Descriptions of how an ADCP operates and measures water and boat velocity can be found in reports produced by ADCP manufacturers (Teledyne RD Instruments, 1996; SonTek/YSI, 2000), by the USGS (Simpson, 2002), and by others not referenced herein. This appendix is not intended to be a comprehensive coverage of information that can be found in other documents, but rather a concise overview of key operation concepts that will help the user understand the capabilities and limitations of ADCPs.

\section{General}

The ADCP transmits acoustic energy at a known frequency and measures the change in frequency of the acoustic energy reflected back (backscattered) from particles in the water column. The velocity of the water along the acoustic path can be computed from equation A1.

$$
V=\frac{C F_{D}}{2 F_{S}},
$$

where

$V \quad$ is the velocity of the water parallel to the acoustic path;

$C$ is the speed of sound in the water;

$F_{D} \quad$ is the difference in frequency due to the Doppler shift $\left(F_{B}-F_{S}\right)$;

$F_{S} \quad$ is the frequency of the transmitted acoustic energy; and

$F_{B} \quad$ is the frequency of the backscattered acoustic energy.

The success of the Doppler approach to measuring water velocity rests on the assumption that a sufficient amount of material is in the water column to reflect sufficient acoustic energy to allow the measurement of the Doppler shift and that the material is traveling at the same velocity as the water. If an object in the water column is large relative to the suspended material and has a velocity that is not dependent on the water velocity (such as fish or woody debris lodged on the bottom), the acoustic energy reflected from this object will not have a Doppler shift that reflects the water velocity and will likely corrupt the velocity profile at and below the depth of the object. Most instruments contain algorithms to detect and filter out data with these types of errors.

\section{Measuring Velocity}

Currently (2013) the two techniques commonly used in an ADCP to measure the Doppler shift can be classified as narrowband or broadband. Each approach has its advantages and disadvantages. A detailed explanation of each technique is beyond the scope of this report, and some of the specifics of their implementation into commercial instruments are considered proprietary. The basics of the two approaches, however, are described using an analogy developed by Joel Gast (Teledyne RD Instruments, oral commun., 1992) and published by Simpson (2002).

\section{Narrowband (Incoherent Processing)}

Consider a freeway at night with traffic moving at a steady rate of speed. A camera has been placed near the freeway, and posts have been installed at set distances within the camera's field of view. A strobe light is actuated and, while the freeway is illuminated by the single-strobe pulse, the camera takes two high-speed photographs. An investigator examines the photographic negatives and lines up the images of the cars on the two photographic negatives. The investigator then determines the distance traveled by the cars by measuring the apparent shift in position of the reference posts (fig. A-1). The speed of the cars can be calculated by dividing distance between the posts by the lag time between the two photographs. If the strobe flashes represent acoustic pulses, the cars represent reflective particles in the water column, and the photographic negatives represent the received reflected signals, this scenario becomes roughly analogous to the workings of a narrowband ADCP system.

The drawback to this approach is that the strobe (pulse length) dissipates very quickly and the two photographs must be taken while the same cars are still illuminated by the strobe. This means that time lag between negatives (received signals) is very short and the distance traveled by the cars (reflectors)

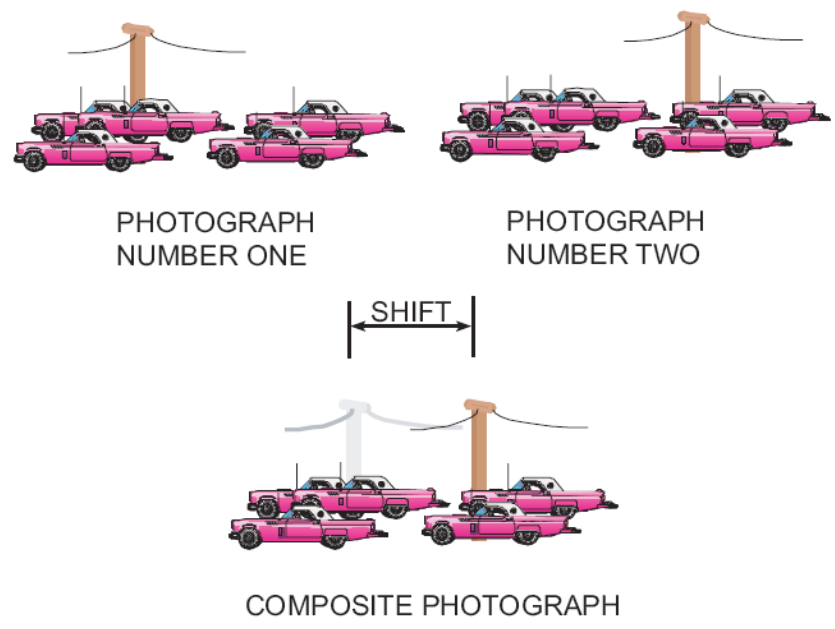

Figure A-1. Freeway strobe-light system used to measure vehicle speed (from Simpson and Oltmann, 1993). 
is very short; therefore, the car speeds cannot be measured precisely. Because of these limitations, velocity measurements made using the narrowband technology are "noisy," which means they have a relatively high random error. The signal is sampled twice during the reception of the reflected signal. Using an autocorrelation technique, the Doppler shift is then calculated. In the narrowband ADCP, the pulse length for incoherent pings depends on the time lag between samples, which is a function of depth-cell size. A filter scheme that looks at the whole returned signal is used to resolve ambiguity.

The high random errors of the incoherent narrowband pings are overcome by averaging. The standard deviation of random error about a true mean is reduced by the square root of the number of measurements used to computed the mean (Ott, 1988). The narrowband ping is simple and can be processed quickly. Current (2013) narrowband systems can ping at rates up to $70 \mathrm{~Hz}$ for incoherent pings. By pinging fast and averaging the velocity measurement of each ping, a narrowband ADCP can measure water velocity with random error standard deviations of about $0.3 \mathrm{ft} / \mathrm{s}$ for 1-second averaging for incoherent pings.

\section{Broadband}

Using the same freeway analogy as before, the investigator installs another camera a distance of 10 or more car lengths (parallel to the freeway) from the first camera. He can now actuate a strobe, take a picture with the first camera, wait a short time, actuate another strobe, and take a picture with the second camera. If the strobes are timed correctly, the cars will travel from the field of view of the first camera into the field of view of the second camera during the time between photographs. The investigator synchronizes the positions of the cars on the two negatives and finds that there is a much longer lag time (time between each strobe versus the time between two photographs taken during the same strobe) and that the cars traveled a longer distance. This longer distance of travel and lag time allows the investigator to calculate the speed of the cars with much greater precision than with the single-strobe system; however, the distance between the cameras and the time between each strobe must be chosen carefully. If the investigator waits too long between strobes, random movement between the cars (passing, slowing down, speeding up, and so forth) will render the two negatives "unmatchable" (uncorrelated). Transmitting a pair of pulses (strobes) into the water allows for much longer lag times (therefore, more precision) than the narrowband system, but some disadvantages are associated with this technique.

One of the most significant disadvantages is self-noise. Self-noise again can be described using the freeway analogy. Suppose that, because of limitations in photographic technology, the freeway cameras have no shutters. Because the investigator must leave the camera shutters open, both cameras will "see" the traffic illuminated by the two strobes; however, only 50 percent of the "scenery" will be usable to both cameras for correlation purposes. For example, the film in camera one is exposed once during the first strobe. The cars then travel out of the field of view of camera one and into the field of view of camera two. However, the film in camera two already has been exposed by the flash of the first strobe and, thus, any cars photographed have left the field of vision. When the second strobe flashes, the film in both cameras is again exposed (double exposed) and the cars that were first photographed by camera one are now photographed by camera two. Because the film has been double exposed, only 50 percent of the scenery in each exposure contains cars that are common to both cameras. As in the film of the freeway cameras, the reflected wave front from the first broadband ADCP (BBADCP) pulse-pair is again "exposed" by the incident wave front of the second pulse and, therefore, is subject to the same "double exposure." The increased noise due to this 50-percent correlation is reduced by data averaging (very narrow pulses can be used, and, therefore, large amounts of data can be collected and averaged). Without a technique called phase coding and a high signal-processing rate, BB-ADCP velocity measurements would be less precise (because of self-noise) than measurements made by the narrowband ADCP system.

The broadband approach makes use of very narrow (short) pulses. If these pulses were so narrow that 100 of them could be placed into the space occupied by the original long pulses, the measurement precision would be increased by the square root of the number of samples (in the case of 100 samples, by a factor of 10). With this increased precision (even with the 50-percent level of self-noise), the broadband ADCP measurement precision surpasses the precision of the narrowband ADCP by almost one order of magnitude. Energy loss caused by the narrow pulses, however, is so great that it renders the system nearly unusable. To overcome this energy loss, the manufacturer developed a design innovation that incorporates most of the advantages of wide and narrow pulses. A wide pulse is transmitted (therefore, delivering more energy into the water than a narrow pulse), but is logically split into many small segments called code elements, each having a phase shift of either 0 or 180 degrees (fig. A-2). The coding order of these phase shifts is pseudorandom (behaves

Narrowband Monochromatic Acoustic Pulse

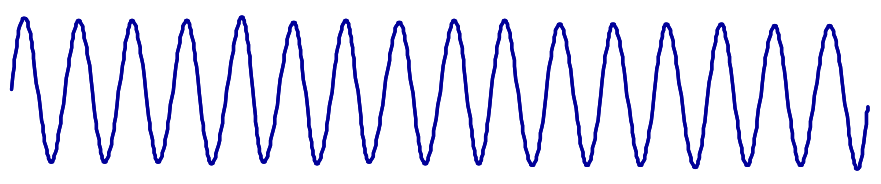

Broadband Coded Acoustic Pulse

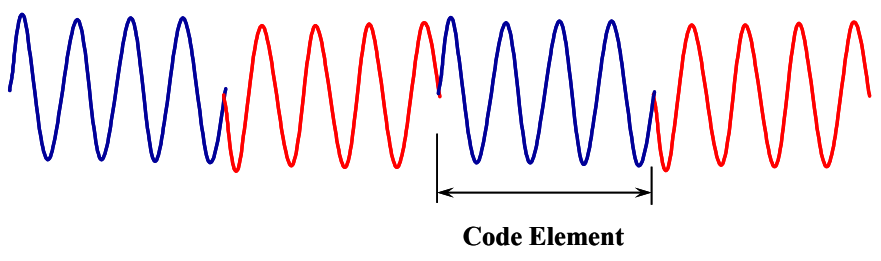

Figure A-2. Acoustic pulses for narrowband and broadband ADCP technologies. 
numerically like a random sequence). The consequence of transmitting this phase-coded pulse-pair series into the water is that even though the pulses are long, the signal processor still must wait the full lag period before achieving an auto-correlation peak of significant amplitude. In other words, because of the phase coding, it is difficult for the autocorrelation algorithm to realize a peak at the wrong interval. The objective of the manufacturer is to achieve decorrelation of adjacent pulse pairs and, therefore, a greater effective $\mathrm{N}$ (number of samples used for data averaging). This pseudorandom code allows many independent samples to be collected from a single ping. The principal reason this technique was named "broadband" is that the bandwidth of the ADCP was increased to accommodate the signal processing of a narrow-pulse pair (coded or not).

Another significant disadvantage for using the increased lag spacing available with the broadband ADCPs is velocity ambiguity. For this analogy, assume that the distance the cars move in the synchronized photographs is measured using an electronic wheel rather than a flat ruler. The process is to push a button to zero the wheel, move the wheel along the distance to be measured, and then push another button for the number of degrees of rotation of the wheel to be reported. By knowing the circumference of the wheel and the amount of rotation, we can compute the distance measured. This electronic wheel does not count the number of rotations; it only measures the rotation of the wheel from 0 to 360 degrees. Because the cars could move in either direction, the measurement is further limited to only half of the wheel, so that half of the wheel measures a positive direction and half measures a negative direction, say from 0 to 180 degrees for the positive direction and from 360 to 180 degrees $(0$ to -180$)$ for the negative direction. This technique works well provided that the relation between the car's speed and lag time between the photographs does not result in more movement than can be measured using 180 degrees of rotation of the wheel. If the lag is too long and (or) the cars are traveling too fast, the distance between the photographs could result in the distance being longer than can be measured by 180 degrees of rotation of the wheel. For example, the distance to be measured requires 190 degrees of rotation, and on the basis of the established reference, 190 degrees would be interpreted as -170 degrees, and the wrong velocity in the wrong direction would be computed. When the rotation exceeds 180 degrees, the velocity measured is ambiguous. It is unknown if the car traveled a distance equal to 190 degrees, -170 degrees, or 550 degrees. The "ambiguity velocity" is the velocity the cars must achieve before this confusing circumstance happens. If the strobe flashes are temporally close, the ambiguity velocity is high (faster than the cars normally travel), but measurement precision is lower because the cars have traveled a shorter distance between strobe flashes. If the time between strobe flashes (lag) is lengthened to improve the measurement precision, the ambiguity velocity becomes lower and limits the maximum velocity that can be measured. How the ambiguity velocity is set or determined in the ADCP is dependent on the water or bottom mode used. Different modes resolve ambiguity differently (see Appendix $\mathrm{C}$ for a discussion of water modes).

\section{Computing Velocity in Orthogonal Coordinates}

The Doppler shift is directional and can only measure the velocity of motion parallel to the acoustic path (radial velocity; fig. A-3). The goal of most engineering applications is to have three-dimensional velocity components measured in an orthogonal coordinate system. To measure a three-dimensional velocity profile requires a minimum of three acoustic beams pointed in known directions. The three beams provide three velocity vectors that can then be resolved into three orthogonal velocity vectors.
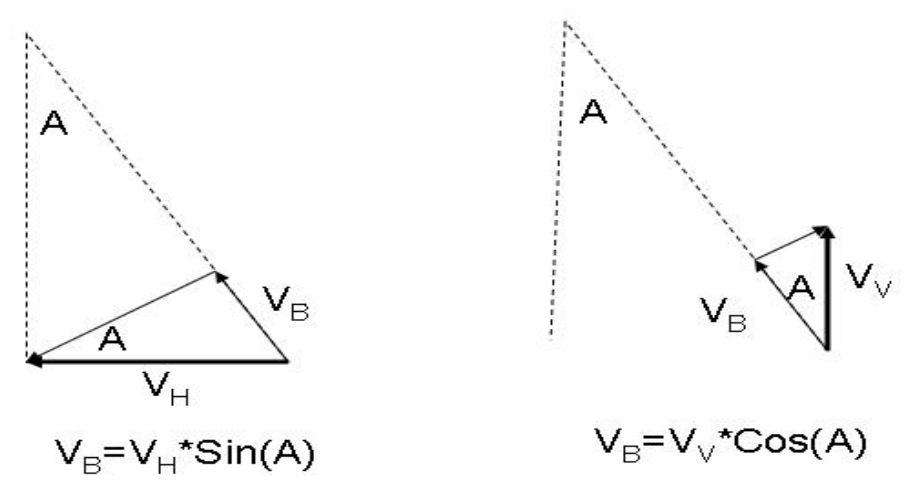

Figure A-3. The horizontal $\left(\mathrm{V}_{\mathrm{H}}\right)$ and vertical velocity $\left(\mathrm{V}_{\mathrm{v}}\right)$ components computed from the velocity measured parallel to the acoustic path $\left(\mathrm{V}_{\mathrm{B}}\right)$.

\section{Piston Transducer ADCPs}

Piston transducer ADCPs typically have used either a four-beam Janus configuration or a simple three-beam configuration. For a three-beam configuration the beams typically are equally distributed around a circular instrument (120-degree spacing) and tilted at a known angle, $\theta$, to the vertical. The equations for a typical three-beam system with beam 1 pointed downstream are:

$$
\begin{aligned}
& V_{y}=\left(B_{2}+B_{3}-2 B_{1}\right) /(3 \operatorname{Sin} \theta), \\
& V_{x}=\left(B_{3}-B_{2}\right) /(\sqrt{3} \sin \theta), \text { and } \\
& V_{z}=\left(B_{1}+B_{2}+B_{3}\right) /(3 \cos \theta),
\end{aligned}
$$

where

$$
\begin{gathered}
V_{y} \quad \begin{array}{c}
\text { is the streamwise velocity assuming } \\
\text { beam } 1 \text { is pointed upstream; }
\end{array} \\
V_{x} \quad \begin{array}{c}
\text { is the cross-stream velocity assuming } \\
\text { beam } 1 \text { is pointed upstream; }
\end{array}
\end{gathered}
$$


$V_{3} \quad$ is the vertical velocity;

$B_{1} \quad$ is the radial velocity measured in beam 1 ;

$B_{2}$ is the radial velocity measured in beam 2 ;

$B_{3}$ is the radial velocity measured in beam 3 ; and

$\theta \quad$ is the tilt angle of the beams referenced to vertical.

The use of four beams in a Janus configuration also is common in ADCPs. The Janus configuration provides some reduction in errors caused by pitch-and-roll and random instrument noise for the orthogonal velocity components. The following equations are for a typical four-beam system with beam 3 pointed forward, and opposing beam pairs are 3 and 4 versus 1 and 2:

$$
\begin{aligned}
& V_{y}=\left(B_{4}-B_{3}\right) /(2 \sin \theta), \\
& V_{x}=\left(B_{1}-B_{2}\right) /(2 \sin \theta), \text { and } \\
& V_{z}=\left(B_{1}+B_{2}+B_{3}+B_{4}\right) /(4 \cos \theta),
\end{aligned}
$$

where

$V_{y} \quad$ is the streamwise velocity assuming beam 3 is pointed upstream;

$V_{x} \quad$ is the cross-stream velocity assuming beam 3 is pointed upstream;

$V_{z} \quad$ is the vertical velocity;

$B_{1}^{z}$ is the radial velocity measured in beam 1 ;

$B_{2}$ is the radial velocity measured in beam 2 ;

$B_{3}$ is the radial velocity measured in beam 3 ;

$B_{4} \quad$ is the radial velocity measured in beam 4 ; and

$\theta \quad$ is the tilt angle of the beams referenced to vertical.

The assumption in applying equations $\mathrm{A} 2-\mathrm{A} 7$ is that the flow measured in each beam is the same (homogeneous). If the flow measured by one beam is different from any of the other beams (one beam is measuring in a vortex and the others are in the free stream), the basic assumption of these equations is violated, and an incorrect velocity will be computed. Therefore, the velocities measured by an ADCP are less certain in flow conditions with high and rapid spatial variations.

Four-beam systems have a redundant beam that can be used to compute a quality check called an error velocity in WinRiver II and a difference velocity in RiverSurveyor Live. The difference velocity is computed as the difference between the vertical velocity computed by opposing beam pairs ( 3 and 4 versus 1 and 2). Adding the opposing pairs cancels the horizontal velocity and leaves only the vertical component.

$$
\begin{aligned}
V_{e}^{u} & =\frac{B_{1}+B_{2}}{2 \cos \theta}-\frac{B_{3}+B_{4}}{2 \cos \theta} \\
& =\left(B_{1}+B_{2}-B_{3}-B_{4}\right) /(2 \cos \theta),
\end{aligned}
$$

where

$$
V_{e}^{u} \text { is the unscaled error velocity. }
$$

TRDI scales the difference velocity to achieve the error velocity so that the standard deviation for the error velocity is equal to the standard deviation of the horizontal velocity. The equation used to compute the scaled error velocity is

$$
\begin{aligned}
V_{\text {error }} & =\left[\left(B_{1}+B_{2}-B_{3}-B_{4}\right) /(2 \cos \theta)\right][1 /(\sqrt{2} \tan \theta)] \\
& \left.=\left(B_{1}+B_{2}-B_{3}-B_{4}\right) / 2 \sqrt{2} \sin \theta\right)
\end{aligned}
$$

where

$$
\begin{aligned}
& V_{\text {error }} \text { is the scaled error velocity computed by } \\
& \text { TRDI ADCPs. }
\end{aligned}
$$

\section{Phased Array Transducer ADCPs}

The equations for a four-beam phased array transducer ADCP are similar to the four-beam piston transducer ADCP except for the effect of the speed of sound on these equations. A phased array ADCP is designed with a nominal beam angle at a nominal speed of sound. The angle of the beams formed by a phased array is dependent on the speed of sound. As the speed of sound changes, the angles of the beams change. The change in angle is such that the horizontal velocity components of a phased array ADCP are independent of the speed of sound. However, this change in beam angle results in the vertical component being more sensitive to speed of sound errors than a piston transducer (Teledyne RD Instruments, 2011). The TRDI RiverRay system is designed with a nominal beam angle of 30 degrees and a nominal speed of sound of $1,536 \mathrm{~m} / \mathrm{s}$. For this system the equations for the orthogonal velocity components are (Teledyne RD Instruments, 2011):

$$
\begin{gathered}
V_{y}=\left(B_{4}-B_{3}\right) \\
V_{x}=\left(B_{1}-B_{2}\right) \\
V_{z}=\frac{B_{1}+B_{2}+B_{3}+B_{4}}{2 \sqrt{\left(\frac{2 c_{0}}{c}\right)^{2}-1}} \\
V_{\text {error }}=\frac{1}{\sqrt{2}}\left(B_{1}+B_{2}-B_{3}-B_{4}\right)
\end{gathered}
$$

where

$c_{o} \quad$ is the nominal speed of sound; and

$c$ is the actual speed of sound at the transducer. 


\section{Measuring a Velocity Profile}

The ADCP profiling capability is accomplished by time gating (and sampling) the received acoustic signal at time intervals as the acoustic-beam wave propagates through the water column. The transmitted acoustic pulse travels at the speed of sound through the water and is reflected back toward the transducer. Acoustic energy reflected from particles deeper in the water column takes a longer time to return to the transducer than does acoustic energy reflected from particles nearer the transducer. By measuring the two-way travel time from transmission of the energy to when the energy is received, the distance from the transducer from which the energy is reflected can be computed. The ADCP transmits a ping along each acoustic beam and then time gates the reception of the returned echo on each beam into depth cells at specified ranges. Speed and direction are then calculated (using a center-weighted mean of the velocities measured in the depth cell) and assigned to the center of each depth cell over the measured vertical.

\section{Computing Discharge}

An ADCP deployed on a moving boat can compute the discharge in real time while traversing the stream from one bank to the other (Simpson and Oltmann, 1993). Unfortunately the ADCP is unable to measure the entire water column (fig. A-4). Near the water surface, an unmeasured zone is associated with immersion of the ADCP into the water, the

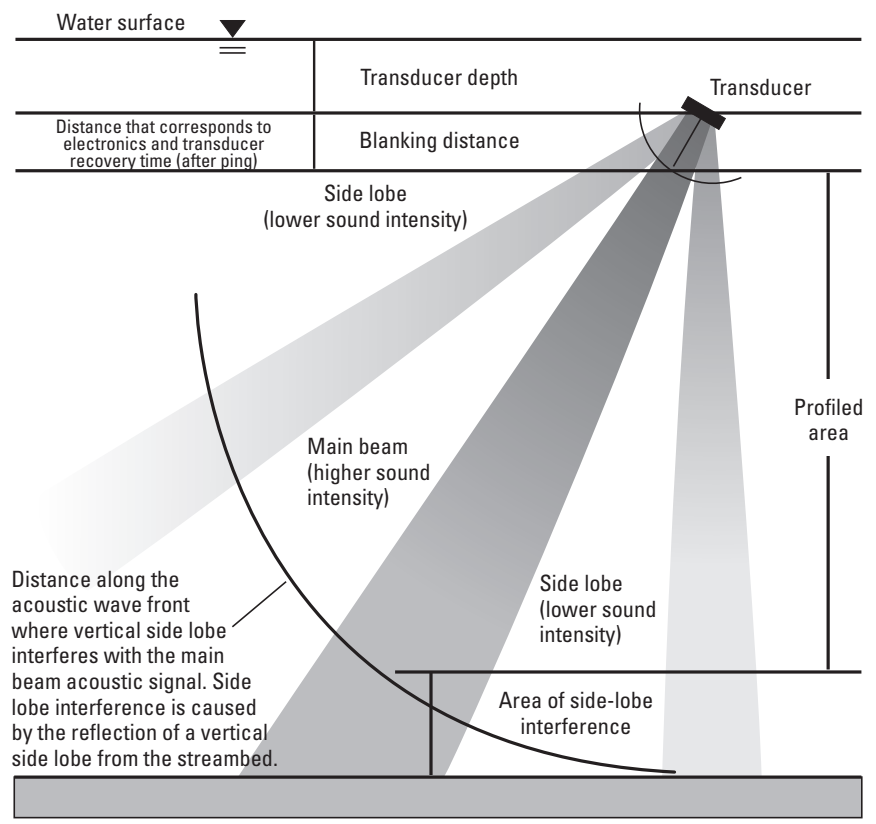

Figure A-4. Acoustic Doppler current profiler beam pattern and locations of unmeasured areas in each profile (from Simpson, 2002). blanking distance is below the transducer where data cannot be collected, and an additional unmeasured range is dependent on the water-mode configuration and the depth-cell size.

The ADCP also cannot measure all the way to the streambed due to the potential for side-lobe interference. As the ADCP approaches a streambank, the depths will eventually get too shallow for valid data collection. Therefore, the discharge computed by an ADCP is a summation of the measured portion of the cross section and extrapolated discharge estimates for unmeasured portions of the cross section at the top, bottom, and both banks. The computation of the measured, top, and bottom portions of the cross section occur for each ensemble, and the discharge for the edges are added to the total.

$$
Q=Q_{\text {LeftEdge }}+Q_{\text {Top }}+Q_{\text {Measured }}+Q_{\text {Bottom }}+Q_{\text {RightEdge }},
$$

where

$$
\begin{aligned}
& Q \quad \text { is the total discharge; } \\
& Q_{\text {LeftEdge }} \text { is the discharge estimated for the } \\
& Q_{T o p} \quad \text { is the discharge estimated for the top } \\
& \text { unmeasured area; } \\
& Q_{\text {Measured }} \text { is the discharge measured directly by the } \\
& \mathrm{ADCP} \text {; } \\
& Q_{\text {Bottom }} \text { is the discharge estimated for the bottom } \\
& \text { unmeasured area; and } \\
& Q_{\text {RightEdge }} \text { is the discharge estimated for the } \\
& \text { unmeasured area near the right bank. }
\end{aligned}
$$

The algorithms commonly used to compute discharge in each portion of the cross section are presented below.

\section{Measured Discharge}

Traditional point-velocity meters (Rantz and others, 1982) compute discharge as the product of the cross-sectional area and the mean water velocity perpendicular to the crosssectional area.

$$
Q=A \bar{V}
$$

where

$$
\begin{aligned}
& \frac{A}{V} \quad \begin{array}{l}
\text { is the cross-sectional area and } \\
\text { is the mean water velocity perpendicular to the } \\
\text { cross-sectional area. }
\end{array}
\end{aligned}
$$

The ADCP discharge computation algorithm is based on this same principle. Figure A-5 illustrates the water and boatvelocity vectors for a single depth cell in an ADCP transect. The cross-sectional area of the depth cell can be computed as the product of the depth-cell size $(d z)$ and ensemble width $(W)$. The depth-cell size is defined by the instrument 


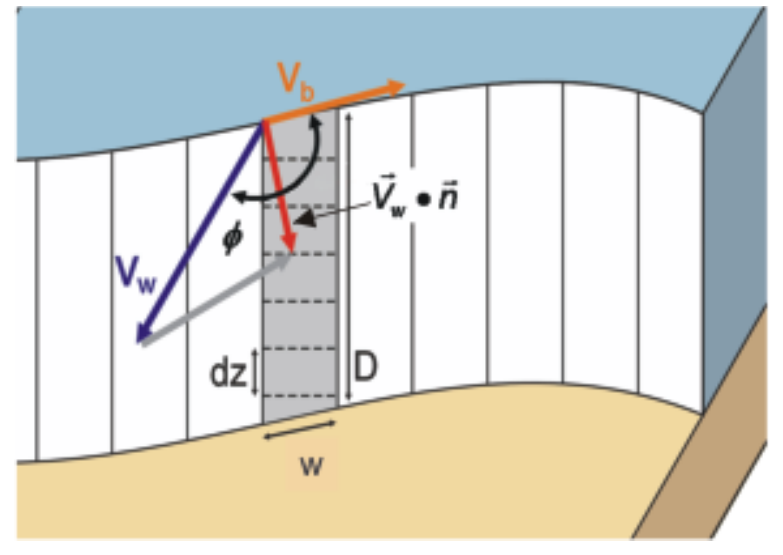

Figure A-5. Boat-velocity $\left(\mathrm{V}_{\mathrm{b}}\right)$ and water-velocity $\left(\mathrm{V}_{\mathrm{w}}\right)$ vectors for a single depth cell in an ADCP ensemble.

configuration. The ensemble width is computed as the product of the boat speed and time between ensembles.

$$
A=W d z=\left|\vec{V}_{b}\right| d t d z
$$

where

$$
\begin{aligned}
& \left|\vec{V}_{b}\right| \text { is the magnitude of the boat-velocity vector and } \\
& d t \quad \text { is the time between ensembles. }
\end{aligned}
$$

The discharge for the first ensemble is zero because to compute the ensemble width, a time for the previous ensemble is needed to compute $d t$. The water velocity can be computed as the product of the magnitude of the water velocity, $\left|\vec{V}_{w}\right|$, and the unit normal vector of the boat velocity, $\vec{n}$.

$$
\bar{V}=\left|\vec{V}_{w}\right| \bullet \vec{n}
$$

The equation for discharge in a depth cell, $Q_{b i n}$, becomes

$$
Q_{b i n}=\left(\left|\vec{V}_{w}\right| \bullet \vec{n}\right)\left|\vec{V}_{b}\right| d t d z .
$$

By applying trigonometric relations, equation A18 can be written as

$$
Q_{b i n}=\left|\vec{V}_{w}\right|\left|\vec{V}_{b}\right| \sin \phi d t d z
$$

The product of the vector magnitudes and sine of the internal angle is defined as the vector cross product, and the equation for $Q_{b i n}$ can be written in terms of the water- and boat-velocity vector components:

$$
Q_{b i n}=\left(\vec{V}_{w} \times \vec{V}_{b}\right) d t d z=\left(V_{w x} V_{b y}-V_{w y} V_{b x}\right) d t d z .
$$

The measured portion of the discharge can then be computed as

$$
Q_{\text {Measured }}=\sum_{j=1}^{\text {Ensembles Bins }} \sum_{i=1} Q_{b i n}
$$

\section{Top Discharge}

The discharge in the unmeasured zone at the water surface must be computed from the measured data. The length of the unmeasured zone at the water surface is determined by the draft of the instrument deployment, the blank required to avoid the effects of ringing, the water mode configuration, and depth-cell size (see the Limitations of ADCPs section for a detailed discussion of ringing). The methods for computing the top discharge can be applied to the individual velocity components (approach used by SonTek/YSI) or to the cross product from equation A16 (approach used by TRDI). Both approaches are mathematically identical. For simplicity, only the equations using the cross product are shown herein. See Huang (2000) for equations based on individual velocity components.

The simplest assumption for estimating the top discharge is to assume the velocity (cross product) in the topmost valid depth cell is a good estimate of the mean velocity between that depth cell and the water surface. This is typically referred to as the constant extrapolation method:

$$
Q_{\text {Top }}=\sum_{j=1}^{\text {Ensembles }} \chi\left(z_{w s}^{b+1}-z_{t b}^{b+1}\right) d t
$$

where

$x \quad$ is the velocity cross product,

$z_{w s}$ is the range from the streambed to the water surface, and

$z_{t b} \quad$ is the range from the streambed to the top of the topmost valid depth cell.

This constant extrapolation method is often used where there is an upstream wind or an irregular velocity profile through the measured portion of the water column.

A valid but slightly more complicated approach is to assume that the water-velocity profile follows a logarithmic distribution. Simpson and Oltmann (1993) attempted to calculate discharge using several different methods for profile estimation (logarithmic and general power law), but found that because of "noisiness" of the ADCP-profile data, the resulting least-squares-derived estimates were unrealistic, especially near the upper part of the profile. A method using a one-sixth power law (Chen, 1989) eventually was chosen because of its robust noise rejection capability during most streamflow conditions. 


$$
x=a z^{b}
$$

where

$a \quad$ is a coefficient derived from a least-squares fit of the equation to the measured data,

$z \quad$ is the range from the streambed to the location of the value of $x$, and

$b \quad$ is the exponent commonly assumed to be $1 / 6$.

The power-law estimation scheme is an approximation only and emulates a Manning-like vertical distribution of horizontal water velocities. Different power coefficients can be used to adjust the shape of the curve fit to emulate profiles measured in an estuarine environment or in areas that have bedforms that produce nonstandard hydrologic conditions. Applying equation A23 and integrating to obtain the top discharge yields

$$
Q_{\text {Top }}=\sum_{j=1}^{\text {Ensembles }} \frac{a}{b+1}\left(z_{w s}^{b+1}-z_{t b}^{b+1}\right) d t
$$

Both SonTek/YSI and TRDI provide additional options to estimate the top discharge for nonstandard profiles. SonTek/ YSI allows the user to select the number of depth cells used in the top constant extrapolation method. TRDI restricts the constant method to use of the top depth cell only. Both manufacturers provide an additional 3-point slope method to fit situations where wind significantly affects the velocity at the water surface. The user is referred to the manufacturer's documentation for more detail on these methods (Teledyne RD Instruments, 2007b; SonTek, 2012).

\section{Bottom Discharge}

ADCPs cannot measure the water velocity near the streambed due to side-lobe interference (see the Limitations of ADCPs section for a detailed discussion of side-lobe interference). Unlike the top discharge estimation problem where the velocity at the water surface is not known, we have some understanding of the water velocity at the streambed. From fluid mechanics, it is known that the water velocity must go to zero at the streambed and that a logarithmic velocity profile is a reasonable approximation of the velocity profile in the boundary layer (Schlichting, 1979). Therefore, the power law is always used to compute the discharge in the bottom unmeasured portion of the water column.

$$
Q_{\text {Bottom }}=\sum_{j=1}^{\text {Ensembles }} \frac{a}{b+1} z_{b b}^{b+1} d t
$$

where

$z_{b b} \quad$ is the range from the streambed to the bottom of the bottom most valid depth cell.

To better apply this method to situations where profile throughout the water column may not follow a logarithmic distribution, such as for bidirectional flow, TRDI adds an additional method to their software called "No-Slip," which applies equation A25 but restricts the least-squares determination of $a$ to depth cells in the bottom 20 percent of the profile, or in the absence of valid depth cells in the bottom 20 percent, the last valid depth cell is used to compute $a$. SonTek/YSI employs a similar approach but allows the user to select the percentage of depth cells near the bottom of the water column that are used in the least-squares determination of $a$.

\section{Edge Discharge}

The unmeasured discharge at the edges of the stream are estimated using a ratio interpolation method presented by Fulford and Sauer (1986), which can be used to estimate a velocity at an unmeasured location between the riverbank and the first or last measured velocity in a cross section (fig. A-6). The equation for the estimate is

$$
\frac{V_{x}}{\sqrt{d_{x}}}=\frac{V_{m}}{\sqrt{d_{m}}}
$$

where

$x \quad$ is a location midway between the riverbank and first or last ADCP-measured ensemble or $\mathrm{L} / 2$,

$V_{x}$ is the estimated mean velocity at location $x$,

$V_{m}$ is the measured mean velocity at the first or last ADCP-measured subsection (fig. A-6),

$d_{x}$ is the depth at location $x$, and

$d_{m}$ is the depth at the first or last ADCP-measured ensemble (fig. A-6). 


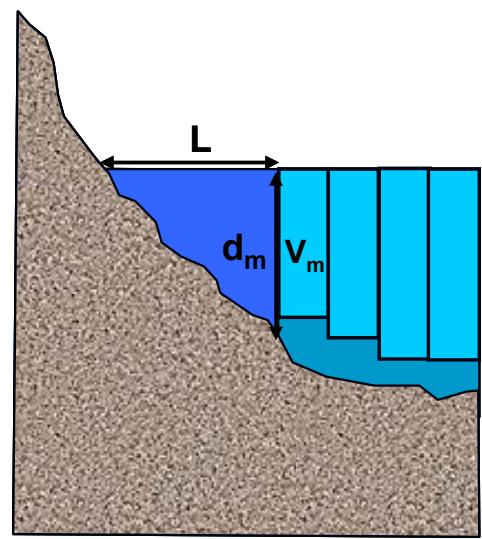

Figure A-6. Components used to calculate estimates of discharge in the unmeasured edges of cross sections.

Fulford and Sauer (1986) defined $d_{m}$ and $V_{m}$ as depth and velocity, respectively, at the center of the first or last measured subsection and not the near-shore edge of the ensemble, as presented in equation A26. However, because the ADCP ensembles purposely are kept very narrow at the start and finish of each measurement, the differences between the two applications are not significant (Simpson and Oltmann, 1993). With the Fulford and Sauer (1986) method, discharge can be estimated by assuming a triangular area at the edge as

$$
Q_{\text {Edge }}=A_{\text {edge }} V_{L / 2}=0.5 L d_{m} * V_{m} \frac{\sqrt{0.5 d_{m}}}{\sqrt{d_{m}}}=0.3535 L d_{m} V_{m} \text {, }
$$

where

$Q_{\text {Edge }}$ is the estimated discharge in the unmeasured edge,

$A_{\text {edge }}$ is the area of the unmeasured edge,

$V_{L / 2}$ is the velocity midway between the bank and the first or last ADCP-measured ensemble, and

$L \quad$ is the distance from the last valid ensemble to the edge of water (fig. A-6).
Equation A27 can be written in a more general form, which utilizes an edge-shape coefficient.

$$
Q_{\text {Edge }}=C_{e} V_{m} L d_{m},
$$

where

$$
C_{e} \text { is an edge-shape coefficient. }
$$

The edge-shape coefficient can be adjusted by the user to reflect unusual edge shapes or roughness but is commonly set to 0.3535 for triangular edges and 0.91 for rectangular edges. The value of 0.91 for rectangular edges was obtained from Oberg and Schmidt (1994). The value for $L$ must be measured and entered by the user (see discussion of laser range finders in the Other Equipment section). It is also recommended that at least 10 ensembles of data be collected in a near-stationary position at the beginning and end of each transect to obtain a good measurement for $V_{m}$. 


\section{Appendix B - Collecting Data in Moving-Bed Conditions}

ADCPs can measure boat velocity by using a technique called bottom tracking, which computes the Doppler shift of acoustic pulses reflected from the streambed. This technique assumes that the streambed is stationary; however, sediment transport on or near the streambed can affect the Doppler shift of the bottom-tracking pulses. In such situations, reflections of bottom-tracking pulses from highly concentrated near-bed sediments contaminate the reflections from the bed.

\section{Cause and Effect of a Moving Bed}

To measure absolute water velocities with an ADCP (water velocities relative to a fixed reference), the ADCP must sense and measure the velocity of the ADCP itself, relative to the river bottom. This is referred to as bottom tracking. Bottom-tracking measurements are similar to water-velocity measurements, but separate acoustic pulses are used. If the velocity of the water is known relative to the ADCP (water tracking), and the velocity of the ADCP is known relative to the river bottom (bottom tracking), then the water velocity relative to the bottom can be calculated. However, for the calculation of actual water velocities to be accurate, the streambed must be stationary.

The bottom-track pulse often is longer than the water-track pulse to allow complete ensonification (the filling of any fluid medium with acoustic radiation, which is then observed and analyzed to study the medium or to locate or image objects within it) of the bottom. For the bottom ping to accurately measure the depth to and Doppler shift from the streambed, the pulse should uniformly ensonify the surface of the streambed so that it will receive uniform backscatter. If the pulse is too short, the echo returns first from the part of the beam closest to the ADCP, followed by successively further areas (fig. B-1). The beam angle is different for the near and far parts of the beam, making analysis of the signal difficult. A pulse ensonifying the entire bottom will produce an accurate and stable measurement of the velocity of the instrument. However, sediment transport on or near the streambed can affect the Doppler shift of the bottomtracking pulses and can cause a measurement error referred to as a moving
Entire beam does not illuminate the bottom at one time

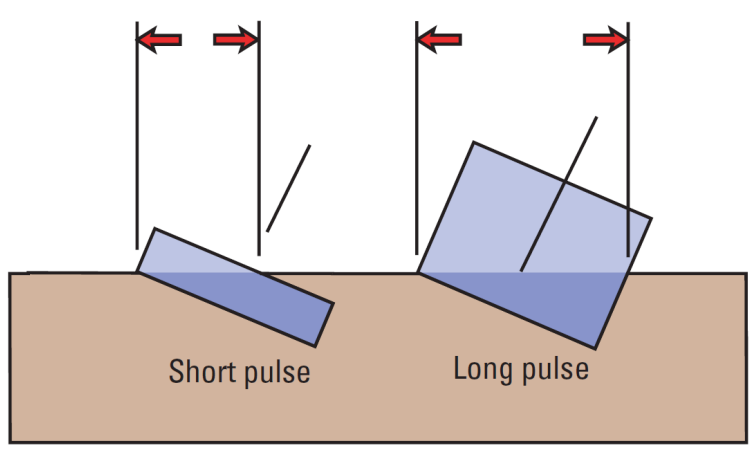

Figure B-1. An example of short and long bottomtrack pulses (from Simpson, 2002). bed. When the bottom is ensonified, the sediment above the bottom also is ensonified and included in the backscattered signal (fig. B-2); therefore, the backscattered signal of the long pulse may be biased by the sediment in the water column just above the streambed. In such situations, reflections of bottom-tracking pulses from highly concentrated near-bed sediments are difficult to distinguish from reflections from the bed. These near-bed sediments typically are being transported in the downstream direction. If bottom tracking is affected by sediment transport, the measured boat velocity will be biased in the opposite direction of the sediment movement, which would make a stationary boat appear to be moving upstream (fig. B-3). Therefore, if sediment moving near the streambed

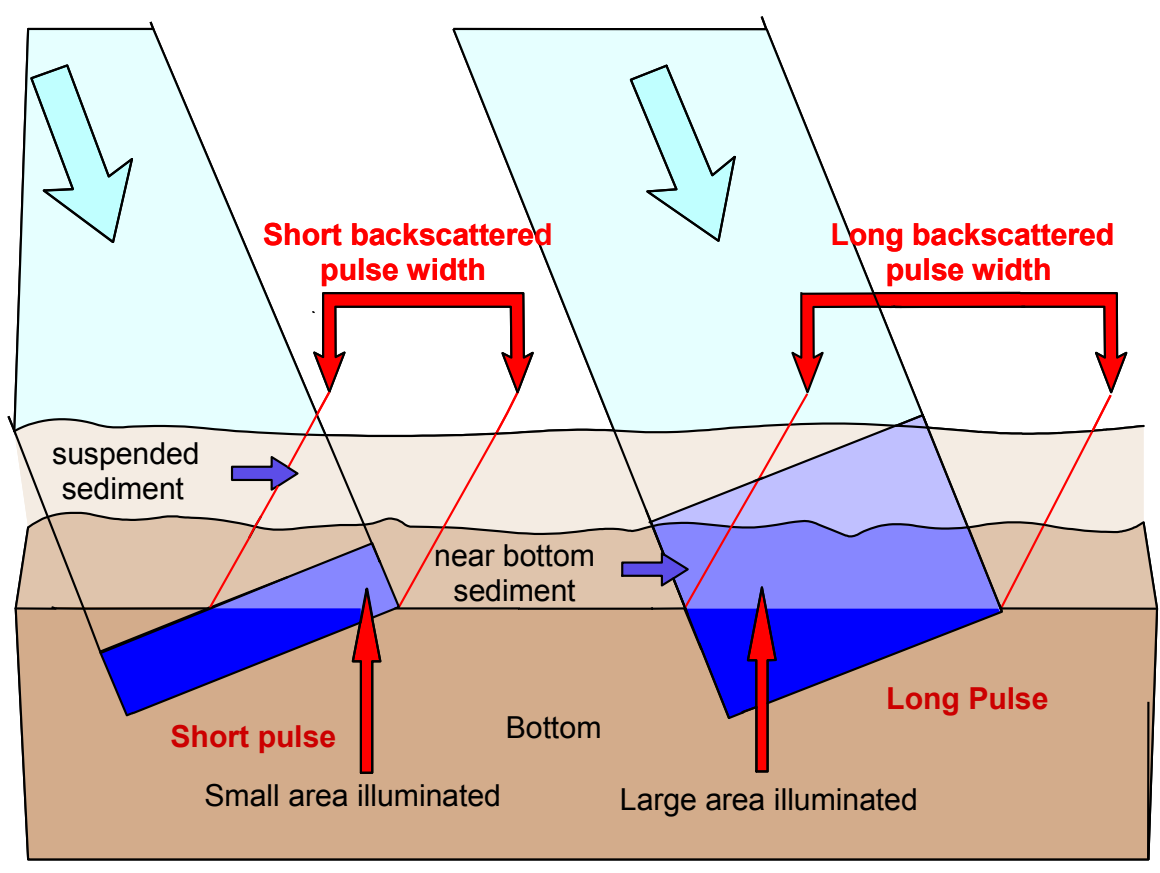

Figure B-2. An example of the potential for water bias (moving bed) for short and long bottom-track pulses (from Simpson, 2002). 


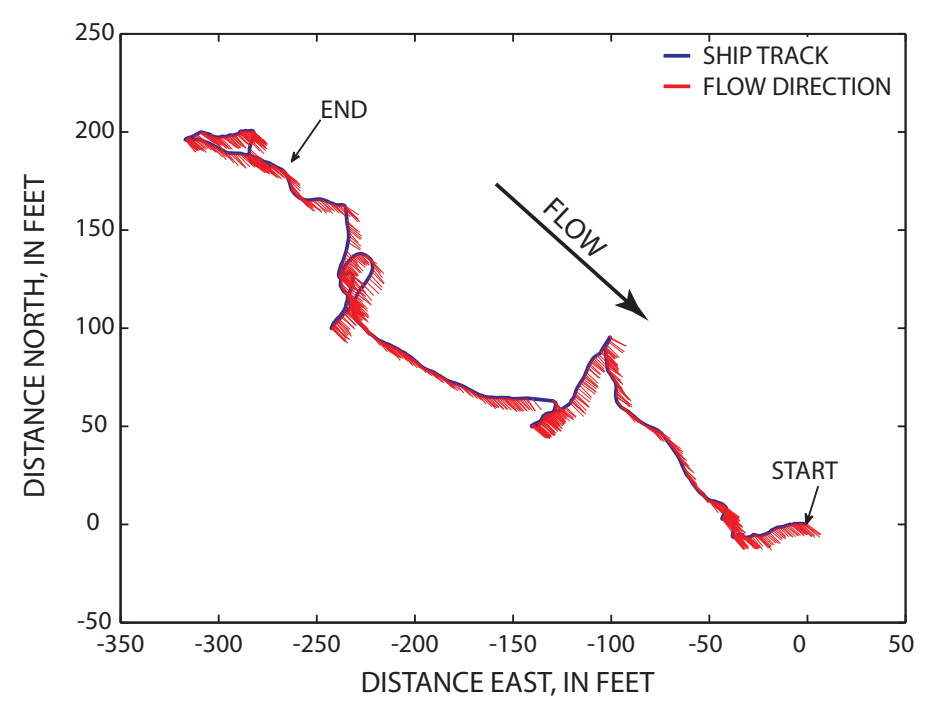

Figure B-3. A moving bed measured with a 1,200-kilohertz acoustic Doppler current profiler (ADCP) on the Mississippi River at Chester, Illinois.

is measured by bottom-tracking measurements, the boat will have an apparent upstream velocity, the calculated downstream water velocity will be reduced, and the corresponding discharge will be biased low.

Determining whether a moving-bed condition exists at a site is not always intuitive to a hydrographer because a moving bed may be measured by an ADCP even in streams where the bed is visually stationary. The detection of a moving bed also is dependent upon the frequency of the ADCP. Higher frequency ADCPs are more sensitive to sediment transport than are lower frequency ADCPs and, therefore, are more prone to detecting a moving bed.

\section{Methods to Identify a Moving Bed}

Field experience has shown that sediment transport characteristics can vary greatly for the same discharge, depending on the hydrograph shape, source of runoff, and season of the year. Thus, a moving bed may be detected at a location and discharge where one was not previously detected, or a moving bed may no longer exist at a location and discharge where one was previously detected. Moving-bed conditions also have been reported in low-velocity environments (less than $1 \mathrm{ft} / \mathrm{s}$ ). Therefore, to ensure the quality of the data collected, every moving-boat measurement made with an ADCP must have a recorded moving-bed test.

A moving-bed test must be conducted prior to making a discharge measurement. This requirement supersedes Oberg and others (2005) and various USGS training materials. If a site routinely has a moving bed and GPS is always used with the ADCP, a moving-bed test is still required. A moving-bed test consists of a valid loop moving-bed test or a stationary moving-bed test. The stationary moving-bed test must be made at the location in the measurement section expected to have the highest potential for a moving bed. Additional stationary moving-bed tests provide a better characterization of the moving-bed conditions in the measurement section, but multiple stationary moving-bed tests are required only if the tests are going to be used to correct the measured discharge for moving-bed conditions.

\section{Stationary Test with No GPS}

The first moving-bed-test method requires that the boat with the ADCP be held in a stationary position while recording ADCP data, using bottom tracking as the boatvelocity reference. If the stationary position is maintained by a tether or anchor so that upstream or downstream movement of the ADCP is not possible, the moving-bed test should be recorded for no less than 5 minutes; however, if the ADCP can move either upstream or downstream, such as when the boat operator is trying to maintain position of the boat, the test should be recorded for no less than 10 minutes. These criteria supersede the guidance on stationary moving-bed tests that have been previously published in Oberg and others (2005) and U.S. Geological Survey (2002b). When a moving-bed condition is present, a stationary boat will appear to have moved upstream (fig. B-3). The error caused by the moving bed can be estimated by dividing the distance of the apparent boat motion in the upstream direction by the duration of the test in seconds. This computation will provide the moving-bed velocity detected by the bottom-tracking technique. This moving-bed velocity can then be divided by the average water velocity from the moving-bed test and multiplied by 100 to yield an estimate of the percent bias error for a water-velocity measurement at this stream location. In the example shown in figure B-3, the distance traveled was approximately $360 \mathrm{ft}$ for a 10 -minute (600-second) period. The estimated moving-bed velocity is $0.59 \mathrm{ft} / \mathrm{s}$. If the mean velocity for the discharge measurement was $4.9 \mathrm{ft} / \mathrm{s}$, the percent bias error in the water-velocity measurement would be estimated to be 12 percent. Criteria for determining if a moving bed is present must account for the accuracy of the test. If the moving-bed test was completed with a fixed tethered deployment, an anchored manned boat, or a manned boat where the user is sure there was little movement of the boat, a moving bed is determined to be present when the measured moving-bed velocity is greater than 1 percent of the mean water velocity at the test location. If the moving-bed test was made using a manned boat that was not anchored and may have moved either upstream or downstream, a criteria of 2 percent instead of 1 percent is used because uncertainty has been introduced into the test by boat movement. Discharge-measurement techniques that are not affected by a moving bed, or that correct for the effect of a moving bed, should be used if a moving bed has been detected. 
When it is not possible to safely anchor the manned boat in the stream because of boat traffic, drift, or other hazardous conditions, holding the boat stationary at the desired location in the measurement section may be difficult. Boat movement in the upstream or downstream direction will introduce errors in the moving-bed test when using this method. A technique for helping the boat operator determine whether the boat is moving excessively in the upstream or downstream direction during a moving-bed test is illustrated in figure B-4. The boat operator selects two distinguishable reference points on shore that are separated by a considerable distance from one another ( $98 \mathrm{ft}$ or more). Examples of distinguishable reference points include telephone or power poles or large trees that can be easily distinguished from other nearby trees. Bridges, bridge piers, and navigation buoys also can be used as reference points for maintaining an approximately stationary position when making a moving-bed test. If the boat changes position appreciably in the upstream or downstream direction, this change should be noted on the field note form, and the test should be repeated, if possible.

The TRDI StreamPro ADCP did not include an internal compass when first released (2003). In 2009 an internal compass was added as an option for the StreamPro, but StreamPros can still be purchased without a compass. The cross product of the water-velocity and boat-velocity vectors, used for the computation of discharge, does not depend on the heading of the instrument (Simpson and Oltmann, 1993). Moving-bed biases have been reported when using the StreamPro without an internal compass where it was apparent from the velocity and bed material that little or no sediment transport was occurring. The false moving bed observed in stationary moving-bed tests conducted with a StreamPro is the result of rotation and lateral movement of the StreamPro on the end of the tether. During a stationary moving-bed test, the StreamPro and float often tend to swim or kite from the end of the tether. A StreamPro without an internal compass will not compensate for instrument rotation in stationary moving-bed tests. The lack of a compass in a StreamPro does not allow the StreamPro to report boat or water velocities referenced to a fixed rotational reference, such as magnetic north; rather, the StreamPro reports velocities in instrument coordinates.

Careful analysis of false moving-bed ship tracks indicates that ship movement (kiting or swimming) typically is perpendicular to the water velocity. When the StreamPro rotates, the boat and water velocities are rotated. Thus, the boat velocity and water velocities remain in the correct orientation relative to each other. This characteristic permits the discharge to be computed without a compass. This characteristic also can be used to determine the velocity of the boat in the upstream direction. The boat velocity in the upstream direction measured during a stationary moving-bed test can be computed using the vector dot product of the boat velocity and water velocity. The use of the dot product for analysis of a moving-bed test was originally suggested by Randy Marsden (Teledyne RD Instruments, oral commun., 2006). This approach subsequently has been developed and applied to

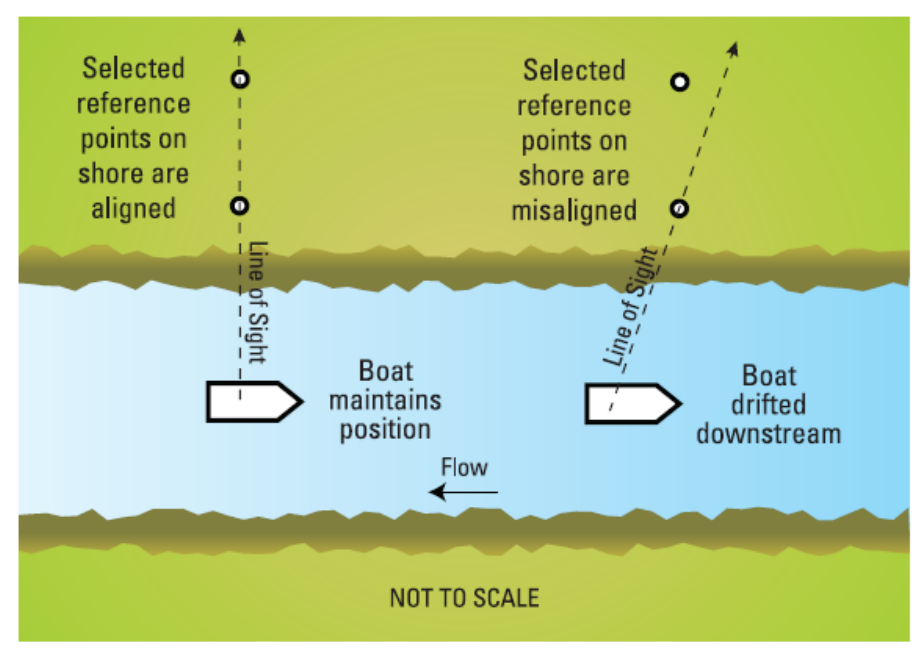

Figure B-4. Method for verifying that upstream/downstream boat movement is minimized during an acoustic Doppler current profiler moving-bed test (modified from Environment Canada, 2004).

the false moving-bed problem associated with the StreamPro ADCP. The USGS has developed software (Stationary Moving Bed Analysis (SMBA)) that applies the dot-product approach and provides a simple and efficient user interface to allow users to apply the dot-product approach to all ADCP stationary moving-bed measurements, which has been shown to eliminate the effect of the boat/instrument motion on the stationary moving-bed test when a valid heading is not available. The SMBA program can be obtained from the USGS at $h t t p: / /$ hydroacoustics.usgs.gov/. SMBA can also be used to analyze stationary moving-bed tests for ADCPs that have compasses. Equivalent algorithms are now (2013) available in both WinRiver II and RiverSurveyor Live.

\section{Stationary Test with GPS}

A more accurate method for estimating the errors introduced by a moving bed can be determined if a GPS is available for use and is interfaced with the ADCP and the data-collection software. The stationary test with GPS method also requires that the ADCP boat be held in a stationary position and a data file recorded for at least 5 minutes, if GPS data are of good quality. Either bottom tracking or GPS can be used for the boat-velocity reference. Using GPS as the reference is often easier during data collection so that the boat operator can use the ship-track display as a means to assist in holding the boat in an approximately stationary position. After the moving-bed test is complete, compare the boat track using ADCP bottom track as reference with the boat track using GPS as the reference. If the bottom-track boat-velocity data indicate apparent upstream movement that the GPS data do not indicate, a moving bed is present. The error caused by the moving bed can be computed in the same manner as 
described for the stationary test with no GPS method, except that the distance in the upstream direction indicated by bottom tracking should be corrected by the distance actually traveled in that direction, as indicated by GPS (Oberg and others, 2005). In the WinRiver II and RiverSurveyor Live software, this distance can be found in the "compass calibration" tabular window and GPS tabular display, respectively, and is labeled "BMG-GMG mag" and "BMG-GMG dir." The direction of the "BMG-GMG dir" should be in the upstream direction. If the measured moving-bed velocity is greater than 1 percent of the mean water velocity at the test location, GPS should be used as the navigation reference.

\section{Loop Method}

If the ADCP can be held stationary, stationary movingbed tests are a good measure of the magnitude of an apparent moving bed; however, these tests represent the moving-bed condition only at the location in the cross section where the test is completed. An alternative to the stationary moving-bed test is the loop method, which is based on the fact that as an ADCP is moved across the stream, a moving bed will cause the bottom-track-based ship track to be distorted in the upstream direction. Therefore, if an ADCP makes a two-way crossing of a stream (loop) with a moving bed and returns to the exact starting position, the bottom-track-based ship track will show that the $\mathrm{ADCP}$ appears to have returned to a position upstream from the original starting position (fig. B-5). The mean moving-bed velocity can be estimated from the distance the ADCP appeared to have moved upstream from the starting position (loop-closure error) and the time required to complete the loop.

$$
\bar{V}_{m b}=\frac{D_{u p}}{T}
$$

where

$$
\begin{aligned}
& \bar{V}_{m b} \text { is the mean moving-bed velocity for the } \\
& \text { measurement section, } \\
& D_{u p} \text { is the loop-closure error (distance made good, } \\
& \text { straight-line distance from starting point to } \\
& \text { ending point), and } \\
& T \text { is the measurement time required to complete } \\
& \text { the loop. }
\end{aligned}
$$

\begin{tabular}{|c|c|c|c|}
\hline \multicolumn{3}{|c|}{ 4-Composite Tabular 1 - TRDI } & \\
\hline \multicolumn{4}{|c|}{ Ens. Nmb. Nmb. of Ens. Lost Ens. } \\
\hline \multicolumn{4}{|c|}{$\begin{array}{rrr}393 & 359 & 17\end{array}$} \\
\hline \multicolumn{4}{|c|}{ \%Bad Bins } \\
\hline 23 & $\mathbf{0} \%$ & 0.80 & \\
\hline \multicolumn{4}{|c|}{ May 25, 2005 14:18:03.29 } \\
\hline Pitch & Roll & Heading & \\
\hline$-0.08^{\circ}$ & $1.15^{\circ}$ & $269.00^{\circ}$ & \\
\hline Temp. & Press.Sensor & & \\
\hline $46.96^{\circ} \mathrm{F}$ & NA & & \\
\hline \multicolumn{3}{|c|}{ Discharge (Ref: BT) Left to Right } & \multirow{9}{*}{$\mathrm{D}_{\text {up }}$} \\
\hline Good Bins & \multicolumn{2}{|c|}{4} & \\
\hline \multirow{2}{*}{$\begin{array}{l}\text { Top Q } \\
\text { Measured Q }\end{array}$} & -148.668 & {$\left[\mathrm{t}^{3 / s}\right]$} & \\
\hline & 148.461 & {$\left[\mathrm{t}^{3 / \mathrm{s}}\right]$} & \\
\hline Bottom Q & -37.011 & {$\left[\mathrm{t}^{3 / s}\right]$} & \\
\hline Left $Q$ & -21.152 & {$\left[\mathrm{t}^{3} / \mathrm{s}\right]$} & \\
\hline Right $Q$ & -20.089 & {$\left[\mathrm{t}^{3} / \mathrm{s}\right]$} & \\
\hline \multirow[t]{2}{*}{ Total Q } & .78 .458 & {$\left[\mathrm{t}^{3} / \mathrm{s}\right]$} & \\
\hline & \multicolumn{2}{|c|}{ Navigation (Ref: BT) } & \\
\hline Boat Speed & 0.171 & {$[\mathrm{t} / \mathrm{s}]$} & \multirow{12}{*}{$\mathrm{V}_{\mathrm{mb}}=\frac{\mathrm{V}_{\mathrm{up}}}{\mathrm{T}}$} \\
\hline Boat Course & 101.17 & {$\left[{ }^{\circ}\right]$} & \\
\hline Water Speed & 1.711 & {$[\mathrm{t} / \mathrm{s}]$} & \\
\hline Water Dir. & 74.99 & {$\left[{ }^{\circ}\right]$} & \\
\hline Calc. Depth & 3.66 & [ft] & \\
\hline Length & 616.67 & {$[\mathrm{ft}]$} & \\
\hline Distance MG & 36.94 & {$[\mathrm{ft}]$} & \\
\hline Course MG & 290.88 & {$\left[{ }^{\circ}\right]$} & \\
\hline Duration & 306.22 & {$[s]$} & \\
\hline \multicolumn{3}{|c|}{ GPS Position } & \\
\hline Latitude & \multicolumn{2}{|c|}{$61^{\circ} 31.8285^{\circ} \mathrm{N}$} & \\
\hline Longitude & \multicolumn{2}{|c|}{$125^{\circ} 24.1972^{\circ} \mathrm{W}$} & \\
\hline
\end{tabular}

These data are readily available from most commercial software used to measure discharge with ADCPs (fig. B-6).

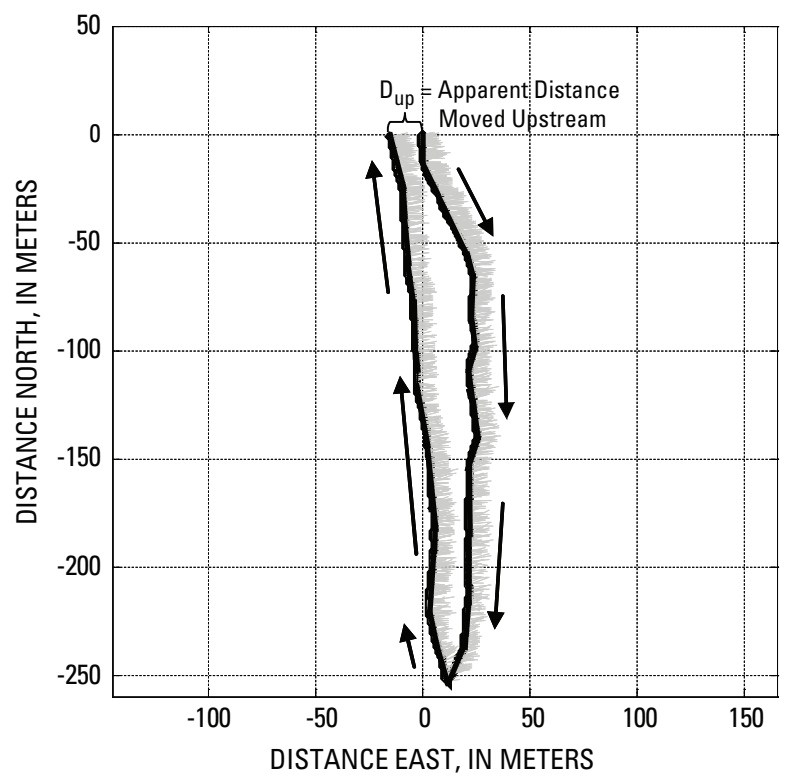

Figure B-5. A distorted ship track in a loop caused by a moving bed.
(A)
(B)

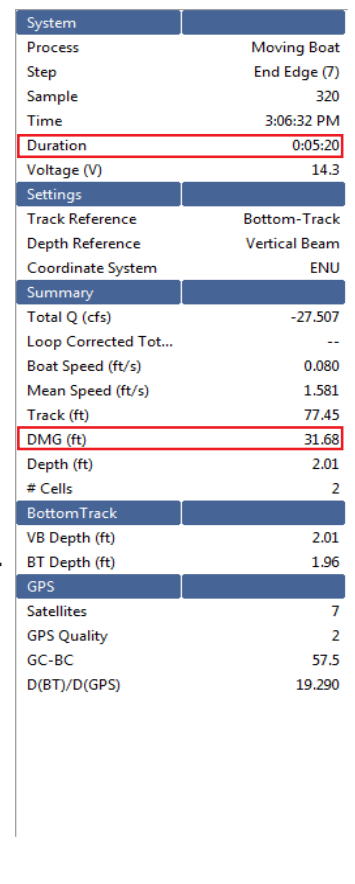

Figure B-6. Example of parameters used to compute the mean correction for data collected with an ADCP and displayed with (A) WinRiver and (B) RiverSurveyor. 
The loop method must be applied properly, or it may produce incorrect results. Anyone planning to use the loop method should read and follow USGS Scientific Investigations Report 2006-5079 (Mueller and Wagner, 2006), which describes the procedures, limitations, and uncertainties associated with the loop method. The following steps are for collecting and analyzing loop-test data.

1. Calibrate the ADCP compass. A compass calibration accuracy of better than 1 degree is desired. The accuracy of the compass calibration is determined by evaluating the compass after it has been calibrated. If the evaluation results in an error greater than 1 degree, the calibration and evaluation should be repeated. If an evaluation of less than 1 degree cannot be obtained after several attempts, appropriate field notes should be recorded to document the problem. Compass errors greater than 1 degree result in increased errors in the loop-method correction. If the calibration software does not have evaluation capabilities and (or) does not report potential error in degrees, obtain the best calibration possible and be sure and use LC (stand-alone version or built into the manufacturers' software) to evaluate the results. LC has a quality-assurance algorithm that looks for potential heading errors.

2. Establish a marked starting point where the ADCP can be returned to the exact location. This point is not required to be as near to a bank as the start and end of a regular transect. For example, with a tethered boat, controlling the boat at the edge of the bank can be difficult because of conditions such as slack water, eddies, or vegetation; therefore, establishing a point farther out in the flow makes navigating the boat back to the starting point more practical. Use of a buoy or other fixed object is recommended.

3. Make a steady pass back and forth across the stream, but do not stop recording at the far bank. At the starting point, make sure the boat is ready to begin the transect before beginning to record. A uniform boat speed is important. Do not spend extra time near the bank. Plan the loop so that a smooth change in boat direction can be achieved near the far bank. Too much time near the banks will result in a low bias.

4. Maintain the proper boat speed. The recommended maximum boat speed should be the lesser of a boat speed that requires no less than 3 minutes to complete the loop or a boat speed that is less than 1.5 times the mean water speed. The longer the duration of the loop test the less influence heading errors will have on the computed moving-bed velocity.

5. Return to the starting point. Accurately returning the ADCP to the starting point is very important. Again longer duration loops will minimize the effect of not returning to exactly the same starting point.
6. Use available computer programs to process the loop. The USGS has developed a stand-alone computer code named LC to process and analyze loop moving-bed tests. Similar algorithms are now (2013) available in both WinRiver II and RiverSurveyor Live. The computerized analysis applies the same basic equation (B1) to compute the moving-bed velocity as the user could apply manually, but it also provides additional quality checks (see Alternatives to Using a GPS - Loop Method for details on quality checks) and automatically applies the proper thresholds for determining if a moving bed has been detected.

7. Use appropriate data-collection methods. If analysis of the loop indicates a moving-bed condition, then a differentially corrected global positioning system (DGPS) or method that accounts for, or corrects for, a moving bed should be used.

\section{Methods to Account for Moving-Bed Effects}

The integration of a GPS to measure the velocity of the ADCP has been shown to alleviate the systematic errors associated with a moving bed (Mueller, 2002) and is the most accurate way to measure discharge in moving-bed conditions. In moving-bed conditions, a GPS should always be used as the navigation reference unless site conditions or inaccurate headings prevent its use. If site conditions do not permit GPS use, methods have been established to correct discharge measurements biased by a moving bed. The use of a GPS and the application of various discharge correction methods are discussed in the following sections.

\section{Using GPS with ADCPs}

Using GPS with ADCPs eliminates the effect of a moving bed on the velocity measurements but introduces several sources of potential error. Understanding how GPS operates and how it is used with ADCPs is important for collecting high-quality ADCP measurements when using GPS data as the boat-velocity reference.

The computation of water velocity from an ADCP mounted onto a moving boat is a vector-algebra problem. The ADCP measures the water velocity relative to the moving boat (relative water velocity), so the velocity of the boat must be accounted for to obtain the true water velocity. The true water velocity is computed by subtracting the bottom-tracking velocity from the water-tracking velocity. When bottom tracking is used, the direction of the boat-velocity vector as measured by bottom tracking $\left(\theta_{B T}\right)$ and water-velocity vector $\left(\theta_{W T}\right)$ are referenced to the ADCP (fig. B-7A). The ADCP has an internal fluxgate compass to measure the orientation of the instrument $\left(\theta_{\text {Inst }}\right)$ relative to the local ambient magnetic field (magnetic north). The water-velocity vector can be easily referenced to 
magnetic north by rotating the vector based on the measured $\theta_{\text {Inst }}$ and to true north by again rotating the vector by a user-specified magnetic variation $\left(\theta_{M a g}\right)$. The magnitude of the water velocity is unaffected by any errors in the measurement of $\theta_{\text {Inst }}$ or entry of $\theta_{\text {Mag }}$ when bottom tracking is used as the boat-velocity reference. The basic equation presented in Simpson and Oltmann (1993) for computing measured discharge (exclusive of unmeasured areas) by use of an ADCP mounted onto a moving boat is

$$
Q=\int_{0}^{T} \int_{0}^{D}\left|\vec{V}_{f}\right|\left|\vec{V}_{b}\right| \sin \theta d z d t
$$

where

$$
\begin{aligned}
& Q \quad \text { is the total discharge, } \\
& T \quad \text { is the total time for which data were collected, } \\
& D \quad \text { is the total depth, } \\
& \vec{V}_{f} \text { is the mean water-velocity vector, } \\
& \vec{V}_{b} \text { is the mean boat-velocity vector, } \\
& \theta \quad \text { is the angle between the water-velocity vector } \\
& \quad \text { and the boat-velocity vector (fig. B-7), } \\
& d_{z} \text { is the vertical differential depth, and } \\
& d_{t} \quad \text { is differential time. }
\end{aligned}
$$

To compute the discharge, only the angle between the water-velocity and the boat-velocity vectors is needed. When GPS is used to determine the boat-velocity vector, this vector is referenced to true north as determined from the GPS data (fig. B-7B). The orientation of the instrument relative to true north must be determined to put the boat-velocity vector and the relative water-velocity vector in the same coordinate system and allow for the computation of the water-velocity vector and $\theta$. The discharge is affected by errors in measuring $\theta_{\text {Inst }}$ and in the determination of the magnetic variation $\left(\theta_{\text {Mag }}\right)$ when GPS is used as the boat reference. The errors associated with $\theta_{\text {Inst }}$ can cause errors in the measured discharge that are proportional to the speed of the boat. Proper setup and calibration of the ADCP's internal compass, determination of the local magnetic variation, and a slow boat speed are critical to quality discharge measurements made using GPS data as the boat-velocity reference.

Errors associated with fluxgate-compass measurements can result from horizontal accelerations of the ADCP or environmental conditions near the instrument. Most fluxgate compasses are gimbal-mounted, which allows them to measure the Earth's horizontal magnetic field. When the instrument is subject to horizontal accelerations, such as when a boat accelerates or turns, the force generated by the acceleration causes the compass to swing out of the vertical position and measure something other than the horizontal magnetic field. Most of the significant errors associated with horizontal accelerations can be eliminated by slow, smooth boat operation.

Errors associated with fluxgate-compass measurements caused by environmental conditions can be classified as one- and two-cycle errors. One-cycle errors are caused by permanent magnets and current-carrying conductors;

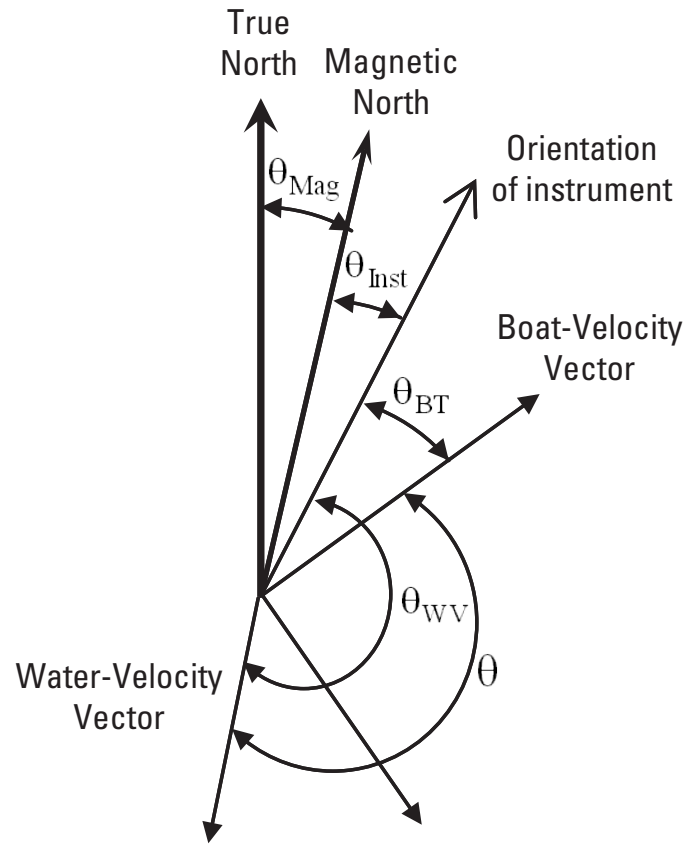

A. Bottom tracking

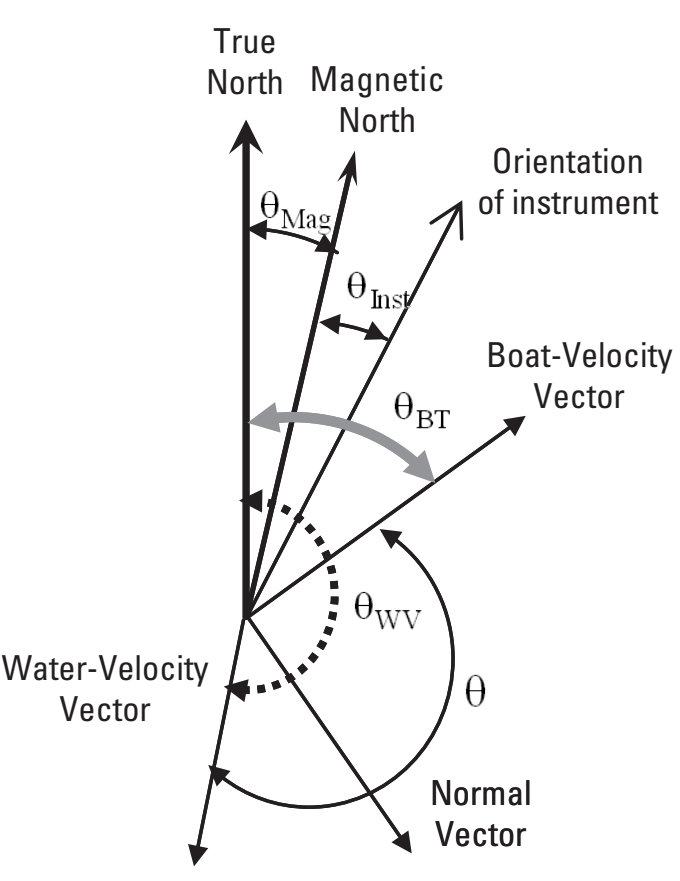

\section{B. Global positioning system (GPS)}

Figure B-7. Boat-velocity vectors referenced by $(A)$ bottom tracking and $(B)$ global positioning system (adapted from Mueller, 2002). 
two-cycle errors are caused by iron and magnetically permeable material. ADCPs manufactured by TRDI and SonTek for making discharge measurements from a moving boat have firmware routines to allow the calibration of the compasses in place to compensate for environmental conditions.

The local magnetic variation (or declination) can be either estimated or measured, depending upon site conditions. Estimates of the local magnetic variation can be obtained from USGS 7.5-minute quadrangle maps, magnetic field charts, and geomagnetic field models. Although these estimated values are often accurate, some areas have appreciable magnetic anomalies that are not accurately predicted by models or general charts. Teledyne RD Instruments (2003) documents a procedure for measuring the magnetic variation onsite by use of an ADCP and a DGPS. This same procedure can be used with RiverSurveyor instruments and RiverSurveyor software from SonTek/YSI. The limitation of this procedure is that there can be no moving-bed conditions because both the bottom tracking and GPS are used in the computations.

The compasses in ADCPs typically are accurate to about 1 to 2 degrees in field applications and the local magnetic variation could vary from the geomagnetic model, so it is reasonable that errors of 2 degrees could occur. Such errors could cause a directional bias in the discharges measured with GPS as the navigation reference. A directional bias is when discharges measured with the boat moving in one direction, say from the left bank to the right bank, are consistently different from the discharges measured when the boat is moving in the opposite direction, say from the right bank to the left bank. If the differences are less than about 5 percent, the average of reciprocal pairs of transects will yield a discharge that is close to the true value. It is possible to reduce the directional bias by manually adjusting the magnetic variation (or adjusting the compass heading correction in RiverSurveyor Live). Any adjustment should be applied to all transects, so that the magnetic variation is consistent between transects. Although adjustments to the magnetic variation may reduce the directional bias, it often has little effect on the final discharge and is generally not worth the time spent on the adjustment. However, given the expected accuracy of the compass and magnetic variation, adjustments of more than 2 degrees would indicate that the compass was not accurately calibrated or the user-entered magnetic variation was incorrect. Adjustments of more than 2 degrees should be made with caution, and documentation is required to justify such manual adjustments.

GPS provides two options for determining boat velocity: (1) differentiated position using the GGA NMEA-0183 sentence and (2) GPS receiver computed velocity reported in the VTG NMEA-0183 sentence. The GGA data sentence broadcast by the GPS includes time, positional data (latitude, longitude, and elevation), and information about the satellite constellation used to reach the position solution. When using the GGA sentence from the GPS to measure the movement of the ADCP, the velocity of the instrument is determined by computing the distance traveled between successive GPS position solutions and dividing that distance by the time between the solutions. Hence, positional accuracy is vitally important to achieve an accurate measure of ADCP movement using the GGA sentence, and therefore, a differential correction signal is required. To use the GGA sentence, DGPS receivers are required, and receivers should have a 95-percent accuracy of about $3.3 \mathrm{ft}$ or less in the horizontal location.

Although the differential correction accounts for errors induced by the ionosphere, atmosphere, and selective availability, the user must be aware of and take action to minimize uncorrectable errors, which can be caused by the user, the satellite configuration, or the characteristics of the site. Place the GPS antenna as near to the center of the ADCP as possible so that the direction of travel is the same for both the antenna and the ADCP during all boat maneuvers. The antenna should be located above the boat cabin or other accessories on the boat to eliminate multipath errors. Multipath errors are positional errors that arise when satellite signals bounce around before getting to the receiver, rather than taking a direct path. The result is a barrage of signals arriving at the receiver: first the direct one, then a series of delayed reflected ones. This creates a noisy signal, and if the bounced signals are strong enough, they can confuse the receiver and cause erroneous positional measurements. Sophisticated receivers use a variety of signal processing techniques to make sure they only consider the earliest arriving signals, which are the direct ones. Although these techniques reduce multipath errors, they do not completely eliminate the problem.

Occasionally, the configuration of the satellites does not allow an accurate determination of the horizontal position. This can be monitored using the horizontal dilution of precision (HDOP). If the HDOP parameter is greater than 2 , or if the HDOP changes by more than 1 during a transect, the quality of the DGPS positions is suspect. Local site characteristics, such as canyon walls, bluffs, tall buildings, and tree cover, can result in poor DGPS positions because of multipath errors and loss of satellite visibility. Poor satellite visibility often results in numerous changes in the number and configuration of satellites used to determine a position. Numerous changes in satellites are another indication that the quality of the DGPS positions may be poor. In addition to horizontal-position coordinates, the DGPS also computes elevation. This elevation is 2 to 4 times less accurate than the horizontal position (Mueller, 2002). The elevation of the boat should be reasonably constant. Changes greater than $11.5 \mathrm{ft}$ in the DGPS-determined elevation indicate that the quality of the DGPS positions may be poor (Teledyne RD Instruments, WinRiver 10.06 Help File, written commun., 2006).

Many GPS receivers can be used to measure velocity relative to ground with an assessment of the Doppler shift in the satellite carrier phase frequencies, which is typically reported in the VTG sentence. The method uses the actual signal frequency, and not a phase angle, to determine the Doppler shift. No ambiguity can be present in the computed velocities. As for the position determination, the velocity 
measurement requires the use of at least four satellites. The quality of the solution also is influenced by the number of satellites and the shape of the constellation (HDOP) during the observation. This alternative has an advantage because it is minimally affected by multipath and satellite changes because of the short sampling time required. In addition, multipath and ionospheric/atmospheric distortions do not affect the precision of the measurement. As a result, the Doppler measurement of velocity can be produced without the need for any differential correction. Wagner and Mueller (2011) concluded that VTG can be a valid alternative for measuring discharge with an ADCP in moving-bed environments without the assistance of differential corrections, but more inaccuracies in VTG-based discharges may occur, particularly for boat speeds less than about $0.8 \mathrm{ft} / \mathrm{s}$. They also observed that errors in boat speed from VTG data are more difficult to detect than from GGA data. Note: Some manufacturers will also use differentiated position to compute the velocity reported in the VTG sentence. In such cases, the advantages of the Doppler shift processing are negated and the same limitations as differentiated position from the GGA sentence apply.

\section{Alternatives to Using a GPS}

The preferred method of making discharge measurements with an ADCP in moving-bed conditions it to use GPS as the navigation reference. GPS is the preferred option for a moving-boat ADCP measurement when the ADCP cannot maintain valid bottom track for boat velocity. GPS systems, however, do not work in all conditions. For example, a GPS will have trouble providing consistently accurate positions and velocities on waterways with dense tree canopy along the banks, in deep valleys or canyons, and near bridges because of multipath and satellite signal reception problems. Alternative methods of correcting for the systematic moving-bed error have been developed for situations where integrating GPS with an ADCP is not possible. The alternative correction methods can only be used when valid bottom-track data can be maintained throughout the cross section and should not be used when there is a significant amount of invalid bottomtrack data.

\section{Loop Method}

The results of a loop method moving-bed test (previously described) can be used to compute the discharge missing from the measurement caused by the moving bed. This computed missing discharge can be added to the measured discharge to yield a corrected discharge.

$$
Q_{T C}=Q_{T M}+Q_{m b}
$$

where

$Q_{T C}$ is the discharge corrected for the moving-bed bias,

$Q_{T M}$ is the measured discharge, and

$Q_{m b}$ is the discharge not measured because of the moving bed.

A detailed analysis of the application of the loop method was conducted by the USGS (Mueller and Wagner, 2006).

Careful field procedures are absolutely critical to the successful application of the loop method. Failure to accurately return the instrument to the starting point, an uncalibrated or improperly calibrated compass, inaccurate headings caused by changes in the magnetic interference in the cross section, or loss of bottom track during the loop will result in unpredictable errors that render this technique unusable. Current research, which is limited by the amount of available field data, indicates that site-specific characteristics and datacollection techniques, such as the shape of the measurement section, distribution of the moving-bed velocity, time spent at the banks, boat speed, and uniformity of the boat speed, can affect the discharge correction by 10 percent or greater. When applied properly, however, this technique should consistently yield total corrected discharges that are within 5 percent of the actual discharge. The loop method cannot be applied with an ADCP that does not have a compass because a valid heading is required.

After completion of a loop method moving-bed test, two methods described by Mueller and Wagner (2006) can be used to correct discharge biased by a moving bed-the mean correction method and distributed correction method. The mean correction method is simple and can be completed with manual computations. The distributed correction method accounts for the velocity distribution and shape of the cross section and requires a computer program.

\section{Mean Correction Method}

A simple method for computing the discharge not measured because of the moving bed is to compute the mean moving-bed velocity and multiply it by the cross-sectional area (measured perpendicular to the flow).

$$
Q_{m b}=\bar{V}_{m b} A
$$

where

$$
\begin{aligned}
& \bar{V}_{m b} \text { is the mean velocity of the moving bed and } \\
& A \quad \text { is the cross-sectional area perpendicular to the } \\
& \text { mean flow direction. }
\end{aligned}
$$

The mean moving-bed velocity can be computed from the distance the ADCP appeared to have moved upstream from the starting position (loop-closure error) and the time required to complete the loop. These data are readily available from most commercial software used to measure discharge with ADCPs. 
The cross-sectional area must be computed perpendicular to the mean flow direction. If the cross-sectional area is computed parallel to the ship track measured by the ADCP, then the cross-sectional area will be computed based on a ship track that is distorted in the upstream direction by the moving bed. The distortion of the ship track by a moving bed will result in a cross-sectional area that is too large. The mean correction method is simple to apply but does not account for the crosssection shape and spatial correlation of the sediment transport with the spatial distribution of the discharge in the cross section. Therefore, streams with high spatial variability in sediment transport and discharge distributions may not be properly represented by using a single mean moving-bed velocity to correct the measured discharge.

\section{Distributed Correction Method}

The actual moving-bed velocity at any point in the stream is unknown, but the moving-bed velocity is assumed to be proportional to the near-bed water velocity (Callede and others, 2000). The distributed correction method uses a $1 / 6$ th power curve to provide a consistent estimate of the near-bed velocity at any point in the cross section. To determine the distributed loop method correction, the measured mean moving-bed velocity from the loop is distributed to each ADCP profile by a ratio of near-bed velocity for each profile and the mean nearbed velocity for the cross section. The distributed moving-bed velocities are then applied to the water and boat velocities for all depth cells in each of the corresponding profiles in the measured portion of the cross section to determine the corrected measured discharge. The total discharge measured by an ADCP consists of a measured portion and estimates of discharge in the unmeasured top, bottom, left, and right edges. The final corrected measured discharge is computed using the ratio of the corrected and uncorrected measured portion of the discharge to correct the sum of the measured and top and bottom estimated discharges. Water velocities near the bank are assumed to be sufficiently low as to not cause a moving bed; therefore, no correction is applied to the left and right edge discharges.

Distribution of the mean moving-bed velocity based on near-bed velocities requires a consistent method of determining near-bed velocities at each measured vertical. Due to side-lobe interference, the lower 6-13 percent, approximately, of each velocity profile is unmeasured. In addition, invalid velocity measurements are common in the lower portions of the profile. Simply using the last valid velocity in each measured velocity profile would result in near-bed velocities at various distances from the streambed. The 1/6th power law has been shown to be consistent with a logarithmic velocity profile and is commonly used to estimate the unmeasured top and bottom discharges for ADCP measurements (Chen, 1989; Simpson and Oltmann, 1993). The near-bed velocity is computed by fitting the $1 / 6$ th power law through zero at the bed and through the mean velocity of the last two valid velocity measurements in the profile.
The computations associated with the distributed correction are best performed using a computer program. One such program, LC, has been developed to perform these computations. Recently (2013), LC has been enhanced to check the quality and validity of the loop. In addition, the capabilities of LC have been incorporated directly into WinRiver II and RiverSurveyor Live. LC computes the magnitude and direction of the distance made good (DMG) from the starting and ending points of the loop. The following quality-assurance checks are made to determine if the loop is valid.

- The navigation reference is set to bottom track; if not, a message to set the reference to bottom track is given to the user.

- The mean water velocity is computed and, if it is less than $0.8 \mathrm{ft} / \mathrm{s}$, a warning message indicating the loop may not be an accurate method for determining moving-bed conditions is displayed.

- The percentage of invalid bottom-track data is determined. If the percentage exceeds 5 percent, a warning is displayed. If it exceeds 20 percent, the loop is invalid.

- The difference in flow direction is computed for the out and return portions of the loop to assess potential heading errors. If the difference in flow direction is greater than 3 degrees and the difference is greater than the 95 percent uncertainty in the flow direction computations and the potential error in discharge exceeds 5 percent, the loop is invalid.

The thresholds that must be met to identify a moving-bed condition include:

- The loop is valid based on the quality checks.

- The direction of the closure error must be $+/-45$ degrees from the upstream flow direction.

- The computed moving-bed velocity is greater than $0.04 \mathrm{ft} / \mathrm{s}$.

- The moving-bed velocity is greater than 1 percent of the mean moving-bed velocity.

The program then computes a corrected discharge for each transect and the corrected mean discharge for the whole measurement. The stand-alone version of LC can be obtained from the USGS at http://hydroacoustics.usgs.gov.

\section{Multiple Moving-Bed Test Method}

The second GPS alternative requires the hydrographer to conduct multiple stationary moving-bed tests across the stream. The advantages to using the multiple moving-bed tests are (1) GPS is not required, (2) no compass calibration is required, and (3) the method can be used where bottom track cannot be adequately maintained to apply the loop method. 
The disadvantages of this method are (1) multiple moving-bed tests are required, (2) ADCP movement is not corrected during the moving-bed tests, (3) the procedure is time consuming, (4) an accurate cross-sectional area projected perpendicular to the mean flow direction is required for all methods except when using the Stationary Moving-Bed Analysis (SMBA) software, and (5) although the discharges are corrected, measured velocities are still uncorrected (biased low).

\section{Field Procedures}

1. Conduct at least three stationary moving-bed tests equally spaced throughout the cross section, and note the location of each test by measuring the distance from shore (if using the subsection method). Additional moving-bed tests will result in a more accurate discharge correction.

2. Each moving-bed test should be 5 to 10 minutes in duration. For details, see the Stationary Test with No GPS section under the Methods to Identify a Moving Bed section.

3. Make a moving-boat ADCP discharge measurement.

\section{Processing Procedures}

The corrected discharge can be computed from the multiple moving-bed tests by using one of three computation methods: (1) subsection method, (2) average moving-bed velocity method, and (3) distributed method using the SMBA software.

\section{Subsection Method}

1. Playback each moving-bed test and determine the mean moving-bed velocity $\left(\bar{V}_{m b}\right)$ for each section, which can be computed from the distance the ADCP appeared to have moved upstream from the starting position and the time required to make each stationary moving-bed test. SMBA can also be used to compute the moving-bed velocity and is required for ADCPs that do not have a compass.

$$
\bar{V}_{m b}=\frac{D_{u p}}{T}
$$

where

$$
\begin{aligned}
& D_{u p} \text { is the DMG in the upstream direction (straight- } \\
& \text { line distance from starting point to ending } \\
& \text { point), and } \\
& T \quad \text { is the time required to complete the test. }
\end{aligned}
$$

2. Process the first transect and manually subsection it such that the moving-bed tests are located near the middle of each subsection.
3. Determine the cross-sectional area perpendicular to the mean flow direction $\left(A_{i}\right)$ for each subsection. The crosssectional area will be affected by the moving bed unless corrected to be perpendicular to the mean flow direction.

4. Compute the corrected discharge for the transect

$$
Q_{\text {corrected }}=Q_{\text {measured }}+\sum\left(\bar{V}_{m b i} A_{i}\right)
$$

where

$$
\begin{aligned}
& \bar{V}_{m b i} \quad \text { is the moving-bed velocity in the } \\
& \text { subsection } i \text {, } \\
& A_{i} \quad \text { is the cross-sectional area perpendicular } \\
& \text { to flow in subsection } i \text {, and } \\
& Q_{\text {measured }} \text { is the total unadjusted (biased) discharge } \\
& \text { for the transect. }
\end{aligned}
$$

5. Follow steps 2 through 4 for each transect used during the discharge measurement. The mean of the $Q_{\text {corrected }}$ for all transects is the corrected discharge for the measurement.

\section{Average Moving-Bed Method}

1. As with the subsection method, the first step is to compute the moving-bed velocity for each moving-bed test by dividing the DMG by time (eq. B6) or by using SMBA.

2. Sum the moving-bed velocities for each test and divide by two more than the number of moving-bed tests, which will account for the absence of a moving bed at both edges of water. Therefore, if three moving-bed tests were made, the sum of the moving-bed test velocities would be divided by 5 .

3. The final step is to compute the corrected discharge. Calculate the discharge correction by multiplying the average moving-bed velocity computed in the previous step by the area of the cross section measured perpendicular to the mean flow direction. Then add the discharge correction to the measured discharge to determine the corrected discharge.

$$
Q_{\text {corrected }}=Q_{\text {measured }}+\left(\bar{V}_{m b} A_{p f}\right)
$$

where

$$
\begin{gathered}
Q_{\text {measured }} \begin{array}{l}
\text { is the total unadjusted (biased) discharge } \\
\text { for the transect, }
\end{array} \\
\bar{V}_{m b} \\
\text { is the average moving-bed velocity in the } \\
\text { measurement section (from step 2), } \\
\text { and } \\
A_{p f} \quad \begin{array}{l}
\text { is the average cross-sectional area } \\
\text { perpendicular to flow in the transect. }
\end{array}
\end{gathered}
$$




\section{Distributed Method Using the SMBA Software}

The distributed method uses the SMBA computer software to automate the correction process. The SMBA program can be obtained from the USGS at http://hydroacoustics. usgs.gov. A distributed method similar to that used in the loop method (Mueller and Wagner, 2006) was developed for multiple moving-bed tests. Instead of using the mean movingbed velocity measured from the loop method, the SMBA program distributes the average moving-bed velocity from the multiple stationary moving-bed tests to each ensemble computing a linear relation between the near-bed velocities and the moving-bed velocities from the stationary tests and using near-bed velocity for each ensemble to compute the distributed moving-bed velocity for each ensemble. The distributed moving-bed velocities are then applied to the water and boat velocities for all depth cells in each of the corresponding ensembles in the measured portion of the cross section to determine the corrected discharge.

\section{Mid-Section Method}

The third GPS alternative is referred to as the mid-section method and uses the ADCP to measure discharge in a manner similar to a mid-section measurement with a mechanical meter. The hydrographer collects $20-25$ velocity profiles with the ADCP at selected locations across the stream. A stationary water-velocity profile is collected by holding the ADCP in a specific location for a specified time and then averaging the data to obtain a mean velocity profile or a depth-integrated mean velocity at that location. The mid-section method is not biased by moving-bed conditions because the ADCP is held stationary for each measurement, and bottom tracking is not referenced; therefore, the velocity measured by the ADCP is only the water velocity. The boat reference must be set to "none" in the software when making a mid-section measurement in moving-bed conditions, or the measured velocity will still be biased by the moving bed.
SonTek and Teledyne RD Instruments have developed software that supports mid-section discharge measurements. The velocity and depth data are collected from the ADCP, and the discharge is computed by using the mid-section method. The width for each measurement section is computed as half the distance from the current section to the previous section, plus half the distance from the current section to the next section. This width is then multiplied by the depth measured during the velocity measurement to compute an area for each section. Discharge for each of the sections is then computed by multiplying the mean water velocity by the cross-sectional area and then the incremental discharges are summed to determine the total discharge.

The advantages to using the mid-section method are (1) a valid boat speed reference (bottom track or GPS) is not required, (2) correct velocities are measured, (3) dischargemeasurements procedures are familiar to hydrographers, and (4) software is available to automate the procedure. The disadvantages are (1) positions must be measured manually, (2) angled flow can introduce errors in the velocity measurement and must be handled carefully, (3) appropriate sampling times are required for each measurement, (4) the ADCP must be kept stationary because ADCP movement is not corrected, and (5) the entire cross section is not measured.

\section{Azimuth Method}

The fourth GPS alternative is referred to as the azimuth method. This method is difficult to accurately conduct in the field and is not recommended. The azimuth method is based on the fact that as an ADCP moves across the stream, a moving bed will cause the bottom-track-based ship track to be distorted in the upstream direction. If the azimuth between the starting and ending point of an ADCP transect is known and the compass on the ADCP has been properly calibrated, the difference in azimuth of the course of the transect from that manually measured and that determined by the ADCP

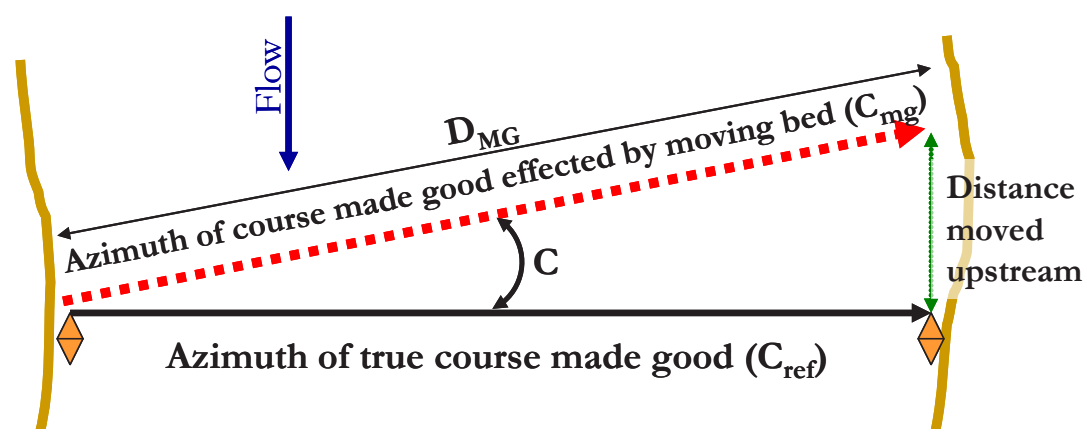

Figure B-8. The azimuth method. 
is a measure of the moving-bed velocity and can be used to compute a correction factor for the transect (fig. B-8). The advantages to using the azimuth method are that a GPS is not required, and computations are simple. The disadvantages are (1) start and stop markers must be established, (2) the accuracy is dependent upon the measured azimuth and actual start and stop locations, (3) a compass calibration is required, (4) an accurate cross-sectional area projected perpendicular to the mean flow direction is required, (5) measured velocities are still biased low, (6) bottom tracking must be maintained, and (7) field applications have shown variable accuracy due to errors in azimuth measurements.

\section{Field Procedures}

1. Establish starting and ending points and mark with buoys or other markers. Start and stop the measurement as closely as possible to these points (within $1 \mathrm{ft}$, if possible).

2. Use a handheld compass to measure the azimuth from one buoy or marker to the other, and record this number.

3. Calibrate the compass on the ADCP using the internal calibration routines.

4. Collect data as you would for a typical discharge measurement, but take special care to start and stop the transects at the buoys or markers.

\section{Processing Procedures}

1. Process the data as you would for a typical discharge measurement.

2. For each transect, note the DMG, the course made good (CMG), and the total time for measuring along the transect.

3. Determine the difference between the measured azimuth and the CMG, and name this difference, $C$. This angle should be in the upstream direction (fig. B-8).

$$
C=\left|C_{m g}-C_{r e f}\right|
$$

where

$$
\begin{aligned}
& C \text { is the angle between the manually measured } \\
& \text { and ADCP-measured course, } \\
& C_{m g} \text { is the azimuth of CMG measured by the ADCP, } \\
& \text { and } \\
& C_{r e f} \text { is the azimuth of CMG measured manually with } \\
& \text { a compass. }
\end{aligned}
$$

4. The moving-bed correction factor for each transect can be computed as:

$$
V_{m b}=\frac{D_{M G} \times \sin (C)}{T}
$$

where

$$
\begin{array}{ll}
V_{m b} \text { is the moving-bed velocity, } \\
D_{M G} \text { is the DMG, and } \\
T \quad \text { is the total measurement time for the transect. }
\end{array}
$$

5. Determine the cross-sectional area perpendicular to the mean flow direction $(A)$ for the transect. The crosssectional area will be affected by the moving bed unless corrected to be perpendicular to the mean flow direction.

6. Compute the corrected discharge for the transect

$$
Q_{\text {corrected }}=Q_{\text {measured }}+\left(V_{m b} A\right)
$$

where

$$
\begin{aligned}
& V_{m b} \quad \text { is the moving-bed velocity for the } \\
& \text { transect, } \\
& \text { A is the cross-sectional area perpendicular } \\
& \text { to flow for the transect, and } \\
& Q_{\text {measured }} \text { is the total unadjusted (biased) discharge }
\end{aligned}
$$

7. Follow steps 2 through 6 for each transect used as part of the discharge measurement. The mean of the $Q_{\text {corrected }}$ for all transects is the corrected discharge for the measurement. 


\section{Appendix C - Description of Water-Tracking Modes}

ADCPs typically have water-tracking modes that are optimized for different water depths and velocities. Modes designed for deeper water and faster velocities have greater random errors in the measured velocity. Special configuration and processing of the acoustic pulse(s) can reduce random errors in velocity measurements and allow velocity measurements to be made in shallow water, but this typically imposes a restriction on the conditions that can be measured. Brief descriptions of the water-tracking modes currently (2013) available for the SonTek and the Teledyne RD Instruments (TRDI) ADCPs are presented to provide users with a better understanding of the advantages and limitations of these modes. The TRDI Rio Grande and StreamPro have watertracking modes that must be configured a priori. Understanding these modes will help optimize the ADCP for making measurements in a variety of site conditions and (or) pick the optimum site. The TRDI RiverRay and SonTek RiverSurveyor both have auto-adaptive configuration of the water modes. The characteristics and ranges of depth and velocity for the various auto-adaptive modes will be discussed to provide the user a better understanding of how the ADCP measures velocity in different conditions.

\section{TRDI Rio Grande and StreamPro Water Modes}

The TRDI Rio Grande has five water modes, and the StreamPro has two water modes available to optimize the ADCP performance for the water velocity, turbulence level, and depth being measured. Because of the potential for large errors in the measured water velocity using Rio Grande water mode 8 , the use of water mode 8 is discouraged, and no discussion of this mode is provided. The other four available Rio Grande water modes include (1) water mode 1-generalpurpose mode (2) water modes 5 and 11-low-velocity and low-turbulence modes, and (3) water mode 12-a fast ping-rate mode. Although the software for the Rio Grande configures the appropriate mode for the user, the user should understand the operation and limitations of the modes in order to collect quality data, even in difficult conditions. The two water modes available in the StreamPro include a generalpurpose mode similar to the Rio Grande water modes 1 and 12 and a low-velocity (less than $0.8 \mathrm{ft} / \mathrm{s}$ ) mode.

\section{Rio Grande Mode 1}

Water mode 1 (WM1) is a general-purpose water mode for TRDI ADCPs (Teledyne RD Instruments, 2003). WM1 typically is used in streams with a mean depth greater than $5 \mathrm{ft}$ and (or) with velocities exceeding $3.3 \mathrm{ft} / \mathrm{s}$. WM1 also can be used to measure slower velocities where water modes 5 and 11 will not work (see discussion of Rio Grande Modes 5/11). All other modes can be explained as a modification or enhancement of WM1. WM1 measures the Doppler shift using two phase-coded broadband pulses separated by a user-specified lag. The lag is inversely proportional to the radial ambiguity velocity, which is the maximum relative radial velocity (including boat speed and water speed) that can be accurately measured by the instrument. If the maximum boat velocity is assumed to equal the water velocity, an appropriate radial ambiguity velocity can be calculated to be approximately equal to the downstream water velocity (Teledyne RD Instruments, 2003). The recommended radial ambiguity velocity range is from 5.7 to $23 \mathrm{ft} / \mathrm{s}$. The depth-cell size and lag between the pulses, and thus the ambiguity velocity, are key variables in determining the standard deviation of the random instrument noise present in velocity measurements. The recommended and commonly used depth-cell sizes for $600-\mathrm{kHz}$ and $1,200-\mathrm{kHz}$ instruments are $1.6 \mathrm{ft}$ and $0.8 \mathrm{ft}$, respectively. This results in standard deviations of instrument noise of between 0.4 and $0.7 \mathrm{ft} / \mathrm{s}$, depending on the radial ambiguity velocity value. The standard deviations will increase greatly for smaller depth-cell sizes.

\section{Rio Grande Modes 5/11}

Water modes 5 and 11 (WM5 and 11) are pulse-to-pulse coherent modes that use short phase-encoded broadband pulses. Similar to WM1, two pulses are transmitted; however, unlike WM1, the lag between the pulses for WM5 and 11 is long and variable. The lag is equal to the time for the first pulse to travel to the bottom and back. After the signal from the first pulse is received at the transducer face, the ADCP transmits the second pulse. The ADCP determines how long to wait before sending the second transmission from the water-depth-measurement part of the bottom-track measurement. This creates a very long lag with extremely low velocity single-ping standard deviations, typically less than $0.06 \mathrm{ft} / \mathrm{s}$ with depth-cell sizes of $0.16 \mathrm{ft}$ and $0.33 \mathrm{ft}$ for $1,200-\mathrm{kHz}$ and $600-\mathrm{kHz}$ instruments, respectively.

A long lag can cause a problem with residence time. Residence time is the time that a group of scatterers remains in a region for both pulses to ensonify the scatterers. If the velocity is very slow, most scatterers will remain in the same region for the time it takes both pulses to pass. Some decorrelation will occur because new scatterers enter the region as others leave. Nevertheless, if the number of scatterers entering and leaving is small, the correlation will be high and the data will be valid. If the velocity is too fast and the scatterers move 
more than one-fourth to one-half of the transducer diameter with new scatterers introduced, the correlation between the two pulses will be low, and the data will be invalid.

The low-velocity standard deviations for WM5 and 11 make them excellent choices for making discharge measurements where stream conditions permit use of these modes. The characteristics of these water modes that produce a low-velocity standard deviation also create significant limitations in the application of these water modes. Because of the long lag, the ambiguity velocity is very low and could render the modes nearly useless; however, an ambiguity-resolving depth cell is used to help resolve the ambiguity and allow a lower ambiguity velocity than the actual velocity of the water (Teledyne RD Instruments, 2003). The time-dilation technique used to determine the velocity in the ambiguity-resolving depth cell and the bin-to-bin tracking algorithm used to apply the ambiguity velocity to consecutive depth cells limit the use of WM5 and 11 to conditions with low turbulence and low shear. In WM5, the ambiguity-resolving depth cell extends from the end of the blank to the lesser of $2 \mathrm{ft}$ or 85 percent of the shallowest beam, and the ambiguity-resolving depth cell must be at least $1 \mathrm{ft}$ long. In WM11, the ambiguity-resolving depth cell is centered between the end of the blank and 85 percent of the shallowest beam and has a maximum length of $7.5 \mathrm{ft}$. Unlike WM5, which requires an ambiguity-resolving depth cell of at least $1 \mathrm{ft}$, WM11 continues to operate but stops computing ambiguity when the ambiguity-resolving depth cell becomes smaller than $1 \mathrm{ft}$. Shear caused by coarse bed material will often cause these modes to fail. Due to the short pulses and long lag, WM5 and 11 are limited to shallow depths (less than $13 \mathrm{ft}$ for $1,200 \mathrm{kHz}$ and less than $26 \mathrm{ft}$ for $600 \mathrm{kHz}$ ) and slow velocities (typically less than $3.3 \mathrm{ft} / \mathrm{s}$ ).

\section{Rio Grande Mode 12}

WM12 was designed to allow data collection in streams shallower than could be measured with WM1 and with velocities greater than could be measured with WM5 and 11 . WM12 is essentially a fast ping rate WM1. The concept for WM12 is based on the fact that random error is reduced by the square root of the number of samples. The velocity standard deviation increases as the WM1 depth-cell size is reduced. One method of reducing the velocity standard deviation is to collect and average more measurements. Averaging multiple WM1 pings (two pulses for each ping) only realizes gains in the transmission time of the data to the computer. WM12 is designed so that the heading and pitch-and-roll sensors are only read at the beginning of the averaging period, the individual pings are averaged in phase space, and only the average is transformed into water velocities. This design eliminates some of the processing overhead and potential for averaging ambiguity velocity errors associated with WM1.

The ping rate for WM1 is approximately $2-3 \mathrm{~Hz}$, and the ping rate for WM12 is $10-20 \mathrm{~Hz}$ (depending on the number of depth cells). However, since the heading and pitch-and-roll sensors are sampled only at the beginning of the averaging period, changes in heading, speed, pitch, or roll will lead to errors in the measured velocity. Thus, the sampling period needs to be short; generally 1 second or less is recommended. Although WM12 was designed for use with small depth cells in shallow water, WM12 can be used anywhere WM1 can be used, provided the ambiguity velocity is set properly as in WM1. The velocity standard deviation for WM12 cannot be stated as broadly as for the other water modes because WM12 is more configurable and the velocity standard deviation is dependent on the sampling period, the depth-cell size, the number of pings fit into the sampling period, and the ambiguity velocity.

\section{StreamPro Mode 12}

The StreamPro does not use water mode 12 as implemented in the Rio Grande, rather water mode 12 in the StreamPro (referred to hereafter as WM12sp) is more similar to a modified multi-ping Rio Grande water mode 1, which pings fast. For every water ping (WP) in WM12sp, the instrument sends and processes eight full WM1 pings. Each ping is fully processed, stored, and averaged with the other seven pings. Users cannot control the eight pings. The user can control the WP setting, which by default is set to 6 to obtain an ensemble output rate of about 1 second. With default settings, $48 \mathrm{WM} 1$ pings are averaged together and reported as the ensemble output. Ambiguity errors could occur in the individual pings and would be hidden by the averaging process; however, the StreamPro has a fixed ambiguity velocity of $11 \mathrm{ft} / \mathrm{s}$, making an ambiguity error nearly impossible for the StreamPro applications. For WM12sp in the long-range mode, the number of pings processed is reduced to maintain an ensemble output rate of about 1 second. The custom commands for WM12sp are limited to the blanking distance $(0-1.6 \mathrm{ft})$, number of depth cells $(0-20$ depth cells in standard configuration and $0-30$ with the long range option), and depth-cell size $(0.06-0.33 \mathrm{ft}$ in standard configuration and $0.06-0.66 \mathrm{ft}$ with long range option).

\section{StreamPro Mode 13, Water Mode C, Low Noise Mode}

The StreamPro has a second water mode that has a lower random error than does WM12sp and that can be used to measure water velocities less than about $0.8 \mathrm{ft} / \mathrm{s}$ in water less than $3.3 \mathrm{ft}$ deep. WM13 is a long-lag pulse coherent mode, which transmits multiple pulses at different lags. WM13 has no ambiguity-resolving depth cell as in Rio Grande WM5 and 11; the ambiguity in each depth cell is resolved using a proprietary approach. 


\section{TRDI RiverRay Auto-Adaptive Configurations}

The RiverRay uses two types of depth cells: standard depth cells and surface depth cells. Surface depth cells are used to measure closer to the transducer face than would be possible with the standard depth cells. Surface depth cells are always $0.33 \mathrm{ft}(10 \mathrm{~cm})$ in size and use a pulse coherent ping configuration with a short transmit length and a proprietary ambiguity resolving scheme (Den Herder, 2011). Pings for both surface and standard depth cells are configured in groups with multiple pings per group and typically multiple groups per ensemble. Each group has a specific purpose: data, ambiguity resolution, or pulse coherent mode testing. All ping groups use a variant of WM12 phase plane averaging to minimize sampling time and maximize the precision of each group (Den Herder, 2011). The raw data are recorded in beam coordinates.

The RiverRay's auto-adaptive configuration algorithm varies the standard depth-cell size, standard depth-cell ping configuration, and number of surface depth cells based on depth and hydraulic conditions. The size of the standard depth cell $(0.33,0.66,1.31$, or $2.62 \mathrm{ft}$ or $10,20,40$, or $80 \mathrm{~cm})$ is based on the range to bottom of the shallowest beam except for the transition between 0.66 and $1.31 \mathrm{ft}$ size, which is based on the deepest beam. The first depth cell is always $0.33 \mathrm{ft}$ $(10 \mathrm{~cm})$ in size and centered at $0.82 \mathrm{ft}(25 \mathrm{~cm})$ from the transducer (Den Herder, 2011). Standard depth cells are shifted deeper into the water column, as needed, to ensure matched depth-cell boundary positions regardless of depth-cell size, and a sufficient number of surface depth cells are collected to provide a continuous velocity profile (fig. C-1).
Standard depth cells use either a pulse coherent or standard (mode 1) ping configuration. A pulse coherent ping configuration is used when (a) the range to bottom is less than $16.4 \mathrm{ft}$, (b) good depths are measured on all four beams, (c) surface depth cells have valid data on all four beams, (d) there is good correlation on a test ping, and (e) the depth multiplied by the velocity is less than $4.9 \mathrm{ft}^{2} / \mathrm{s}$. The lag for pulse coherent pings varies by beam and is based on the depth of that beam. A mode 1 type ping configuration is used for standard depth cells if any of the conditions for using a pulse coherent ping configuration are not met. A summary of the various configurations is presented in table $\mathrm{C}-1$.

\section{SonTek RiverSurveyor Auto-Adaptive Configuration}

SonTek's auto-adaptive configuration algorithm for the RiverSurveyor M9/S5 supports use of multiple frequencies, variable depth-cell sizes, and pulse-coherent, broadband, and incoherent ping configuration and processing techniques. The RiverSurveyor has parallel processing capabilities that allow the system to ping while it is processing the return from the previous set of pings. The continuous processing allows the system to optimize the next ping configuration for the conditions encountered. Between 8 and 10 different ping configurations may be used. In the case of the M9, the bottom track and water track may use different frequencies. During data collection, the heading, pitch, and roll sensors are read multiple times, the temperature sensor is read once, and the type and number of water, bottom, and vertical transducer pings are

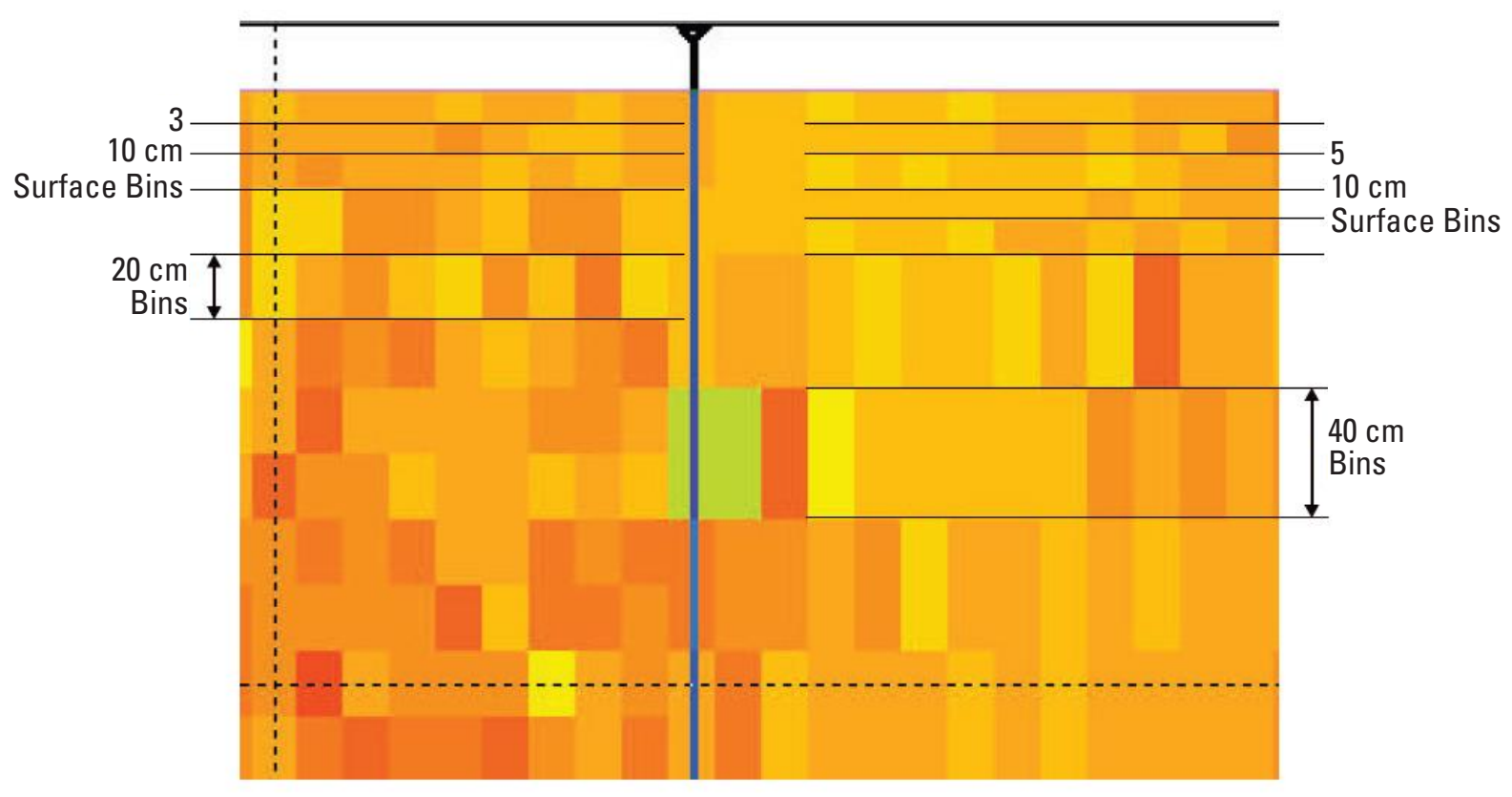

Figure C-1. Illustration of variable number of surface depth cells used to maintain consistent depth-cell boundaries as the standard depth-cell size change (Teledyne RD Instruments, 2009, p. 4, used with permission). 
Table C-1. Characteristics of Teledyne RD Instrument RiverRay acoustic Doppler current profiler auto-adaptive configuration.

[ft, feet; ft/s, feet per second; cm, centimeter; NA, not applicable; >, greater than]

\begin{tabular}{|c|c|c|c|c|c|}
\hline \multirow[b]{2}{*}{ Range to bottom, in ft } & \multicolumn{2}{|c|}{ Deep depth cell } & \multicolumn{3}{|c|}{ Surface depth cell } \\
\hline & $\begin{array}{l}\text { Depth-cell size, } \\
\text { in } \mathrm{ft}\end{array}$ & $\begin{array}{l}\text { 1-second standard } \\
\text { deviation }{ }^{\mathrm{a}} \text {, in } \mathrm{ft} / \mathrm{s}\end{array}$ & $\begin{array}{c}\text { Number of } \\
\text { surface cells }\end{array}$ & $\begin{array}{l}\text { 1-second standard } \\
\text { deviation }{ }^{\mathrm{a}} \text {, in } \mathrm{ft} / \mathrm{s}\end{array}$ & $\begin{array}{c}\text { Depth-cell size, } \\
\text { in } \mathrm{ft}\end{array}$ \\
\hline 1.5-6.6 (Pulse coherent) & $0.33(10 \mathrm{~cm})$ & $0.11-0.15$ & 0 & N/A & N/A \\
\hline $2.3-6.6$ & $0.33(10 \mathrm{~cm})$ & $0.37-0.48$ & $0-2$ & $0.11-0.15$ & $0.33(10 \mathrm{~cm})$ \\
\hline 6.6-16.4 (Pulse coherent) & $0.66(20 \mathrm{~cm})$ & $0.03-0.07$ & 3 & 0.11 & $0.33(10 \mathrm{~cm})$ \\
\hline $6.6-16.4$ & $0.66(20 \mathrm{~cm})$ & 0.09 & 3 & 0.11 & $0.33(10 \mathrm{~cm})$ \\
\hline $16.4-32.8$ & $1.31(40 \mathrm{~cm})$ & 0.21 & 5 & 0.11 & $0.33(10 \mathrm{~cm})$ \\
\hline$>32.8$ & $2.62(80 \mathrm{~cm})$ & 0.16 & 5 & 0.11 & $0.33(10 \mathrm{~cm})$ \\
\hline
\end{tabular}

${ }^{\mathrm{a}}$ Approximate values may vary with hydraulic conditions.

optimized to provide the lowest water-velocity standard deviation that can be achieved at a 1 second update rate.

The RiverSurveyor S5 has four 3-MHz profiling beams angled at 25 degrees and one 1-MHz vertical beam that measures depth only. All water and bottom tracking is accomplished with the $3-\mathrm{MHz}$ beams. The water tracking may be either pulse coherent or incoherent depending on depth and velocity. For depths up to $4.9 \mathrm{ft}$ and water velocity of about $1.3 \mathrm{ft} / \mathrm{s}$ at the depth (faster velocities can be measured at shallower depths), the S5 uses $0.07 \mathrm{ft}$ depth cells and pulse coherent ping configuration and processing. Ambiguity is resolved using a proprietary method. If the depth and (or) velocity exceed the capabilities of the pulse coherent ping type, incoherent pings are used. For incoherent pings, the depth-cell size is $0.33 \mathrm{ft}$ for depths less than $6.6 \mathrm{ft}, 0.66 \mathrm{ft}$ for depths between 6.6 and $13.1 \mathrm{ft}$, and $1.31 \mathrm{ft}$ for depths greater than $13.1 \mathrm{ft}$ (SonTek, 2012).

The RiverSurveyor M9 has four 3-MHz and four 1-MHz profiling beams angled at 25 degrees, and one $500-\mathrm{kHz}$ vertical beam that measures depth only. Both the $3-\mathrm{MHz}$ and $1-\mathrm{MHz}$ frequencies are used for bottom tracking and water tracking depending on water depth. Bottom tracking uses the 3-MHz frequency for depths less than about $2.5 \mathrm{ft}$ and the $1-\mathrm{MHz}$ frequency for greater depths. The frequency, depth-cell size, and ping type for water tracking are dependent on both the water depth and velocity (table C-2).

Table C-2. Summary of water-tracking frequency, depth-cell size, and ping type for RiverSurveyor M9.

[MHz, megahertz; ft, feet; ft/s, feet per second; <, less than; >, greater than]

\begin{tabular}{ccccl}
\hline $\begin{array}{c}\text { Frequency, } \\
\text { in MHz }\end{array}$ & Depth, in ft & $\begin{array}{c}\text { Maximum } \\
\text { velocity, } \\
\text { in ft/s }\end{array}$ & $\begin{array}{c}\text { Depth-cell size, } \\
\text { in ft }\end{array}$ & Ping type \\
\hline 3 & $<4.9$ & $1.3^{\mathrm{a}}$ & 0.07 & Coherent \\
1 & $<16.4$ & $1.3^{\mathrm{a}}$ & 0.20 & Coherent \\
3 & $<6.6$ & $>20 \mathrm{ft} / \mathrm{s}$ & 0.33 & Incoherent \\
3 & $6.6-13.1$ & $>20 \mathrm{ft} / \mathrm{s}$ & 0.66 & Incoherent \\
3 & $13.1-16.4$ & $>20 \mathrm{ft} / \mathrm{s}$ & 1.31 & Incoherent \\
1 & $15.4-32.8$ & $>20 \mathrm{ft} / \mathrm{s}$ & 1.64 & Incoherent \\
1 & $32.8-65.6$ & $>20 \mathrm{ft} / \mathrm{s}$ & 3.28 & Incoherent \\
1 & $>65.6$ & $>20 \mathrm{ft} / \mathrm{s}$ & 6.56 & Incoherent \\
\hline
\end{tabular}

${ }^{a}$ This is the maximum velocity at the specified maximum depth. Shallower depths will permit greater velocities (SonTek, 2012). 


\section{Appendix D - Beam-Alignment Test}

The accuracy of the bottom-track and water-track velocities used in the computation of discharge is dependent on the conversion of the velocities measured along the beam (beam velocities) into orthogonal coordinates (x, $\mathrm{y}$, and $\mathrm{z}$ ). This conversion is accomplished by multiplying the beam velocities with a transformation matrix that accounts for the threedimensional orientation of the beams. The beam-alignment test checks the accuracy of the transformation matrix by comparing the straight-line distance (commonly called the distance made good) measured by bottom tracking to a known distance in the laboratory or to a distance measured by GPS in the field.

\section{Introduction}

One source of error in ADCP measurements is misalignment of beams in the instrument. This error can be checked by the user. The equations presented in Appendix A assume that the beams are in perfect alignment and result in nominal transformation matrices. The nominal transformation matrix for a 20-degree four-beam piston transducer system using TRDI's beam numbering system (TRDI Rio Grande and TRDI StreamPro), is

$$
\left[\begin{array}{cccc}
1.4619 & -1.4619 & 0 & 0 \\
0 & 0 & -1.4619 & 1.4619 \\
0.2661 & 0.2661 & 0.2661 & 0.2661 \\
1.0337 & 1.0337 & -1.0337 & -1.0337
\end{array}\right]
$$

The nominal transformation matrix for a 25-degree four-beam piston transducer system (SonTek RiverSurveyor M9 $3 \mathrm{MHz}$ and S5 $3 \mathrm{MHz}$, transducers numbered according to SonTek's convention, which is different than equations in Appendix A) is

$\left[\begin{array}{cccc}1.1831 & 0 & -1.1831 & 0 \\ 0 & 1.1831 & 0 & -1.1831 \\ -0.2758 & -0.2758 & -0.2758 & -0.2758 \\ 0.5517 & -0.5517 & 0.5517 & -0.5517\end{array}\right]$

The nominal transformation matrix for a 25-degree four-beam piston transducer system with transducers Janus configuration rotated 45 degrees (SonTek RiverSurveyor M9 1 MHz, transducers numbered differently than equations in Appendix A) is

$\left[\begin{array}{llll}0.8366 & -0.8366 & -0.8366 & 0.8366 \\ 0.8366 & 0.8366 & -0.8366 & -0.8366 \\ -0.2758 & -0.2758 & -0.2758 & -0.2758 \\ 0.5517 & -0.5517 & 0.5517 & -0.5517\end{array}\right]$

The nominal transformation matrix for the 30 -degree four-beam phased array TRDI RiverRay is

$\left[\begin{array}{cccc}1 & -1 & 0 & 0 \\ 0 & 0 & -1 & 1 \\ 0.2887 & 0.2887 & 0.2887 & 0.2887 \\ 0.7071 & 0.7071 & -0.7071 & -0.7071\end{array}\right]$

If the beams were misaligned during manufacturing, a custom transformation matrix to correct the misalignment is required. If the wrong transformation matrix is used, the water and bottom-track velocities will be consistently biased. The validity of the transformation matrix stored in the instrument can be determined by computing the ratio of the bottom-track and GPS straight-line distances over a long course, provided the instrument has a compass. Note: Procedures presented herein may not be practical for field evaluations of StreamPro and M9 ADCPs. The StreamPro was designed for deployment in a float with the transducers in a fixed orientation. Rotation of the instrument to accomplish the beam-alignment test would require a special mount. The 1-MHZ beams in an M9 requires that the water depth remain more than about $2.5 \mathrm{ft}$ deep, which should not be a problem; however, the 3-MHz beams in an M9 requires the test to be completed in water less than about $2.5 \mathrm{ft}$ deep, which may not be practical for field evaluations.

\section{Description of Procedure}

The beam-alignment test is conducted in the field by traversing a long (1,200-2,500 ft) course at a constant compass heading and speed while simultaneously recording GPS (GGA or VTG) and ADCP data. The length of the course depends on the accuracy of the GPS being used. The length of the course should be such that the error in GPS position is less than 0.1 percent of the length of the course. Testing in a laboratory environment could be accomplished over a much shorter distance provided the accuracy of the independent distance measurement is less than 0.1 percent of the length traversed. The ratio of the straight-line distance traveled (commonly called the DMG) as measured by bottom tracking with the ADCP and the straight-line distance traveled as measured by the GPS or laboratory instrument is computed. This ratio is referred to as the bottom-track-to-reference ratio. A reciprocal traverse, which is a course of the same length at a heading 
approximately 180 degrees from the previous pass, is made, and the ratios of the two passes are averaged. This procedure is repeated for a total of four times (eight passes altogether) while rotating the ADCP 45 degrees relative to the direction of travel (axis of the boat, if using a manned boat) between each pair of courses. A well-calibrated ADCP should have bottomtrack-to-reference ratios of approximately 1.00. For TRDI Rio Grande ADCPs, the USGS has historically used an acceptable range of 0.995 to 1.003 (Oberg, 2002). A value for the bottomtrack-to-reference ratio of 0.995 corresponds to a -0.5 -percent error in bottom-track velocity measurements. A value for the bottom-track-to-reference ratio of 1.003 corresponds to $\mathrm{a}+0.3$-percent error in bottom-track velocity measurements. The skewed criteria are due to a known potential for ADCPs to have a slight negative bias caused by terrain effects. The criteria for a given ADCP should be based on the bottomtrack accuracy specification provided by the manufacturer of that $A D C P$. A form for documenting the beam-alignment tests is shown in figure D-1 (Oberg and others, 2005).

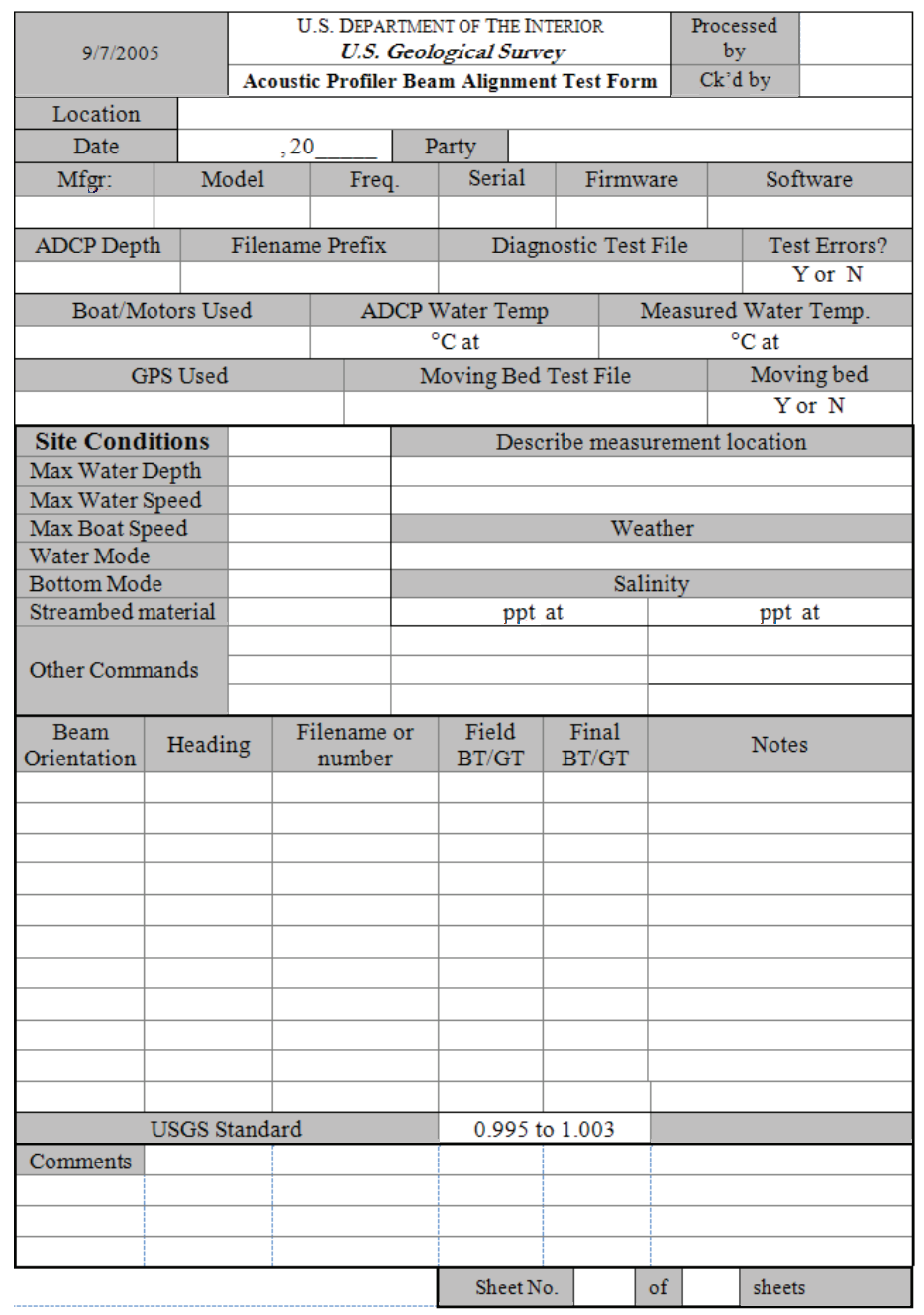

Figure D-1. Acoustic Doppler current profiler (ADCP) beam-alignment test form.

\section{Step-by-Step Field Procedure}

The following procedures should be followed when conducting the distance tests.

1. Conduct internal ADCP diagnostic tests (if available).

2. Lower the ADCP into the water, noting which beam is facing forward.

3. Using the data-collection software, begin pinging, but do not begin recording data.

4. Open a window in the software that will display the bottom-track-to-GPS DMG ratio.

5. Bring the boat to a constant speed and heading and note the heading. The speed should be fast enough to traverse the course in a reasonable time but not so fast as to cause invalid bottom-track data.

6. Once the boat is at the desired speed and heading, begin recording data. After traveling a at least 1,2002,500 $\mathrm{ft}$ (the accuracy of the GPS should be better than 0.1 percent of the distance traveled), record the bottomtrack-to-GPS DMG ratio, stop recording, and then slow the boat and turn to a heading 180 degrees from the previous heading.

7. Bring the boat to a constant speed. Record data for this reciprocal pass. At the end of the pass, record the bottomtrack-to-GPS ratio again. It is important to NOT slow the boat or change heading until recording is stopped.

8. Repeat this procedure while rotating the ADCP 45 degrees relative to the direction of travel (axis of boat if using a manned boat) between each pair of courses until the ADCP has been rotated four times.

9. Average the bottom-track-to-GPS DMG ratio for each reciprocal pair.

10. Review the averaged bottom-track-to-GPS DMG ratio for all rotations and verify that all values are within the manufacturer's specifications. If values are outside of this range, have the instrument serviced by the manufacturer. 


\section{Appendix E - Forms and Quick-Reference Guides}

\begin{tabular}{|c|c|}
\hline $\begin{array}{l}\text { Equipment } \\
\text { Available }\end{array}$ & Equipment List \\
\hline & Basic ADCP Equipment \\
\hline & - ADCP with attachments; bolts and nuts \\
\hline & - ADCP cable(s) \\
\hline & - Field computer with appropriate software \\
\hline & - Screen shade/rain protection for field computer \\
\hline & - Spare batteries with appropriate wiring assembly \\
\hline & - Power inverters and power bars, if needed \\
\hline & - Laser rangefinder, or some other distance measurement device \\
\hline & - Battery charger \\
\hline & - ADCP measurement toolkit \\
\hline & - Field notes or electronic field notes software \\
\hline & - Tools \\
\hline & - Thermometer \\
\hline & - Multimeter \\
\hline & - Safety line \\
\hline & Boat Deployment \\
\hline & $\cdot$ ADCP mount \\
\hline & - Marker buoys (Optional) \\
\hline & Tethered / Remote-Controlled (RC) Boat Deployment \\
\hline & - Tethered boat and hareness / RC boat \\
\hline & - Long rope for use as tether for tethered boat \\
\hline & - Radio modems and cables \\
\hline & - Batteries and charger \\
\hline & - Boat repair kit \\
\hline & - Sea anchor (for slow velocities) \\
\hline & - Weight for tether (for fast velocities) \\
\hline & - Hand-held walkie-talkie type radios \\
\hline & DGPS Deployment \\
\hline & - DGPS and power/data cables \\
\hline & - DGPS antenna and cable \\
\hline & - Pole for mounting DGPS antenna over ADCP \\
\hline & - Battery for DGPS \\
\hline & - Spare fuses \\
\hline & - Additional serial port for laptop, if needed \\
\hline & Echo Sounder \\
\hline & - Echo sounder and associated cables \\
\hline & - Mounting bracket for echo sounder \\
\hline & - Equipment for bar check \\
\hline & - Battery for echo sounder \\
\hline & - Additional serial port for laptop, if needed \\
\hline
\end{tabular}




\begin{tabular}{|c|c|c|c|c|c|c|c|c|c|}
\hline \multicolumn{7}{|c|}{ Acoustic Profiler Discharge Measurement Notes } & \multicolumn{3}{|c|}{ Filename Prefix: } \\
\hline Left Bank: & \multicolumn{5}{|c|}{ Sloping Vertical Other: } & \multirow{3}{*}{$\begin{array}{c}\text { Right Bank: } \\
\begin{array}{c}\text { Total } \\
\text { Discharge }\end{array}\end{array}$} & Sloping & Vertical & Other: \\
\hline \multirow{2}{*}{ Transect No. } & \multicolumn{3}{|c|}{ Starting } & \multicolumn{2}{|c|}{ Ending } & & \multirow{2}{*}{\multicolumn{3}{|c|}{ Notes }} \\
\hline & Bank & Time & Distance & Distance & Time & & & & \\
\hline & $\mathrm{L} R$ & & & & & & & & \\
\hline & $\mathrm{L} \quad \mathrm{R}$ & & & & & & & & \\
\hline & $L R$ & & & & & & & & \\
\hline & $\mathrm{L} R$ & & & & & & & & \\
\hline & $L R$ & & & & & & & & \\
\hline & $L \quad R$ & & & & & & & & \\
\hline & $\mathrm{L} R$ & & & & & & & & \\
\hline & $\mathrm{L} \quad \mathrm{R}$ & & & & & & & & \\
\hline & $\mathrm{L} \quad \mathrm{R}$ & & & & & & & & \\
\hline & $\mathrm{L} \quad \mathrm{R}$ & & & & & & & & \\
\hline & $L R$ & & & & & & & & \\
\hline & $\mathrm{L} \quad \mathrm{R}$ & & & & & & & & \\
\hline & $L \quad R$ & & & & & & & & \\
\hline Notes & . & & & & & & & & \\
\hline
\end{tabular}

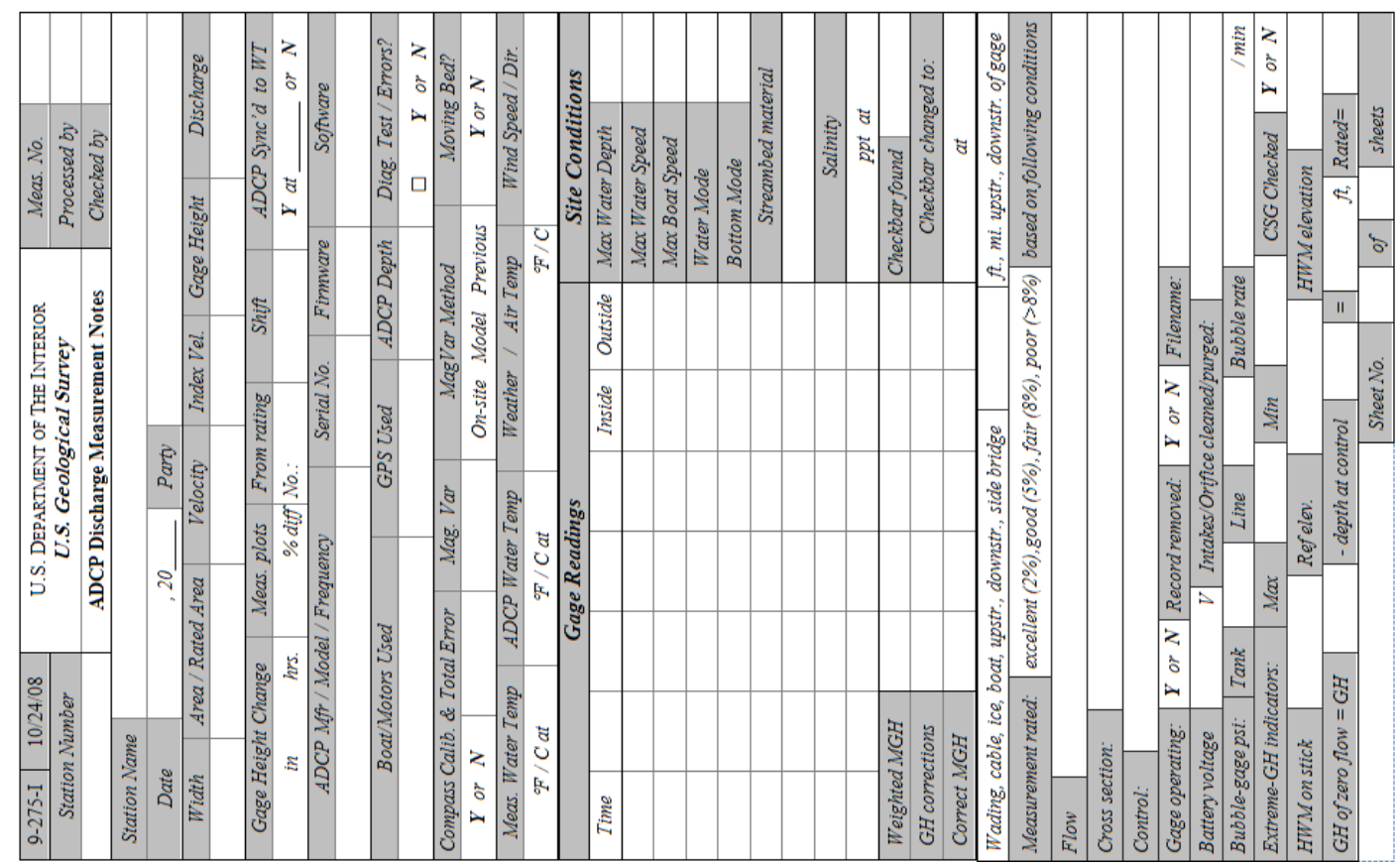




\begin{tabular}{|c|c|c|}
\hline$\checkmark$ & $\begin{array}{l}\text { MOVING-BOAT ADCP DISCHARGE MEASUREMENT } \\
\text { PROCEDURE }\end{array}$ & $\begin{array}{l}\text { TYPICAL DEPLOYMENT } \\
\text { CHALLENGES }\end{array}$ \\
\hline & 1. Setup ADCP and Other Equipment & \multirow{6}{*}{$\begin{array}{l}\text { Slow - Collect more transects; } \\
\text { Be smooth; Use tagline/line } \\
\text { pulley system } \\
\text { Fast - MB expected; Increase } \\
\text { draft; Control pitch; Rio } \\
\text { Grande: WM12 or WM1 }\end{array}$} \\
\hline & a. Attach ADCP to mount or tethered boat & \\
\hline & b. Attach safety line to ADCP & \\
\hline & c. Connect ADCPIGPSIfield computerldata radios & \\
\hline & d. Verify communication with all devices & \\
\hline & e. Check and set ADCP clock time to appropriate time & \\
\hline & 2. Configure ADCP & \multirow{2}{*}{$\begin{array}{l}\text { Bi-directional - Adapt } \\
\text { extrapolation methods; Enter } \\
\text { into eddies }\end{array}$} \\
\hline & $\begin{array}{cc}\text { a. } & \text { Locate appropriate cross-section / collect trial transect, if } \\
\text { needed }\end{array}$ & \\
\hline & surement site with uniform flow, no rapid drop-offs & \multirow{3}{*}{$\begin{array}{l}\text { Shallow - Consider wading } \\
\text { with mechanical current meter } \\
\text { or FlowTracker }\end{array}$} \\
\hline & c. Minimize unmeasured area & \\
\hline & Determine maximum profiling depth, when required to configure & \\
\hline & $\begin{array}{l}\text { e. Measure salinity if expected to be }>6 \text { ppt and enter salinity in } \\
\text { ADCP software }\end{array}$ & \multirow{2}{*}{$\begin{array}{l}\text { Deep - Use lower kHz ADCP } \\
\text { Vertical Wall - Keep distance } \\
\text { from wall = depth }\end{array}$} \\
\hline & f. $\quad$ Measure ADCP depth and record (beware of pitch and roll) & \\
\hline & If needed, configure ADCP using automated software tools & \multirow{2}{*}{$\begin{array}{l}\text { Rough bed - Slow for boat } \\
\text { speed, Higher exponent likely } \\
\text { for extrapolation }\end{array}$} \\
\hline & h. Fill out all field notes with special attention to site conditions & \\
\hline & 3. Prepare for discharge measurement & \multirow{2}{*}{$\begin{array}{l}\text { Wind - Note conditions; Adapt } \\
\text { extrapolation methods }\end{array}$} \\
\hline & a. Perform ADCP diagnostic tests & \\
\hline & $\begin{array}{r}\text { b. Perform c } \\
\text { pref }\end{array}$ & \multirow{4}{*}{$\begin{array}{l}\text { High sediment load - MB } \\
\text { expected; Use lower } \mathrm{kHz} \\
\text { ADCP; GPS; Echo sounder } \\
\text { Salinity - Measure salinity } \\
\text { level to adapt computations } \\
\end{array}$} \\
\hline & c. Measure water temperature, Compare to ADCP and record & \\
\hline & Record moving-bed test (stationary or loop) & \\
\hline & Use GPS or other appropriate technique, if a moving bed is & \\
\hline & & \multirow{10}{*}{$\begin{array}{l}\text { Moving Bed Tests } \\
\text { Stationary: } \\
\text { - } \quad \text { Duration }>300 \mathrm{~s} \\
\text { - } \quad \text { Where moving-bed } \\
\text { potential is greatest } \\
\text { - } \quad \text { If uncertain, collect in } \\
\text { multiple locations } \\
\text { - } \quad \text { Minimize upstream and } \\
\text { downstream motion } \\
\text { - } \quad \text { Use SMBA or equivalent }\end{array}$} \\
\hline & Verify start/end points of transects & \\
\hline & i. Need minimum of two valid depth cells on each edge & \\
\hline & $\begin{array}{l}\text { ii. May use buoys, poles, or other reference (avoid ferrous } \\
\text { objects) }\end{array}$ & \\
\hline & 3. Collect Transect Data & \\
\hline & a. Position boat at starting & \\
\hline & i. Begin recording da & \\
\hline & ii. Meas & \\
\hline & Hold position collecting a minimum of 10 ense & \\
\hline & Move boat across the river & \\
\hline & i. Keep speed less than water speed, when practical & \multirow{10}{*}{ 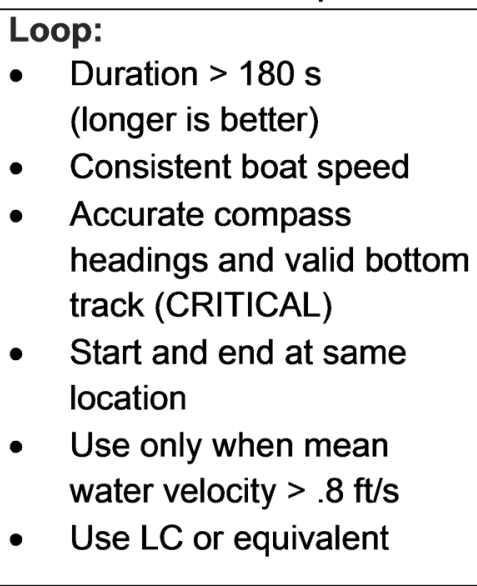 } \\
\hline & $\begin{array}{r}\text { ii. Be a smooth operator, a consistent boat speed and } \\
\text { direction is more important than going slowly }\end{array}$ & \\
\hline & d. Approach ending shore slowly & \\
\hline & $\begin{array}{l}\text { i. Hold position collecting a minimum of } 10 \text { ensembles at } \\
\text { edge }\end{array}$ & \\
\hline & ii. End recording of transect & \\
\hline & $\begin{array}{l}\text { iii. Measure and record distance to shore. } \\
\text { iv. Verify software estimated edge discharges are reasonable }\end{array}$ & \\
\hline & e. Collect reciprocal transects until measurement duration $>720 \mathrm{~s}$ & \\
\hline & f. Evaluate data in field, looking for potential problems in the data & \\
\hline & $\begin{array}{l}\text { g. Compare measurement to rating and make check } \\
\text { measurement if required }\end{array}$ & \\
\hline & h. Make temporary backups before leaving the site & \\
\hline
\end{tabular}




\section{TRDI ADCP QuickSheet}

\begin{tabular}{|l|c|c|c|c|}
\hline & StreamPro & \multicolumn{2}{|c|}{ Rio Grande } & RiverRay \\
\hline Frequency & $2,000 \mathrm{kHz}$ & $1,200 \mathrm{kHz}$ & $600 \mathrm{kHz}$ & $600 \mathrm{kHz}$ \\
\hline Blank & $0.10 \mathrm{ft}(3 \mathrm{~cm})$ & $0.82 \mathrm{ft}(25 \mathrm{~cm})$ & $0.82 \mathrm{ft}(25 \mathrm{~cm})$ & $\sim 0.52 \mathrm{ft}(16 \mathrm{~cm})$ \\
\hline $\begin{array}{l}\text { Minimum Depth } \\
\text { Cell Size }\end{array}$ & $0.07 \mathrm{ft}(2 \mathrm{~cm})$ & $0.16 \mathrm{ft}(5 \mathrm{~cm})$ & $0.33 \mathrm{ft}(10 \mathrm{~cm})$ & $0.33 \mathrm{ft}(10 \mathrm{~cm})$ \\
\hline $\begin{array}{l}\text { Typical Maximum } \\
\text { Profiling Depth }\end{array}$ & $\begin{array}{c}6.6 \mathrm{ft}(\text { Standard) } \\
19.7 \mathrm{ft} \text { (Extended) }\end{array}$ & $65 \mathrm{ft}$ & $230 \mathrm{ft}$ & $197 \mathrm{ft}$ \\
\hline
\end{tabular}

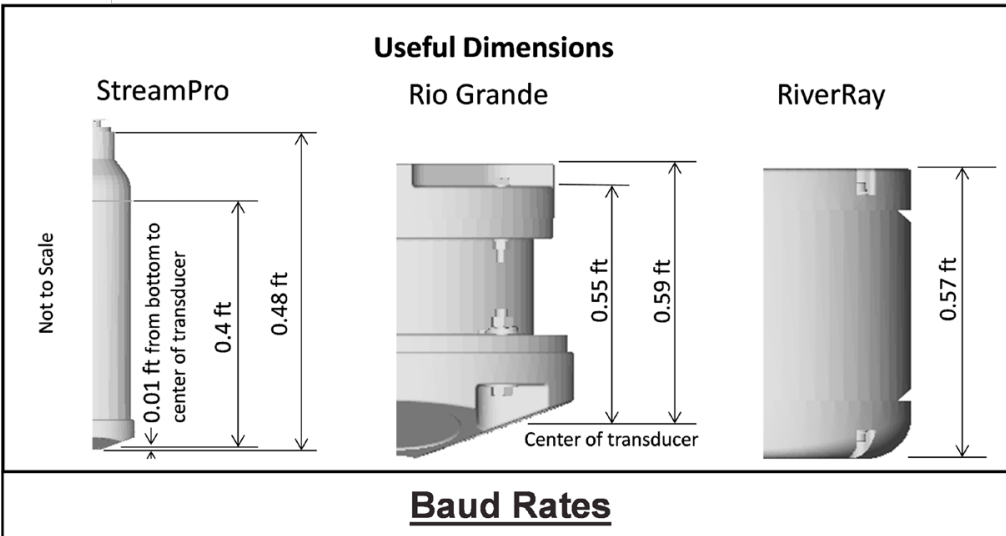

Rio Grande and RiverRay Baud Rate: $\mathrm{A}$ baud rate lower than $38.4 \mathrm{k}$ baud may result in less data being collected. Set ADCP baud rate in BB-Talk using CB to set baud rate. 9600 - CB411, 19.2k - CB511, 38.4k - CB611, 57.6k - CB711, 115.2k - CB811. Set BB-Talk to "Send CK on Baud Rate change (CB command)".

Baud Rate for RiverRay Bluetooth: Requires 115.2k - CB811.

StreamPro Baud Rate: Always 115.2k.

GPS Baud Rate: The minimum acceptable GPS baud rate depends on the number of NMEA 0183 data types being output. The following guidelines are good for typical NMEA output of GGA, VTG, and ZDA.

\begin{tabular}{||l|l|}
\hline GPS Update Rate & Minimum Baud Rate \\
\hline $1 \mathrm{~Hz}$ & 4800 or higher \\
\hline $5 \mathrm{~Hz}$ & $19.2 \mathrm{k}$ or higher \\
\hline $10 \mathrm{~Hz}$ & $38.4 \mathrm{k}$ or higher \\
\hline
\end{tabular}

Rio Grande Operating Modes $1200 \mathrm{kHz}$ [600 kHz, when different] Mode 1-General Purpose-Best in deeper water, turbulence and shear; high random error in slow velocities; use when boat motion is erratic with high pitch/roll

Depth: $4.5-65 \mathrm{ft}[7.5-230 \mathrm{ft}]$

Velocity: $<32 \mathrm{ft} / \mathrm{s}$

Mode 12-High Resolution General Purpose-Allows for smaller depth cells

than Mode 1 due to added sub-pings. ADCP orientation should not change

significantly between ensembles. High random error in slow velocities.

Depth: $2.5-65 \mathrm{ft}[3-230 \mathrm{ft}$ ]

Velocity: $<32 \mathrm{ft} / \mathrm{s}$

Mode 5-Shallow and Slow Flow-Slow laminar flow with little shear. Precise

velocities. Similar to Mode 11

Depth: $1.7-13 \mathrm{ft}[3-26 \mathrm{ft}]$

Velocity $<2.3 \mathrm{ft} / \mathrm{s}[<3.3 \mathrm{ft} / \mathrm{s}]$

Mode 11-Shallow and Slow Flow-Slow laminar flow with little shear. Precise

velocities. Similar to Mode 5 .

Depth $2.2-13 \mathrm{ft}[3-26 \mathrm{ft}]$

Velocity $<2.3 \mathrm{ft} / \mathrm{s}[<3.3 \mathrm{ft} / \mathrm{s}]$

Bottom Mode 5-General Purpose-Used for most conditions

Depth $>2 \mathrm{ft}$

Bottom Mode 7-Shallow-May be preferred in shallow or highly sloping depths

Depth: $>1 \mathrm{ft}$

\section{Data Problems}

Lost Ensembles: Lost ensembles are a result of a communications problem. Solution:

1. Disable power management.

2. Try lowering the baud rate.

3. Change serial ports or serial port adapters.

4. Close color contour plot window.

Bad Ensembles: Bad ensembles are a result of site conditions or water mode selection.

Solution:

1. Try a different cross section.

2. If using WM 5, 11, or 13, try WM 12 .

3. If bad ensembles are caused by bottom track, change bottom mode, if available, or use GPS

\section{WinRiver II Shortcuts}

F3 Configuration Settings

F4 Start/Stop Pinging

F5 Start/Stop Transect

F9 Ensemble Header Tabular view

F11 Detailed Discharge/Composite Tabular view

F12 Discharge Summary Tabular view

Shift+F4 Set ADCP Clock

Shift+F8 ADCP Test

Shift+F10 Compass Calibration

Ctrl-B Reference - Bottom Track

Ctrl-G Reference - GPS (GGA)

Ctrl-V Reference - GPS (VTG)

Ctrl-N Reference - None

(when Measurement Ctrl selected)

Ctrl-K Add Note

(when Stick Ship plot selected)

Ctrl-PgDn Scale Sticks Down

Ctrl-PgUp Scale Sticks Up

\section{StreamPro Operating Modes}

Mode 12-General Purpose-better in turbulence

and shear, high random error in slow velocities

Range $0.5 \mathrm{ft}$ to $6.6 \mathrm{ft}$ (19.7 extended range_

Velocity $0.2 \mathrm{~m} / \mathrm{s}$ to $16 \mathrm{ft} / \mathrm{s}$ (standard float <

$6 \mathrm{ft} / \mathrm{s}$

Mode 13-Low Noise Mode-Shallow with

low velocities, low shear and turbulence.

Depth $<3.3 \mathrm{ft}$

Velocity $<.82 \mathrm{ft} / \mathrm{s}$ 
SonTek RiverSurveyor QuickSheet

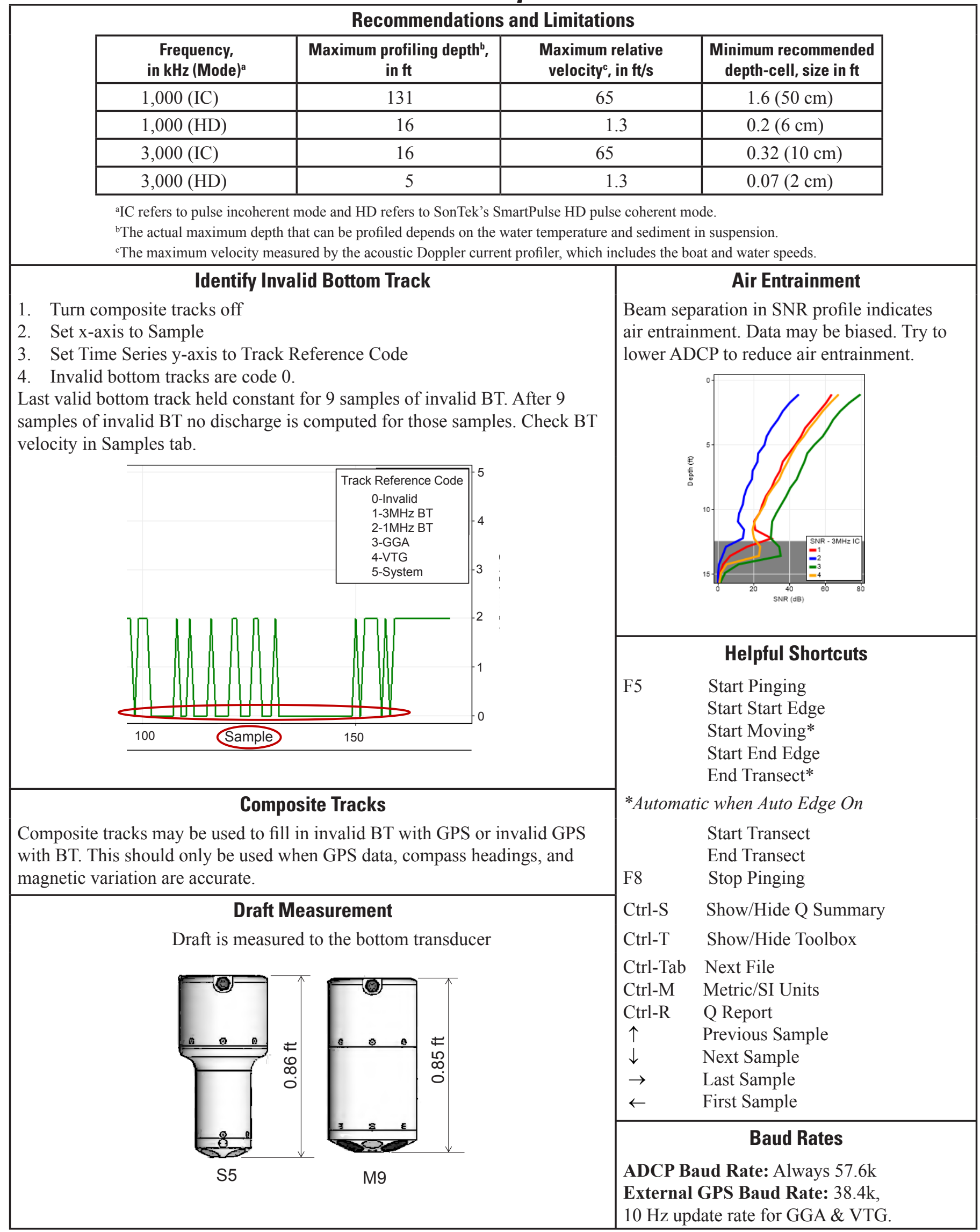




\section{Appendix F - Measurement Processing Procedures}

The purpose of the measurement processing procedures presented herein is to provide the hydrographer with a structured approach to ensure the quality of the collected data, verify user input data, and make necessary adjustments to the computational parameters. These procedures should be completed in the field by the hydrographer collecting the data prior to leaving the site. Understanding the principles of operation for ADCPs and the potential effects of site conditions on the measurement will help the hydrographer determine the severity of any observed issues, how or if the issue could have been avoided during data collection, and if the issue can be corrected during processing.

The procedures have been organized based on the typical user interface of the manufacturers' data-collection software. The general procedure consists of eight steps:

1. Evaluate QA/QC

2. Verify User Input

3. Evaluate Tabular Data

4. Evaluate Ship Track and Velocity Vector Plot

5. Evaluate Velocity Contour Plot

6. Evaluate Echo Intensity Profile Plot

7. Select Proper Extrapolation Methods

8. Evaluate Discharge Summary

The purpose and specific issues to be evaluated for each of these steps are discussed in the section Step by Step Procedure Details. For a good measurement with no major issues, processing the measurement should not take more than about 10 to 15 minutes. If problems are identified, then additional evaluation and problem resolution may be required to finalize the measurement. Several problems and how to identify and (or) resolve them are discussed in the section Additional Details. If major problems with the measurement cannot be resolved with post-measurement procedures, then the measurement should be repeated in a manner to eliminate or reduce the problems or if that is not possible, the reasons should be documented.

\section{Step-by-Step Procedure Details}

\section{Step 1. Evaluate $\mathbf{Q A} / \mathbf{O C}$}

Evaluate the quality-assurance data to verify that the ADCP is working properly, the compass has been accurately calibrated, if appropriate, and that the measurement is collected and processed consistent with the moving-bed conditions at the site.

\section{ADCP Test}

Evaluate the ADCP self-test. Different ADCPs provide different levels of information in a self-test. An error does not mean the ADCP cannot be used or that the collected data are invalid. As an example, the receive test for TRDI ADCPs will sometimes report an error when performed in fast-flowing water but when repeated in slack water will pass. In either case, this error is typically not critical. If the self-test reports an error, the ADCP's manual should be consulted to determine the severity and potential resolution for the error.

\section{Compass Calibration}

Valid compass headings are critical for loop moving-bed tests and when using GPS for reference. If the compass calibration method for the ADCP provides an evaluation of the calibration and (or) reports the potential error in degrees, the potential error should be less than 1 degree. If an error of 1-degree or less is not achieved after multiple attempts, the problem should be documented and the measurement data evaluated closely for effects from heading errors (see Additional Details - Identifying Magnetic Compass Heading Errors). If the ADCP compass calibration method does not provide a quantitative error in degrees, the accuracy of the compass calibration cannot be determined. In such situations, the calibration should follow recommended criteria and the measurement data should be evaluated closely for effects from compass errors (see Additional Details - Identifying Magnetic Compass Heading Errors).

\section{Moving-Bed Tests}

Evaluate stationary moving-bed tests in SMBA and loop moving-bed tests in $\mathrm{LC}$ or equivalent versions of these utilities that have been integrated into the manufacturers' software. If a moving bed is detected, GPS should be used as reference whenever accurate and reliable GGA or VTG and ADCP heading data can be collected. If GPS cannot be used, the bottom-track discharge must be corrected appropriately using the techniques in SMBA, LC, or equivalent. The validity of the loop moving-bed test is dependent on continuous bottom track and accurate compass headings, especially when the boat 
is changing directions or in areas where a moving bed is more likely. Therefore, if there is substantial invalid bottom track or the headings are inaccurate, the loop will be inaccurate. LC and equivalent utilities in the manufacturers' software provide quality-assurance checks on the loop. In addition to these quality checks, the user should evaluate the ship track in the manufacturers' software to ensure the track reflects the path taken by the ADCP. If the loop moving-bed test is inaccurate or invalid, a stationary moving-bed test should be used.

\section{Water Temperature}

Verify that the water temperature measured by the ADCP is within 2 degrees Celsius $\left({ }^{\circ} \mathrm{C}\right)$ of the water temperature measured near the transducers by an independent instrument. If the temperature does not agree, check the temperature time series to ensure that the temperature measured by the ADCP has reached equilibrium. If it is determined that the temperature measured by the ADCP is in error (see Pre-Measurement Field Procedures - Water Temperature in main body of this report for more details), a manual water temperature, or corresponding speed of sound, should be entered and the temperature sensor of the ADCP should be tested and (or) repaired, as necessary.

\section{Step 2. Verify User Input}

Before processing the collected data, verify that the user inputs have been entered correctly.

\section{Depth of Transducer (Draft)}

Verify that the distance from the water surface to the center of the transducer for TRDI ADCPs and the bottom of the vertical beam for SonTek RiverSurveyors was measured and entered into the software using the correct units.

\section{Magnetic Variation}

If GPS is used, the magnetic variation must be correct. It is always acceptable and encouraged to enter the magnetic variation so that the velocity vectors and ship track are oriented relative to true north.

\section{Salinity}

When measuring in water where the salinity is expected to be greater than 5 parts per thousand (ppt), the salinity should be measured near the transducer face, recorded in the field notes, and entered in the software. Verify that the value recorded in the field notes matches the value entered in the software.

\section{Edge Types}

Verify that the edge types are consistent with the site conditions. If the edge is irregular, documentation should be provided to justify use of a nonstandard edge type or computation method.

\section{Distance to Shore}

Verify that the distance to shore for the start and end edge of each transect is correct. In rare cases where good field procedures were not used or erroneous data were collected near the transect edges, it may be necessary to correct the edges by subsectioning. However, subsectioning should be done carefully with full understanding of the effects it will have on the discharge computation (see Additional Details Subsectioning Transects in WinRiver II).

\section{Start Edge}

Verify that the correct start edge is specified for each transect. If the wrong start edge is specified, the resulting discharge for that transect will have the wrong sign.

\section{Step 3. Evaluate Tabular Data}

The tabular data are typically presented in a window along one side of the manufacturers' software. The location and data available may vary.

\section{Duration}

Check that the duration of the transect is appropriate for the water velocity and channel width. Short durations may result in higher uncertainty in the measured discharge. However, it is important that the boat speed is such that a smooth course can be maintained and the distribution of the measured data is appropriate (see Step 4. Evaluate Ship Track and Velocity Vector Plot).

\section{Invalid or Missing Data}

During a measurement it is not uncommon for some of the data to be missing or invalid. The number of missing or invalid ensembles should not be excessive. This information is provided in the tabular view for WinRiver II but not for RiverSurveyor Live. Missing or lost ensembles indicate communication problems between the ADCP and the computer. The computer may not be able to keep up with the incoming data or may have gone to sleep and missed incoming data. Power to the ADCP may have been interrupted, the communications cable may not have been attached securely, or interference with wireless communications may have occurred. Invalid or bad ensembles indicate that the ADCP was unable to measure 
the velocities in a portion of the cross section. For an invalid ensemble, the software receives all of the data from the ADCP, but the data do not meet the criteria for a valid velocity measurement. Invalid ensembles can be caused by (a) invalid bottom tracking, which would provide no boat reference from which to compute the velocity, (b) invalid bottom depths, which would provide no cutoff for the profile at the bottom, (c) decorrelation of the acoustic pulse (from turbulence, high shear, submerged debris, or fish), which would not permit an accurate measurement of the Doppler shift, (d) low backscatter, which results in an insufficient amount of acoustic energy reflected back to the transducer to allow the ADCP to measure the Doppler shift, (e) the blocking of acoustic pulses by air entrainment, or (f) user-specified data-quality thresholds.

TRDI and SonTek currently (2013) handle invalid and missing data differently. TRDI WinRiver II provides a quantitative display of the number of invalid (bad) or missing (lost) ensembles. TRDI uses algorithms in WinRiver II to estimate the unmeasured portions of the cross section using the next valid ensemble to back compute the discharge for that portion of the cross section. Therefore, the number of missing or invalid ensembles that will result in a poor measurement is difficult to establish because the location and clustering of the missing or invalid ensembles is important. If 50 percent of the ensembles were missing or invalid, but every other ensemble was valid, the measurement could still be a good measurement. However, if 10 percent of the ensembles were missing or invalid, but they all occurred in one location where the neighboring valid data would be a poor representation of what was unmeasured, the measurement would be poor.

RiverSurveyor Live provides a warning for missing data due to communications problems, and the transect file recorded in the ADCP must be retrieved and used in processing, because it will contain all of the data. However, invalid data are more difficult to identify in RiverSurveyor Live (see Additional Details - Invalid Data in RiverSurveyor Live) and when more than nine consecutive samples have invalid data, there is no algorithm currently (2013) provided to compute the discharge for that part of the cross section with invalid data, and the resulting total is biased low.

\section{Step 4. Evaluate Ship Track and Velocity Vector Plot}

The ship track and velocity vector plot provides a plan view of the path made by the ADCP during the transect and the magnitude and direction of the flow throughout the cross section. The objective of this step is to verify that the ship track and velocity magnitudes and directions are consistent with site conditions. If GPS data are collected in addition to bottom track, it is often helpful to compare the different references. If the ship track or velocity vectors (sticks) are irregular and (or) do not represent the flow and ADCP path, the following are possible causes and solutions.

\section{Bottom-Track Problems}

Irregular bottom-track referenced ship track that does not follow the known ADCP path may be caused by bottom-track errors (fig. F-1). Bottom-track problems are more common in streams with rough and irregular streambeds and on steep slopes. Irregular bottom track may also be caused by compass interference. To eliminate the possibility that the irregularity is caused by heading errors, evaluate the heading time series. If the heading time series appears uniform, the problem is likely bottom-track errors. Note: If bottom track is used as the navigation reference for discharge computation, heading errors will not result in errors in discharge. For TRDI ADCPs, the bottom track may be able to be improved by setting bottomtrack thresholds or other processing settings in WinRiver II (see Additional Details - Using Processing Filters in WinRiver II).
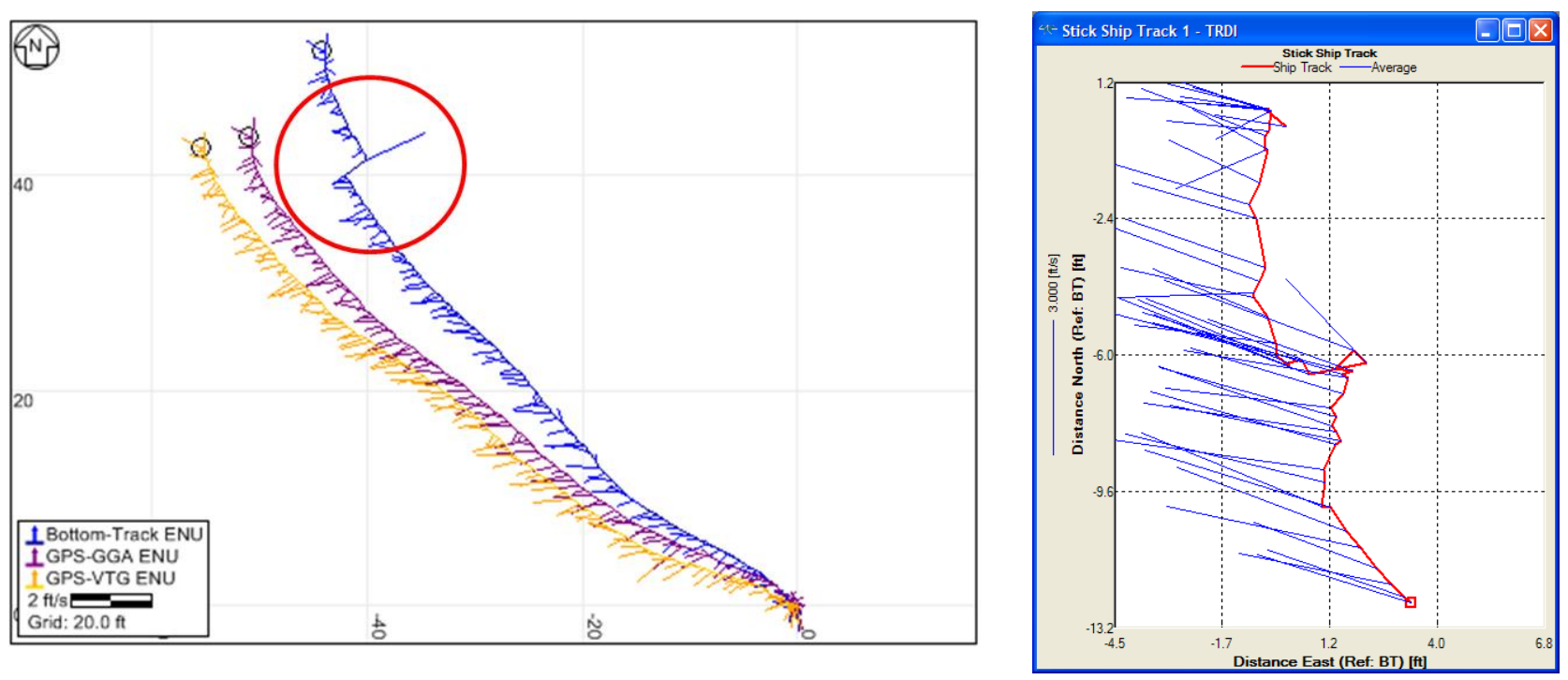

Figure F-1. Examples of irregular ship track caused by errors in the bottom track. 


\section{GPS Errors}

When collecting GPS data near bridges, in narrow valleys, and (or) near stream banks with tree canopy, multipath errors and (or) satellite changes (See Additional Details - Identifying Poor GPS Quality) can cause inaccurate and irregular positions to be reported in the GGA sentence (fig. F-2). Multipath errors and (or) satellite changes caused by tree canopy at the banks will result in irregular GGA referenced ship track near the stream banks. If GPS is the desired navigation reference, try using VTG, which typically is less susceptible to multipath errors.

\section{Moving-Bed Condition}

A moving bed will cause the bottom-track referenced ship track to appear to move in the upstream direction. If the ADCP was moved along a tagline strung perpendicular to the flow direction, the ship track would have an upstream angle but the water-velocity vectors (sticks) would be in the correct downstream direction (fig. F-3). In other words, the angle between the ship track and water-velocity sticks would be consistently different from 90 degrees. If GPS data were collected, a comparison of the GPS referenced ship track to the bottom-track referenced ship track should show the bottom-track referenced ship track to deviate from the GPS referenced ship track in the upstream direction on reciprocal transects (fig. F-3). If the deviation on reciprocal transects is not equal in both directions, this could indicate that there is also a compass or heading issue.

\section{Incorrect Magnetic Variation or Inaccurate Compass Calibration}

Compare GPS and bottom-track referenced ship tracks. If deviations between the two ship tracks are not consistent on reciprocal transects or if the bottom-track ship track is consistently downstream from the GPS referenced ship track, the likely cause is an incorrect magnetic variation or an inaccurate compass calibration (fig. F-4). Enter the correct magnetic variation for the location or if the correct magnetic variation has been entered see Additional Details - Adjusting Magnetic Variation.

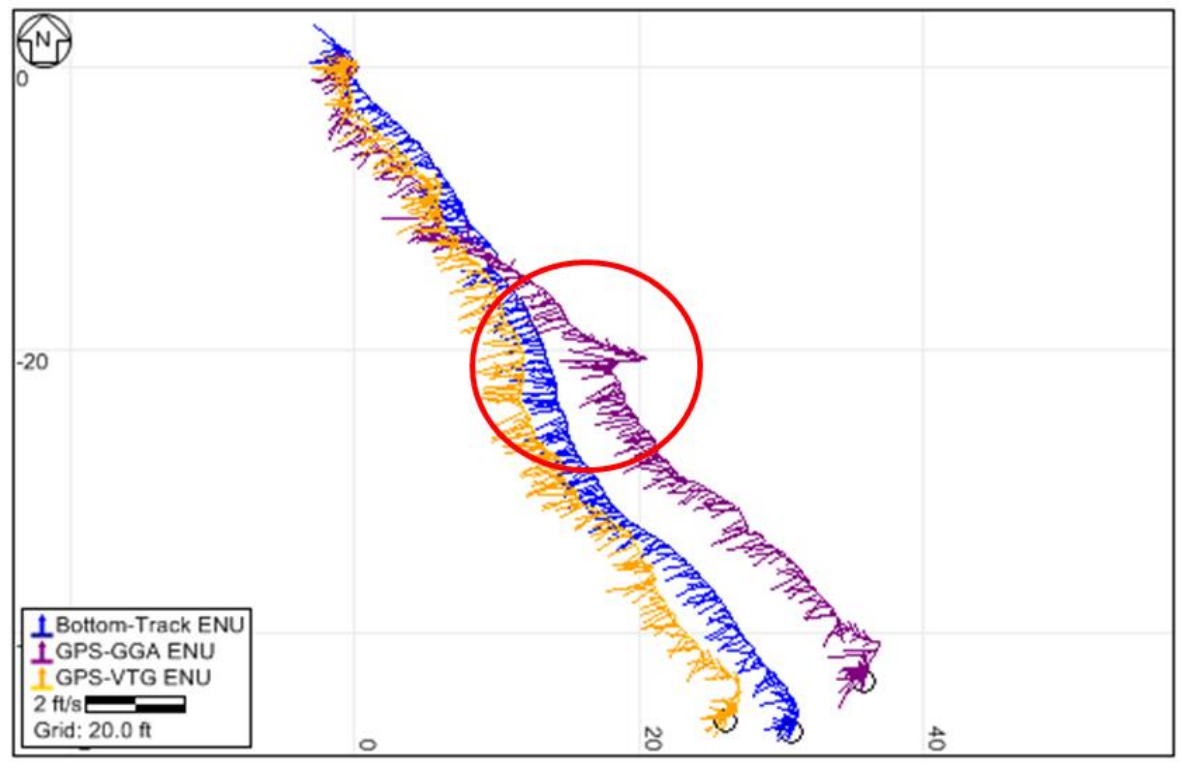

Figure F-2. Example of multipath errors in GGA data. 


\section{A. WinRiver II}

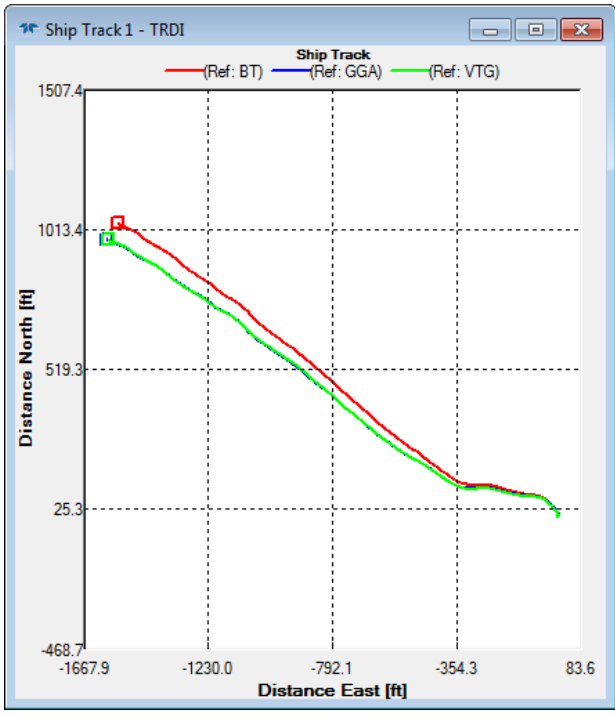

B. RiverSurveyor Live

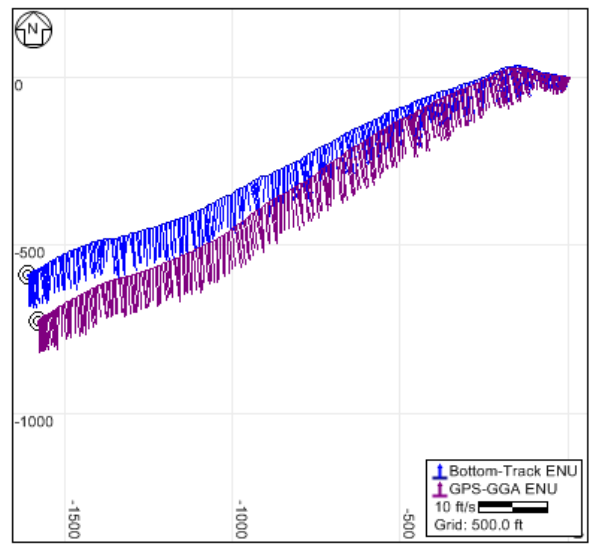

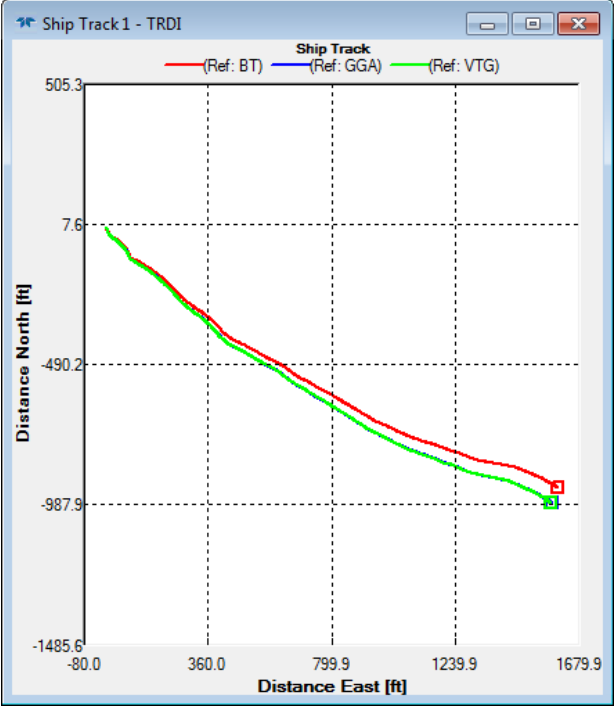

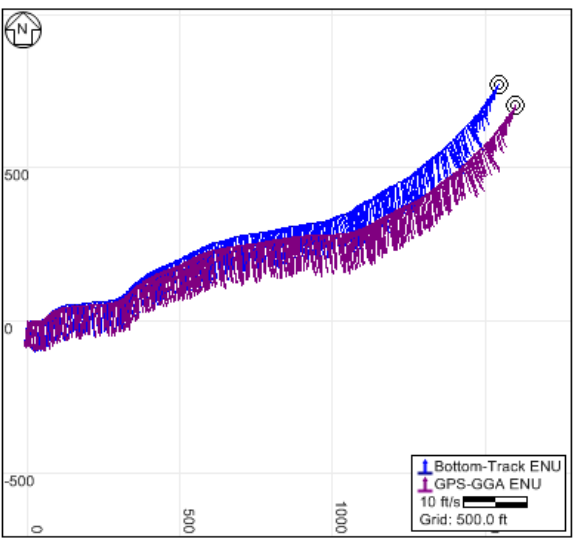

Figure F-3. Examples of moving-bed condition comparing bottom track to GPS referenced ship tracks with bottom track skewed upstream for reciprocal transects, (A) Win River II, (B) RiverSurveyor Live. 


\section{A. WinRiver II}
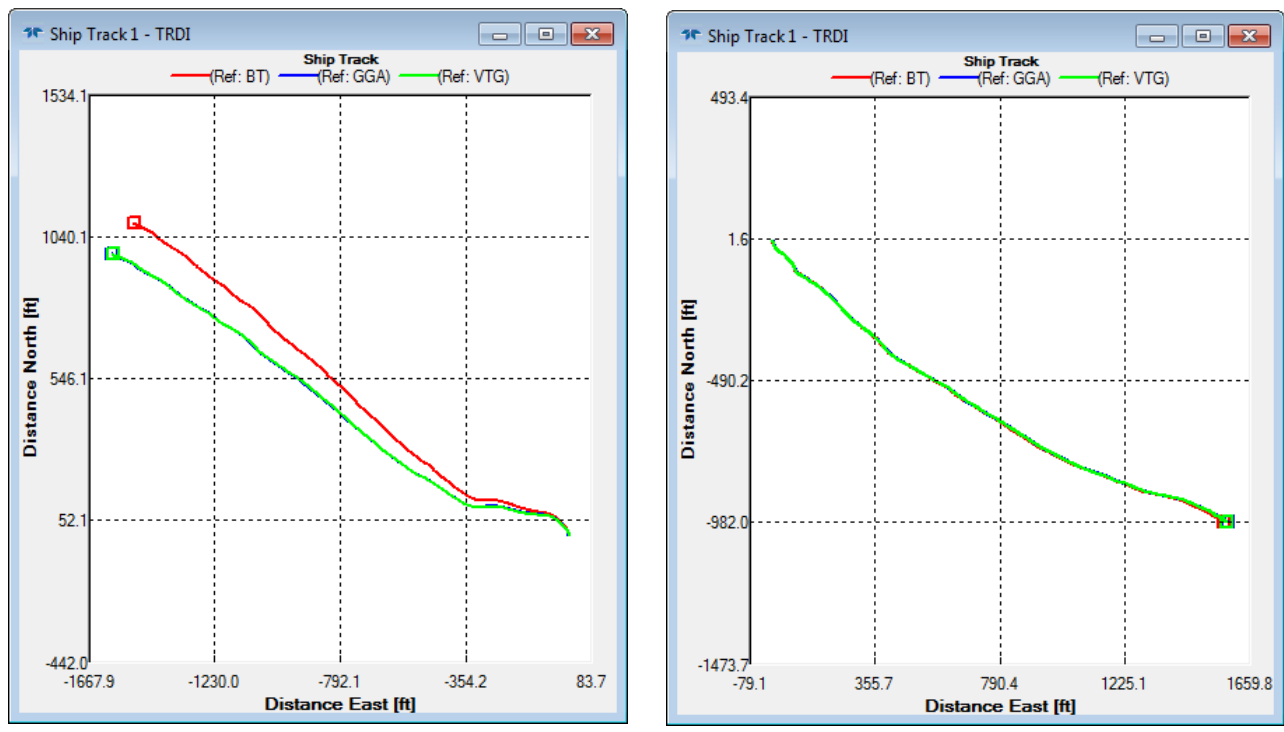

\section{B. RiverSurveyor Live}
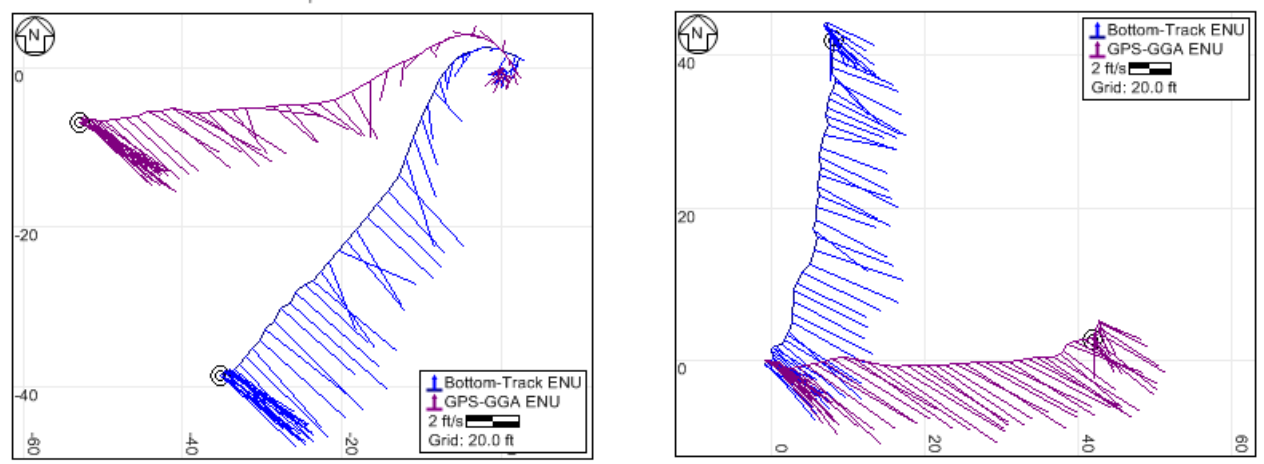

Figure F-4. Example of inconsistent deviations between bottom track and GPS referenced ship tracks for reciprocal headings (A) Win River II, (B) RiverSurveyor Live. 


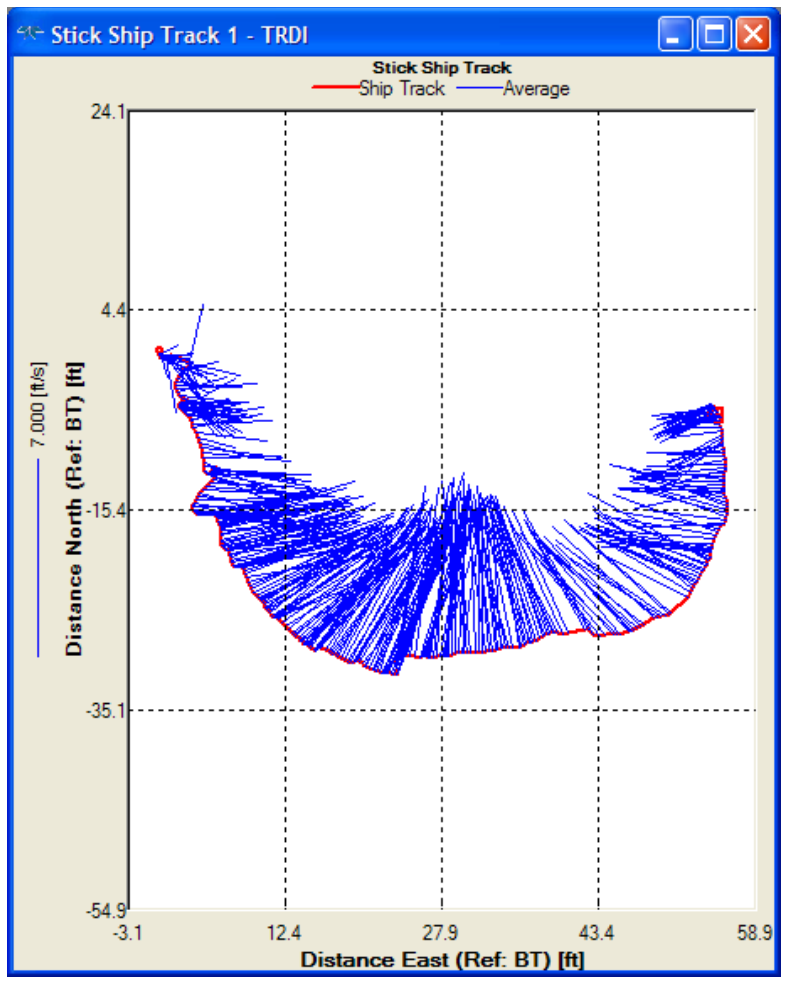

Figure F-5. Example of magnetic interference affecting the bottom-track referenced ship track. Notice the watervelocity sticks remain perpendicular to the ship track.

\section{Magnetic Interference on Compass}

Severe compass interference can occur when collecting data close to a steel structure or pier. If the ADCP travels too close to the magnetic interference, the compass may lock onto the ferrous object resulting in an obviously incorrect ship track and water-velocity direction but the water-velocity vectors (sticks) will maintain a correct orientation relative to the ship track (fig. F-5). Note that varying magnetic interference in a cross section, such as changing proximity to bridge piers or other ferrous objects, cannot be resolved by compass calibrations. If navigation reference is bottom track, the computed discharge should still be correct.

\section{Velocity Errors}

Errors in velocity measurements will show up as velocity spikes when compared with the neighboring valid velocity measurements (fig. F-6). Typically, ambiguity errors only occur in pulse-coherent modes. WinRiver II allows various thresholds to be set to filter out ambiguity errors (see Additional Details - Using Processing Filters in WinRiver II). Not all velocity errors can be eliminated using the available filters without excessive filtering out of valid data. The user must consider the effect of the filter or remaining erroneous data on the final discharge.

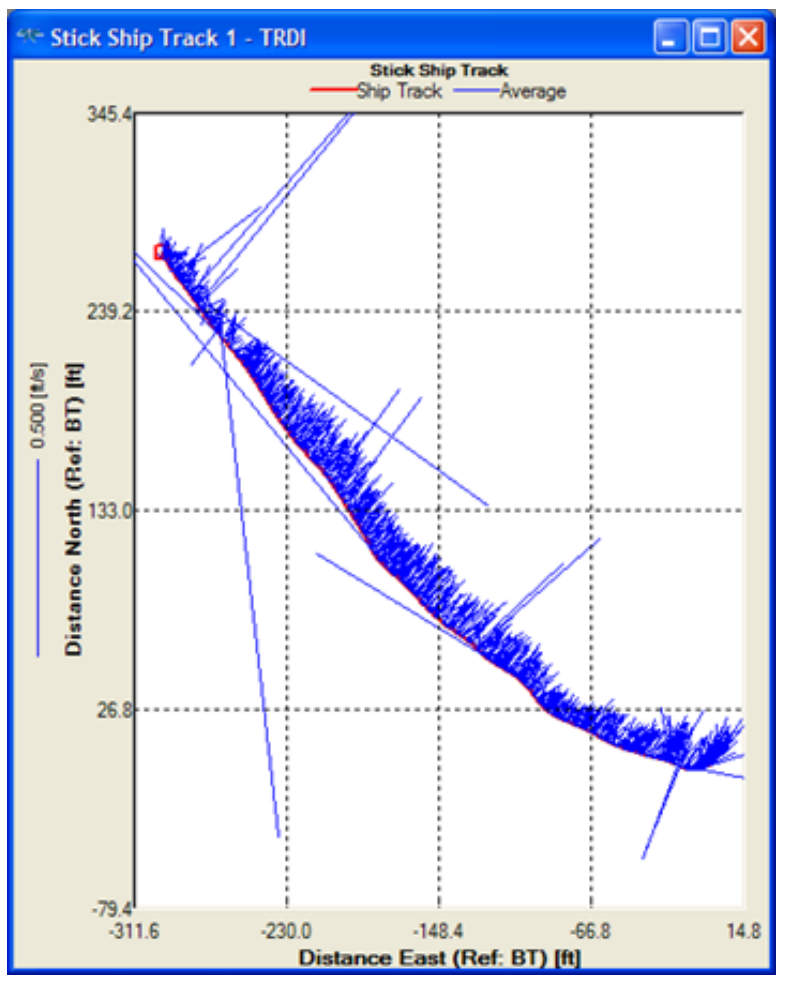

Figure F-6. Example of ambiguity velocities in stick ship track plot from WinRiver II.

\section{Composite Track Used Improperly (SonTek Only)}

SonTek RiverSurveyor Live provides the capability to substitute GPS data for invalid bottom track and vice versa. Although this can be a helpful feature when the compass is calibrated and the correct magnetic variation is entered, it can also cause unexpected confusion and inaccurate data when used improperly. If composite tracks are turned on and bottom track is lost but the compass has not been properly calibrated and the proper magnetic variation entered, the GPS referenced data used when bottom track is lost will not have the same directional reference as the bottom-track data. In addition, it is not obvious when any of the references are invalid or change (see Additional Details - Invalid Data in RiverSurveyor Live). If no GPS data are collected but composite tracks are on, the GPS referenced ship tracks will simply use the bottom-track data and appear to be referenced to GPS even though no GPS data were collected (fig. F-7). Only use the composite track feature when GPS data have been collected, the heading is accurate, and the magnetic variation has been correctly entered. 


\section{A. Composite Tracks On}

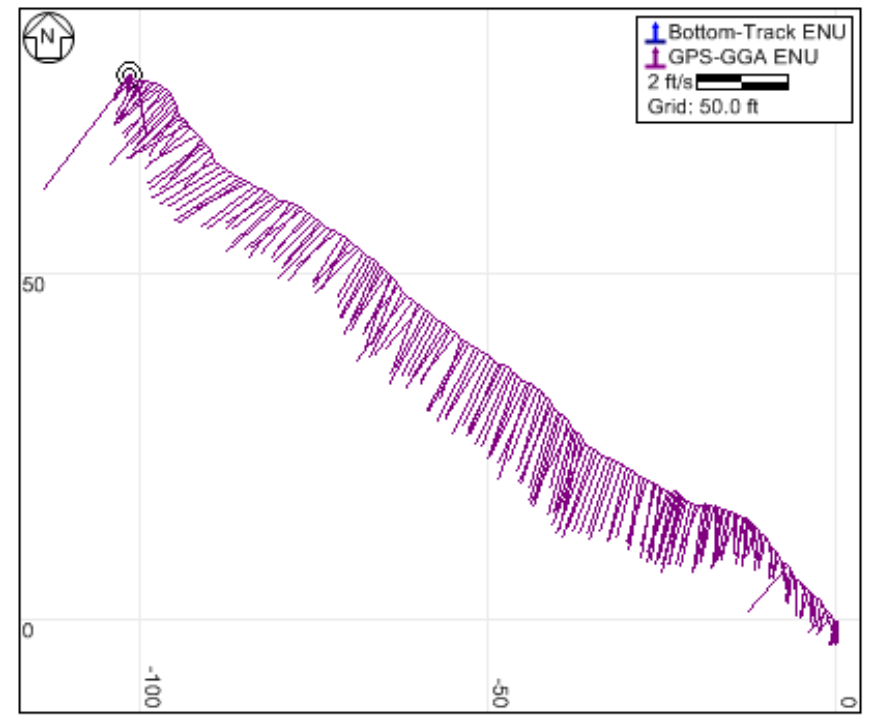

\section{B. Composite Tracks Off}

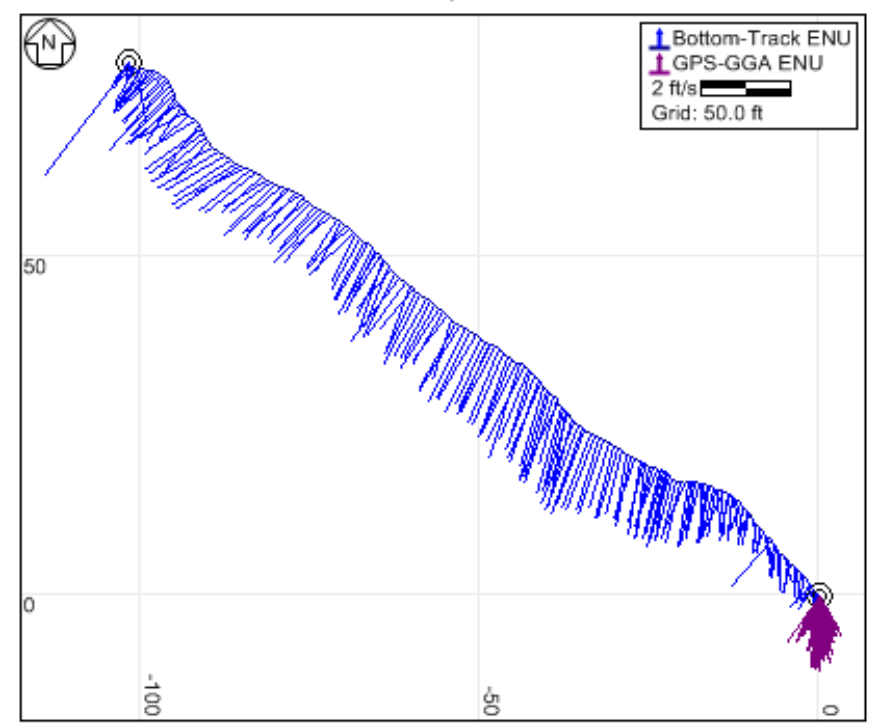

Figure F-7. Example showing GGA ship track with composite tracks turned (A) on and (B) off when no GPS data were collected. In $A$, it appears that GPS is valid because it is substituting bottom track for the invalid GPS data; however, in B, with composite tracks off, it is obvious that there is no valid GPS data.

\section{Step 5. Evaluate Velocity Contour Plot}

The velocity contour plot provides a cross-section view of the velocity magnitudes (by default). The velocity distribution should be representative of the site conditions with no unusual or unexplainable patterns (fig. F-8). Figure F-9 shows a situation where the ADCP was positioned too close to a vertical wall, and a beam reflection from the wall was digitized as the depth. This causes the total depth to be biased shallow and the side-lobe cutoff to be computed from the reflection off the wall. Unusual or unexplainable patterns should be further investigated to determine their cause and potential solution (see Additional Details - Using Processing Filters in WinRiver II). The shape of the cross section should be consistent with site conditions with few irregularities (figs. F-10 and F-11). Spikes in the bottom profile may be removed using the screen depth filter in WinRiver II or changing the bottom depth reference in RiverSurveyor Live. The

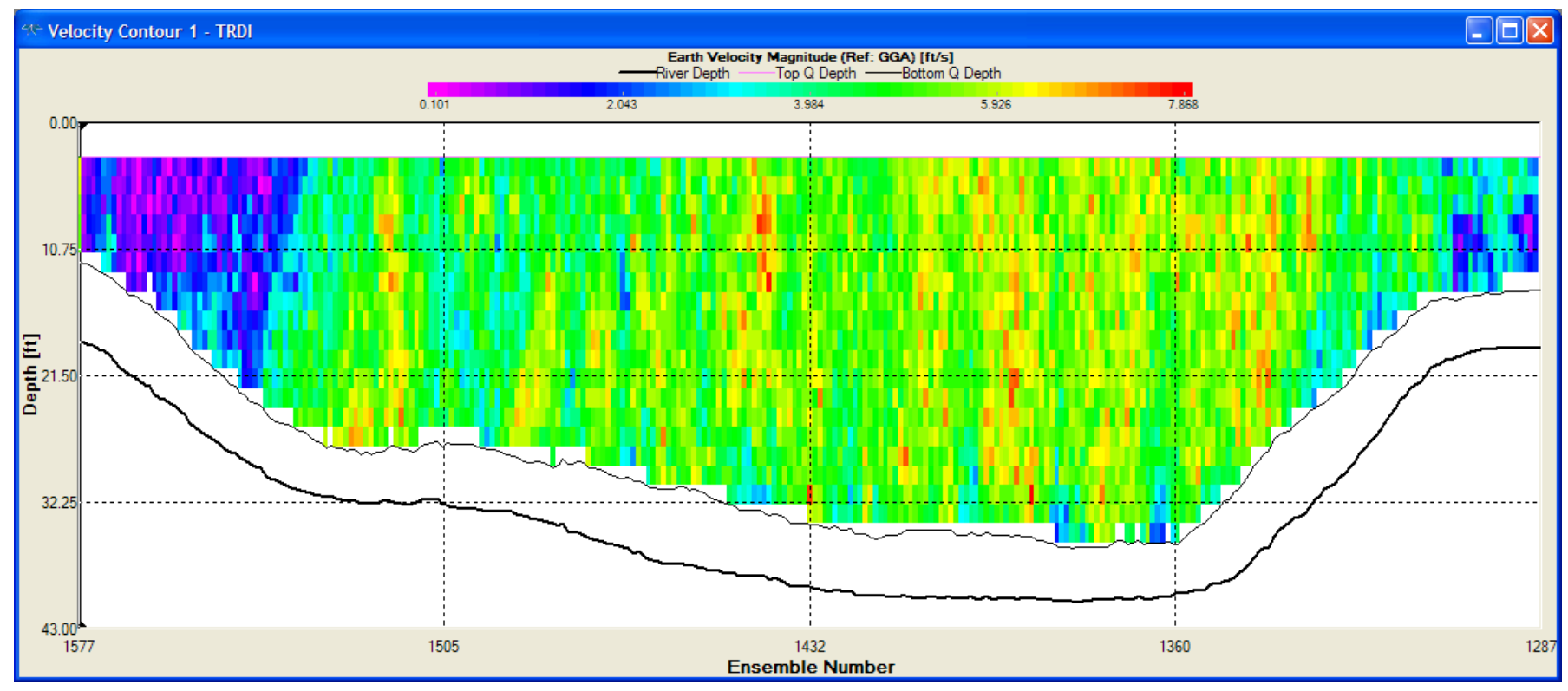

Figure F-8. Example of a color contour plot showing a typical distribution of water velocities. 


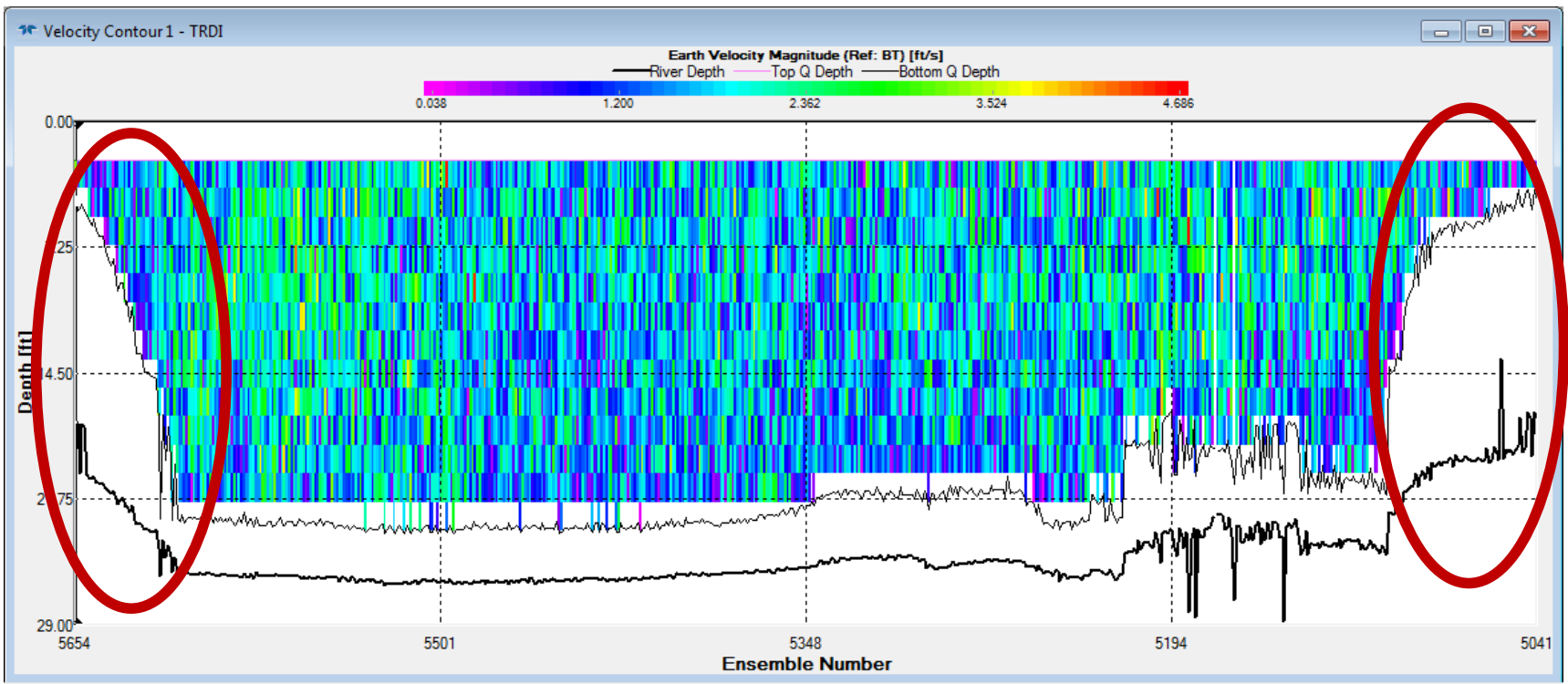

Figure F-9. Example of ADCP positioned too close to a vertical wall causing the side-lobe cutoff to be high in the water column and the total depth to be biased low (red indicating affected areas).

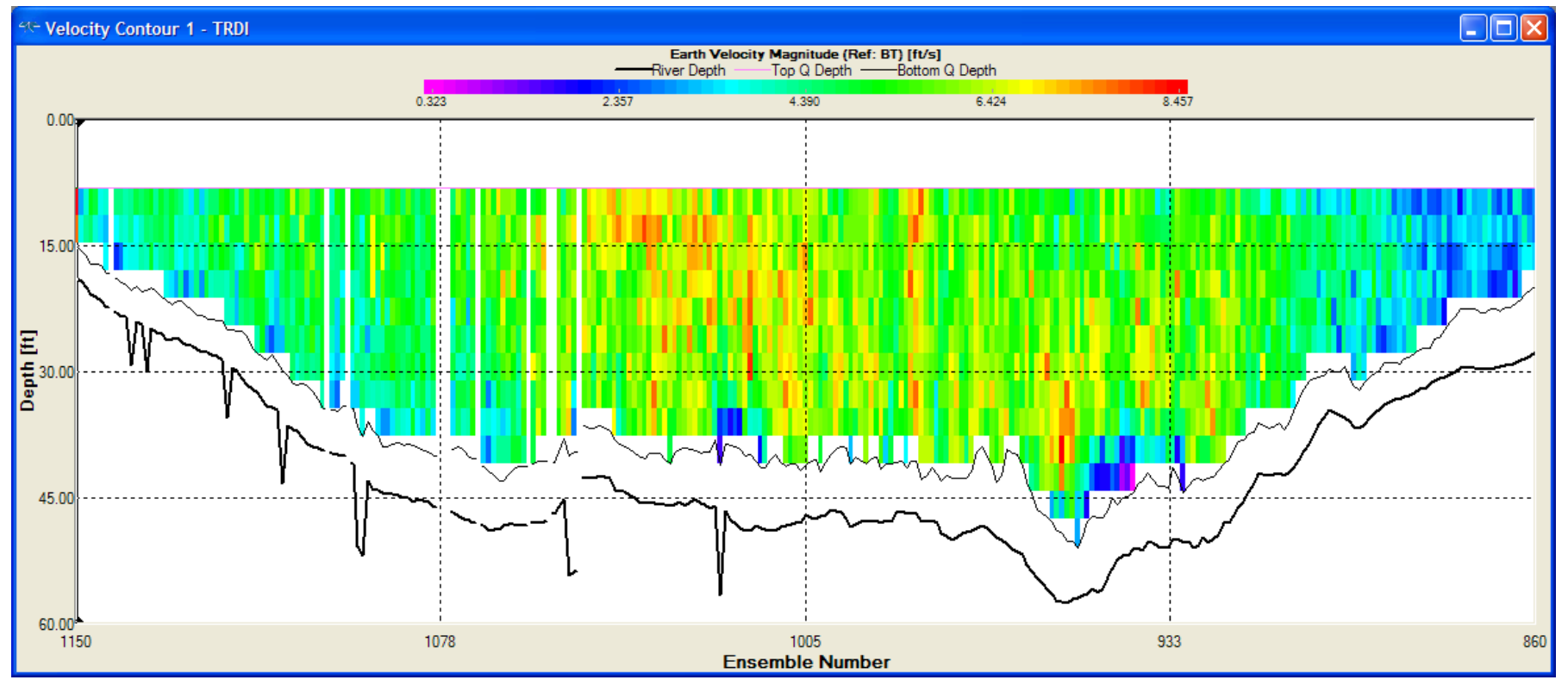

Figure F-10. Example of color contour plot showing spikes in the streambed. 


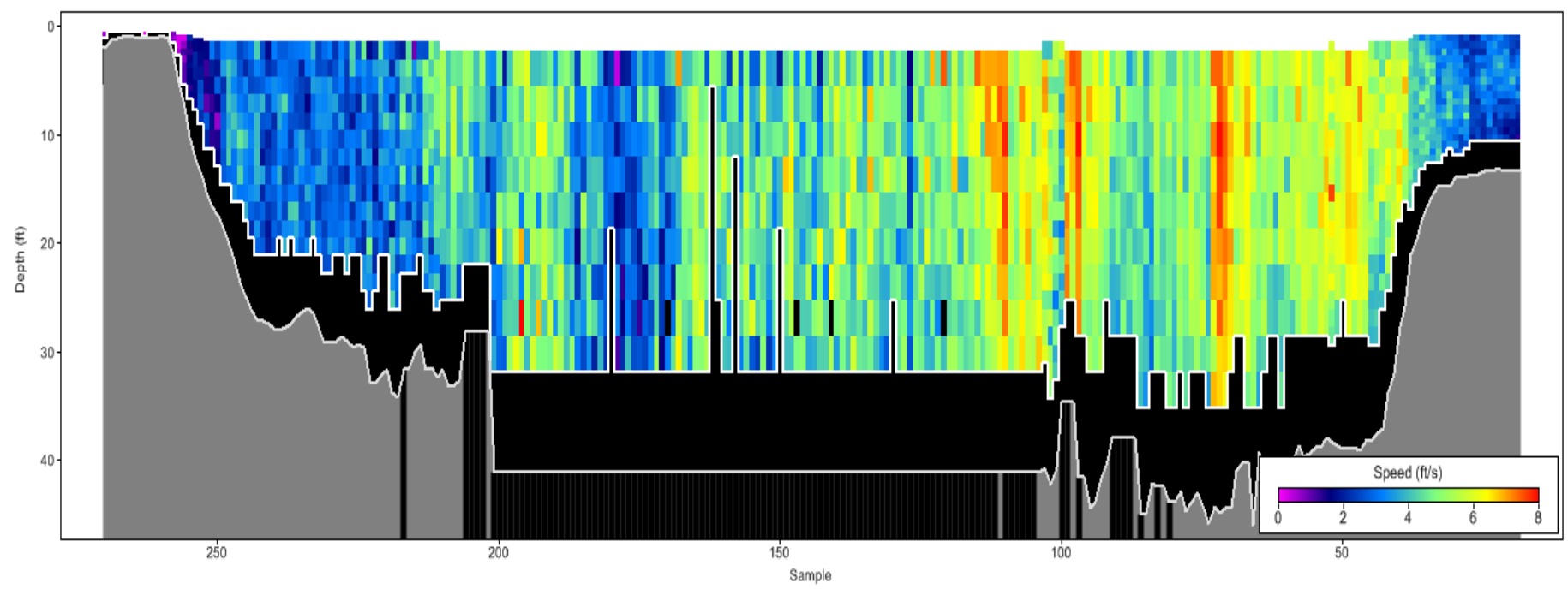

Figure F-11. Example of RiverSurveyor Live holding depth constant due to invalid depths being collected.

distribution and potential impact on the discharge computation of any invalid or missing data should be assessed (fig. F-12). If a substantial amount of data are invalid or missing in one portion of a transect and the valid data do not represent the flow in the cross section adequately, that transect should not be included in the computation of discharge. A removed transect should be replaced with another transect in the same direction to maintain reciprocal transects. If an additional transect cannot be collected, consider eliminating a valid transect to maintain reciprocal transects (for RiverSurveyor Live see Additional Details - Invalid Data in RiverSurveyor Live).

\section{Step 6. Evaluate Echo Intensity Profile Plot}

The echo intensity plot is referred to as the intensity profile plot in WinRiver II and the signal to noise ratio (SNR) profile plot in RiverSurveyor Live. These plots provide feedback on the magnitude of the acoustic return from the water column. Generally the signal should be high at the transducer and smoothly decrease in magnitude as the distance from the transducer increases (fig. F-13). Three potential problems can be identified using these data.

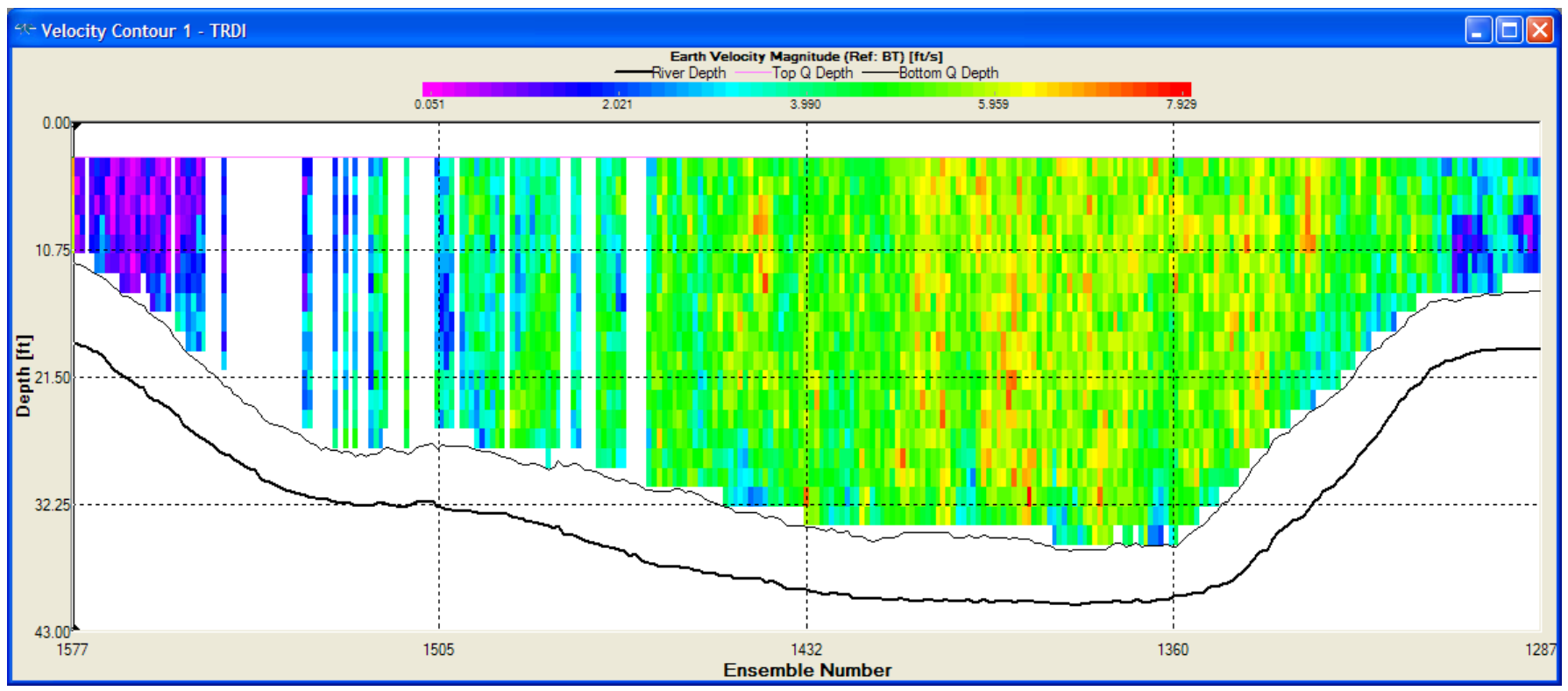

Figure F-12. Example of color contour plot from WinRiver II showing invalid and missing data. 

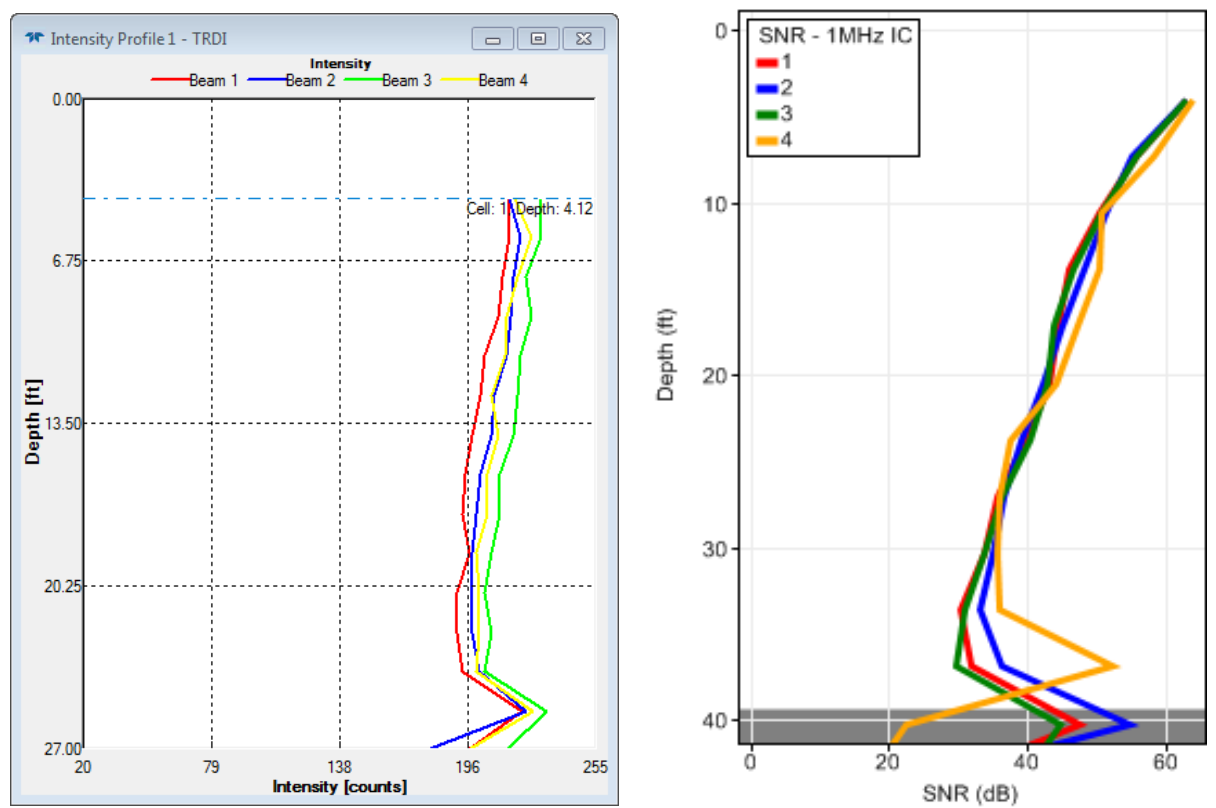

Figure F-13. Examples of typical intensity profile from WinRiver II (including data below the side-lobe cutoff and streambed) and signal to noise ratio profile from RiverSurveyor Live.

\section{Air Entrainment}

If the ADCP is not deployed far enough below the water surface, air may be entrained in the water beneath the ADCP and affect the acoustic signal from the transducers. The entrained air may block all or part of one or more transducer(s) causing a loss or degradation in backscatter energy and (or) the acoustic signal to be transmitted at an angle different from the design beam angle. This situation can be identified by a noticeable reduction in the intensity of one or more beams (figs. F-14 and F-15) and may result in an incorrect velocity measurement that appears to be valid.

\section{Influence of Backscatter Material}

Both high and low concentrations of suspended material in the water column can cause a problem for ADCPs. ADCPs require some material in the water column to reflect the acoustic signal back to the transducers. If there is insufficient material in the water column, the return signal is too weak to make a Doppler measurement (fig. F-16). Conversely, if there is too much material in the water column, the acoustic signal may attenuate before it reaches the bottom (fig. F-17B) or the ADCP may have a problem discriminating the water return from the bottom return (fig. F-17A). If the ADCP cannot discriminate the bottom return, an external echo sounder may help (see Echo Sounder in main body of this report).

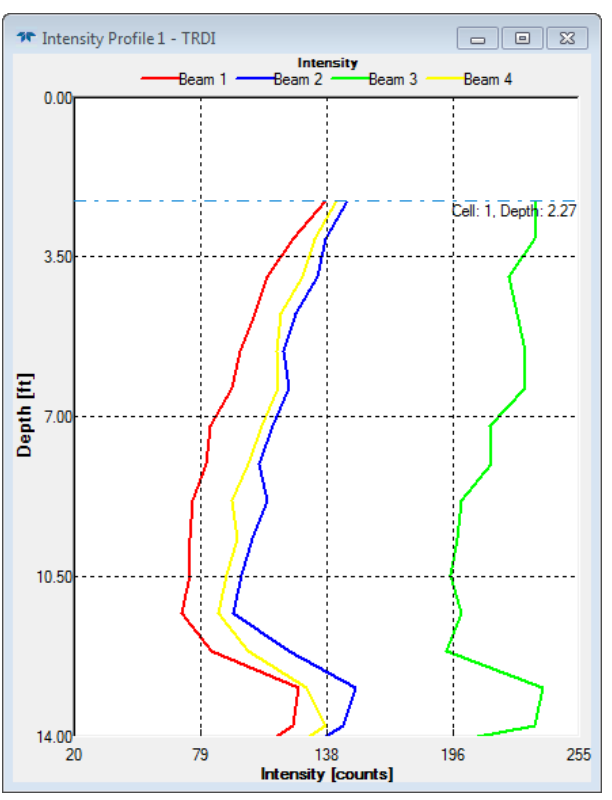

Figure F-14. Example of air entrainment degrading the intensity of the acoustic signal in beams 1, 2, and 4 from WinRiver II (including data below the side-lobe cutoff and streambed). 


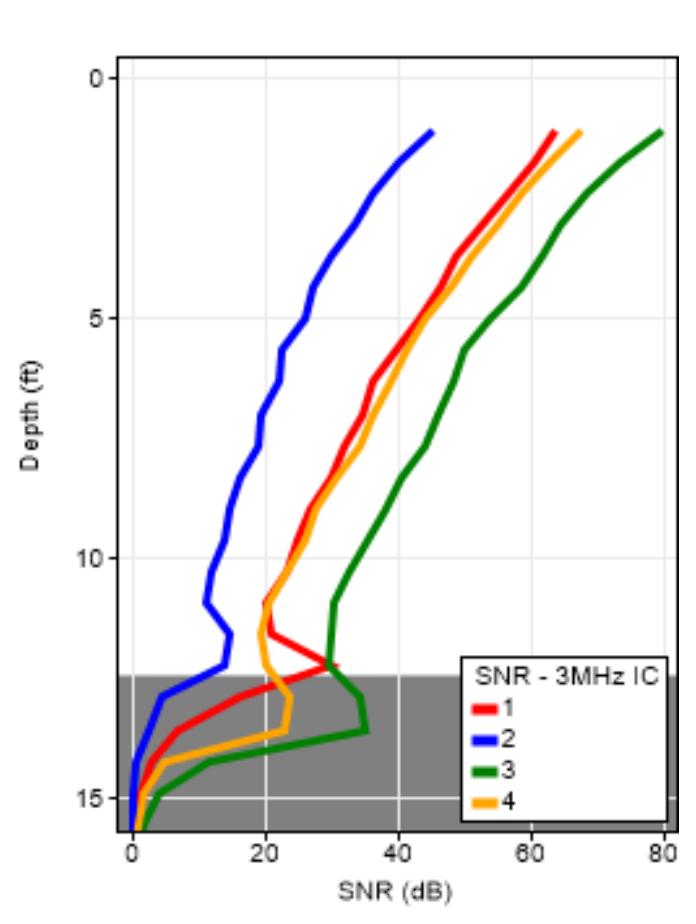

Figure F-15. Example of air entrainment partially blocking the acoustic signal in beam 1 from RiverSurveyor Live.

\section{A. Shallow water}

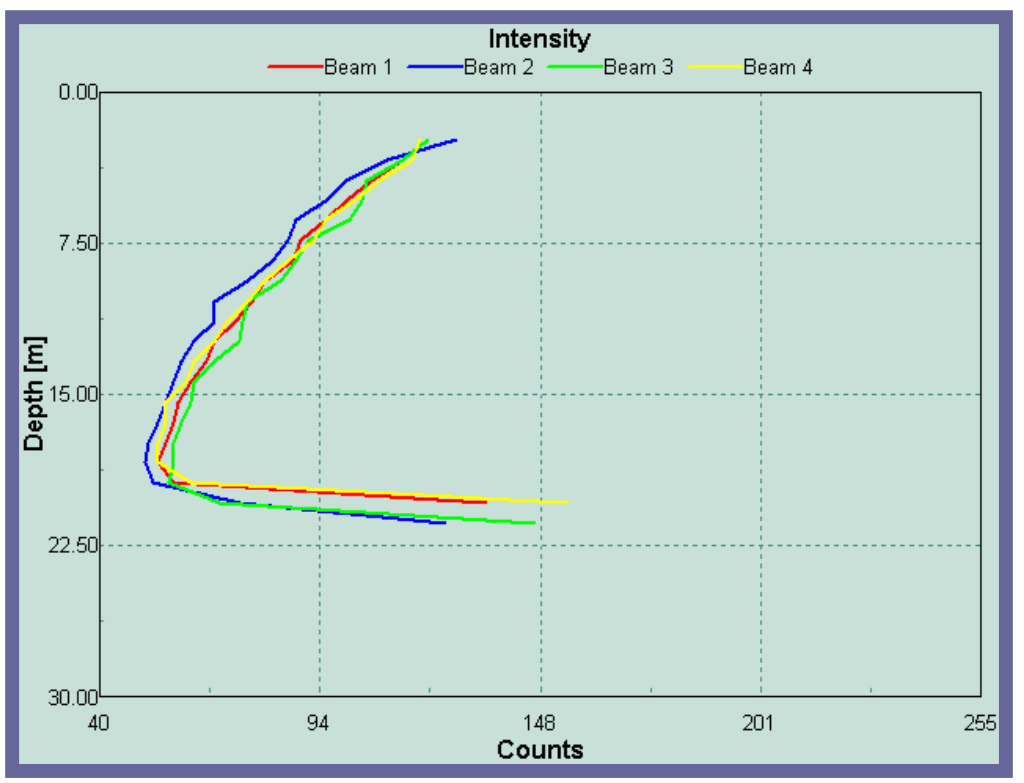

\section{B. Deep water}

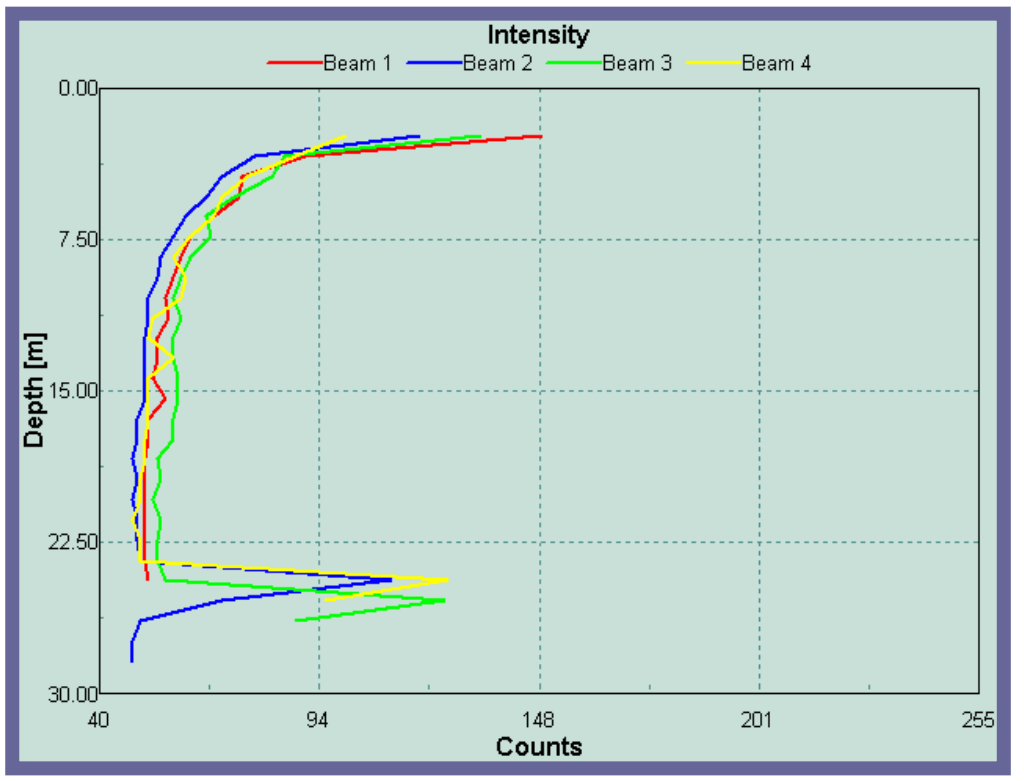

Figure F-16. Example of intensity profiles when there is insufficient backscatter material in the water column. In A, the water is shallow and the intensity does not reach the base noise level before the signal encounters the bottom reflection; however, in $B$, the water is deep and the signal attenuates to the base noise level before reflecting off of the bottom. Note: These examples are from WinRiver II and display data below the side-lobe cutoff and streambed ranges. 

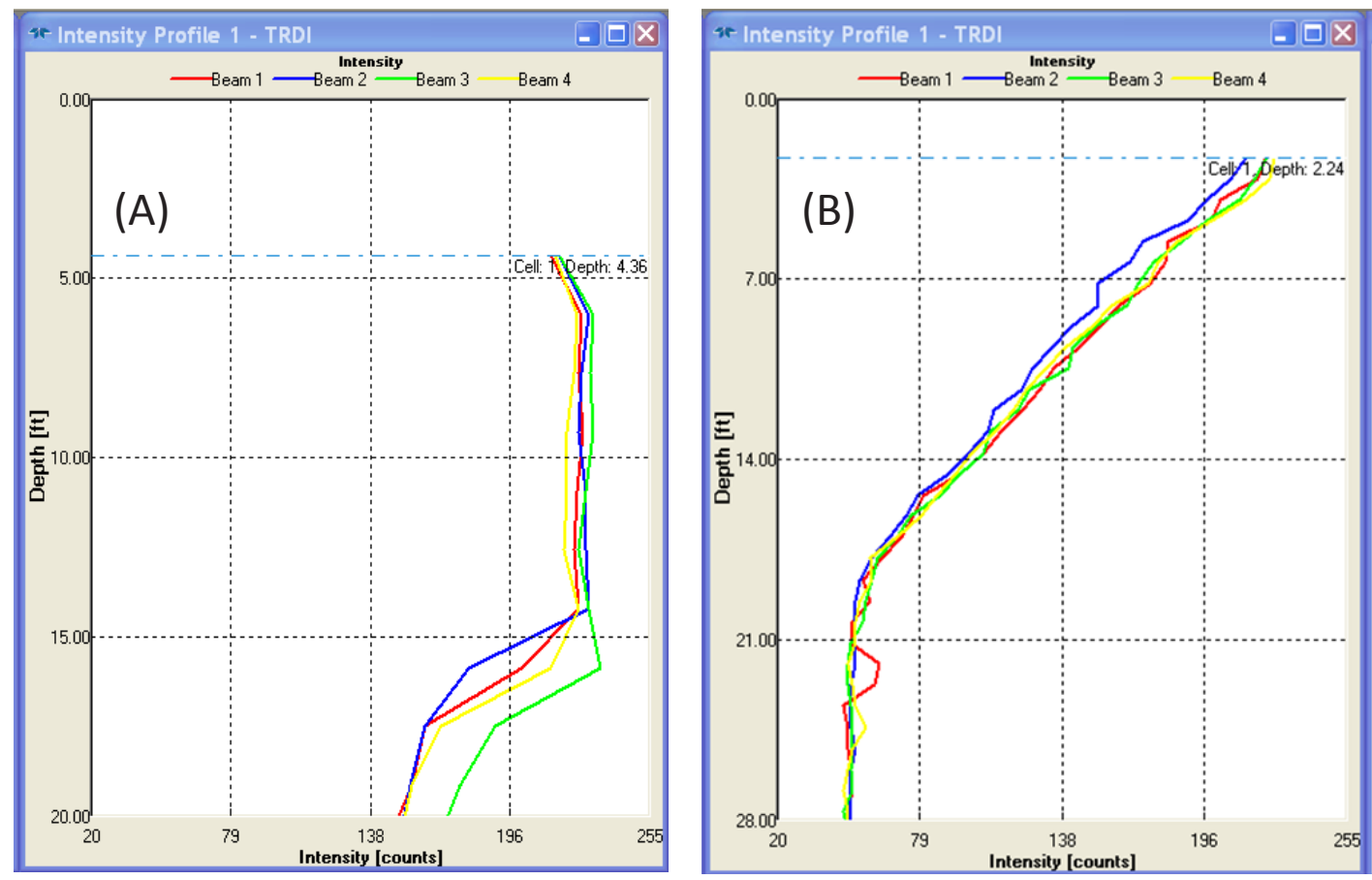

Figure F-17. Example of intensity when there is too much backscatter material in water column. In A, the sediment concentration and composition is such that the intensity remains high and the bottom reflection is not distinct and obvious; however, in $B$, the sediment concentration and composition is such that the acoustic signal is attenuated to the base noise level and no reflection from the bottom is present. Note: These examples are from WinRiver II and display data below the side lobe cutoff and streambed ranges.

\section{Objects in the Water Column}

An object in the water column above the streambed will reflect a greater amount of acoustic energy than the surrounding water. A fish or submerged vegetation may cause a sudden increase in signal intensity in one beam (fig. F-18). If the object is large enough to be measured as the depth of a beam, the data will be cut off because the side-lobe limit is based on the shallowest beam. Typically, objects in the water column are rare and generally do not create a problem for discharge measurements. In some situations, however, they can be a problem and generally the best solution is to measure at a different location. The general rule of thumb for measuring near vertical walls is to keep the ADCP a distance from the wall equal to the depth of the water.

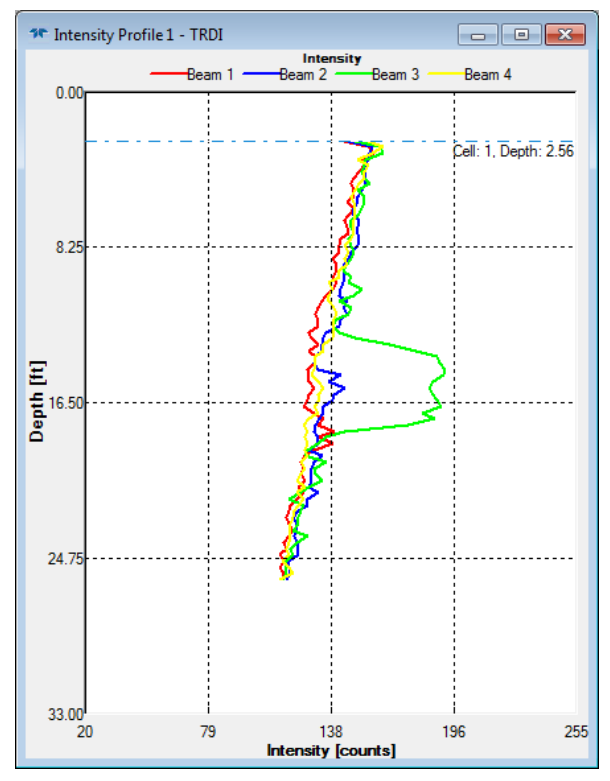

Figure F-18. Example of spike in intensity profile due to one beam hitting something in the water column. 


\section{Step 7. Select Proper Extrapolation Methods}

The extrapolation methods chosen to compute the unmeasured top and bottom portions of the water column are important and may make a substantial difference in the final discharge. The discharge profile should be evaluated and appropriate extrapolation methods selected for each measurement. Generally the selected extrapolation methods and exponent should be applicable to the entire measurement; they should not vary among transects that make up a single measurement without proper justification. If the site conditions are changing sufficiently to cause a substantial change in the extrapolation methods or exponent, then it may be best to split the measurement into multiple measurements that are representative of the different site conditions (see Unsteady Flow Conditions in main body of this report). To effectively and efficiently evaluate the discharge profile, a method that allows proper development of a mean profile for the whole measurement, such as the extrap program (Mueller, 2013; http://hydroacoustics.usgs.gov), is recommended (fig. F-19). In addition, comparing the effect of different extrapolation methods and (or) exponents and evaluating the effect of the extrapolation methods on the final discharge can be helpful in choosing the proper method (extrap provides this comparison). Although automated methods of selecting the extrapolation method and exponent may be available in some software, the hydrographer is responsible for the evaluation of the profile and the selection of the appropriate extrapolation method and exponent based on the measured data, and their knowledge of the hydraulic characteristics of the channel and information about site conditions at the time. The selected extrapolation method and exponent must be entered in the software used to process the measurement and the final discharge computed.
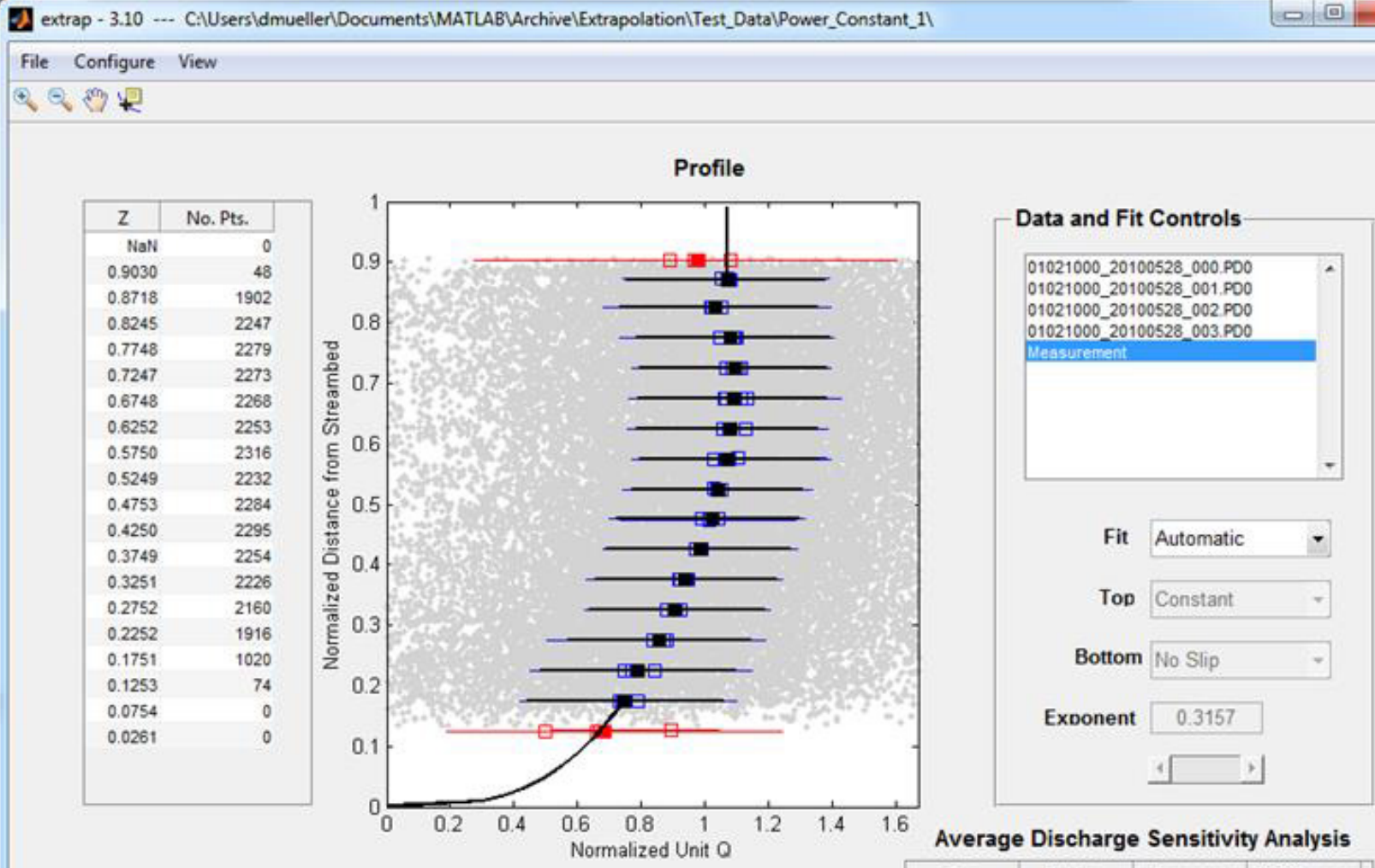

For WR2 data, extrap only uses bottom track reference. If bottom track is not valid, the data in that ensemble will not be used in extrap. WR2 also limits the exponent range to 0.001 to 0.5 .

Figure F-19. Extrap user interface. 
A. RiverSurveyor Live

\begin{tabular}{|c|c|c|c|c|c|c|c|c|c|c|c|c|c|c|c|c|c|c|c|}
\hline \multicolumn{20}{|c|}{ Discharge Summary } \\
\hline \multicolumn{20}{|c|}{ 国 $\times \times$ Post.Processing } \\
\hline & File & & Start Date & Start Ti... & Duration & $\begin{array}{l}\text { Track } \\
\text { (ft) }\end{array}$ & $\begin{array}{l}\text { DMG } \\
(\mathrm{ft})\end{array}$ & $\begin{array}{l}\text { Width } \\
\text { (ft) }\end{array}$ & $\begin{array}{l}\text { Area } \\
(\mathrm{ft2})\end{array}$ & $\begin{array}{c}\text { Mean Vel } \\
(\mathrm{ft} / \mathrm{s})\end{array}$ & $\begin{array}{l}\text { 3oat Speec } \\
(\mathrm{ft} / \mathrm{s})\end{array}$ & $\begin{array}{l}\text { Left Q } \\
\text { (cfs) }\end{array}$ & $\begin{array}{l}\text { Right Q } \\
\text { (cfs) }\end{array}$ & $\begin{array}{l}\text { Top Q } \\
\text { (cfs) }\end{array}$ & $\begin{array}{l}\text { Middle Q } \\
\text { (cfs) }\end{array}$ & $\begin{array}{l}\text { Bottom Q } \\
\text { (cfs) }\end{array}$ & $\begin{array}{l}\text { Total Q } \\
\text { (cfs) }\end{array}$ & $\begin{array}{l}\text { ó Measure } \\
(\%)\end{array}$ & ^ \\
\hline ■\$ & $200903 \ldots$ & $4 \operatorname{arc} 80$ N & $25 / 03 / 2 \ldots$ & $11: 47: 24$ & $0: 07: 40$ & 2026.56 & 1873.44 & 1958.44 & 60929.9 & 5.091 & 4.406 & 223.79 & 2844.00 & $26905.6 \ldots$ & $249992 \ldots$ & $30249.5 \ldots$ & $310215 \ldots$ & 80.6 & \\
\hline 曰 $\$$ & 200903... & 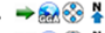 & $25 / 03 / 2 \ldots$ & $11: 55: 16$ & 0:08:08 & 1869.97 & 1733.71 & 1833.71 & 56720.0 & 4.985 & 3.832 & -177.98 & 2348.81 & $24508.5 \ldots$ & $229481 \ldots$ & $26566.4 \ldots$ & $282727 \ldots$ & 81.2 & \\
\hline ఐ & $200903 .$. & 4 tas 80 & $25 / 03 / 2 \ldots$ & $12: 03: 46$ & $0: 05: 40$ & 1749.73 & 1719.36 & 1816.36 & 55615.3 & 5.163 & 5.146 & 461.63 & 2773.34 & $24682.8 \ldots$ & $231190 \ldots$ & $28026.9 \ldots$ & $287134 \ldots$ & 80.5 & \\
\hline 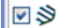 & $200903 \ldots$ & $\Rightarrow \sec 80 \mathrm{~N}$ & $25 / 03 / 2 \ldots$ & $12: 09: 45$ & $0: 07: 00$ & 1816.50 & 1730.02 & 1817.02 & 55918.9 & 4.734 & 4.325 & 321.57 & 2960.94 & $22874.8 \ldots$ & $212971 \ldots$ & $25616.8 \ldots$ & $264745 \ldots$ & 80.4 & \\
\hline$\square \gg$ & $200903 .$. & $\Rightarrow \operatorname{arc} 80$ & $25 / 03 / 2 \ldots$ & 12:09:45 & $0: 07: 00$ & 1816.50 & 1730.02 & 1817.02 & 55918.9 & 4.734 & 4.325 & 321.57 & 2960.94 & $22874.8 \ldots$ & $212971 \ldots$ & $25616.8 \ldots$ & $264745 \ldots$ & 80.4 & \\
\hline ( & $200903 \ldots$ & 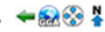 & $25 / 03 / 2 \ldots$ & 12:17:05 & $0: 05: 13$ & 1798.97 & 1730.52 & 1821.52 & 55554.1 & 5.280 & 5.747 & 428.93 & 3129.17 & $25200.7 \ldots$ & $236776 \ldots$ & $27816.2 \ldots$ & $293351 \ldots$. & 80.7 & \\
\hline$\square \gg$ & $200903 \ldots$ & $\Rightarrow a 8$ N & $25 / 03 / 2 \ldots$ & $12: 22: 34$ & 0:07:00 & 1833.74 & 1744.94 & 1821.94 & 56455.0 & 5.099 & 4.366 & 234.06 & 2610.09 & $24878.5 \ldots$ & $232421 \ldots$ & $27736.2 \ldots$ & $287880 \ldots$ & 80.7 & \\
\hline \multirow[t]{4}{*}{$\nabla \$$} & $200903 \ldots$ & - बलिख & $25 / 03 / 2 \ldots$ & $12: 29: 52$ & $0: 05: 15$ & 1773.40 & 1748.25 & 1818.25 & 55002.7 & 5.223 & 5.630 & 293.21 & 1809.06 & $24957.7 \ldots$ & $232248 \ldots .$. & $27969.5 \ldots$ & $287278 \ldots$ & 80.8 & \\
\hline & & & & Mean & 0:06:37 & 1835.67 & 1751.28 & 1838.03 & 56514.4 & 5.039 & 4.722 & 263.35 & 2679.54 & $24610.4 \ldots$ & $229756 \ldots$ & $27449.8 \ldots$ & $284759 \ldots$ & 80.7 & \\
\hline & & & & Stad Dev & 0:01:02 & 79.81 & 46.95 & 45.82 & 1741.7 & 0.194 & 0.651 & 184.26 & 398.17 & $1217.03 \ldots$ & 11389.02 & $1421.17 \ldots$ & 13913.92 & 0.2 & \\
\hline & & & & COV & 0.000 & 0.043 & 0.027 & 0.025 & 0.031 & 0.039 & 0.138 & 0.700 & 0.149 & 0.049 & 0.050 & 0.052 & 0.049 & 0.003 & 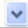 \\
\hline
\end{tabular}

\section{B. WinRiver II}

\begin{tabular}{|c|c|c|c|c|c|c|c|c|c|c|c|c|c|c|c|c|c|c|}
\hline \multicolumn{18}{|c|}{ 4- Discharge Summary - TRDI } & \multirow{2}{*}{$\begin{array}{c}-10 x \\
\text { Flow Dir. } \\
\text {. }\end{array}$} \\
\hline Transect & Start Bank & \#Ens. & Start Time & $\begin{array}{c}\text { Total } Q \\
\mathrm{At}^{2} / \mathrm{s}\end{array}$ & $\begin{array}{c}\text { Delta Q } \\
\%\end{array}$ & $\begin{array}{l}\text { Top Q } \\
\mathrm{ft}^{2} / \mathrm{s}\end{array}$ & $\begin{array}{c}\text { Meas. Q } \\
\mathrm{ft}^{2} / \mathrm{s}\end{array}$ & $\begin{array}{c}\text { Bottom Q } \\
\mathrm{ft}^{\mathrm{t}} / \mathrm{s}\end{array}$ & $\begin{array}{l}\text { Left Q } \\
\mathrm{At}^{2} / \mathrm{s}\end{array}$ & $\begin{array}{l}\text { Left Dist. } \\
\mathrm{ft}\end{array}$ & $\begin{array}{l}\text { Right } Q \\
\mathrm{ft}^{2} / \mathrm{s}\end{array}$ & $\begin{array}{c}\text { Right Dist. } \\
\mathrm{ft}\end{array}$ & $\begin{array}{c}\text { Width } \\
\mathrm{ft}\end{array}$ & $\begin{array}{c}\text { Total Area } \\
\mathrm{t}^{2}\end{array}$ & $\begin{array}{l}\text { Q/Area } \\
\mathrm{ft} / \mathrm{s}\end{array}$ & $\begin{array}{c}\text { Boat Speed } \\
\mathrm{f} / \mathrm{s}\end{array}$ & $\begin{array}{c}\text { Flow Speed } \\
\mathrm{f} / \mathrm{s}\end{array}$ & \\
\hline 03284500000 & Right & 359 & $\begin{array}{l}13: 50: 56 \\
\end{array}$ & 4724.881 & 0.75 & 506.699 & 3528.248 & 629.450 & 18.863 & 23.00 & 41.620 & 29.00 & 332.35 & 7875.69 & 0.600 & \begin{tabular}{|l|}
1.016 \\
\end{tabular} & \begin{tabular}{|l|l|}
0.685 \\
\end{tabular} & 349.31 \\
\hline 03284500001 & Left & 368 & 13:56:03 & 4688.940 & .0 .01 & 521.386 & 3521.543 & 591.697 & 14.691 & 20.00 & 39.623 & 36.00 & 333.19 & 7881.46 & 0.594 & 0.978 & 0.669 & 351.98 \\
\hline 03284500002 & Right & 407 & 14:01:20 & 4610.965 & .1 .68 & 492.993 & 3431.314 & 652.191 & .0 .989 & 22.00 & 35.456 & 28.00 & 325.06 & 7783.57 & 0.594 & 0.863 & 0.653 & 351.57 \\
\hline 03284500003 & Left & 377 & 14:07:12 & 4733.437 & 0.94 & 529.826 & 3551.879 & 591.485 & 16.845 & 24.00 & 43.366 & 28.00 & 336.56 & 7876.51 & 0.600 & 0.984 & 0.666 & 352.63 \\
\hline Average & & 377 & & 4689.556 & .0 .00 & 512.726 & 3508.246 & 616.206 & 12.353 & 22.25 & 40.016 & 30.25 & 331.79 & 7854.31 & 0.597 & 0.960 & 0.668 & \\
\hline Std Dev. & & 21 & & 55.828 & 1.19 & 16.260 & 52.912 & 29.901 & 9.056 & 1.71 & 3.403 & 3.86 & 4.84 & 47.23 & 0.004 & 0.067 & 0.013 & \\
\hline Std./| Avg.| & & 0.06 & & 0.01 & 0.00 & 0.03 & 0.02 & 0.05 & 0.73 & 0.08 & 0.09 & 0.13 & 0.01 & 0.01 & 0.01 & 0.07 & 0.02 & \\
\hline$<$ & & & & & & & & & & & & & & & & & & ( \\
\hline
\end{tabular}

Figure F-20. Examples of discharge summaries from (A) RiverSurveyor Live and (B) WinRiver II.

\section{Step 8. Evaluate Discharge Summary}

The discharge summary provides a summary of each transect and the whole measurement with mean and variability statistics (fig. F-20). The following should be evaluated in the discharge summary:

1. Even number of reciprocal transects: A measurement should always consist of reciprocal transects, which helps average and minimize any variation due to directional bias.
2. Directional bias: Directional bias is common for GPS referenced discharges due to heading errors or incorrect magnetic variation (fig. F-21). Generally these errors are small and the average of reciprocal transects yields an accurate discharge. If the errors are greater than 5 percent, consider adjusting the magnetic variation (see Incorrect Magnetic Variation or Inaccurate Compass Calibration under step 4).

\begin{tabular}{|c|c|c|c|c|c|c|c|c|}
\hline \multicolumn{7}{|c|}{ Tr Discharge Summary - TRDI } & \multicolumn{2}{|c|}{$\square \quad \square \quad x$} \\
\hline Transect & Start Bank & \# Ens. & Start Time & $\begin{array}{c}\text { Total Q } \\
\mathrm{ft}^{3} / \mathrm{s}\end{array}$ & $\begin{array}{c}\text { Delta Q } \\
\%\end{array}$ & $\begin{array}{c}\text { Top Q } \\
\mathrm{ft}^{3} / \mathrm{s}\end{array}$ & $\begin{array}{c}\text { Meas. Q } \\
\mathrm{ft}^{3} / \mathrm{s}\end{array}$ & $\begin{array}{c}\text { Bottom Q } \\
\mathrm{ft}^{3} / \mathrm{s}\end{array}$ \\
\hline ky04000 & Right & 275 & $16: 28: 19$ & 44987.725 & -4.82 & 4702.990 & 35871.538 & 4202.913 \\
\hline ky04001 & Left & 320 & $16: 31: 45$ & 50766.287 & 7.40 & 5245.192 & 40052.052 & 5171.114 \\
\hline ky04002 & Right & 260 & $16: 35: 37$ & 42792.503 & -9.47 & 4269.595 & 34146.917 & 4233.931 \\
\hline ky04003 & Left & 276 & $16: 38: 44$ & 50526.152 & 6.89 & 5312.509 & 39915.071 & 5137.814 \\
\hline Average & & 282 & & 47268.167 & 0.00 & 4882.571 & 37496.395 & 4686.443 \\
\hline Std Dev. & & 26 & & 4003.469 & 8.47 & 491.369 & 2957.507 & 540.743 \\
\hline Std./| Avg.| & & 0.09 & & 0.08 & 0.00 & 0.10 & 0.08 & 0.12 \\
\hline \multicolumn{9}{|c|}{ ' III } \\
\hline
\end{tabular}

Figure F-21. Example of directional bias in GGA referenced discharges caused by an incorrect magnetic variation. 
3. Exposure time greater than 720 seconds: Discharge measurements made from a moving boat under approximately steady-flow conditions will consist of an even number of transects (at least two) having a total exposure time of 720 seconds or greater (U.S. Geological Survey, 2011b).

4. Consistency in measurement characteristics: Unless one or more transects are collected in a different location (which should be documented in the field notes), the characteristics of the measurement and cross section should be similar among the transects. Check for consistency in area, width, boat speed, flow direction, and flow speed. Also verify that the boat speed is appropriate for the water speed and site conditions. Check the field notes or further investigate any significant inconsistencies.

\section{Additional Details}

Additional detailed data processing and analysis may be needed based on potential issues identified in the initial eight-step procedure.

\section{Identifying Magnetic Compass Heading Errors}

A poor magnetic compass calibration or magnetic interference during a transect may cause errors in the ship track and result in inaccurate velocities and discharges. Such errors can usually be identified by careful evaluation of the ship track and velocity vector plot and discharge summary. Because the heading of the ADCP typically is different on reciprocal transects, a heading error will cause the ADCP course or direction of the ship track to change. Since the water-velocity direction is also determined from the heading, the water-velocity direction will also change with the ship track, such that the water-velocity direction relative to the ship track is consistent but different between reciprocal transects. This behavior can be identified by comparing the ship track and velocity vector plots of reciprocal transects (fig. F-3) or by evaluating the difference in flow direction reported in the discharge summary (fig. F-22), or if a loop moving-bed test was collected, the loop processing software quality-assurance checks should identify the heading error. A variation in flow direction of a few degrees is not unusual, but if the variation is correlated with the direction of boat travel it is likely due to a heading error. If GPS data are collected, the difference in bottom track and GPS referenced ship tracks can be compared. A moving bed would consistently bias the bottom track upstream from the GPS referenced ship track (fig. F-3), but heading errors are often opposite on reciprocal transects so the bottom track may be upstream from the GPS based ship track in one direction and downstream in the other direction (fig. F-4). If a heading error is identified, the effect on discharge should be assessed. Heading errors do not affect the total discharge if the ADCP bottom track is used as the reference for boat velocity. Heading errors can affect the results of a loop moving-bed test or total discharge for any transects that use GPS as the reference for boat velocity. If the effect is significant, the best recourse is to recalibrate the compass and recollect the data. If this is not possible, then small adjustments to the magnetic variation may improve the measurement (see Additional Details, Adjusting Magnetic Variation).

\section{Identifying Poor GPS Quality}

When using GPS as the track reference, GPS quality can be checked by monitoring, the GGA quality code, the horizontal dilution of precision (HDOP), and the number of satellite changes. The GGA quality code typically should be 2 (differentially corrected) or 4 (real-time kinematic). Some GPS receivers use other codes for different types of GPS corrections. A GGA quality code of 1 (no differential correction) will result in noisy GGA referenced velocities, although VTG referenced velocities may be acceptable. The GGA quality code can be monitored using the time series plots in both WinRiver II and RiverSurveyor Live. High HDOP (typically greater than 2, or changes of more than 1 during a transect) would indicate low GPS accuracy. The time series plot of HDOP (for both WinRiver II and RiverSurveyor Live) can be used to evaluate the HDOP along a transect and indicate where (and how much) GPS data may be suspect. Satellite changes taking place near the edges of the river or stream should be evaluated. Special attention should be paid to such changes when occurring in the middle reaches of a measurement as they may then induce a strong error in the resulting discharge. VTG may be suspect when the boat velocity is less than $0.8 \mathrm{ft} / \mathrm{s}$. In such conditions, differentiated GGA may provide better data, if differentially corrected.

\begin{tabular}{|c|c|c|c|}
\hline \multicolumn{4}{|c|}{ Tr Discharge Summary - TRDI } \\
\hline Transect & Start Bank & \# Ens. & Start Time \\
\hline 01034500_20090916000 & Right & 309 & 07:52:45 \\
\hline 01034500_20090916001 & Left & 314 & $07: 56: 53$ \\
\hline 01034500_20090916002 & Right & 323 & 08:01:26 \\
\hline $01034500 \_20090916003$ & Left & 304 & 08:05:39 \\
\hline Average & & 312 & \\
\hline Std Dev. & & 8 & \\
\hline Std./| Avg.| & & 0.03 & \\
\hline \multicolumn{4}{|c|}{ ( III } \\
\hline
\end{tabular}

\begin{tabular}{|c|c|c|c|} 
Flow Speed & Flow Dir. & End Time & Duration \\
$\mathrm{ft} / \mathrm{s}$ & ${ }^{\circ}$ & & $\mathrm{s}$ \\
\hline 1.096 & 189.59 & $07: 56: 38$ & 232.97 \\
1.176 & 215.85 & $08: 00: 48$ & 234.86 \\
1.068 & 188.38 & $08: 05: 28$ & 242.02 \\
1.180 & 214.80 & $08: 09: 27$ & 228.16 \\
\hline 1.130 & & & \\
0.057 & & & \\
0.05 & & & \\
\hline
\end{tabular}

Figure F-22. Example of discharge summary showing difference in flow direction for reciprocal transects. 


\section{Invalid Data in RiverSurveyor Live}

Invalid data can occur in either water or boat-velocity (bottom track or GPS) data. For RiverSurveyor M9/S5 ADCPs, invalid boat velocities are the most common invalid data observed and are not easily identified from the default user interface in RiverSurveyor Live. If both GPS and bottomtrack data are collected, RiverSurveyor Live can substitute valid boat velocities from GPS for invalid bottom track or vice versa using a feature called Composite Tracks. This feature should only be used if the compass has been calibrated and the magnetic variation for the site entered. When Composite Tracks is turned off and the selected reference is invalid, or when all available boat velocities are invalid, RiverSurveyor Live uses the last valid boat velocity for up to nine samples to compute discharge, but if more than nine consecutive samples have invalid boat velocities, no discharge is computed for the additional consecutive samples with invalid boat velocities. Thus, if more than nine consecutive samples have invalid boat velocities, the computed discharge will be biased low. Unfortunately the current (2013) RiverSurveyor Live user interface does not indicate in the stick ship track plot or the color contour plot which samples have invalid boat velocities with discharge computed from substituted velocities (Composite Tracks) or computed using a prior valid bottom-track velocity or those for which no discharge is computed. The easiest way to identify invalid boat velocities or when the boat-velocity reference changes is to

1. set the track reference to the desired reference (BT, GGA, VTG, LC, SMBA);

2. set one axis on the time series plot to Track Reference Code; and

3. set the $\mathrm{x}$-axis on the time series plot to samples.

To identify invalid boat velocities turn Composite Tracks off, then all samples with a track reference code of zero are invalid for the selected track reference (fig. F-23). If both GPS and bottom track have been collected, the compass calibrated, and the magnetic variation entered, turning on Composite Tracks will allow substitution of other valid track references for the invalid samples of the selected reference. This can also be seen in the time series plot. When Composite Tracks is turned on, changes in the Track Reference Code from GGA, VTG, or one of the bottom-track codes indicates that Composite Tracks has automatically changed the reference because the selected reference was invalid (fig. F-24). It is recommended that the track reference code be displayed and monitored during data collection and post measurement processing.

Although the time series plot of the Track Reference Code will show if there are invalid boat velocities in the transect, it is difficult to determine if the threshold of nine consecutive invalid samples has been exceeded. The easiest way to determine if the transect contains samples with no computed discharge is to view the samples in the tabular data in the Samples tab. In the Samples tab, make sure Boat Speed and Total Discharge are displayed and then scroll through the data. When the velocity is invalid, the boat speed will be identical for consecutive samples. If nine consecutive samples with invalid boat velocity are exceeded, the boat speed will be zero and the values of Total $Q$ will be constant.

The RiverSurveyor has two sources for depth (a) the vertical beam and (b) an average of the beams used for bottom tracking. The user must select the primary source for depth. If the depth from the primary source is invalid, the depth from the other source is used, if it is valid. If neither source has a valid depth, the last good depth is repeated indefinitely until another valid depth is sampled (fig. F-11).

Currently (2013), the only user-controlled filtering of water track data in RiverSurveyor Live is the SNR threshold, which is set to 1 decibel $(\mathrm{dB})$ by default. There has been no indication from the evaluation of hundreds of field measurements that this value needs to be changed. It is conceivable that, in some extreme situations where a low SNR is causing a bias in the water-velocity measurements, this threshold may need to be adjusted.

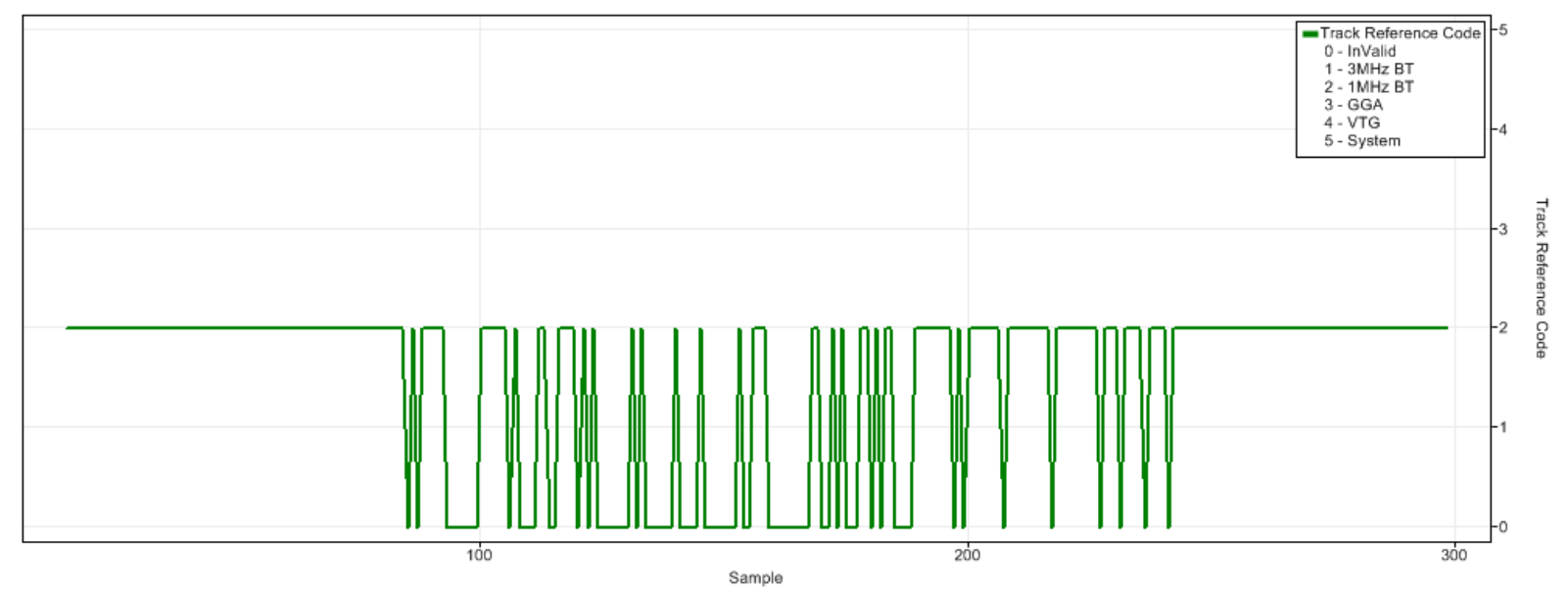

Figure F-23. Example of time series plot of track reference code in RiverSurveyor Live illustrating invalid bottom track. 


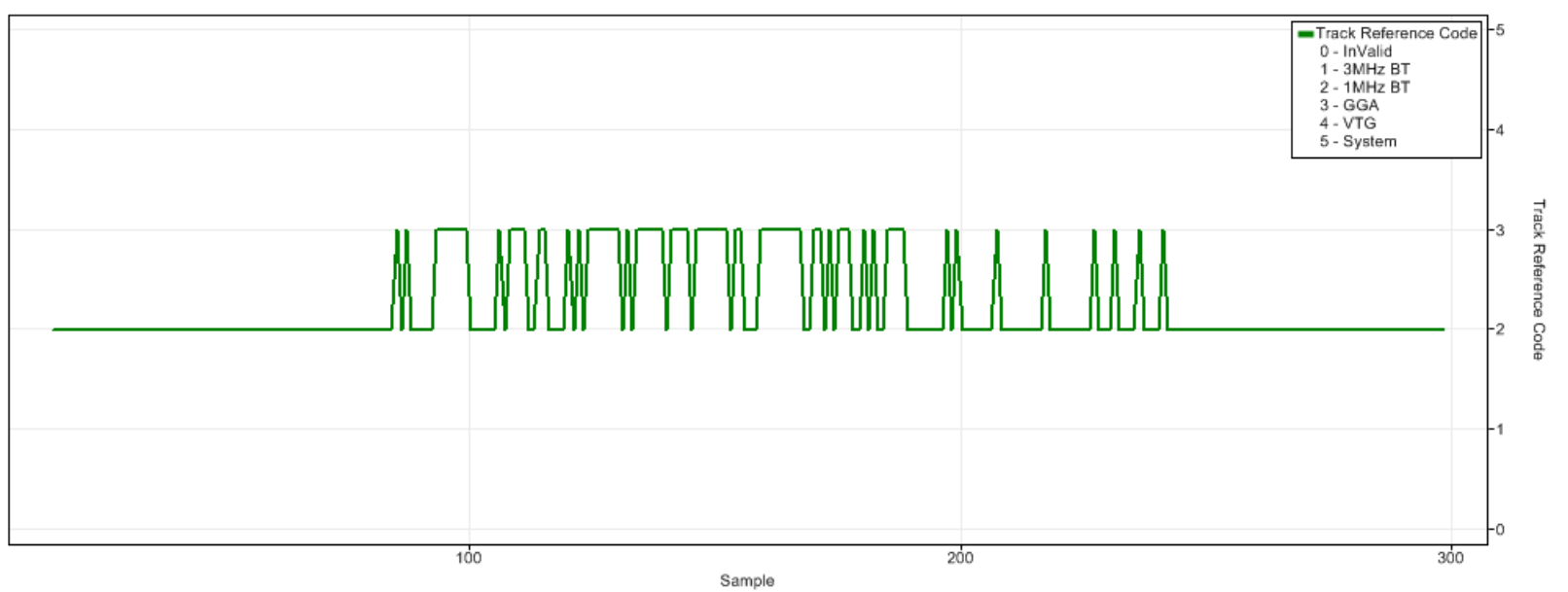

Figure F-24. Example of time series plot in RiverSurveyor Live illustrating the changing of the track reference with Composite Tracks turned on.

\section{Using Processing Filters in WinRiver II}

The data screening and threshold settings in the Processing dialog of WinRiver II can be used to filter out problematic bottom track, water track, and depth data. Data filtered out are marked invalid. An entire ensemble will be invalid if at least one of the following is true: (a) all depth cells are invalid, (b) no depths are valid, or (c) no valid boat speed. Discharge for the invalid ensembles is computed using data from the next valid ensemble. Discharge for invalid depth cells is interpolated from depth cells above and below the invalid cell or from the top and bottom extrapolation methods if there are no valid depth cells above and below the invalid depth cell.

\section{Bottom Track}

Irregularities or spikes in the bottom track identified through analysis of the stick ship track plot (fig. F-1) or from the boat speed time series (fig. F-25) may be able to be filtered out by either eliminating three-beam solutions or changing the bottom track up or error velocity thresholds. Turning off three-beam solutions and then reevaluating the bottom track is usually the first approach that should be used. If this does not resolve the problem or results in too much data being marked invalid, then the bottom track up and error velocity thresholds can be changed to filter out the problematic data. The best way to determine the appropriate thresholds is to look at the

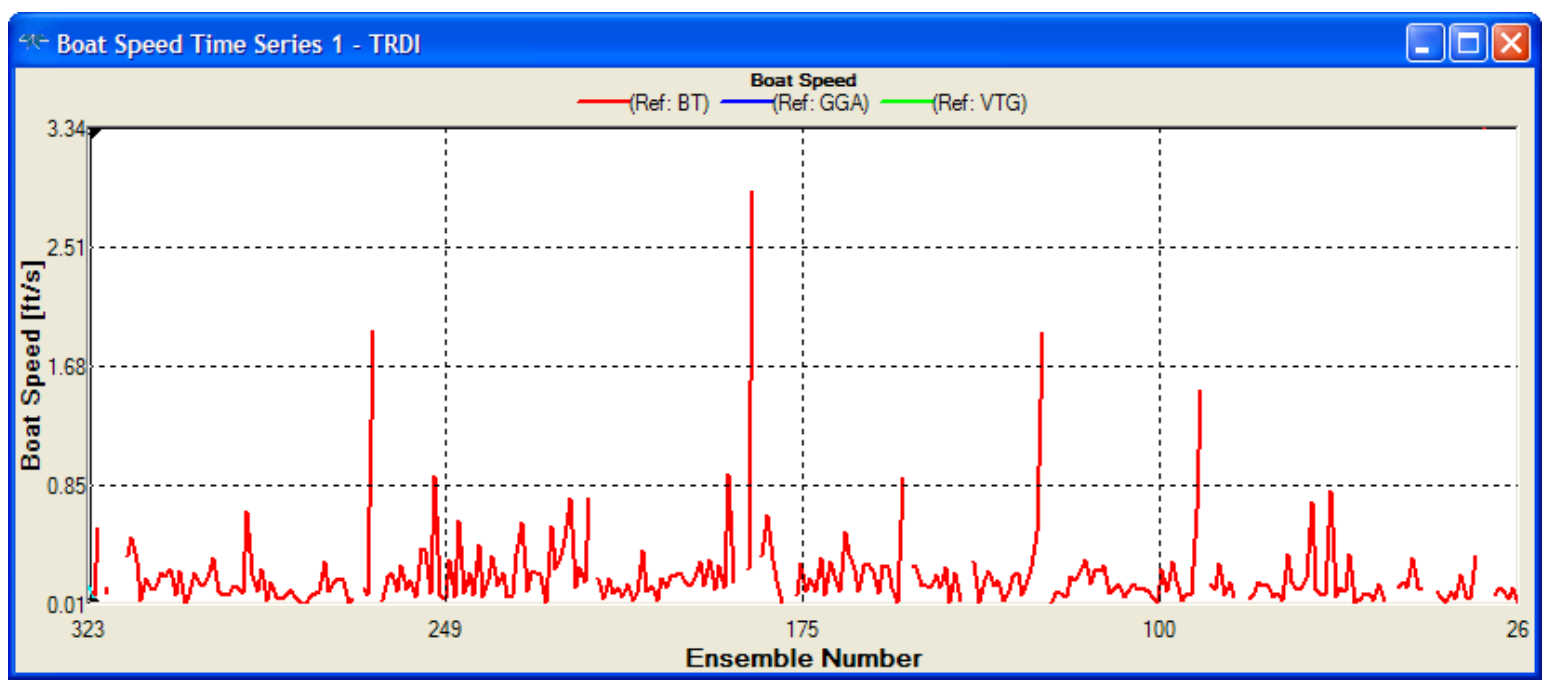

Figure F-25. Example of spikes in boat velocity in the boat speed time series from WinRiver II. 
bottom track up and error velocity values for the problematic data compared to surrounding good data and set the thresholds just below the values observed in the problematic data. It is important to reevaluate the data after setting thresholds to ensure that the problematic data have been marked invalid without marking too much good data invalid.

\section{Water Track}

Unexpected or unexplainable patterns in the water velocities identified in the color contour plot (fig. F-26) may be able to be filtered out by eliminating three-beam solutions or setting the water track up or error velocity thresholds. (Note: StreamPro firmware requires four-beam solutions and is not user selectable.) Turning off three-beam solutions and then reevaluating the water velocity is usually the first approach that should be used. If this does not resolve the problem or results in too much data being marked invalid, then the water track up and error velocity thresholds can be changed to filter out the problematic data. The best way to determine the appropriate thresholds is to look at the color contour plots for water error and up velocities (fig. F-27). Sometimes it is necessary to rescale the color map to identify patterns in the data. Typically the problems will display as vertical stripes in the data that show entire ensembles having significantly different magnitudes of water track up and (or) error velocity values for the problematic data compared to surrounding good data. Set the thresholds just below the values observed in the problematic data. It is always important to reevaluate the data after setting thresholds to ensure that the problematic data have been marked invalid without marking too much good data invalid.

\section{Depths}

Spikes in the depth data caused by a multiple return being identified as the depth in one or more beams (fig. F-10) can be resolved by turning on "Screen Depth" (leave "Screen Depth Using BT Vel" off). Using "Screen Depth" will mark those ensembles with depths that do not meet the screening criteria invalid.

\section{Adjusting Magnetic Variation}

If GPS referenced discharges display a directional bias (fig. F-21), this bias may be able to be reduced by adjusting the magnetic variation (in RiverSurveyor Live you could also use the heading correction variable, the result is the same). Adjusting the magnetic variation is justified based on the fact that the magnetic variations obtained from a geomagnetic model are not exact and the compass in an ADCP is probably only accurate to 1 to 2 degrees. The magnetic variation should be adjusted uniformly for all transects within about 2 degrees of the initial value to obtain consistent deviations between the ship tracks and reduce or eliminate the directional bias in the measured discharges. If consistency cannot be obtained within a 2 degree adjustment, the cause of the deviations are likely a substantial compass error, which cannot be objectively corrected.

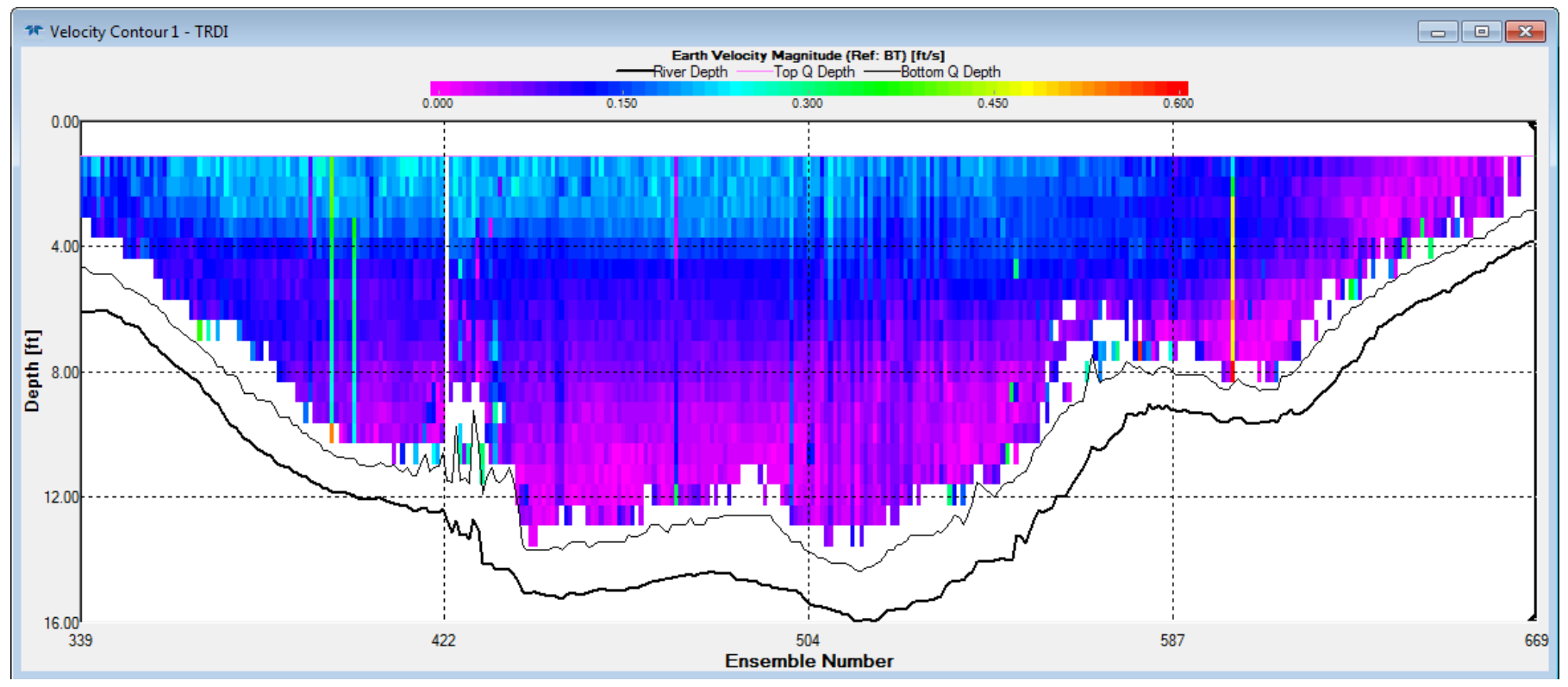

Figure F-26. Example of color contour plot from WinRiver II showing patterns in the velocity magnitudes. 


\section{A. Error velocities}

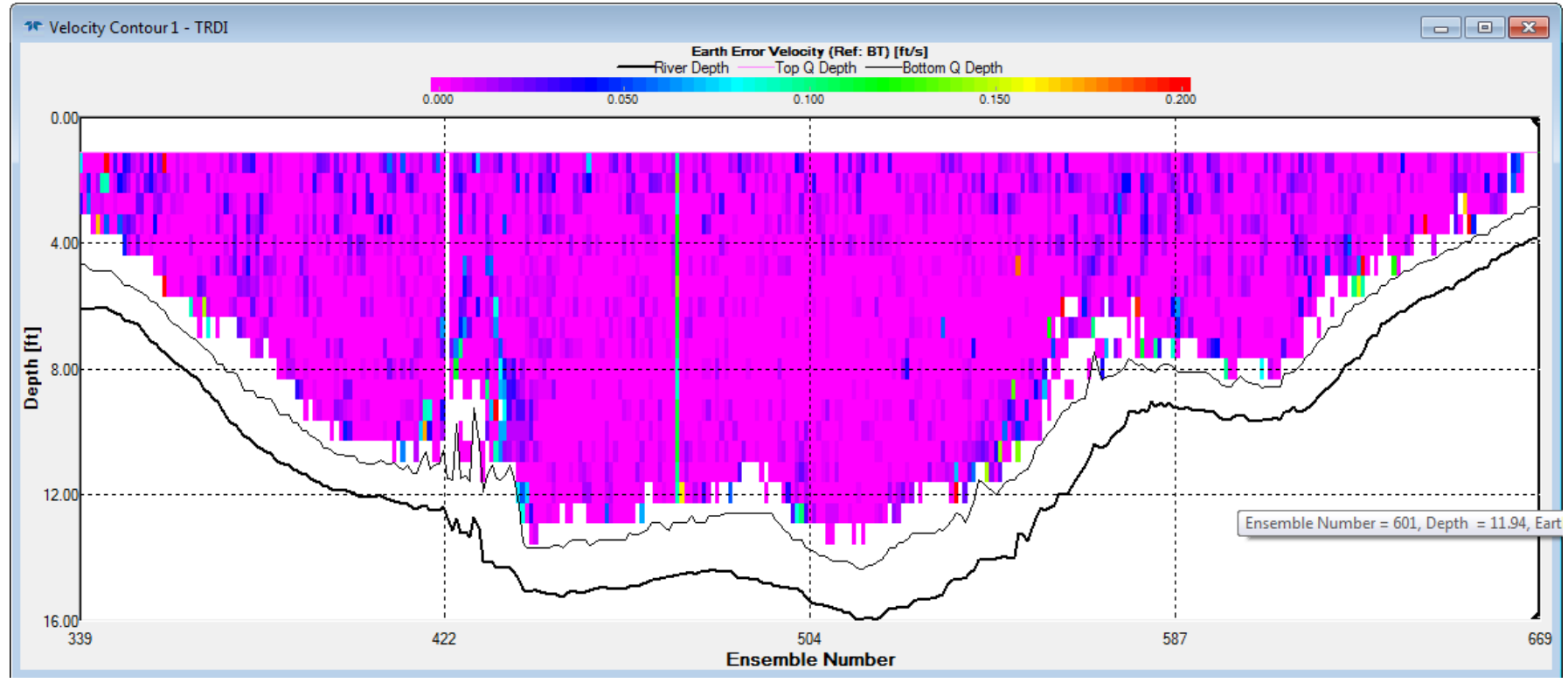

\section{B. Up velocities}

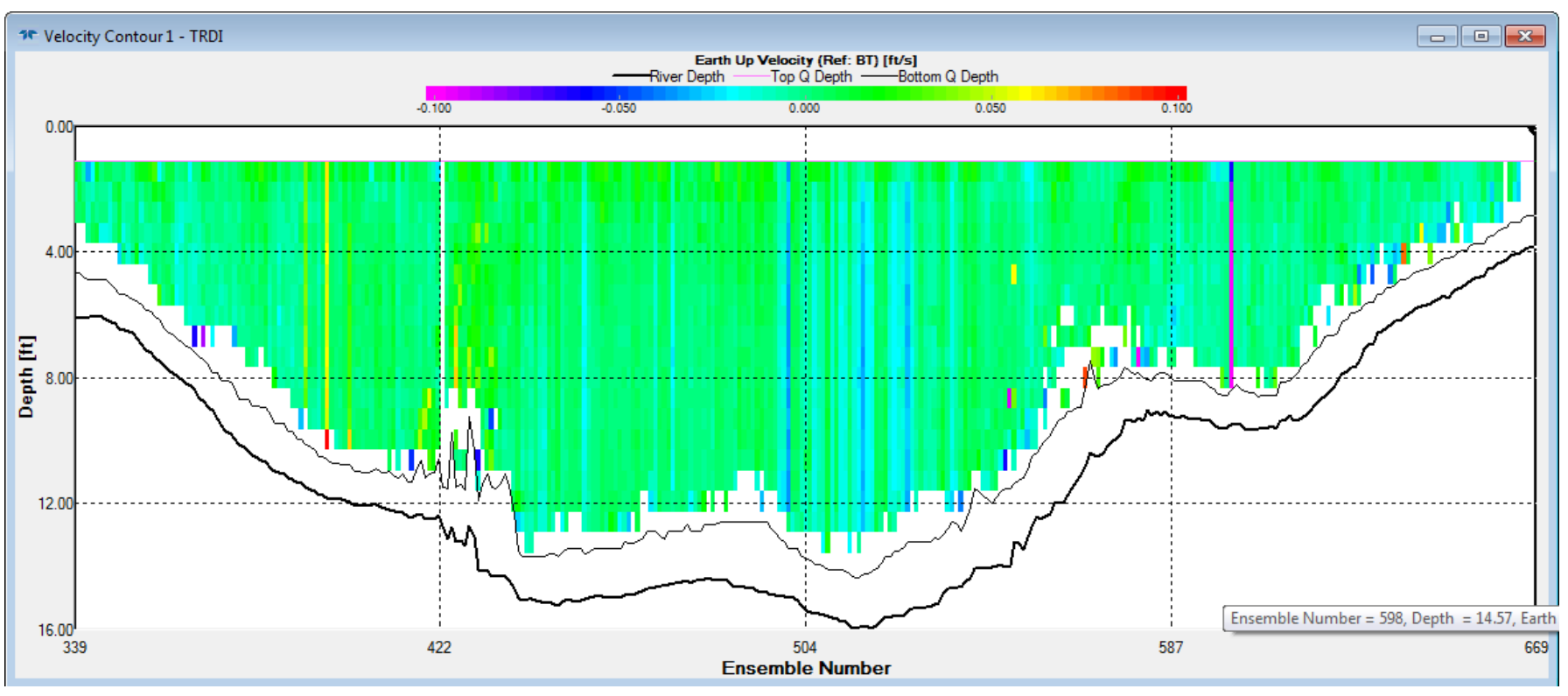

Figure F-27. Example of patterns in the color contour plot of error and up velocities in WinRiver II. 


\section{Subsectioning Transects in WinRiver II}

Subsectioning of transects should rarely be needed and can almost always be avoided with good field technique. The need for subsectioning can occur due to

- a number of invalid ensembles at the start or end of a transect that result in incorrect edge or ensemble discharge,

- erroneous data at the start or end of a transect that should not be used in the edge discharge computation, and

- a beam impinging on a vertical wall.

Subsectioning while eliminating the problem ensembles can create additional problems that need to be understood. Subsectioning may remove the ensembles that were collected while the boat was stationary and, thus, after subsectioning, the average velocity used to compute the edge discharge is averaged from 10 ensembles while the boat is moving away from (start edge) or toward (end edge) the edge of the water. The user must determine if the resulting average is representative of the edge and if not adjust the number of ensembles used for the edge estimate. The distance to shore from the subsectioned end of the transect may need to be adjusted. If bottom track is maintained, then the distance made good and ship track plot in WinRiver II can be used to adjust the edge distance. Note the distance made good before subsectioning the transect. Subsection one edge and subtract the new distance made good from the original to obtain the additional distance that should be added to the distance to shore value for that edge (fig. F-28). Subsection the second edge, if needed, and subtract the new distance made good from the previous value with only one edge subsectioned to get the additional distance for the second edge. Do not simply use the distance made good for the ensembles that were subsectioned as that distance may not be perpendicular to the bank. Using the whole transect's distance made good as described above minimizes this error. However, if the ensembles were invalid due to invalid bottom track, the movement of the boat is not recorded in WinRiver II and the user must rely on field observations and notes to correct the edge distance.

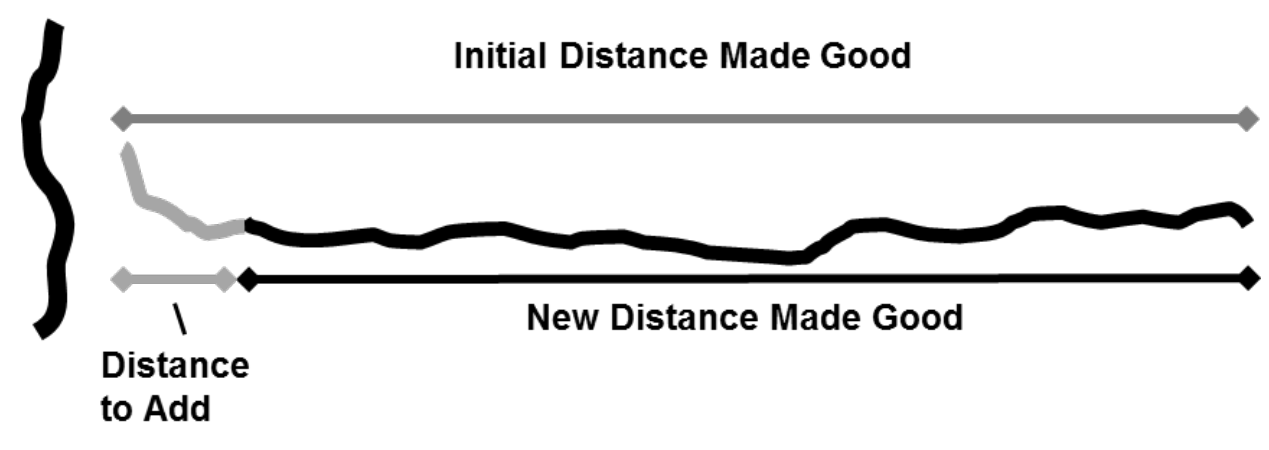

Figure F-28. Example of using distance made good for the original and subsectioned transect to compute the distance to add to the subsectioned edge 

Approved for publication on October 22, 2013

\section{Prepared by:}

USGS Science Publishing Network

Raleigh Publishing Service Center

3916 Sunset Ridge Road

Raleigh, NC 27607

For additional information regarding this publication, contact: David S. Mueller

Office of Surface Water

9818 Bluegrass Parkway

Louisville, Kentucky 40299

phone: 1-502-493-1935

email: dmueller@usgs.gov 
